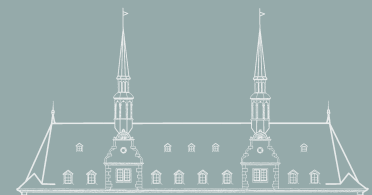

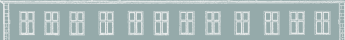
田田田田田田田时田田田田 田田田田田田田田田田田田

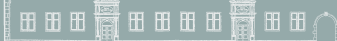

\author{
Irene Dingel \\ Christiane Tietz (Hg.) \\ Unter Mitarbeit von Marion Bechtold-Mayer
}

Säkularisierung und Religion Europäische Wechselwirkungen

VER

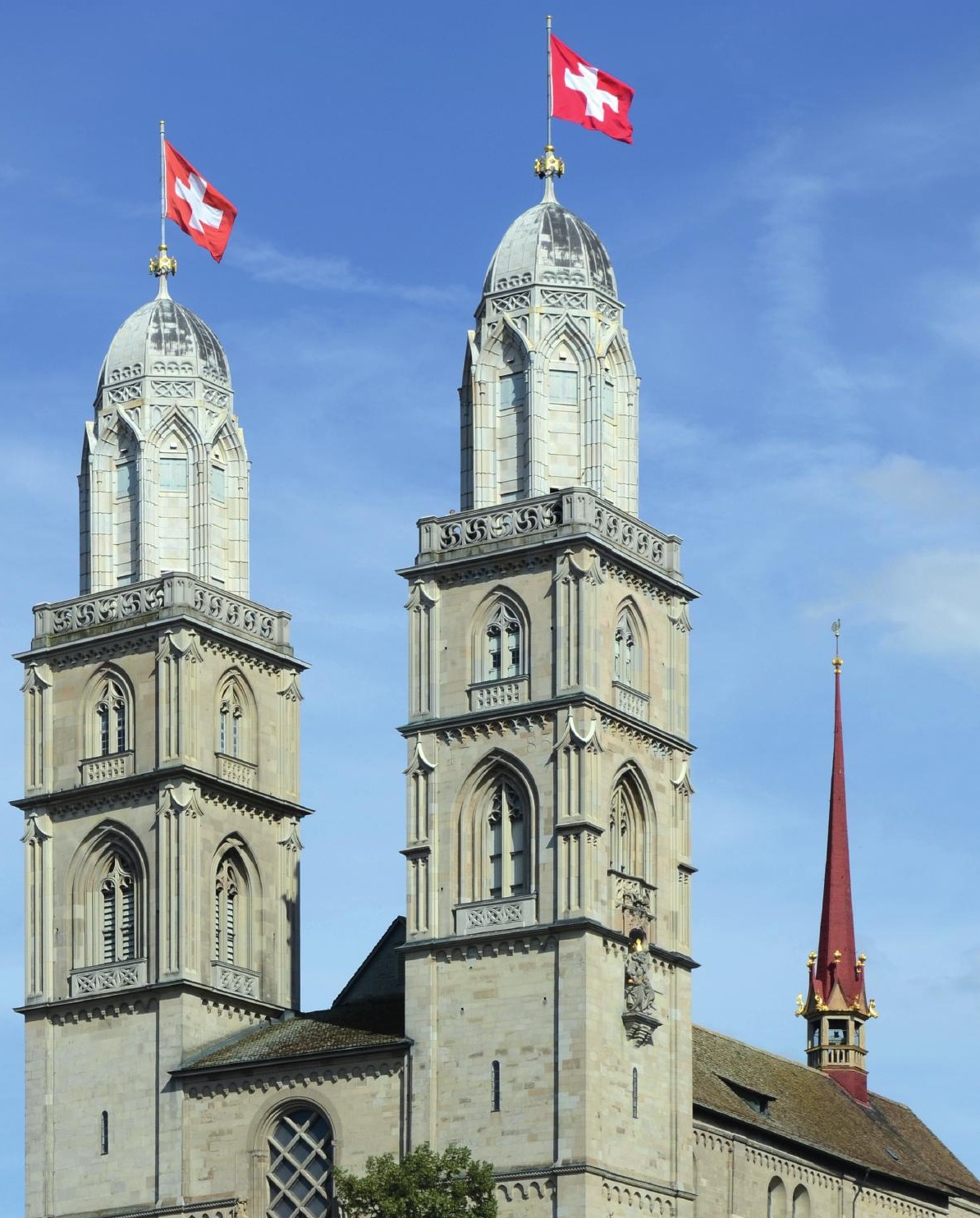




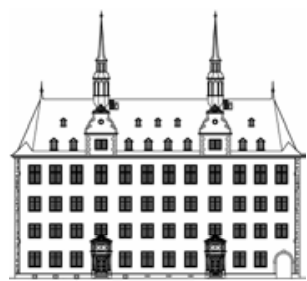




\section{Veröffentlichungen des \\ Instituts für Europäische Geschichte Mainz}

Abteilung für Abendländische Religionsgeschichte

Herausgegeben von Irene Dingel

Beiheft 123 


\title{
Säkularisierung und Religion
}

Europäische Wechselwirkungen

\author{
Herausgegeben von \\ Irene Dingel und Christiane Tietz
}

Unter Mitarbeit von
Marion Bechtold-Mayer

Vandenhoeck \& Ruprecht 
Bibliografische Information der Deutschen Nationalbibliothek: Die Deutsche Nationalbibliothek verzeichnet diese Publikation in der Deutschen Nationalbibliografie; detaillierte bibliografische Daten sind im Internet über https://d-nb.de abrufbar.

(C) 2019, Vandenhoeck \& Ruprecht GmbH \& Co. KG, Theaterstraße 13, D-37073 Göttingen

Dieses Werk ist als Open-Access-Publikation im Sinne der Creative-CommonsLizenz BY-NC-ND International 4.0 (»Namensnennung - Nicht kommerziell Keine Bearbeitungen «) unter dem DOI 10.13109/9783666570933 abzurufen.

Um eine Kopie dieser Lizenz zu sehen, besuchen Sie

https://creativecommons.org/licenses/by-nc-nd/4.0/.

Jede Verwertung in anderen als den durch diese Lizenz zugelassenen Fällen bedarf der vorherigen schriftlichen Einwilligung des Verlages.

Coverabbildung: Grossmünster, Zürich, Wikimedia Commons,

CC-BY-SA-3.0, () Marcin Białek, 2012.

Satz: Vanessa Weber, Mainz

Vandenhoeck \& Ruprecht Verlage | www.vandenhoeck-ruprecht-verlage.com

ISSN 2197-1056

ISBN 978-3-666-57093-3 


\section{Inhaltsverzeichnis}

Vorwort

I. Säkularisierung - Diskussionen um ein Forschungsparadigma

Hartmut von Sass

Von Deutungsmächten wunderbar verborgen. Habermas, Taylor

und die Metakritik der Säkularisierungstheorie

Detlef Pollack

Religion in der Moderne

II. Historische Zugänge und Perspektiven

Christopher Voigt-Goy

Naturwissenschaft als »Leitwissenschaft«? Zum Verhältnis von

naturwissenschaftlicher Methode und Religion in der Frühen Neuzeit ..

Jan Kusber

Politische Ideologien und ihre säkularisierende Wirkung das Beispiel Russland im 20. und 21. Jahrhundert

III. Perspektiven auf Säkularisierung in der Gegenwart

Manfred Sing

Der Islam als Kontrastfolie in der Säkularisierungsdebatte.

Ein mehrfaches Missverständnis?

Rebecca Milena Fuchs

Glaube durch Denken ins Gespräch bringen und zum

»Tisch des Lebens« (Joseph Ratzinger) einladen. Phänomene des

Säkularismus als Ansporn für kirchliche Selbstreflexion

und theologische Konzentration 
Matthias Felder und Frank Mathwig

Bekennen und Säkularisierung. Zur gesellschaftlichen Verortung der Kirche aus reformierter Sicht

Michael Germann

Säkularisierung und Religion in der Perspektive

des Religionsverfassungsrechts

Autoren- und Mitarbeiterverzeichnis

Orts- und Personenregister 


\section{Vorwort}

In den vergangenen Jahren ist das historisch-soziologische Narrativ, das die Entstehung der modernen Welt auf bereits in der Frühen Neuzeit einsetzende und sich im Zuge der Jahrhunderte verstärkende Säkularisierungsprozesse zurückführt, zunehmend in die Kritik geraten. Gleichzeitig mehren sich Stimmen, die fast aggressiv eine noch stärkere Säkularisierung fordern. Eine interdisziplinäre Tagung, die in Zürich vom 4. bis 6. Dezember 2015 in Zusammenarbeit mit Prof. Dr. Richard Amesbury stattfand, vom Schweizerischen Nationalfond unterstützt wurde und in diesem Band in Auswahl dokumentiert wird, hatte sich deshalb zum Ziel gesetzt, Licht auf die Säkularisierungsthese bzw. auf das Säkularisierungsparadigma selbst zu werfen.

Nach grundlegenden Klärungen der Begrifflichkeit sowie der Theorien und Theorieentwicklungen werden sowohl historische als auch gegenwartsbezogene Zugänge entfaltet, um die Säkularisierungsthese und ihre Anwendbarkeit auf den Prüfstand zu stellen.

Zur Sprache kommen zunächst Säkularisierungsschübe und deren Auslöser in der Geschichte; dabei interessiert besonders die Frage, wie weit Religion und religiöse Praxis tatsächlich verdrängt wurden. Wie haben Säkularisierungsprozesse gelebte Religion verändert? Und welche gesellschaftlichen und politischen Folgen gingen damit einher? Kam es zu einem Rückzug der Religion aus der Öffentlichkeit oder gerade zu ihrer Selbstbehauptung gegen säkularisierende Tendenzen?

Für die Gegenwart werden die Perspektiven unterschiedlicher christlicher Konfessionen sowie des Islam berücksichtigt und eine religionsverfassungsrechtliche Einschätzung vorgelegt. Dadurch erhalten gegenwärtige Debatten über die Rolle von Religion in säkularisierten Gesellschaften sowie Forderungen nach notwendigen Säkularisierungen eine differenziertere Gestalt.

Ganz am Ende soll der Dank stehen, und zwar an all diejenigen, die zum Entstehen dieses Bandes beigetragen haben. Eine besonderer Dank geht an Dr. Christiane Bacher und Vanessa Weber für die geduldige und kompetente Betreuung der Drucklegung in der Redaktion des Leibniz-Instituts für Europäische Geschichte.

Mainz und Zürich, den 2. Februar 2019

Irene Dingel und Christiane Tietz 


\section{SÄKULARISIERUNG - DisKUSSIONEN UM EIN FORSCHUNGSPARADIGMA}




\title{
Hartmut von Sass
}

\section{Von Deutungsmächten wunderbar verborgen}

\author{
Habermas, Taylor und die Metakritik der Säkularisierungstheorie
}

\section{Auftakt: Die Säkularisierung in Zeiten ihrer Nachrufe}

Das Ableben der Säkularisierungsthese dauert schon jetzt länger als ihre vitale Existenz in vergangenen Dekaden. Der zeitgenössische Daseinsmodus jener These gleicht insofern den Variationen ihrer heutigen Traueranzeige. Es waren spätestens die mittleren 1990er Jahre, die den kumulativ herbeigeführten Bruch mit jener früheren Erfolgsgeschichte besiegeln sollten. Der Gestus reichte von einer unversöhnlichen Verabschiedung, die Rodney Stark »Secularization, R.I.P.« titeln ließ $\beta^{1}$, bis hin zu einer vorsichtigeren Differenzanamnese à la David Martin oder José Casanova, die jene Großthese bekanntlich in Subthesen einer Aufsplitterung sozialer Systeme, der Privatisierung, Urbanisierung, Modernisierung zergliederten ${ }^{2}$.

Alle diese Reaktionen zwischen Verabschiedung und Differenzierung zollten dem Umstand Tribut, dass sich die Säkularisierungstheorie in ihrer klassischen Gestalt entweder als schlicht falsch erweisen musste, konfrontierte man sie endlich mit der Normativität des Faktisch-Empirischen ${ }^{3}$, oder aber als uninformativ, weil die von ihr behaupteten korrelativen oder gar kausalen Verhältnisse als zu unspezifisch, ambivalent und mit Blick auf unterschiedliche Zeiten, Kulturen und Milieus invariant und darum unsensibel daherkamen ${ }^{4}$. Die methodischen Implikationen umfassender, ja global angelegter Generalisierung soziologischer Erklärungen haben sich als der-

1 Siehe Rodney Stark, Secularization, R.I.P., in: Sociology of Religion 60/3 (1999), S. 249-273, bes. S. 260f. und 270.

2 Dazu José Casanova, Public Religions in the Modern World, Chicago, IL u.a. 1994, Kap. 1: Secularization, Enlightenment, and Modern Religion und bes. S. 211f.

3 Dazu Peter L. Berger, The Desecularization of the World. A Global Overview, in: Ders. (Hg.), The Desecularization of the World. Resurgent Religion and World Politics, Grand Rapids, MI 1999, S. 1-18, bes. S. 3; Hans JoAs, Glaube als Option. Zukunftsmöglichkeiten des Christentums, Freiburg 2012, Kap. 1 und 3.

4 Siehe Hartmut Lemmann, Säkularisierung. Der europäische Sonderweg in Sachen Religion, Göttingen ${ }^{2} 2007$, Kap. 3: Säkularisierung, Transformation der Religion oder Rückkehr der Religionen; Johannes ZAChнubER, Die Diskussion über Säkularisierung am Beginn des 21. Jahrhunderts, in: Christina von Braun u.a. (Hg.), Säkularisierung. Bilanz und Perspektiven einer umstrittenen These, Berlin 2007, S. 11-42, bes. S. 14-19. 
art problematisch herausstellt, dass das Projekt der Säkularisierungstheorie nicht einfach faktisch gescheitert ist. Vielmehr scheint es so zu sein, dass die diagnostischen oder gar explikativen Hoffnungen, die auf jener Theorie ruhten, von vornherein uneinlösbar waren. Das theoretische Ergebnis immer neuer Dekonstruktionen vormaliger Allgemeinheitsansprüche liest sich wie der Beipackzettel zu den unübersehbaren "Risiken und Nebenwirkungen" einfachster Präparate. An die Stelle des Generalschlüssels, der Modernitätssteigerung noch mit Religionsrückzug parallelisieren konnte, treten nun weitaus zurückhaltendere Befunde. Sie implementieren zusätzliche kulturelle, historische, intellektuelle Parameter in die soziologische Theoriebildung. $^{5}$. Mit der handlichen These von der Säkularisierung ist es seitdem vorbei, angebrochen ist hingegen längst die Zeit tentativer Verallgemeinerungen bestenfalls mittlerer Reichweite ${ }^{6}$. Damit ist die derart provinzialisierte Säkularisierung als theologisches und philosophisches Thema wenn nicht uninteressant geworden, dann immerhin erheblich marginalisiert.

Doch stellt sich diese in sich komplexe Debatte nur als erste Phase der Kritik am Säkularisierungsparadigma heraus. Sie sei als die intern-soziologische bezeichnet. Eine zweite Periode schloss sich seit den frühen Nullerjahren an, die auf die gesellschaftlich schwerwiegenden Resultate der Säkularisierung und ihre gegenläufigen Revisionen aufmerksam machte. Jene antizipative Kritik als - so im Untertitel - »Metakritik« könnte die extern-ideenpolitische genannt werden. Ging es im ersten Fall noch um die Widerlegung einer allzu forsch formulierten Säkularisierungstheorie mit den bekannten proto-ideologischen Beimischungen vom »Ende der Religion ${ }^{7}$, geht es im zweiten Fall jenseits der Alternative zwischen wahrhafter Säkularisierung und der »Wiederkehr der Götter ${ }^{8}$ um die Implikationen beider Szenarien für die individuelle Identität, die kollektiven Wertungen und die Legitimierung von Staat

$5 \mathrm{Zu}$ diesen Differenzierungen und dem daraus folgenden Begriff der Säkularisierung siehe C. John Sommerville, Secular Society/Religious Population. Our Tacit Rules for Using the Term »Secularization", in: JSSR 37/2 (1998), S. 249-253.

6 Die säkularisierungstheoretischen Annahmen sind demnach nicht einfach unzutreffend, sofern sie in einem case-by-case-Vorgehen mit spezifischem soziologischen Fokus erprobt werden; dazu wiederum BERGER, The Desecularization of the World. A Global Overview, S. 18. - Es sei, so José Casanova, daher für eine sensible Formulierung der Säkularisierungstheorie nötig, die protestantische Spezialperspektive, die Präferenz für liberale Konzeptionen des Politischen und die methodische Referenz auf den souveränen Staat soziologisch aufzugeben; so in CASANOva, Public Religions in the Modern World, S. 39.

7 Vgl. Jörg Dierken, Religion am Ende - am Ende (doch) Religion? Soziologische und theologische Perspektiven, in: Ders., Ganzheit und Kontrafaktizität. Religion in der Sphäre des Sozialen, Tübingen 2014, S. 23-42.

8 Vgl. Friedrich Wilhelm Graf, Die Wiederkehr der Götter. Religion in der modernen Kultur, München ${ }^{3} 2007$. 
und Gesellschaft unter pluralistischen Vorzeichen. Während die intellektuelle Gestimmtheit zunächst die der offensiven Kritik war, ist sie nun die der abwägenden Warnung.

Von dort aus ist es kein allzu weiter - und dennoch sehr gewagter - Sprung in eine dritte Phase, die sich zur zweiten zeitlich nur leicht versetzt abzeichnete und die die involviert-gegenmissionarische genannt sei ${ }^{9}$. Die Bedenken steigern sich hier in ein parteiliches Engagement für die Desäkularisierung in doppelter Frontstellung zu allen post-Weberschen Theoremen, aber auch gegenüber allen als allzu seicht empfundenen returns zu irgendwelchen Göttern im Dunstkreis kitschiger Spiritualität. Nicht Kritik dominiert in dieser dritten Phase, auch nicht nur die Warnung vor den unwiederbringlichen Verlusten gerade erfolgreicher Säkularisierungen. Denn diese Warnung wird nun zu einer "äußeren Mission« amplifiziert, einer Mission zugunsten der Wiederaneignung anderenfalls verschollener Sinnressourcen, Identitätsstifter, Existenzvertiefer, Akzeptanzbeschaffer.

Im Folgenden wird die These vertreten, dass Jürgen Habermas und Charles Taylor - ein sich nicht unbedingt sympathisches Gespann - keineswegs zur ersten Phase gehören, sondern der "religiös unmusikalische« Habermas zur zweiten der Warnung und der praktizierende Katholik Taylor zur dritten der Gegenmission $^{10}$. Dazu werden zunächst kurze Abrisse ihrer theoretischen Anliegen mit Blick auf die Frage der Säkularisierung angeboten (1), anschließend zentrale Motive durchgegangen, die in einem inszenierten Dialog zwischen beiden problemorientiert besprochen werden (2), um mit einem Vorschlag zu enden, wie Habermas und Taylor im Blick auf die skizzierte Diskussion neu gelesen werden könnten (3).

\section{Habermas und Taylor über Säkularisierung: Ein doppeltes abstract}

Die klassische Theorie der Säkularisierung besagt, Module der Modernität verhielten sich korrelativ oder verursachend umgekehrt proportional zum Florieren des Religiösen. Die Intensivierung aller Konkretionen der Moderne ginge demnach, so Weber, Durkheim und all ihre Jünger »zweiter Hand«, mit einer Erosion religiöser Praxis in privaten Zirkeln sowie einer

9 Vielleicht ist es insofern angebracht, statt von »Phasen« innerhalb einer Entwicklung eher von »Dimensionen « einer Debatte zu sprechen.

10 Zur Religion als analogon einer musikalisch metaphorisierten Stimmung, Dynamik, Atmosphäre siehe klassisch Georg Simmel, Die Religion (1912), in: Martin Buber (Hg.), Die Gesellschaft. Sammlung sozialpsychologischer Monographien, Bd. 2, Frankfurt a.M. 1912, bes. S. 12 und 42. 
Entkirchlichung im öffentlichen Raum einher ${ }^{11}$. Eben diese Hybridtheorie krankte von vornherein an zwei Irritationen, deren Beachtung zugleich den schleichenden, dann sich beschleunigenden Abtragungsprozess einläutete, welchen wir heute eher zur Kenntnis nehmen, als wirklich noch diskutieren: Zum einen passten prominente Weltregionen nicht ins global angelegte Raster der Säkularisierung. Die USA zur "great exception from the rule« zu erklären, war daher lediglich religionssoziologische Kosmetik, die ihren Dienst allerdings erstaunlich lange verrichtete. Zum anderen fungierte das schillernde Etikett der »Säkularisierung« nie als rein deskriptiv-analytischer Term. Schon die theoretisch wie empirisch ungedeckten Extrapolationen, die besagten, die Säkularisierung münde in ein »religionsloses Zeitalter«, überzogen das diagnostische Konto beträchtlich. Profitieren konnte davon eine negativ gefärbte, von vielen jedoch mit Genugtuung rezipierte Eschatologie der Post-Religion ${ }^{12}$.

Diese hier nur skizzierte Debatte gehört in die erste Phase, die gerade als intern-soziologische der Kritik vorgestellt wurde. Zwar bildet sie den Hintergrund, nicht aber das Zentrum des Interesses unserer beiden Begleiter. Worum aber geht es ihnen dann? Als Jürgen Habermas im Oktober 2001 das Rednerpult der Frankfurter Paulskirche betrat, lag das, was sich als "nine/eleven" ins kollektive Gedächtnis eingebrannt hat, nur einige Tage zurück. Unter dem Titel »Glauben und Wissen«, mit dem sich der Friedenspreisträger in die Tradition von Hegel und Adorno stellte, zeigte der erklärte Atheist Habermas eine diagnostische Sensibilität, die er in Sachen Religion zuvor nie hat bekunden wollen. Es hätte nahe gelegen, die »Theorie des kommunikativen Handelns « unter dem Eindruck pseudo-religiös motivierten Terrors von einer methodischen Religionsdistanz zu einer programmatischen Religionsaversion fortzuschreiben. Genau dies ist - zur Überraschung vieler Kollegen und zur verfrühten Freude einiger Theologen - nicht geschehen. Habermas hielt sich an ein Diktum, welches sich bereits im 1981 veröffentlichten Hauptwerk findet; dort heißt es:

Die Fähigkeit, die besten Traditionen anzueignen und zu verarbeiten, ist [...] ein Zeichen für die Anschlussfähigkeit und die Fassungskraft von Gesellschaftstheorien, die immer auch auf die Durchsetzung eines bestimmten, im kollektiven Selbstverständnis verwurzelten Paradigmas von Gesellschaft abzielen ${ }^{13}$.

11 Vgl. den Überblick bei ZaChHuber, Die Diskussion über Säkularisierung am Beginn des 21. Jahrhunderts, Abschnitt 1 und 2.

12 Dazu bereits Emile Durkheim, Die Grundformen des religiösen Lebens (1912), in: Friedrich Fürstenberg (Hg.), Religionssoziologie, Neuwied u.a. ${ }^{2} 1970$, S. 35-55.

13 Jürgen Habermas, Theorie des kommunikativen Handelns, Bd. 1: Handlungsrationalität und gesellschaftliche Rationalisierung, Frankfurt a.M. 1981, S. 269. 
Habermas löste diese methodische Regel genau 20 Jahre später so ein, dass er die zum Teil drastisch veränderten Parameter im Abendland mit in die »Fassungskraft« seiner Gesellschaftstheorie produktiv aufnahm. Folglich bewährte die Theorie des kommunikativen Handelns ihre »Anschlussfähigkeit» gerade dadurch, dass sie »der « Religion nicht konfrontativ, sondern invitativ begegnete ${ }^{14}$. Habermas blieb ganz Habermas, sofern er nicht primär von der Binnenlogik der Religion her dachte; angetrieben war er vielmehr von der bedrohlichen Herausforderung des Rechtsstaates durch Gewaltakte unterschiedlichster Couleur, die auf ein Motivationsdefizit eben dieses Rechtsstaates aufmerksam machten. Für diese motivationalen Leerstellen stellten Religionen gerade nicht das Problem dar, sondern womöglich einen Teil der Lösung.

Dabei erweist sich für Habermas nicht die Legitimierung des Rechtsstaates als die eigentliche Schwierigkeit; hier ist er ganz Kantianer, insofern die Autonomie der Moral auf die politische Ebene gehoben wird, sodass das Politische in seiner Fundierung selbstgenügsam wirkt. Heteronome Quellen der Legitimierung hingegen müssten alles nur durcheinander bringen ${ }^{15}$. Habermas geht es weit eher um politische (Sekundär-)Tugenden - wie Solidarität, Engagement, Empathie -, die sich Fragen der Begründung offenbar entziehen, für das Funktionieren eines Staatsgebildes jedoch unhintergehbar seien. In leichter Abwandlung der berüchtigten Böckenförde-Doktrin stellt Habermas fest: »Der liberale Staat ist langfristig auf Mentalitäten angewiesen, die er nicht aus eigenen Ressourcen erzeugen kann ${ }^{16}$. Was hier als »Mentalitäten« angesprochen ist, beinhaltet Motivationen und Haltungen, die ihrerseits Elemente der Sinnstiftung voraussetzen, als deren »Sitz im Leben« Habermas vornehmlich die Religion ausmacht.

Nicht die Religion als autarkes und aus internen Gründen zu stärkendes, ja zu pflegendes Sozialsystem spielt für Habermas die maßgebliche Rolle; ihm geht es hingegen um das Anzapfen motivationaler Leistungen, die mit dem Rechtsstaat kompatibel sind, sich in ihm selbst jedoch nicht finden lassen. Daraus ergeben sich bereits die zwei wesentlichen Aspekte, die Habermas' Lagebericht als problematische Beigaben mit sich führt: Denn so sehr die Habermas'sche Wertschätzung der vor allem nicht-kognitiven Aspekte der Religion einen merklich neuen Ton anschlug, wurde die oben zitierte

14 Vgl. Jan Philip Reemtsma, »Laudatio« zur Verleihung des Friedenspreises des Deutschen Buchhandels 2001, S. 2-8, hier S. 2, URL: <http://www.friedenspreis-desdeutschen-buchhandels.de/sixcms/media.php/1290/2001_habermas.pdf $>$ (05.05. 2016).

15 Dazu Jürgen Habermas, Religion in der Öffentlichkeit. Kognitive Voraussetzungen für den »öffentlichen Vernunftgebrauch« religiöser und säkularer Bürger, in: Ders., Zwischen Naturalismus und Religion. Philosophische Aufsätze, Frankfurt a.M. 2005, S. 119-154, hier S. 126.

16 Ders., Einleitung, in: Ders., Zwischen Naturalismus und Religion, S. 7-13, hier S. 9. 
»Anschlussfähigkeit« seiner Theorie den Vorwurf der Funktionalisierung der Religion als Sozialkitt »höherer Ordnung« kaum los. Zudem wiederholte sich das Ausgangsproblem der (partiellen) Inkompatibilität von Staat und Kirche nun innerhalb der Theorie als potenzielle Unversöhnlichkeit säkularer mit religiösen Überzeugungen. Entsprechend entwickelt Habermas das Kommunikationsparadigma fort zu einer Analytik bürgerlicher Übersetzungsrechte und -pflichten.

Habermas' Beitrag zur Säkularisierungstheorie liegt demnach nicht in einer neuen Version der Theorie selbst. Unter Rückgriff auf Tendenzen klassischer Säkularisierung in Mitteleuropa sowie mit Blick auf dazu gegenläufige Prozesse florierender Religiosität und deren erneuter Prominenz stellt er die Frage nach den nichtrechtsstaatlichen Gründen des Rechtsstaates. Anlass dazu ist in gleichen Maßen die "Dekonstruktion des Christentums $«{ }^{17}$ sowie ein verstärkter Pluralismus, für den der religiös zunehmend unüberschaubare Markt nur eine weitere Zutat bildet. Habermas wird daher nicht müde davor zu warnen, das Verschwinden christlich imprägnierter Sinnquellen einfach hinzunehmen bzw. diese neue Pluralität theoretisch zu ignorieren. Dabei ist der Respekt vor »der« Religion immer schon mit Blick auf die Stabilität des Rechtsstaates ausgedrückt; sie ist also stets mit Hintergedanken formuliert, die Habermas seit seiner Friedenspreisrede antizyklisch vorträgt: Säkularisierungen im doppelten Modus von Erosion und Pluralisierung sind solange eine ernsthafte Bedrohung für den Rechtsstaat, als sich keine postreligiösen Äquivalente (er)finden lassen ${ }^{18}$. Da diese Substitution manchen als nicht praktikabel oder gar unmöglich, jedenfalls illusorisch erscheint, wäre die Säkularisierung als Bedrohung des Rechtsstaates auf Dauer geschaltet.

Geht es Habermas um die Religion als Integral einer rechtsstaatlichen Stabilisierung, entnimmt Charles Taylor die Religion, insbesondere das abendländische Christentum, dieser instrumentalisierenden Klammer. Nun

17 So Jean-Luc Nancy, Dekonstruktion des Christentums. Aus dem Französischen von Esther VON DER Osten, Zürich u.a. 2008, bes. S. 237-264.

18 Dazu bes. Jürgen Habermas, Ein Bewusstsein von dem, was fehlt (2007), URL: <http://www.nzz.ch/articleevb7x-1.110807> (05.05.2016) - Das sehen Autoren wie Richard Rorty ganz anders: Solidarität, Engagement, Empathie und insgesamt ein Sinn für Empfindsamkeit könnten sich der Welt der Literatur verdanken, dazu Richard RoRTy, Der letzte Intellektuelle in Europa. Orwell über Grausamkeit, in: Ders., Kontingenz, Ironie und Solidarität. Übersetzt von Christa KrüGer, Frankfurt a.M. 1992, Kap. 8; ders., Der Roman als Mittel zur Erlösung aus der Selbstbezogenheit, in: Joachim KüPper / Christoph Menke (Hg.), Dimensionen ästhetischer Erfahrung, Frankfurt a.M. 2003, S. 49-66, bes. S. 57. - Zudem ließe sich die angebliche Säkularisierungsresistenz christlicher Feste als Kulminationspunkte lebensweltlicher Orientierung und Sinnstiftung diskutieren. Beweist nicht gerade Weihnachten - ich muss zugeben: heute ist der 25. Dezember - gerade die bereits vollzogenen Transformationen, welche die christliche Botschaft durch nicht-christliche Elemente in den Hintergrund treten lässt. 
geht es nicht mehr um eine Warnung vor den motivationalen Untiefen bürgerlicher Partizipation in Zeiten verstärkter Pluralisierung, sondern um ein umfassendes Narrativ, das auf eine Pointe hin zugeschnitten ist: die engagierte Wiedergewinnung dessen, von dem jene letztlich unentbehrliche Großerzählung kündet ${ }^{19}$. In einem ideen- und mentalitätsgeschichtlichen Zugriff mit materialen Grundentscheidungen, die sich aus bestimmten kommunitaristischen, sprachphilosophischen, aber auch persönlich-religiösen Präferenzen speisen, versucht Taylor, eine Frage zu beantworten und sie mit einer Verlustgeschichte zu flankieren. Die Frage lautet: „Warum war es in unserer abendländischen Gesellschaft beispielsweise im Jahre 1500 praktisch unmöglich, nicht an Gott zu glauben, während es im Jahre 2000 vielen von uns nicht nur leichtfällt, sondern geradezu unumgänglich vorkommt?« (51; vgl. 899 und 927) ${ }^{20}$.

Sieht man für einen Moment von den weitreichenden Prämissen, die diese Frage mit Blick auf die religiöse Vergangenheit und Gegenwart mit sich führt, ab, öffnet sich sogleich der Blick für Taylors Passionsgeschichte mit ausführlicher Einleitung; denn sofern die Säkularisierung als Erosion des privat und öffentlich kodierten Glaubens erfolgreich ist, führe sie zu einer existentiellen Leere, lebensweltlichen Verflachung, einer verkümmerten Artikulationsfähigkeit, die einem öden Humanismus das Feld überlassen muss (988) - uns aber als Wesen ohne »Fülle« $(36,1206)$ zurücklasse. Taylors pessimismusaffiner Katholizismus gibt sich also als Gegenwartsdiagnose aus, greift aber immer wieder ins Register antizipierter Bedrohung. Deren Summar findet sich in der Klage eines elementaren Transzendenzverlusts (512), wobei die explizite Parteilichkeit der Beschreibung zusehends und im letzten Kapitel von A Secular Age dann ganz offensiv in ein desäkularisierendes Manifest übergeht. Unter der Zwischenüberschrift "Conversions" liefert Taylor die Heiligen-Vita einiger religiöser Überläufer, deren deskriptive und konfessionelle Einseitigkeit - um es mit Günter Thomas zu sagen - »unverschämt» zu nennen ist ${ }^{21}$.

Doch die Dinge liegen bei Taylor auch hier weitaus komplizierter. Parallel zur Säkularisierung als Verlustgeschichte revidiert Taylor genau dieses vertraut gewordene Narrativ, indem der angebliche Verlust eines glaubenden Engagements in Formen der Umbesetzung und Transformation seinerseits umkodiert wird. Zwar leugnet Taylor klassische Säkularisierungsprozesse

19 So Charles Taylor gegen Lyotard in: Charles TAYLOR, Ein säkulares Zeitalter. Aus dem Englischen von Joachim Schulte, Frankfurt a.M. 2009, S. 958.

20 Die Seitenzahlen in Klammern beziehen sich bis zum Ende des Abschnitts auf TAYLOR, Ein säkulares Zeitalter.

21 Günter Thomas, Die Versuchung religiöser Nostalgie. Eine protestantische Lektüre von Charles Taylors »Ein säkulares Zeitalter«, in: EvTh 73/6 (2013), S. 421-436, hier S. 431. 
keineswegs (859), hält aber immer wieder dagegen, dass die »Formen des Religiösen in der Gegenwart« (so der Titel der 1999 gehaltenen Giffordlectures) ganz unterschiedlichen Zuschnitts seien, die mit einem eindeutigen Verlust gerade nichts zu tun haben müssen.

Dabei ist nicht immer klar, ob Taylor die Säkularisierungsprozesse im Sinne der Erosion anders und zurückhaltender beurteilt oder ob er sie anerkennt, aber auf andere als von der Säkularisierungstheorie vorgesehenen Gründe zurückführt. Immerhin wird von hier aus die Differenzierung dreier Arten der Säkularisierung verständlich, deren Vermischung Taylor wiederholt anprangert ${ }^{22}$. Demnach ist als Säkularisierung 1 die Trennung von Öffentlichkeit (aus der sich die Religion zurückziehe oder verdrängt werde) und Privatem (wo sie ihr Refugium finde) zu verstehen (13). Als Säkularisierung 2 bezeichnet Taylor den schwer greifbaren Rückgang religiöser Praxis als solcher (14). Diese beiden Formen der Säkularisierung interessieren Taylor allerdings nur peripher, weil sein Interesse einer dritten, den beiden anderen vorgelagerten Form gilt. Die Säkularisierung 3 reagiert auf die oben zitierte Frage, um den Bedingungen der Möglichkeit offiziellen Unglaubens und damit der Faktizität des Optionalen des Glaubens nachzugehen (15, 34 und 703f.). Noch einmal Taylor im Original: »Eine säkulare Epoche ist eine, in der der Niedergang aller über das menschliche Gedeihen hinausgehenden Ziele denkbar wird « (43).

Der entscheidende Term ist »denkbar«; denn »säkular« meint nun gerade nicht säkularisiert, sondern jenseits der gewählten Option von Glaube, Nichtglaube, Andersglaube nimmt der Begriff auf die Notwendigkeit Bezug, sich aus einem religiösen Spektrum zu entscheiden, und die Möglichkeit, ein bestimmtes Leben zu führen im Bewusstsein der Kontingenz der eigenen Wahl angesichts lebensweltlicher Alternativen $(31)^{23}$.

Um zusammenzufassen: Habermas befindet sich im Modus permanenter Sorge; diese gilt nicht der Religion selbst, sondern der Stabilität des Rechtsstaates, der in motivationaler Hinsicht unterversorgt sei und daher auf Quellen des Engagements angewiesen bleibe, die entweder durch klassische Säkularisierung erodierten oder durch einen zersplitterten lebensanschaulichen Pluralismus unter Druck gerieten. Vorausgesetzt ist folglich, dass Religionen jenes Defizit begleichen könnten, und verständlich wird, dass selbst bei religiöser Unmusikalität die Erosion oder Zergliederung der Religion gerade

22 Allerdings, so kritisiert Hans Joas, vermische Taylor selbst mit den unterschiedenen Arten der Säkularisierung ganz divergente Entwicklungen und Fragestellungen; dazu JoAs, Glaube als Option, S. 73.

23 Dazu Richard Amesbury, Religious Neutrality and the Secular State. The Politics of God's Absence?, in: Ingolf U. DAlferth (Hg.), The Presence and Absence of God, Tübingen 2008, S. 201-221, hier S. 218. 
kein Evangelium für die »Habermasse $\aleph^{24}$ darstellt. Taylor hingegen vollführt eine Doppelbewegung, indem mittels eines weiten Begriffs der religio Erosionen öffentlicher Religionspraxis im Gefolge Hans Blumenbergs als Umbesetzungen gedeutet werden ${ }^{25}$. Sogleich setzt Taylor jene zuvor abgewiesene Verlustgeschichte voraus, um der Drohgebärde lebensweltlicher Verflachung etwas Dringlichkeit einzuhauchen und um zum Schluss im Aufweis der Möglichkeit des Glaubens in einem säkularen Zeitalter ideenpolitische Agitation gegen den Religionsverlust zu betreiben. Während Habermas in der extern-ideenpolitischen Phase im Modus der Warnung vor der Bedrohung eines instabilen Rechtsstaates verbleibt, gehört Taylor in die involviertgegenmissionarische Phase, um die Gebietsverluste des Transzendenzbezugs zumindest im Modus der Möglichkeit potenziell zu dementieren.

\section{Der Dissens im Dialog: Fünf Exemplare}

Es mag deutlich geworden sein, dass das Interesse an den Dynamiken der Säkularisierung bei Habermas und Taylor ganz unterschiedliche Formen annimmt. Diese Differenz lässt sich auf verschiedene Ausrichtungen philosophischer Theoriebildung zurückführen, sicher aber auch auf fast gegenläufig ausgeprägte intellektuelle Stimmungen. Am nachhaltigsten wirkt die Divergenz in der Stellung zur christlichen Tradition: Habermas verpflichtet sich zu genau jener Neutralität, die er dem Rechtsstaat weltanschaulich abverlangt, um jene Äquidistanz ein ums andere Mal zugunsten rechtsstaatlicher Stabilisierungsmaßnahmen bewusst zu suspendieren. Taylor hingegen steht von

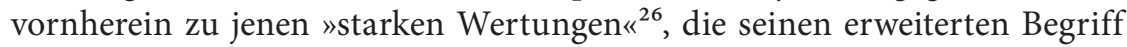
der Säkularisierung informieren. Die hermeneutische Regel der Abtragung oder zumindest Explikation der an den Gegenstand des Verstehens immer schon herangetragenen (Vor-)Urteile wird umfunktioniert, um eben jenes Voreingenommensein zum veritablen Zugang zur Materie zu erklären. Es deutet sich hier ein Dissens an, dem nun anhand von fünf miteinander verwobenen Momenten genauer nachzugehen ist.

24 Jacob Taubes, Ad Carl Schmitt. Gegenstrebige Fügung, Berlin 1987, S. 63.

$25 \mathrm{Vgl}$. Hans Blumenberg, Säkularisierung und Selbstbehauptung [Erweiterte und überarbeitete Neuausgabe von Legitimität der Neuzeit (1966)], Frankfurt a.M. 1974, S. 19, 90, 232.

26 Charles Taylor, Self-Interpreting Animals, in: Ders., Philosophical Papers, Bd. 1: Human Agency and Language, Cambridge 1985, ND 2005, S. 45-76, hier S. 65. 


\subsection{Motivationsdefizite des Rechtsstaats}

Der Rechtsstaat lebt nach Habermas über seine Verhältnisse, insofern sich die Motivation des autark legitimierten Staates aus Quellen speisen müsse, die über die engen Grenzen des Rechtlichen hinausgingen. Gerade in Zeiten des Terrors und der Gewalt verweist Habermas auf die bleibende Relevanz religiöser Symbolhaushalte für den Staat, aber auch die Gesellschaft, die sich diesen Staat gibt und wählt. Zwar sei die ehemals religiös kodierte Legitimierung längst profaniert ${ }^{27}$, während sich evaluative Aspekte lebensweltlicher Orientierung und biographischer Signifikanz einer derartigen Abtragung entzögen oder zumindest entgegenstellten.

Entsprechend sei es im Eigeninteresse des Verfassungsstaates, mit den kulturellen und darin auch religiösen Quellen von Normbewusstsein, Gemeinschaftssinn und Solidarität »schonend « umzugehen ${ }^{28}$. Habermas setzt demnach immer schon voraus, dass jene Quellen legitimationsfördernd wirken könnten, obschon es diese Quellen selbst sein mögen, die unter einem zunehmenden Anerkennungs- und Begründungsdefizit leiden. Die gesellschaftlich wie politisch weitaus realistischere Inversion der genannten BöckenfördeDoktrin findet bei Habermas daher keine Erwähnung; es könnte doch sein, dass die Religion langfristig auf Mentalitäten angewiesen ist, die sie nicht aus eigenen Ressourcen erzeugen kann $^{29}$. Für Habermas hingegen zeichnet sich die post-säkulare Gesellschaft gerade dadurch aus, sich auch in ihren dezidiert säkularisierten Elementen »einen Sinn für die Artikulationskraft religiöser Sprachen « zu bewahren ${ }^{30}$. Oder noch etwas emphatischer ausgedrückt: »(D)ie profane, aber nicht-defätistische Vernunft (hat) zu viel Respekt vor dem Glutkern, der sich an der Frage der Theodizee immer wieder entzündet, als dass sie der Religion zu nahe treten würde ${ }^{31}$.

27 Vgl. Jürgen Habermas, Glauben und Wissen. Rede zum Friedenspreis des Deutschen Buchhandels 2001. Laudatio: Jan Philipp Reemtsma, Frankfurt a.M. 2001, S. 12; dazu auch Nicholas Adams, Habermas and Theology, Cambridge 2006, Kap. 1: Religion in Public und Kap. 4: Sacred and Profane.

28 Ders., Vorpolitische Grundlagen des demokratischen Rechtsstaats?, in: Ders. / Joseph Ratzinger, Dialektik der Säkularisierung. Über Vernunft und Religion, Freiburg u.a. 2005, S. 15-37, hier S. 33.

29 Dazu Hans-Joachim HöHN, Gewinnwarnung. Religion - nach ihrer Wiederkehr, Paderborn 2015, S. 70. - Eben diese Lage zwischen Legitimationsdefizit und Handlungsnotwendigkeit nennt Hans Blumenberg die »rhetorische Situation «, sodass nun das Verhältnis Religion / Politik bzw. Religion / Rhetorik neu zu bedenken wäre; dazu Markus Buntfuss, "Modere Religion« als Antwort auf die »rhetorische Situation" des neuzeitlichen Christentums, in: Philipp Stoellger (Hg.), Rhetorik und Religion, Berlin u.a. 2015, S. 143-153.

30 Habermas, Glauben und Wissen, S. 13.

31 Ebd., S. 15. 
Der gegen dieses irenische Bild gerichtete Einwand einer Indienstnahme der Religion für die motivationalen Abgründe des Rechtsstaates ist bereits angesprochen worden. Dabei verweist Habermas gegen Kritiker wie Christian Danz mit gewissem Recht darauf, dass seine Verhältnisbestimmung von Staat und religiöser Tradition den intrinsischen Wert der Religion überhaupt nicht ausschließ $\mathrm{e}^{32}$. Doch scheint die hier implizit mitlaufende politische Theologie auf ein Friedensangebot an die etwas erlahmte Religion Zentraleuropas hinauszulaufen, die die Kirchen als institutionelle Vertreter jener Religion kaum werden annehmen können oder wollen. Selbst Theologen liberaler Tradition werden die »gegenpolitischen« Tendenzen der Kirche zur politischen Agenda des Staates verteidigen, zumal Religion zur Kultur auch im Modus der religiösen Kritik der Kultur gehört ${ }^{33}$.

Insofern müssten Habermas' Hoffnungen auf religiöse Stabilisierungsdienste zugunsten eines verlässlichen Staatsgebildes nicht nur gedämpft, sondern gerade mit zusätzlichen Herausforderungen konfrontiert werden: So sehr die christliche Religion eine der Nächsten- und Fernstenliebe sein mag, ist damit noch nicht ausgemacht, ob die rechtstaatliche Solidarität wirklich gestärkt würde, wenn sich etwa ein christlich motivierter Pazifismus in friedensethische Debatten einschaltete. Gerade dieses (gegen-) politisch ganz ernstzunehmende Engagement könnte es sein, das die säkulare Kritik des Staates erweitert, sodass die Religion mit jener »Obrigkeit« nun keinesfalls "schonend « umgehen wird ${ }^{34}$. Mit Charles Taylor ließe sich in Umkehrung der Habermas'schen Prämissen gar vermuten, ein Rechtsstaat, der tatsächlich Respekt vor dem religiösen »Glutkern« zeige, setze genau jene innere Stabilität für den Konflikt mit der Religion voraus, den sich der Staat gerade von der »Artikulationskraft« der Religion zu erhalten erhoffte ${ }^{35}$. Unter Habermas' Parametern läge eine Privatisierungsdoktrin, die die sonst öffentlich beunruhigende Religion domestizierte, viel näher, wenn die Stabilitätsrate des Rechtsstaates ein bestimmtes Maß unterschreitet. Also: Die

32 So ders., Ein Symposion über Glauben und Wissen. Replik auf Einwände, Reaktion auf Anregungen, in: Ders., Nachmetaphysisches Denken II. Aufsätze und Repliken, Berlin 2012, S. 183-237, hier S. 187.

33 Vgl. Dierken, Religion am Ende - am Ende (doch) Religion?, S. 41f. - Für einen stärkeren Begriff des Gegenpolitischen siehe Stanley Hauerwas, The Reality of the Church. Even a Democratic State is not the Kingdom, in: Ders., Against the Nations. War and Survival in a Liberal Society, Minneapolis, MN u.a. 1984, S. 122-131; ders., With the Grain of the Universe. The Church's Witness and Natural Theology, Grand Rapids, MI 2001, Kap. 4 und 5.

34 Dazu Hartmut von SAss, Politik des Pazifismus. Eine theologische Verteidigung, in: ZEE 60/1 (2016), S. 41-47.

35 Vgl. Charles Taylor, Die Politik der Anerkennung, in: Ders., Multikulturalismus und die Politik der Anerkennung. Aus dem Amerikanischen von Reinhard KaIser, Frankfurt a.M. 2009, S. 11-66, bes. S. 41-49. 
Religion als Inbegriff ihrer konfessionellen Pluralität wird den Staat viel eher irritieren, als sich für die Lieferung sonst fehlender Motivationsreserven einspannen zu lassen.

\section{2 Übersetzungsleistungen}

Eben jene Spannungen auf institutioneller Ebene spiegeln sich auch auf sprachlicher. Es ist wiederum Habermas, der den potenziellen Konflikt zwischen Rechtsstaat und Religion als ein Kollidieren unterschiedlicher Sprachspiele beschreibt. Es entsteht somit das Bild von zwei separaten sets an Artikulationsformen in der Spannung von Eigentümlichkeit und Übertragbarkeit, von Abkapselung und Anschlussfähigkeit. Dabei erkennt Habermas durchaus die Grenzen simpler Eingemeindung der "semantische(n) Erbschaft religiöser Überlieferungen ${ }^{36}$. Im Gefolge von Kierkegaard (sowie in Opposition zu Schleiermacher) arbeiteten Barth und Bultmann, so Habermas, »an der christlichen Glaubensbotschaft das Nicht-Integrierbare heraus, die unversöhnliche Opposition von Glauben und Wissen « $^{37}$.

Da es keinen Metadiskurs gebe, der jenseits der Alternative zwischen säkularen und religiösen Sprachspielen liege, sei eine Übersetzung in eine Richtung vonnöten - und zwar in die säkularen und als solche für alle verständlichen Diskurse. Es sei eine Suche nach der »rettende(n) Formulierung" notwendig, damit jene "Erbschaft « erfolgreich angetreten werden könne. Schließlich vollziehe sich eine Säkularisierung, die nicht vernichte, »im Modus der Übersetzung « ${ }^{38}$.

Zwar unterstreicht Habermas zuweilen den komplementär-gegenseitigen Lernprozess, sodass sowohl die Aufklärungstradition als auch der religiöse Lehrbetrieb zur Reflexion anzutreten hätten ${ }^{39}$. Doch diese Komplementarität besteht nicht in dem Versuch, die Sprachspiele gegebenenfalls in beide Richtungen zu übertragen, sondern in der Verteilung der Übersetzungslasten auf beide Seiten der Trennlinie, die zwischen säkularen und religiösen

36 Jürgen Habermas, Die Grenze zwischen Glauben und Wissen. Zur Wirkungsgeschichte und aktuellen Bedeutung von Kants Religionsphilosophie, in: Ders., Zwischen Naturalismus und Religion, S. 216-257, hier S. 218.

37 Ebd., S. 246.

38 Ders., Glauben und Wissen, S. 15; dazu Christiane Tietz, Habermas's Call for Translating Religion into Secular Language, in: Michael P. DeJonge/Christiane Tietz (Hg.), Translating Religion. What is Lost and Gained?, New York u.a. 2015, S. 104122, bes. S. 115-117; Stephan Jütte, Analogie statt Übersetzung. Eine theologische Selbstreflexion auf den inneren Zusammenhang von Glaubensgrund, Glaubensinhalt und Glaubensweise in Auseinandersetzung mit Jürgen Habermas, Tübingen 2016, Abschnitt 5.2.

39 Vgl. Habermas, Vorpolitische Grundlagen des demokratischen Rechtsstaats?, S. 17. 
Artikulationen verläuft. Allerdings ist auch dies bei Habermas so eindeutig nicht. Manches Mal klingt es so, dass allein die religiösen Bürger sich zu bemühen hätten, den Standards des säkularen Diskurses zu genügen, so sie sich in den "Diskurs der Moderne« tatkräftig einbringen wollen. Die kognitive Dissonanz als Bewohner zweier Staaten - civitas Dei et civitas terrena - zu verarbeiten, bedeutete dann, Übersetzungsarbeiten in der Hoffnung zu vollbringen, die zuvor beschworenen semantischen Sinnressourcen tatsächlich in der Übersetzung retten zu können. Dann aber klingt es etwas versöhnlicher, wenn Habermas jene Lasten auf potenziell alle Diskursteilnehmer verteilt. Der liberale Staat kann sogar von Ungläubigen erwarten, so Habermas weiter, dass sie eigene Anstrengungen unternehmen, um religiöse Gehalte in eine säkular zugängliche Sprache zu übertragen ${ }^{40}$. Und dann wiederum finden sich bei Habermas Einlassungen, in denen die Übersetzungsforderung ganz aufgegeben zu sein scheint, sodass auch genuin religiöse Gründe den »Zwanglosen Zwang des besseren Arguments« stiften könnten: Nicht immer werde übersetzt und nicht immer sei die Nichtübersetzung mit Unverständlichkeit gleichzusetzen ${ }^{41}$.

Abgesehen von diesem dritten, gleichsam pragmatisch entkräfteten Fall und abgesehen von der unentschiedenen Frage, wer die Subjekte des Übersetzens zu sein haben, bleibt das Problem, wie die "Erfahrung der säkularisierenden Entbindung religiös verkapselter Bedeutungspotentiale « ${ }^{42}$ produktiv eingebracht werden könnte. An welche »rettenden Übersetzungen« denkt Habermas und wo sieht er sie erfüllt? Es ist nicht so, dass Habermas keine Beispiele gäbe; hier ist eins: "Mit seinem Begriff der Autonomie zerstört er [Kant, H. von Sass] zwar die traditionelle Vorstellung der Gotteskindschaft. Aber den banalen Folgen einer entleerenden Deflationierung kommt er durch eine kritische Anverwandlung des religiösen Gehaltes zuvor « ${ }^{43}$.

Doch auch hier drängt sich der Verdacht auf, Habermas' Beschreibung der Lage spiele die Tiefe des "garstig breiten Grabens« zwischen säkularen und religiösen Äußerungen herunter. Schon diese simple Entgegensetzung ist unglücklich, zumal sich beide Seiten noch einmal in unterschiedliche »Dialekte« aufsplittern. Dann aber muss auch der faktische Primat, den der säkulare Diskurs genießt, problematisch erscheinen, weil in Zeiten seiner Pluralisierung das Vokabular, in welches übersetzt werden müsste, selbst zur Disposition steht ${ }^{44}$. Setzen wir jedoch einmal voraus, dass Her-

40 So ebd., S. 26; ders., Religion in der Öffentlichkeit, S. 136-138.

41 Vgl. ebd., S. 133f. und 136.

42 Ders., Vorpolitische Grundlagen des demokratischen Rechtsstaats?, S. 32.

43 Ders., Glauben und Wissen, S. 13.

44 Ein Teil der Debatte gehört einem Dialog zwischen Habermas und Joseph Ratzinger an, in welchem letzterer auf jene Pluralität des Sprachlichen und damit Rationalen aufmerksam macht - ohne (zumindest hier) auf die katholisch naheliegende 
kunfts- und Zielsprache eindeutig wären, ist immer noch zu diskutieren, ob nicht die gesamte Idee der »rettenden Übersetzung « von einer sprachphilosophischen Konfusion lebt. Schon das von Habermas selbst gegebene Beispiel, nach dem die »Gotteskindschaft« in das Sprachspiel der »Autonomie« geglückt übertragen sei, belegt eher das Gegenteil des Behaupteten; denn es illustriert gerade treffend - so wäre wiederum mit Taylor einzuwenden ${ }^{45}$ - das Scheitern der vermeintlichen Rettung jener semantischen Potenziale am metaphorischen Mehrwert religiöser Artikulation. Also: Um die Eigenheit religiöser Sprachspiele wirklich wertzuschätzen, ist deren partielle Unübersetzbarkeit gerade anzuerkennen; nicht der Text dürfte an einem ihm externen Standard gemessen werden, um diskursiv akzeptabel zu sein, sondern für ein wirkliches Verstehen wäre die umgekehrte Richtung einzuschlagen, um sich mit der internen Grammatik der Texte vertraut zu machen.

\section{$2.3 »$ Subtilere« Sprachen}

Die konservativ-pessimistische Klage über den Verlust einer moralisch treffenden, in ihrer Tiefe und ihrem Reichtum wirklich signifikanten Sprache findet sich zumeist gar nicht bei liberalen Diskursethikern. Viel häufiger trifft man sie auf einer der Gegenseiten an, nämlich bei kommunitaristischen Tugendethikern wie Alasdair McIntyre, der meint, die Sprache der Moral befinde sich gegenwärtig in einem »state of grave disorder ${ }^{46}$. Aus dieser Unordnung folgen dann kritische Einlassungen gegen zahlreiche Ismen wie Individualismus, Pragmatismus und Naturalismus, denen entsprechend sprachkreativ oder in Rückbesinnung auf das Erlernen der "alten Sprache" zu begegnen wäre. Dabei wird allerdings häufig übergangen, dass die Zeit

Gegenposition zu verfallen, nach der die Religion über jene im Rationalen vergeblich gesuchte Einheit verfüge; siehe Joseph RATzinger, Was die Welt zusammenhält. Vorpolitische moralische Grundlagen eines freiheitlichen Staates, in: HABERMAs / ders., Dialektik der Säkularisierung, S. 39-60, bes. S. 55. - Dass der Debatte eine ebenso unglückliche Entgegensetzung von »Vernunft « und »Religion « zugrunde liegt, ist in jenem Kontext vielleicht sogar unvermeidbar; zum Problem siehe Herbert SchnäDElbach, In der Höhle des Löwen. Zur Diskussion zwischen Jürgen Habermas und Kardinal Ratzinger. Ein Nachtrag, in: Ders., Religion in der modernen Welt, Frankfurt a.M. 2009, S. 147-152; Ingolf U. DALFERTH, Glaube oder Vernunft? Kritik einer Konfusion, in: Ders., Transzendenz und säkulare Welt. Lebensorientierung an letzter Gegenwart, Tübingen 2015, S. 129-177.

45 Dazu Charles Taylor, Heidegger on Language, in: Hubert L. Dreyfus / Mark A. Wrathall (Hg.), A Companion to Heidegger, Oxford 2008, S. 433-455, hier S. 441f.

46 Alasdair MacIntyre, After Virtue. A Study in Moral Theory, Notre Dame ${ }^{2} 1984$, S. 2; ähnlich: Elizabeth Anscombe, Modern Moral Philosophy, in: Philosophy 33/1 (1958), S. 1-19. 
der Heraufkunft genau jener Ismen religionssemantisch eine "pluralistische Sprachrevolution ${ }^{47}$ im ausgehenden 19. Jahrhundert gewesen ist, in der insbesondere der "Sprachgeist ${ }^{48}$ Schleiermachers nachwirken konnte. Mit Blick auf unser Thema wäre es demnach verfrüht bis verfehlt, Säkularisierungsprozesse mit Spracherosionen gleichzusetzen. Im Gegenteil scheint es so zu sein, dass die in Zeiten der Industrialisierung etwa in England und Deutschland einsetzende Entkirchlichung eine Suche nach neuen Artikulationsformen freisetzte, deren Intensität jedoch zugleich die Dringlichkeit dieses Projekts bezeugte.

Doch Habermas und mehr noch Taylor erzählen die Geschichte ganz anders. Für sie zeichnet sich in der Tat ein Konnex zwischen Säkularisierungsschüben und Spracheinbußen ab, wobei nicht immer klar ist, was als Ursache und was als Wirkung fungiert. Gegen rein prozedurale Ethiken (wie bei Richard Dworkin) macht Taylor geltend, dass wir uns einen "Sinn für das, was gut, heilig, bewundernswert ist ${ }^{49}{ }^{9}$, zu erhalten haben. Und da jede Erfahrung ein Vokabular voraussetze, schrumpfe das Erfahrene und damit zugleich der orientierende Sinn fürs Gute, Heilige und Bewundernswerte, wenn es zu semantischen Verlusten komme. Hier bedient sich Taylor eines sprachidealistischen Arguments, in welchem Sprache nicht nur Ausdruck bleibt, auch nicht nur als quasi transzendentale Ermöglichung von Erfahrungen fungiert, sondern auf diese Erfahrung gar ursächlich wirken könnte ${ }^{50}$.

Neben dieser intellektualisierenden Analyse bietet Taylor eine historische Symptomerkundung, die jene semantische Verlustgeschichte bebildern und darin erhärten soll. Bereits in seinem Buch Quellen des Selbst verfolgte Taylor das Schwinden der »subtileren Sprachen« der Romantik, die heute an Resonanz und Kraft eingebüßt hätten und einem instrumentellen Sinn der Sprache hätten weichen müssen ${ }^{51}$. Die daraus gefolgerte Verflachung und Reduktion unserer Lebensvollzüge gießt Taylor dann in ein umfassendes

47 Friedrich Wilhelm Graf, Die Wiederkehr der Götter. Religion in der modernen Kultur, München ${ }^{3} 2007$, S. 171; vgl. ferner: ders., Kirchendämmerung. Wie die Kirchen unser Vertrauen verspielen, München ${ }^{3} 2013$, Kap. 1: Erste Untugend: Sprachlosigkeit.

48 Blumenberg, Säkularisierung und Selbstbehauptung, S. 132 - Vielleicht hatte Blumenberg dabei an folgende Passage gedacht: "Das Christenthum hat Sprache gemacht. Es ist ein potenzirender Sprachgeist von Anfang an gewesen und noch«: Friedrich D.E. Schleiermacher, Hermeneutik. Neu nach den Handschriften hg. und eingel. von Heinz Kimmerle, Heidelberg ${ }^{2} 1974$, S. 38.

49 TAYlor, Die Politik der Anerkennung, S. 59.

50 Vgl. ders., Lichtung or Lebensform. Parallels between Heidegger and Wittgenstein, in: Ders., Philosophical Arguments, Cambridge u.a., S. 61-78; ders., Die Formen des Religiösen in der Gegenwart. Aus dem Englischen von Karin Wördemann, Frankfurt a.M. 2002, S. 30f.

51 Vgl. Charles Taylor, Quellen des Selbst. Die Entstehung der neuzeitlichen Identität. Aus dem Englischen von Joachim Schulte, Frankfurt a.M. 1996, Kap. 23; ders., 
Narrativ, das sich seinerseits in (ungefähr) fünf Kapitel teilen lässt: Es beginnt mit den frühneuzeitlichen Verinnerlichungsschüben, die schließlich in eine »Apotheose des modernen Subjekts« mündeten und einen gesellschaftlich katastrophalen Individualismus begründeten. Für diesen verantwortlich seien vor allem Luther, Descartes und Rousseau ${ }^{52}$. Aus diesem Bild subjektivistischer Ich-AG’s ergebe sich ein »Providenzieller Deismus«, der den anthropozentrischen Wandel in einer unpersönlichen Ordnung der Welt spiegele $^{53}$. Die unvermeidliche Folge bestehe darin, dass der Sinn für jenseitige Ziele verkümmere, um sie so sehr herunter zu drosseln, dass man für die Erreichung der Vorhaben keine divine Hilfe mehr benötige: Gnade wird entbehrlich ${ }^{54}$. Über die Zwischenstufen eines ausgrenzenden Humanismus mit Blick auf den Menschen ${ }^{55}$ und eines exklusiven Naturalismus mit Blick auf die Umwelt ${ }^{56}$ gelangt Taylor schließlich zu dem, was er »immanent frame« nennt. Während wir zunächst als "poröse Selbste« existierten, die die Osmose zwischen Lebenswelt und Jenseits zuließen, glichen wir nun »abgepufferten Monaden ", die in einem moralischen und epistemischen Kokon dahinsiechen. Irritationen von außen seien da nicht nur unerwünscht, sondern verunmöglicht. Doch das irgendwie sich bewahrende Bedürfnis nach "mehr" breche sich irgendwann Bahn, sodass Taylor bereits im Präteritum feststellt: »Es verband das Gefühl, der immanente Rahmen sei einengend, ja erdrückend und lasse etwas Lebenswichtiges unberücksichtigt, mit dem rückwärtsgewandten Blick auf die tiefen Wurzeln der Kultur und der Ordnung ${ }^{57}$.

Bei aller Sympathie für Taylors Sprachidealismus und bei aller Bewunderung für seine Geduld, narrativ weit auszuholen, muss sich Widerstand gegen diese nostalgischen Anwandlungen regen. Ähnlich wie Rodney Starks Einwand gegen klassische Säkularisierungsprozesse, der darauf beruht,

Ein säkulares Zeitalter, S. 1252; »Subtilere Sprachen« ist eine Wendung, die auf den englischen Schriftsteller Percy Shelley zurückgeht, der allerdings - und das will zu Taylors Sicht nicht ganz passen - ein strenger Verfechter des Atheismus gewesen war.

52 Siehe TAYLOR, Ein säkulares Zeitalter, S. 363 und 1213.

53 Dazu ebd., Kap. 6.

54 So ebd., S. $418 f$.

55 Vgl. ähnliche Kritiken bei Alain BAdiou, Nachwort: Das gemeinsame Verschwinden von Mensch und Gott, in: Ders., Das Jahrhundert. Aus dem Französischen von Heinz JATHo, Berlin u.a. ${ }^{2} 2010$, S. 203-219; Ulrich H.J. KÖRTNER, Wiederkehr der Religion? Das Christentum zwischen neuer Spiritualität und Gottvergessenheit, Gütersloh 2006, S. 172.

56 Dazu auch Jürgen Habermas, der meint: »Der Fluchtpunkt dieser Naturalisierung des Geistes ist ein wissenschaftliches Bild vom Menschen in der extensionalen Begrifflichkeit von Physik, Neurophysiologie oder Evolutionstheorie, das auch unser Selbstverständnis vollständig entsozialisiert" (Glauben und Wissen, S. 11).

57 TAYLOR, Ein säkulares Zeitalter, S. 1215; zu den Wendungen des "porösen« und "abgepufferten« Selbst siehe ebd., bes. S. 72. 
dass mit dem Mythos vom wahrhaft christianisierten Abendland Schluss gemacht wird, um auch die Säkularisierung als Abtragung einstiger Ideale zu verabschieden ${ }^{58}$, könnte man Taylors Voraussetzung anzweifeln, dass der »immanente Rahmen« die Konklusion aus Sprachverlusten bilde. Weder ist einzusehen, warum uns die Zeit um 1500 semantisch überlegen gewesen sei, noch ist zu erkennen, dass jener Sprachverlust mit klassischen Säkularisierungseffekten Hand in Hand gehe. Taylor begeht hier denselben Kurzschluss, den er strukturell an der Säkularisierung 1 und 2 bemängelte. Also: Das alte Bild einer korrelativen oder kausalen Relation zwischen Moderne und Säkularisierung wird ersetzt durch modernen Sprachverlust, der erodierend auf das sonst porös-offene Ich wirke. Selbst wenn man Taylors Skizze der lebensweltlichen Immanentisierung zustimmt, könnte sie auf ganz andere als semantische Einbußen zurückgehen, auf Gründe, die Taylor selbst mit der Resonanzlosigkeit religiöser Bilder - Ursünde, Sühnetod, leibliche Auferstehung - zumindest gestreift hat.

\subsection{Was fehlt: Zum Diskurs über Leerstellen}

Taylors Litanei über die zu (er)tragenden Einbußen existentieller Artikulation hat prominente Vorgänger, aber auch zahlreiche Ableger in gegenwärtigen Diskursen. Diese haben sich mittlerweile zu einem eigenen Genre verdichtet: dem Genre der Intimbekenntnisse im Blick auf das, was einem selbst noch im Nicht-Glauben fehle - Fehlermeldungen eben. Hölderlins »Fehl Gottes« wird entsprechend dankbar oder reserviert aufgenommen, um genauer zu verorten, wo man als Atheist oder angefochten Glaubender heute eigentlich steht. So hält Herbert Schnädelbach fest, "fromme Atheisten« leisteten sich gerade keine Verachtung der Religion, sondern bewahrten sich einen Sinn für das, was fehlt ${ }^{59}$. Martin Walsers Erkundungen zur Institution der Rechtfertigung im Kontrast zum bloßen Rechthaben gehen in eine ähnliche Richtung. Nach Walser leugne der etwas altmodische Atheist zwar Gott, bleibe aber ahnungslos, wenn er nicht sofort dazu sage, dass der gerade geleugnete Gott fehle, um dem Einzelnen als ein bleibender Mangel gegenwärtig zu sein ${ }^{60}$. Allerdings leidet die Gegenseite keineswegs an nur

58 Dazu Stark, Secularization, R.I.P., bes. S. 254.

59 So Herbert SchnäDelbach, Der fromme Atheist, in: Ders., Religion in der modernen Welt, S. 78-85, hier S. 85.

60 So Martin WALSER, Über Rechtfertigung, eine Versuchung, Reinbek bei Hamburg 2012, S. 33; dazu Ulrich H.J. KörTner, Über den Fehl Gottes im Gespräch mit Martin Walser, in: Ders., Gottesglaube und Religionskritik, Leipzig 2014, S. 43-64; Hartmut von SAss, Fehlermeldung. Über Martin Walsers Versuchungen, in: HBl 1/2 (2014), S. 127-138 (zu » )Umgang mit Unsäglichem‘. Martin Walser und die Rechtfertigungsfrage $)$. 
vakanten Positionen, etwa wenn der Mainzer Philosoph Kurt Flasch - analog zu Thomas Nagels Erkundungen »what is it like to be a bat - bekundet, »wie es sich anfühlt, kein Christ zu sein «" ${ }^{61}$.

Habermas' und Taylors Beiträge zur Säkularisierung gehören in weiten Teilen genau dieser Fehlermeldungsgattung an. So lesen wir beim späten Habermas:

Religiöse Überlieferungen leisten bis heute die Artikulation eines Bewusstseins von dem, was fehlt. Sie halten eine Sensibilität für Versagtes wach. Sie bewahren die Dimensionen unseres gesellschaftlichen und persönlichen Zusammenlebens, in denen noch die Fortschritte der kulturellen und gesellschaftlichen Rationalisierung abgründige Zerstörungen angerichtet haben, vor dem Vergessen. Warum sollten sie nicht immer noch verschlüsselte semantische Potentiale enthalten, die, wenn sie nur in begründende Rede verwandelt und ihres profanen Wahrheitsgehaltes entbunden würden, eine inspirierende Kraft entfalten können? ${ }^{62}$

Habermas bestimmt hier gerade nicht das Wegbrechen religiöser Bestände als Grund der Leere, sondern sieht diese Traditionen als verbleibende Artikulationen genau dessen, was fehlt. Dabei nennt er konkrete dogmatische und lebensweltliche Exemplare dieser prekären Dimension: Der Verlust des Auferstehungsglaubens hinterlasse eine »spürbare Leere ${ }^{63}$; oder aus Zürich und der Beisetzung Max Frischs 1991 zurückkehrend dokumentiert Habermas die Hilflosigkeit der Moderne, ein angemessenes Äquivalent für die Bewältigung des unversöhnlichen Endes zu finden ${ }^{64}$. Taylor stimmt $\mathrm{zu}$ und steigert den Befund:

Wer für das geordnete, unpersönliche Universum optiert - sei's in seiner wissenschaftlich-materialistischen Form oder in einer eher spiritualisierten Spielart -, spürt den drohenden Verlust einer Welt der Schönheit, des Sinns, der Wärme und der Perspektive einer über das Alltägliche hinausgehenden Selbsttransformation ${ }^{65}$.

Die Welt, die nun durch die fünf oben skizzierten Stadien - Subjektivismus, Deismus, Humanismus, Naturalismus, Immanentisierung - hindurchgegangen sei - also unsere Welt -, lasse uns im »tiefempfundene(n) Verlust « und demnach in ihrer eigenen Verflachung, "Selbstverkleinerung«, Sinnlosigkeit,

61 Vgl. Kurt Flasch, Warum ich kein Christ bin. Bericht und Argumentation, München 2013, Kap. 9; siehe ferner Thomas NAGEL, What is it Like to Be a Bat?, in: PhRev 83/4 (1974), S. 435-450.

62 Habermas, Einleitung, in: Ders., Zwischen Naturalismus und Religion, S. 13.

63 Ders., Glauben und Wissen, S. 13.

64 Vgl. ders., Ein Bewusstsein von dem, was fehlt.

65 TAYLOR, Ein säkulares Zeitalter, S. 987. 
Fragilisierung, einer nagenden Unzufriedenheit am Transzendenzverlust und den rasch sich revidierenden Utopien zurück ${ }^{66}$. Zwar schränkt Taylor sofort ein, dass jenes »Unbehagen an der Immanenz« keineswegs nahelege, sich nach dieser proto-apokalyptischen Bestandsaufnahme zu den Fleischtöpfen Ägyptens zurückzubegeben - aber diese Bekundung bleibt reine Makulatur ${ }^{67}$. Denn genau das hat Taylor im Sinn, sodass seine Erwägungen zu den Quellen des säkularisierten Selbst das vorsichtige Abwägen immer mehr einbüßt, um der historisch wie argumentativ so ungedeckten wie unvorbereiteten Parteinahme für einen theistisch kodierten Katholizismus Platz zu machen. Doch dieser ist selbst Teil des Problems.

Zuweilen unterlegt Taylor sein Engagement für die Rückgewinnung transzendenzbezogener Selbsttransformationen mit einer Doktrin, die man den »religiösen Energieerhaltungssatz« nennen könnte. Wir kennen diese Lehre von Autoren wie Thomas Luckmann und seinen Überlegungen zur unsichtbaren Religion, die nach der Entkirchlichung des Glaubens in weniger greifbare Formen entgleite ${ }^{68}$. Das Potenzial des Religiösen bleibe demnach konstant, ihre Erscheinungen aber wechselten. Eine Säkularisierung als Verlust religiöser Bedürfnisse und Orientierungen sei nur eine Konfusion, weil es lediglich Umbesetzungen, aber keine wahrhaften Verluste geben könne. Taylor könne sich, so bekennt er, nicht vorstellen, dass die "Nachfrage nach Religion « einfach so verschwinde, Menschen verfügten nun einmal über die Vorstellung lebensweltlicher »Fülle«, sodass es einen »absoluten Nullpunkt« nicht wird geben können. Wie einst für Schleiermacher ausgeschlossen blieb, mit einem radikalen Atheismus zu rechnen, scheint es bisweilen auch für Taylor unmöglich, Säkularisierung als effektive Erosion zuzulassen. Religionen bleiben faktisch säkularisierungsresistent, selbst wenn sie, so Taylor, nicht als anthropologische Konstante missverstanden werden sollten ${ }^{69}$.

Schon bei Habermas, mehr noch bei Taylor ist zuletzt nicht mehr klar, mit welcher Stimme sie sprechen: Ist es die des Philosophen, des Religionssoziologen, des Gegenwartsdiagnostikers - oder eben des religiös BewegtInspirierten? Vor allem bei Taylor zeichnet sich eine Entwicklung ab, die all diese Stimmen zugunsten der letzten integriert. Dass das Schlusskapitel von A Secular Age ein ungedeckter Scheck bleibt, ist oft genug festgestellt wor$\operatorname{den}^{70}$. Aber es ist eine andere Frage zu stellen, und sie zu stellen, heißt schon,

66 Vgl. ebd., S. 516, 523, 892.

67 Ebd., S. 525.

68 Dazu Thomas Luckmann, The Invisible Religion (1967), dt.: Die unsichtbare Religion. Mit einem Vorwort von Hubert KNoblaUch, Frankfurt a.M. 1991.

69 Vgl. TAYlor, Ein säkulares Zeitalter, S. 726 und 1273 bzw. 887, Anm. 48.

70 Etwa Tobias Braune-KrickaU, Charles Taylors religionsphilosophische Rehabilitierung der christlichen Religion in »Ein Säkulares Zeitalter«, in: NZSTh 53/4 (2011), S. 357-373, hier S. 360. 
sie beantwortet zu haben: Können und möchten wir uns gerade im Blick auf Fragen von Sinn und Orientierung zu Taylors ambivalenter Narration verstehen, ist es möglich, sich diese Großerzählung wahrhaft anzueignen, finden wir uns in jenem apokalyptischen Szenario mit seiner eigenen, auch eigentümlichen Unversöhnlichkeit wirklich wieder?

\subsection{Post-säkular: Drei Lesarten}

Wir begeben uns zurück auf solideren Boden, wenn es nun um die Lesart des Post-Säkularen geht, die sich aus Taylors Bestimmung der Säkularisierung 3 ergibt. Sie hebt sich von zwei anderen Ansätzen ab, die im einen Fall traditionell-deskriptiv, im anderen Fall logisch-normativ erscheinen. Das traditionelle Verständnis findet sich bei Habermas. Dabei fungiert das Attribut "post-säkular" als Bestimmung von Gesellschaften oder Staaten und reagiert auf das Wiedererstarken religiöser Traditionen. Demnach gelte, dass eine postsäkulare Gesellschaft eine solche sei, »die sich auf das Fortbestehen der Religion in einer sich fortwährend säkularisierenden Umgebung einstellt ${ }^{71}$. »Post-säkular« reflektiert demnach unter klassisch säkularisierungstheoretischen Prämissen noch unverständliche Gegenbewegungen, die zugleich mit einem tief ins Gesellschaftlich-Politische hineinwirkenden Mentalitätswandel einhergehen. Der Term "post-säkular« ist demnach eine Abbreviatur der Kritik der herkömmlichen Säkularisierungstheorie. Während sich nun der Staat »lernbereit« gegenüber vormals verabschiedeten Sinnressourcen zeige, müsse das religiöse Bewusstsein zwar die konfessionelle Pluralität, die Autorität der Wissenschaft und die Prämissen des Verfassungsstaates akzeptieren, dürfe sich aber auf die Offenheit von Staat und Gesellschaft für seinen politischen Beitrag unbedingt verlassen ${ }^{72}$.

Ein anders gelagerter Begriff des Post-Säkularen findet sich bei Ingolf Dalferth. Hier spielt die deskriptive Funktion des Begriffs ebenso wenig eine Rolle wie religionssoziologisch greifbare Tendenzen gegenwärtiger »Frömmigkeit« oder »Spiritualität«. Vielmehr wird der Begriff als Element allein staatlichen - und also nicht: gesellschaftlichen oder gar persönlichen Selbstverständnisses verwendet, um anzuzeigen, dass sich Staaten etwa in ihrer Rechtsprechung und -ordnung weder affirmativ, noch reserviert, sondern gar nicht auf Religion(en) beziehen. Wir lebten noch, so Dalferth,

71 Habermas, Die Grenze zwischen Glauben und Wissen, S. 251.

72 Vgl. ders., Religion und nachmetaphysisches Denken. Eine Replik, in: Ders., Nachmetaphysisches Denken, Bd. 2: Aufsätze und Repliken, Berlin 2012, S. 120-182, hier S. 121; ferner Hans-Joachim HöHN, Gewinnwarnung, S. 47-54 und 60-70. 
im säkularen Staat, solange die definitorische Referenz auf die Religion selbst noch in Neutralitätsbekundungen fortbestehe. Entsprechend führt Dalferth aus:

Das Bild ändert sich, wenn man den Operator »post« nicht nur auf »säkular«, sondern den ganzen Sinnkontrast von »säkular vs. religiös« bezieht, also nicht nur die Überwindung einer säkularen Moderne meint, sondern die Überwindung einer Moderne, die sich durch Absetzung von einer religiösen Vormoderne als säkular bestimmt hat ${ }^{73}$.

Wirklich säkular lebten wir erst, wenn gar kein Anlass mehr bestünde, sich genau so $\mathrm{zu}$ charakterisieren ${ }^{74}$. Erst wenn wir uns weder religiös, noch säkular bestimmen und weder nicht-religiös, noch nicht-säkular, um uns $\mathrm{zu}$ beschreiben, habe man die säkulare Moderne wirklich verlassen. „Postsäkular« zeigt also die erfolgreiche Verabschiedung des Säkularen an, indem Letzteres »definitiv« nicht mehr Verwendung findet.

Vor diesem doppelten Hintergrund des Post-Säkularen im Sinne der konfliktträchtigen »Rückkehr der Religion ${ }^{75}$ bzw. als kritische Anzeige, nach der die Bezugnahme auf die Religion für den Staat obsolet geworden ist (oder werden soll?), mag verständlicher werden, wie der Taylor'sche Begriff des Post-Säkularen aussehen müsste, zumal Taylor selbst keinen tragenden Gebrauch des Begriffs macht ${ }^{76}$, und dies aus nachvollziehbaren Gründen: Wenn ein »säkulares Zeitalter« als ein solches definiert wird, das die Unerschütterlichkeit des Glaubens durch den Nicht-Glauben als »lebendige Option« untergraben hat, bezeichnete die »post-säkulare« Ära das demgegenüber fortgeschrittene Stadium, in welchem der Glaube gar keine Option, nur noch eine historische Reminiszenz bleibt. Insofern ist es eine gute Nachricht, wenn wir zumindest in einer durch die Säkularität 3 gekennzeichneten Zeit leben, weil sie den Glauben als veritable Möglichkeit sehr wohl kennt. Mit dem Post-Säkularen ist hingegen der Verlust eben dieser Möglichkeit bezeichnet ${ }^{77}$.

73 Ingolf U. DALfERTh, Religionsfixierte Moderne? Der lange Weg vom säkularen Zeitalter zur post-säkularen Welt, in: Denkströme. Journal der Sächsischen Akademie der Wissenschaften 7 (2011), S. 9-30, 25; vgl. ders., Orientieren durch Unterscheiden. Christlicher Glaube und säkulare Welt, in: Ders., Transzendenz und säkulare Welt. Lebensorientierung an letzter Gegenwart, Tübingen 2015, S. 1-54.

74 Ders., Religionsfixierte Moderne?, S. 10.

75 Dazu Martin Riesebrodt, Die Rückkehr der Religionen. Fundamentalismus und der »Kampf der Kulturen«, München 2000, bes. S. 35-58.

76 Zuweilen verwendet Taylor "post-säkular« ähnlich wie es Habermas in der ersten Version tut, als Anzeige wiedererstarkender Religionen; siehe TAYLOR, Ein säkulares Zeitalter, S. 895.

77 Dieses Stadium, in dem auch der Glauben keine Option darstellen, kann Säkularisierung 4 genannt werden; so Hans-Martin BARTH, Konfessionslos glücklich. Auf dem Weg zu einem religionstranszendenten Christsein, Gütersloh 2013, S. 60f. 
Während die erste Version auf Beobachtungen religionspolitischer Verschiebungen in der Gegenwart beruht, macht die zweite Variante auf eine definitorische Möglichkeit staatlicher Selbstverortung aufmerksam. Erst die letztgenannte Lesart des Post-Säkularen bei Taylor führt in die Zukunft, sofern die post-säkulare Zeit noch nicht angebrochen sei. Kommt es allerdings dazu, wäre es um den Glauben als existentielle Möglichkeit geschehen. Bei Taylor steht "post-säkular« daher für eine kritische Problemanzeige (ver-)schwindender Optionen, sodass die Erhaltung des secular age einer Angelegenheit lebensweltlichen »Möglichkeitssinns« gleichkommt.

\section{Desäkularisierung und Deutungsmacht: Ein Lektürevorschlag}

Gegen Ende zurück an den Anfang: Dort wurden drei Phasen der Debatte um die Säkularisierung unterschieden, um Habermas der extern-ideenpolitischen Periode zuzuordnen, die im Modus der Warnung und im Gestus der Befürchtung auf die potenziellen Resultate erfolgreicher Säkularisierungen und ihrer zeitgenössischen Gegenbewegungen aufmerksam macht. Taylor jedoch gehört in die involviert-gegenmissionarische Phase, deren Modus das Engagement und deren Stimmung die des verhaltenen Trotzes ist, um den Gang der Dinge literarisch nicht ganz sich selbst zu überlassen. Der Negativbefund liegt damit auf der Hand: Zur religionssoziologischen Debatte über den Zuschnitt gegenwärtiger Säkularisierungsprozesse haben beide nichts Neues beizutragen ${ }^{78}$. Vielmehr setzen sie das Bild der Säkularisierung als Inbegriff in sich widersprüchlicher (De-)Säkularisierungsprozesse bereits voraus.

Will man hingegen näherbestimmen, worin ihr konstruktiver Bezug zur Debatte besteht, sind Thema und Perspektive zu wechseln. Nicht um eine Kritik der Säkularisierung geht es dann, sondern um eine metakritische Position, nicht um religionsdiagnostische Ermittlungen dreht sich der Diskurs, ist er doch längst in die Ergreifung religionspolitischer Maßnahmen übergegangen. Mit anderen Worten: Habermas und Taylor sind - bei allen

78 Dazu Charles Larmore, der dies mit einer fundamentalen Kritik an Taylors A Secular Age verbindet: "But A Secular Age is a deeply disappointing - and in some ways maddening - book", denn Taylor »has not a single word to say about the great figures of twentieth-century Protestant theology - Barth, Bultmann, Bonhoeffer - whose concern lay centrally with modern secularization, though he goes on at length about Catholic theologians such as Jacques Maritain and Ivan Illich. [...] This is not just a book written by a Christian for Christians. It is a book written by a Catholic for Catholics «: Charles Larmore, How Much can we Stand? (Book Review), in: The New Republic 6/238 (2008) (online: URL: <http://www.newrepublic.com/article/books/ how-much-can-we-stand $>)(05.05 .2016)$. 
phasenbedingten Differenzen - als Teilnehmer eines Diskurses zu lesen, der die distanzierte Bestandsaufnahme latent oder ganz explizit durch engagierte Intervention eingetauscht hat. Säkularisierungen und ihre kritischen Revisionen müssen dann zu Fragen miteinander konkurrierender Deutungsmächte werden ${ }^{79}$.

Diese Umstellung der Blickrichtung von der Analyse sozialer Dynamiken zur Analyse des Diskurses über sie hat Anhalt an der Geschichte des Säkularisierungsparadigmas und dessen Aneignung, insbesondere der theologischen. So lässt sich Friedrich Gogartens im doppelten Sinn legendäre Wertschätzung der Säkularisierung als veritable Erbschaft des Christentums als eine deutungsmächtige Eingemeindung gegenläufiger, ja feindlicher Mächte seinerseits deuten ${ }^{80}$. Zwar ist es zutreffend, dass etwa Elemente der klassischen Schöpfungslehre (die Differenz von Schöpfer und Schöpfung) bzw. reformationstheologische Individualisierungsprozesse (der unvermittelte Bezug des Menschen zu Gott) faktisch gefördert haben, was heute als Säkularisierung bezeichnet wird. Doch der sich langsam formierenden Lehre von der Schöpfung oder der dogmatisch zentralen Betonung glaubender Individualität zu unterstellen, sie seien, so Gogarten, Kapitel theologisch gewollter Säkularisierungen, bildet ein anachronistisches Narrativ verspäteter Harmonisierung. Gogartens deutungsmächtige Geste erlaubt es zwar, auch aus innertheologischen Gründen Prozesse glückender Säkularisierung im normativen Kontrast zum »Säkularismus" mit dogmatisch offenen Armen (und Augen) zu empfangen. Die ganze Dramatik, ja Tragik in der Beziehung von Christentum und Moderne droht dann jedoch - trotz des Titels »Verhängnis und Hoffnung der Neuzeit« - aus dem diagnostischen Blick kritischer Theologie zu geraten.

Gogartens Tendenzanalyse sei hier nur als prominentes Exempel für die Architektur des gesamten Diskurses herangezogen. Sie als Beispiel zu betrachten, heißt zu behaupten, dass es sich nicht um einen Einzelfall handelt, sondern wir es mit einem das Säkularisierungsparadigma durchziehenden Kennzeichen zu tun haben ${ }^{81}$. Demnach geht es nicht länger um die soziologisch zu beschreibenden und ggf. theologisch zu bewertenden Prozesse, sondern um die mit dem Etikett der Säkularisierung erzeugte Sicht auf diese in

79 Dies ist also so ziemlich das Gegenteil dessen, was in der Wittgensteinschen Tradition als »cool« bzw. "contemplative philosophy« bekannt ist; dazu Ingolf U. DALFerTh / Hartmut von Sass (Hg.), The Contemplative Spirit. Dewi Z. Phillips on Religion and the Limits of Philosophy, Tübingen 2010.

80 Siehe Friedrich Gogarten, Verhängnis und Hoffnung der Neuzeit. Die Säkularisierung als theologisches Problem, Stuttgart 1953, vor allem Kap. 9; dazu ferner HeinzDietrich Wendland, Das Problem der Säkularisation in der Sozialethik, in: Ders., Grundzüge der evangelischen Sozialethik, Köln 1968, S. 76-87, bes. S. 79.

81 Dazu Jan N. Bremmer, Secularization. Notes Toward a Genealogy, in: Hent De VRIES (Hg.), Religion. Beyond a Concept, New York, NY 2008, S. 432-437. 
sich verzweigten Dynamiken. Trutz Rendtorff ist daher ganz zuzustimmen, wenn er summiert: »Die Säkularisierungsthese ist [...] religionssoziologisch nicht mehr materialiter interessant, sondern als ein Moment in der Analyse der gegenwärtigen Selbstauslegung der Gesellschaft [zu verstehen] $\aleph^{82}$.

Die Säkularisierung als Element der Deutungsmacht und damit unter den Motiven lebensweltlicher Entlastung, narrativer Brauchbarkeit, nachgereichter Rechtfertigung oder hermeneutischer Verdrängung alternativer Lesarten zu betrachten ${ }^{83}$, bringt eine zweifache Bewegung von Deutung und Macht ins Spiel: Es geht zum einen um die Macht zur Deutung durch positionellen Einfluss und diskursive Gewalt. Und es geht zum anderen um die Macht der Deutung durch expressive Prägnanz und hermeneutische Aneignung. Im ersten Fall haben wir es mit personalen Mächten intentionaler Einflussnahme zu tun, im zweiten Fall hingegen mit strukturellen Dynamiken faktischer Durchsetzung eminenter Muster der Deutung ${ }^{84}$. Dass allerdings gedeutet werden muss, kann entweder an der Ubiquität des Deutens liegen (nichts gibt es, das nicht gedeutet wäre; weiter Deutungsbegriff) oder aber an der Insuffizienz des Faktischen, an deren Grenzen die Deutungen erst beginnen (wenn die Tatsachen enden, geht das Deuten los; enger Deutungsbegriff). Diese Alternative ist zwar eine hermeneutische Karikatur, doch zeigt sie die Endpunkte eines Spektrums notwendigen Deutens und eines interpretativen Spielraums an, der machtvoll genutzt werden darf.

Dabei bleibt es nicht bei interpretatorischen Rückblicken auf die Vergangenheit wie noch bei Gogarten. Deutungsmacht verwirklicht sich vor allem in der Logik des Prognostizierens und im vorgreifenden und darin eingreifenden Blick nach vorn. So wurde oftmals mit leichtem Bedauern festgestellt, dass die Erzählung von der säkularen Moderne einer self-fulfilling prophecy gleichkomme, deren Advent performativ - theologisch präziser: sakramental - wirke. Die Ankündigung ihrer Heraufkunft ist Teil ihrer Wirklichkeit ${ }^{85}$. Und in der Tat gibt es effektive Relationen zwischen System und Systembeschreibung: Während bei Wetterberichten diese Beziehung noch

82 Trutz Rendtorff, Zur Säkularisierungsproblematik. Über die Weiterentwicklung der Kirchensoziologie zur Religionssoziologie, in: Joachim Matтhes, Religion und Gesellschaft, Reinbek bei Hamburg 1967, S. 208-229, hier S. 220; vgl. ders., Säkularisierung als theologisches Problem, in: NZSTh 4/4 (1962), S. 319-339, hier S. 330-335 (kritisch zu Friedrich Gogarten).

83 Dazu bes. Philipp Stoellger (Hg.), Deutungsmacht. Religion und Belief Systems in Deutungsmachtkonflikten, Tübingen 2014 - in Aufnahme der Machtdiskurse seit Nietzsche und bei Foucault, Levinas und Derrida.

84 Dazu Brad S. Gregory, The Unintended Reformation. How a Religious Revolution Secularized Society, Cambridge, MA 2011.

85 So Casanova, Public Religions in the Modern World, S. 30-34; Taylor, Ein säkulares Zeitalter, S. 877; ferner (und mit Blick auf die Kirchen in der DDR) Johannes ZachHuber, Zur Freiheit befreit. Theologische Erinnerung an den Herbst 1989 im Licht gegenwärtiger Herausforderungen, in: EvTh 70/2 (2010), S. 96-105, hier S. 97. 
kaum gegeben ist - die Regenankündigung bringt keinen Niederschlag -, verhalten sich die Dinge bei der Berichterstattung zum Börsen- und Aktienhandel ganz offensichtlich anders - die publizierte Gewinnerwartung eines Großkonzerns macht die Dividende wahrscheinlicher. Das Narrativ der Säkularisierung liegt, so die zumindest implizite Unterstellung unserer beiden Begleiter, näher am ökonomischen und weiter entfernt vom meteorologischen »Diskurs der Moderne«.

So ist auch Habermas' besorgter Verweis auf die Legitimationsdefizite des Rechtsstaates (2.1) und die bürgerlichen Übersetzungsleistungen im Blick auf weltanschauliche Sinnressourcen (2.2) als Exemplar prognostischer Deutungsmacht verständlich. Trotz seiner wiederholten Befürchtung, wir könnten die moralische Sensibilität verlieren, die traditionell religiös eingeübt worden sei, bzw. der Sorge, wir würden künftig am »Defizit an glücklichen Bildern « religiöser Traditionsbestände leiden ${ }^{86}$, bleibt seine Distanz zur Religion auch im Spätwerk überall spürbar ${ }^{87}$. Kaum geht es Habermas um die Religion selbst; wo sie wohlwollend herangezogen wird, ist das Thema zumeist ihre Schutzfunktion gegenüber einer »entgleisenden« Moderne samt einer Vernunft, der die Tendenz zum Defätismus zukomme. Die Säkularisierung habe keineswegs die Funktion eines Filters, der kognitiv obskure Gehalte ausmustere, als vielmehr die Aufgabe eines Transformators, der die traditionellen Bestände umwandele ${ }^{88}$.

Eine postsäkulare Gesellschaft stellt sich demnach auf das Fortleben der Religion so ein, das sie diese unter dem epistemisch verbindlichen Primat der prozeduralen Vernunft eingemeindet. Den Befürchtungen, die der post-säkular verstärkte Pluralismus generiert, begegnet Habermas mit einer antizipatorischen Konfrontationstherapie, die selbst noch die Gefahren wiederkehrender Religionen umkodiert, indem diese als Sinnressource quasi ökonomisiert werden und als solche genau jene Motivationen nachreichen, die sich der Rechtstaat niemals selbst wird geben können. Der Gang von der säkularen zur post-säkularen Gesellschaft läuft über die Indienstnahme der Religion als ihre rechtsstaatliche Domestizierung.

Das sieht bei Taylor etwas anders aus. Nicht um faktische Neutralisierung der Religion zwischen Transformation und Erodierung, sondern um ihre Wiedergewinnung geht es. Der apologetische Gestus der Sorge weicht nun der Verlustwarnung samt Missionsbefehl. Die Suche nach der »subtileren

86 Habermas, Ein Symposion über Glauben und Wissen, S. 227; ders., Konservative Politik, Arbeit, Sozialismus und Utopie heute, in: Ders., Die Neue Unübersichtlichkeit. Kleine Politische Schriften, Bd. 5, Frankfurt a.M. 1985, S. 59-76, hier S. 69.

87 Dazu Peter Daвrock, Öffentlichkeit und Religion. Aktualisierungen der Gemeinwohl-Tradition in sozialethischer Perspektive, in: MJTh 26 (2014), S. 77-124, hier S. 98.

88 Vgl. Habermas, Ein Bewusstsein von dem, was fehlt. 
Sprache« (2.3) und die Vermessung der von den Religionen zurückgelassenen Leerstelle (2.4) sieht Taylor treffend in einem Song der 1960er Jahre zusammengefasst. In ihm fragt Peggy Lee süffisant-jazzig: »Is that all there is?«. Nein, ruft uns Taylor zu, die nur immanente, entzauberte, entleerte Welt ist nicht alles, was es gibt.

Insofern ist die Kunde von der - noch - säkularen Welt eine gute Nachricht, enthält sie doch als eines ihrer Implikate die Auskunft, dass der religiöse Glaube als Ausdruck eines Transzendenzbedürfnisses immer noch eine »lebendige Option « darstellt. Im Anschluss an William James bleibt der Glaube nicht nur eine logische, vielleicht schon erstorbene Möglichkeit, sondern ist für Menschen nach wie vor eine lebensweltlich relevante Option ${ }^{89}$. Taylor erkennt allerdings die Gefahr, dass sich dieses Fenster sehr bald schließen könnte und die Option des Glaubens erlischt, sodass der missionarische Eifer gegen Ende von A Secular Age nachvollziehbar wird. Taylors Vernachlässigung der Säkularisierung als Trennung von Privatem und Öffentlichem bzw. als Erosion religiöser Praktiken und seiner Betonung der Veränderungen in den Bedingungen des Glaubens ist vor diesem pragmatistischen Hintergrund zu verstehen. Demnach lässt Taylor die bloße Analyse jener Konditionen hinter sich, um diese selbst ideengeschichtlich und insofern deutungsmächtig zu stärken. Seine Einführung der »Säkularisierung 3 « ist daher kein Beitrag zur Säkularisierungsdebatte, sondern die Lizenz zum gegenmissionarischen Aufweis, dass die Frage »Is that all there is?« verneint werden kann. Leider unterschlägt Taylor, dass Peggy Lee weitersingt: »if that's all there is, then let's keep dancing".

\section{Zum Schluss - oder: »Erwarten wir getrost, was kommen mag»}

Was ist von alldem theologisch zu halten? Auf Habermas' Wertschätzung der Religion sich theologisch einzulassen, wird schwer fallen. Zu instrumental ist sein Zugriff, als dass er theologisch akzeptabel scheint - bei allen potenziellen Überschneidungen in der Diagnose zu Vernunft und Moderne. Taylors finales Plädoyer hingegen ist viel näher an der theologischen Pulsader, gerade deshalb aber umso gefährlicher. Sein theistischer Katholizismus samt modernekritischer Nostalgie - bekannt von den Vertretern der radical orthodoxy $y^{90}$ - ist wohl so fremd, dass man tatsächlich lieber tanzen gehen möchte, als in Taylors wiederverzauberter Welt zu existieren.

89 Vgl. TAYlor, Ein säkulares Zeitalter, S. 917, 919 und 960; zu William James siehe ders., Die Formen des Religiösen in der Gegenwart, S. 42-50; ferner Hauerwas, With the Grain of the Universe, Kap. 2 und 3.

90 Die Verwandtschaft zur Modernekritik der radical orthodoxy spricht Taylor selbst an; vgl. TAYLOR, Ein säkulares Zeitalter, S. 1280f. 
Zum Schluss fragt sich, ob »Säkularisierung» eine theologisch überhaupt sinnvolle Kategorie bietet und - weit darüber hinausgehend - ob das mit jenem Label Bezeichnete theologisch noch relevant sei. Sofern die Annahmen klassischer Säkularisierungen zumindest für unsere Breitengrade zutreffen, mag auf die Chancen hingewiesen werden, die in jenen Dynamiken für die Kirche stecken. Kann man sich dann nicht wieder auf das genuin Christliche besinnen?, so fragt José Casanova ${ }^{91}$. Ist die Verbannung der Religion in die Sphäre des Privaten nicht zugunsten eben jener Religion vorgenommen worden?, so mutmaßt Richard Rorty im Anschluss an Thomas Jefferson ${ }^{92}$. Ist nun nicht die Religion befreit, sich ganz auf die Botschaft des Evangeliums jenseits anderer Autoritäten zu konzentrieren?, so gibt wiederum Volker Gerhardt zu bedenken ${ }^{93}$.

Das aber kommt auf die theologisch prekäre Bewertung der Differenz von Religion und Kultur an, einer Bewertung, die zwischen liberalen und offenbarungstheologischen Entwürfen umstritten bleiben wird. Ist der christlichen Wahrheit der Vorrang einzuräumen vor ihrem Einfluss in pluralen Gesellschaften, dem Text der Botschaft vor seiner Nutzbarkeit durch die Leserschaft, der Authentizität des "Ärgernisses« vor seiner verdaulichen Aneignung? Wer das bejaht, für den ist die Säkularisierung als ein genuin theologisches Thema wohl verabschiedet - selbst dann, wenn sie erfolgreich ist.

91 Vgl. Casanova, Public Religions in the Modern World, S. 21.

92 Siehe Richard Rorty, Religion As Conversation-Stopper, in: Ders., Philosophy and Social Hope, London 1999, S. 168-174, hier S. 169; dazu Hartmut von SAss, Religion in a Private Igloo? A Critical Dialogue with Richard Rorty, in: IJPR 70/3 (2011), S. 203-216.

93 Dazu Volker Gerhardt, Vom säkularen Geist der Politik, in: Ders., Exemplarisches Denken. Aufsätze aus dem Merkur, München 2009, S. 237-251, hier S. 250. 


\section{Detlef Pollack}

\section{Religion in der Moderne}

Als Pastor David Yonggi Cho am 15. Mai 1958 in Seoul seine missionarische Tätigkeit mit einem Hausgottesdienst begann, nahmen an dem Gottesdienst fünf Personen teil. Nach Monaten voller Gebete und harter Arbeit war die Gottesdienstgemeinde des Pastors auf 50 gewachsen und musste in ein Zelt überwechseln. David Yonggi Cho klopfte an Türen, organisierte Hilfe für Arme, betete für die Kranken und verkündigte, dass körperliche Gesundheit und finanzieller Wohlstand ebenso Teil des göttlichen Heilsplans seien wie die Rettung der Seelen. Anfang 1961 hatte seine Kirche die Zahl von 1000 Mitgliedern erreicht. Die Gemeinde musste das Zelt verlassen und eine Kirche bauen. 1964 hatte sie 3000, 1968 über 6000 Mitglieder. Cho teilte Seoul in einzelne Distrikte ein, in denen die dort lebenden Kirchenmitglieder kleine Zellen bildeten, die sich werktags zu Gebet und Bibelstudium in Privatwohnungen trafen. Die Zellmitglieder luden ihre Freunde und Bekannten ein, bis die Zelle so groß war, dass sie geteilt werden musste. Aus 125 Zellen im Jahr 1967 wurden bald mehrere tausend. 1973 baute die Gemeinde eine neue moderne Kirche mit einem Auditorium für 12.000 Gottesdienstbesucher. Heute ist die von David Yonggi Cho gegründete Gemeinde die größte der Welt. Ihr gehören mehr als 800.000 Mitglieder an. Sie feiert nicht nur enthusiastische Gottesdienste, sondern unterhält auch Krankenhäuser und Universitäten, Missionsstationen und Verlage. Es handelt sich um die Yoido Full Gospel Church in Seoul.

Das Wachstum der Yoido Full Gospel Church in Seoul ist einzigartig, aber für den religiösen Wandel in Südkorea durchaus nicht untypisch. Seit den 1950er Jahren, als der Anteil der Protestanten an der Gesamtbevölkerung etwa 3 Prozent ausmachte, stieg die Zahl der protestantischen Gläubigen bis auf etwa 20 Prozent im Jahr 1990 an. Seitdem stagniert das Wachstum ${ }^{1}$. Der dynamische Anstieg bei den Katholiken setzte erst in den 1980er Jahren ein, hält aber bis heute an. Auch der Anteil der Buddhisten hat sich nach dem Zweiten Weltkrieg deutlich erhöht, geht aber seit den 1990er Jahren wieder leicht zurück.

1 Vgl. auch Yee-heum Yoon, Zur religiös-kulturellen Situation im Korea der Gegenwart, in: Siegfried KeIL u.a. (Hg.), Modernisierung und Religion in Südkorea. Studien zur Multireligiosität in einer ostasiatischen Gesellschaft, München 1998, S. 77-86. 
Die beschriebenen Veränderungen auf dem religiösen Feld in Südkorea in den letzten 70 Jahren werfen die Frage auf, wie sich der Rückgang des Anteils der Religions- und Konfessionslosen und der Bedeutungszuwachs des Christentums und des Buddhismus in der zweiten Hälfte des 20. Jahrhunderts erklären lassen. Die Frage verschärft sich, wenn man bedenkt, dass diese Jahrzehnte zugleich auch eine Periode des rasanten wirtschaftlichen Wachstums in Südkorea waren. Der Anteil der Personen in Großstädten stieg von 28 Prozent im Jahr 1960 auf 78 Prozent im Jahr 1995², die Mobilität explodierte, das Bildungsniveau ging in die Höhe. Das politische System transformierte sich von einem autoritären Regime in eine Demokratie (1987). Trotz des Modernisierungsprozesses ging die Kirchenbindung aber nicht zurück, sondern stieg an. Geläufige Vorstellungen von einem positiven Zusammenhang zwischen Modernisierung und Säkularisierung verkehren sich hier in ihr Gegenteil.

Gerade das Beispiel Südkoreas macht indes deutlich, worauf es in soziologischen Analysen des religiösen Wandels ankommt. In ihnen sollte es nicht darum gehen, theoretisch abgeleitete Thesen über den religiösen Wandel in modernen Gesellschaften empirisch bestätigen zu wollen, sei es die These des Bedeutungsverlusts der Religion oder die ihrer Wiederkehr, sondern darum, empirisch zu analysieren, wie sich die soziale Signifikanz von Religion in ihren unterschiedlichen Facetten in modernen Gesellschaften verändert hat und welche Faktoren und Bedingungen zu diesen Veränderungen beigetragen haben. Gerade bekannte Ansätze in der religionssoziologischen Forschung wie die Säkularisierungstheorie oder das marktökonomische Modell genügen dieser Anforderung nicht. Der säkularisierungstheoretische Ansatz untersucht den religiösen Bedeutungsrückgang in ausgewählten Regionen und Zeitepochen sowie im interregionalen und epochenübergreifenden Vergleich und zieht zu seiner Erklärung Faktoren heran, unter denen der Anstieg des materiellen Wohlstands, die Erhöhung des Bildungsniveaus, der Abbau sozialer Ungleichheit, die Entwicklung des Wohlfahrtsstaates oder auch Prozesse des Wertewandels einen prominenten Platz einnehmen. Eine solche Vorgehensweise ist nicht einfach falsch, sie ist aber mit einem entscheidenden Nachteil erkauft, denn das Resultat dieser Untersuchungen scheint im Vorhinein festzustehen: dass die soziale Bedeutung von Religion sinkt. Rodney Stark ${ }^{3}$ zieht aus diesem offenbar theoretisch vorbestimmten Ergebnis säkularisierungstheoretischer Analysen dann auch den Schluss, dass sie so nutzlos seien wie ein Fahrstuhl, der nur nach unten geht. Sucht

2 Don BAKe, Modernization and Monotheism. How Urbanization and Westernization have Transformed the Religious Landscape of Korea, in: Sang-oak LeE u.a. (Hg.), Pathways into Korean Language and Culture, Seoul 2003, S. 471-507, hier S. 378.

3 Rodney STARK, Secularization, R.I.P., in: Sociology of Religion 60 (1999), S. 249-273, hier S. 272. 
man nach verallgemeinerbaren Theorien, müssen sie so konzipiert sein, dass sie nicht nur den religiösen Niedergang, sondern auch den religiösen Aufschwung erklären können.

Diese Forderung ist auch an das ökonomische Marktmodell zu richten, das oft als Alternative zur Säkularisierungstheorie behandelt wird. Im Unterschied zur Säkularisierungsthese ist dieser Ansatz geneigt, überall und jederzeit religiöse Zuwächse zu entdecken. Religiöse Gemeinschaften profitieren dem Marktmodell zufolge von staatlicher Deregulierung ${ }^{4}$. Religiöse Organisationen blühen auf, wenn der Staat in religiöse Angelegenheiten nicht interveniert und keine religiöse Gemeinschaft gegenüber anderen bevorzugt oder benachteiligt. Das gelte generell. Dem ökonomischen Marktmodell zufolge stärkt es die Resistenz religiöser Gemeinschaften aber auch, wenn sie staatlich verfolgt werden, denn Unterdrückung erhöhe das Niveau der Entfremdung und befeuere insofern den religiösen Impuls ${ }^{5}$. Mit anderen Worten, es ist gut für religiöse Gemeinschaften, wenn sie unter fairen Wettbewerbsbedingungen operieren; ungünstige Kontextbedingungen tun ihnen aber auch gut. Offensichtlich ist das Marktmodell so nutzlos wie ein Fahrstuhl, der nur nach oben geht.

Die theoretischen Annahmen des Marktmodells und der Säkularisierungsthese sind so eng mit feststehenden Erwartungen an die empirische Wirklichkeit verknüpft, dass abweichende empirische Befunde in der Regel nicht zu einer Revision der theoretischen Rahmenannahmen führen, sondern dazu, entweder die Beschreibung der Phänomene den jeweiligen Theoriekonstruktionen anzupassen oder aus den Theoriemodellen nicht abgeleitete theoretische Zusatzannahmen einzuführen. Steve Bruce zum Beispiel führt zur Erklärung von religiösen Zuwächsen die Theoreme des cultural defence und der cultural transition ein ${ }^{6}$, die seinem Ansatz ad hoc angefügt sind, ohne sich aus ihm zu ergeben. Rodney Stark wiederum ergänzt seine Wettbewerbsthese durch eine Konflikthypothese, ebenfalls ohne letztere aus ersterer herzuleiten oder theoretisch in Beziehung zu setzen ${ }^{7}$.

4 Rodney Stark / Roger Finke, Acts of Faith. Explaining the Human Side of Religion, Berkeley, CA u.a. 2000.

5 Ebd., S. 73f.

6 Mit cultural defence ist gemeint, dass angesichts einer empfundenen Bedrohung durch externe Kulturen oder Mächte religionsinterne Selbstbehauptungsprozesse einsetzen können, mit cultural transition, dass Immigranten ihre Religion in die Aufnahmegesellschaft mitbringen und in ihren religiösen Gemeinschaften solidarische Netzwerke finden, die ihnen die Integration in die Aufnahmegesellschaft erleichtern (Steve BRUCE, God is Dead. Secularization in the West, Oxford 2002, S. 31-36). Durch beide Mechanismen erhöhen sich die religiösen und kirchlichen Bindungen.

7 Nachdem Frank Lechner (Frank Lechner, Secularization in the Netherlands?, in: JSSR 35 (1996), S. 252-264, hier S. 257) für den Fall der Niederlande aufgewiesen hat, dass zunehmender religiöser Pluralismus in der zweiten Hälfte des 20. Jahrhunderts nicht mit einer Intensivierung der Kirchenbindung, sondern mit ihrem dramatischen 
Widersprüche zwischen Theorie und Empirie lassen sich aber auch durch Umbauten in der empirischen Analyse verringern. Ein solcher Fall liegt vor, wenn Säkularisierungstheoretiker die Attraktivität von Religionsgemeinschaften in den hochmodernen USA durch Verweis auf die innere Säkularisierung der nordamerikanischen Religiosität ${ }^{8}$ und die Psychologisierung des Übernatürlichen ${ }^{9}$ bagatellisieren oder Markttheoretiker den hohen Säkularisierungsgrad in westeuropäischen Ländern darauf zurückführen, dass es in Westeuropa keine Religionsfreiheit gebe, die Kirchen subventionierte Staatskirchen seien und der Klerus daher dazu tendiere, faul und nachlässig zu werden ${ }^{10}$.

Um die Vertreter religionssoziologischer Ansätze von dem Zwang zu befreien, zur Erfassung theoretisch nicht vorgesehener Befunde entweder Zusatztheoreme begründungslos einzuführen oder aber ihre Beschreibung an die Theorieannahmen anzupassen, ist es erforderlich, theoretische Modelle zu entwickeln, die schärfer zwischen Theorieannahmen und empirischen Aussagen differenzieren. Ein solches Insistieren auf schärfere Differenzierung zwischen Theorie und Empirie besteht darauf, dass theoretische Annahmen die empirische Analyse nicht übermächtigen dürfen und empirisch erhobene Fakten gegenüber der Theorie ein Vetorecht besitzen; sie ist aber kein Plädoyer für einen Verzicht auf Theoriearbeit. Theoretische Unterscheidungen stellen die unhintergehbare Voraussetzung aller wissenschaftlichen Analyse dar, denn empirisch gewonnene Daten sind nicht als solche aussagekräftig, sondern als hergestellte Fakten stets interpretierte Wirklichkeiten. Schon die Entscheidung darüber, welche Fakten zählen sollen und welche nicht, fällt auf der theoretischen Ebene. Am Anfang von Analysen zum Verhältnis von Religion und Moderne muss daher die theoretische Reflexion über den zugrunde gelegten Moderne- und Religionsbegriff stehen. Was macht moderne Gesellschaften aus und unterscheidet sie von vormodernen sozialen Ordnungen? Welche Merkmale charakterisieren Religionen und heben sie von nichtreligiösen Phänomenen ab?

Einbruch verbunden war, verlässt Rodney Stark (Rodney STARK / Laurence IANNACCONE, Response to Lechner: Recent Religious Declines in Quebec, Poland, and the Netherlands. A Theory Vindicated, in: JSSR 35 (1996), S. 265-271, hier S. 269) die Prämissen seiner Argumentation und führt den Rückgang der Kirchlichkeit nicht etwa auf eine zunehmende Homogenisierung des religiösen Feldes zurück, sondern auf den Zusammenbruch der bis zur Jahrhundertmitte bestehenden Versäulung und leitet ihn damit aus der Ermäßigung religiöser Konflikte statt aus der Zunahme religiöser Homogenität ab.

8 Bryan Wilson, Religion in Secular Society, London 1966, S. 122; ders., Religion in Sociological Perspective, Oxford 1982.

9 Steve BRUCE, Amerika ist keine Ausnahme, in: Ulrich Willems u.a. (Hg.), Moderne und Religion. Kontroversen um Modernität und Säkularisierung, Bielefeld 2013, S. 331-354, hier S. 335.

10 Stark / Finke, Acts of Faith, S. 228-236. 


\section{Theoretische Überlegungen}

\subsection{Moderne Gesellschaften}

Klassische Vertreter der Modernisierungstheorie wie Tocqueville, Parsons oder Giddens nehmen an, dass die Moderne durch ein Ensemble miteinander zusammenhängender Eigenschaften charakterisiert ist. Sie behaupten einen Zusammenhang von wirtschaftlichen, politischen, rechtlichen, kulturellen Veränderungen wie zum Beispiel Wohlstandsanhebung, Demokratisierung, Menschenrechtsgarantie und Individualisierung und heben diese miteinander verbundenen Veränderungsprozesse von der Geschichte der vormodernen Welt ab. Um der Kennzeichnung moderner Gesellschaften ein höheres Abstraktionsniveau zu geben, sollen hier nicht weitere Merkmale, die man als charakteristisch für moderne Gesellschaften ansehen könnte, aufgelistet werden, sondern denkbare Charakteristika zu drei Gesichtspunkten verdichtet werden. Die Behauptung lautet, dass sich durch diese drei miteinander verbundenen Gesichtspunkte Gesellschaften als moderne bestimmen und von vormodernen Gesellschaften unterscheiden lassen.

1. Moderne Gesellschaften zeichnen sich erstens durch Prinzipien der funktionalen Differenzierung aus. Dies meint, dass sich im Unterschied zu vormodernen Gesellschaften in der Moderne unterschiedliche gesellschaftliche Funktionsbereiche - Recht, Wissenschaft, Ökonomie, Politik, Bildung - herausbilden, die sowohl durch ein hohes Maß an Eigendynamik als auch durch wechselseitige Abhängigkeit voneinander charakterisiert sind. Im Unterschied zum europäischen Mittelalter folgen die einzelnen Bereiche nicht mehr gesellschaftsübergreifenden Normen, Weltbildern und Werten, sondern unterscheiden sich durch je spezifische Codes und Institutionen voneinander, die sich wechselseitig nicht anleiten können. Die Politik kann nicht vorgeben, was wissenschaftlich wahr ist, die Wissenschaft nicht, was moralisch geboten ist, und die Moral kann nicht diktieren, wie wirtschaftlich gehandelt werden sollte. Zugleich sind die einzelnen gesellschaftlichen Bereiche auf die Leistungen anderer Teilsysteme angewiesen. Insofern beruht die Integration funktional differenzierter Gesellschaften auf der Leistung, die die einzelnen Funktionssysteme füreinander erbringen ${ }^{11}$.

2. Quer zur funktionalen Differenzierung, die horizontal verläuft, gibt es in modernen Gesellschaften auch eine Form der vertikalen Differenzierung. Es treten nicht nur die Funktionsbereiche, sondern auch die Konstitutionsebenen des Sozialen - Individuum, Interaktion, Gemeinschaft,

11 Niklas Luhmann, Die Gesellschaft der Gesellschaft, Frankfurt a.M. 1997. 
Organisation, Markt, Gesellschaft - mehr und mehr auseinander. In der Moderne lassen sich Gesellschaften nicht mehr auf Personen, aber auch nicht mehr auf Interaktionen zwischen Anwesenden, Gemeinschaften oder Organisationen zurückführen. Diese sozialen Ebenen differenzieren sich vielmehr zunehmend voneinander. Aufgrund der zunehmenden Ebenendifferenzierung kommen den mittleren Ebenen, insbesondere der Organisationsebene (man denke etwa an Gewerkschaften, Kirchen, Parteien, Freiwilligenorganisationen, Betriebe, Kliniken, Schulen usw.), in hohem Maße Aufgaben der Vermittlung zwischen Individuum und Gesellschaft zu. Organisationen sind es, die einerseits gesellschaftliche Erwartungen an den Einzelnen adressieren und andererseits individuelle Wünsche und Bedürfnisse aufnehmen und gesellschaftlich weiterleiten.

3. Die einzelnen gesellschaftlichen Funktionssysteme sind in den Prozess der funktionalen Differenzierung in unterschiedlicher Weise involviert. Manche Systeme sind diesem Prozess eher reaktiv ausgesetzt, andere wie Wirtschaft, Politik oder Wissenschaft treiben ihn voran. Entscheidend für diese Unterscheidung ist die Tatsache, ob die gesellschaftlichen Systeme Foren des Wettbewerbs, also Märkte eingerichtet haben, in denen die unterschiedlichen Anbieter um Akzeptanz ringen. Märkte stellen einen Anreiz zur Leistungssteigerung und wechselseitigen Überbietung dar und sind insofern die Motoren des gesellschaftlichen Wandels. Nichts findet um seiner selbst willen Anerkennung, vielmehr besitzt alles lediglich den Status eines vorläufig besten Angebots, das nur darauf wartet, vom nächst besseren Angebot überholt zu werden. Auf diese Weise werden soziale Praktiken der permanenten Überprüfung ausgesetzt und immer wieder im Lichte neuer Informationen reformiert. Keine Institution, keine soziale Praxis, kein Wissensbestand kann sich dem Prozess der permanenten Veränderung entziehen. In dem Prozess der fortgesetzten Umgestaltung kann es ein letztes Ziel, auf das hin die gesellschaftliche Umgestaltung erfolgen soll, nicht geben. Vielmehr wird alles Aktuelle stets in das Licht potentieller Möglichkeiten gerückt und damit reflexiv transzendiert. Märkte dynamisieren nicht nur die gesellschaftliche Entwicklung; aufgrund ihrer hohen Effektivität tendieren sie auch dazu, sich weltweit auszudehnen. Oder wie es Marx im Kommunistischen Manifest sagt: "Die wohlfeilen Preise der Waren der Bourgeoisie sind die schwere Artillerie, mit der sie alle chinesischen Mauern in den Grund schießt $\varkappa^{12}$.

12 Karl Marx/Friedrich Engels, Manifest der Kommunistischen Partei, in: Dies., Werke, Bd. 4. Berlin ${ }^{6} 1972$, S. 459-493, hier S. 466. 


\subsection{Religion}

Die Bestimmung des Religionsbegriffes muss ähnlich kurz ausfallen. Jede Religion - so lautet unser Vorschlag - vollzieht eine zweifache Operation. Sie überschreitet das Immanente und führt gleichzeitig die sozial unkontrollierbare und intersubjektiv unzugängliche Sphäre des Transzendenten in die Immanenz wieder ein. Auf diese Weise wird Transzendenz intersubjektiv verfügbar und kommunizierbar gemacht. Die damit repräsentierte Gleichzeitigkeit von Immanenz und Transzendenz besitzt in der Lebenswelt der Individuen unterschiedliche Dimensionen. Wir unterscheiden die Dimension (a) der religiösen Zugehörigkeit bzw. Identität, (b) der religiösen Praxis sowie (c) der religiösen Vorstellungen, Überzeugungen und Erfahrungen. Dabei kann die Zugehörigkeitsdimension durch Indikatoren wie Kirchenzugehörigkeit, Kirchenaustritt, Kircheneintritt, Vertrauen in die Kirche oder auch das Gefühl der Verbundenheit mit der Kirche, die Praxisdimension durch Kirchgang, Gebet, Meditation, Taufe oder Kommunion und die Überzeugungs- und Erfahrungsdimension durch Variablen wie den Glauben an Gott, an Himmel, Hölle, Dämonen, Ahnen, Geister, an die Wirkungen von Esoterik, Spiritismus, Nirwana, durch Erfahrungen der Nähe Gottes oder auch durch Konversionen empirisch erfasst werden. Charakteristisch für diese individuellen religiösen Phänomene ist, dass sie nicht einfach nur auf der Unterscheidung von Immanenz und Transzendenz aufbauen, sondern das Immanente mit einem transzendenten Sinn versehen. Das gilt nicht nur für religiöse Vorstellungen, Erfahrungen und Praktiken, sondern auch für religiöse Zugehörigkeiten, die insofern eine transzendente Bedeutung transportieren, als es sich um Zugehörigkeiten zu sich als heilig verstehende Gemeinschaften handelt. Ohne die Bezugnahme auf individuelle Bedeutungszuschreibungen lassen sich beobachtbare Zugehörigkeiten, Praktiken, Vorstellungsgehalte, Semantiken und Diskurse nicht als religiös ausweisen.

\section{Leitende Fragestellungen und methodologische Vorüberlegungen}

Welche Muster und Kausalbeziehungen zwischen religiösen und gesellschaftlichen Wandlungsprozessen in der Moderne bestehen, ergibt sich nicht zwangsläufig aus der Theorie der Moderne. Vielmehr erlaubt die hier vorgeschlagene Kennzeichnung moderner Gesellschaften die Behauptung eines Spannungsverhältnisses von Religion und Moderne ebenso wie die ihrer Kompatibilität. Es verwundert daher nicht, dass in der religionssoziologischen Diskussion die Bestimmung des Verhältnisses von Religion und Moderne umstritten ist. In der religionssoziologischen Literatur 
lassen sich im Hinblick auf die Verhältnisbestimmung von funktionaler Differenzierung, vertikaler Differenzierung sowie Pluralisierung und religiösem Wandel jeweils geradezu entgegengesetzt argumentierende Positionen beobachten.

1. Funktionale Differenzierung: Auf der einen Seite stehen Soziologen wie Karel Dobbelaere, Niklas Luhmann, Jörg Stolz oder auch Pippa Norris und Ronald Inglehart, die zwischen Funktionsprinzipien der Moderne und Religion ein Spannungsverhältnis wahrnehmen. Funktionale Differenzierung erschwere die einheitliche religiöse Interpretation der Welt ${ }^{13}$. Aufgrund funktionaler Differenzierung kämen mehr und mehr attraktive säkulare Alternativen zu den religiös-kirchlichen Angeboten auf, die diese unter Plausibilisierungsdruck setzten ${ }^{14}$. Der mit der funktionalen Differenzierung einhergehende Ausbau ökonomischer, wohlfahrtsstaatlicher, medizinischer, rechtsstaatlicher und kultureller Institutionen stelle Leistungen bereit, die dazu beitrügen, dass der Bedarf an der Vermittlung religiöser Gewissheiten und Hoffnungen zurückgehe ${ }^{15}$.

Auf der anderen Seite wird in der religionssoziologischen Literatur aber auch die Annahme vertreten, dass mit funktionaler Differenzierung Religion an teilsystemspezifischer Autonomie gewinne, von der Berücksichtigung außerreligiöser Gesichtspunkte unabhängiger werde und ein höheres Maß an selbstbegründeten Gestaltungsfreiheiten erlange ${ }^{16}$.

2. Vertikale Differenzierung: Die Auswirkungen der Abstandsvergrößerung zwischen den Konstitutionsebenen des Sozialen auf das religiöse Feld sehen manche Religionssoziologen wie der frühe Peter L. Berger ${ }^{17}$, Bryan Wilson ${ }^{18}$ oder Steve Bruce ${ }^{19}$ darin, dass das Individuum in der Moderne mit seinen religiösen Überzeugungen und Handlungen mehr und mehr auf sich selbst gestellt ist und auf institutionelle und gemeinschaftliche Unterstützung zunehmend verzichten muss. Seine religiösen

13 Niklas Luhmann, Funktion der Religion, Frankfurt a.M. 1977, S. 79f.

14 Jörg Stolz u.a., Religion und Spiritualität in der Ich-Gesellschaft. Vier Gestalten des (Un-)Glaubens, Zürich 2014.

15 Pippa Norris / Ronald Inglehart, Sacred and Secular. Religion and Politics Worldwide, Cambridge 2004, S. 18f.

16 Volkhard KRECH, Über Sinn und Unsinn religionsgeschichtlicher Prozessbegriffe, in: Karl Gabriel u.a. (Hg.), Umstrittene Säkularisierung. Soziologische und Historische Analysen zur Differenzierung von Religion und Politik, Berlin 2012, S. 565602, hier S. 574; im Anschluss an Niklas Luhmann, Die Religion der Gesellschaft, Frankfurt a.M. 2000, S. 146; vgl. auch ders., Funktion der Religion, S. 248, 263.

17 Peter L. Berger, The Heretical Imperative. Contemporary Possibilities of Religious Affirmation, Garden City, NY 1979 [dt.: Der Zwang zur Häresie: Religion in der pluralistischen Gesellschaft, Frankfurt a.M. 1980].

18 Wilson, Religion in Sociological Perspective.

19 BRUCE, God is Dead. 
Vorstellungen und Praktiken würden daher in modernen Gesellschaften unsicherer und poröser werden.

Dominant ist in der gegenwärtigen religionssoziologischen Diskussion jedoch eine Gegenposition: die sogenannte Individualisierungsthese, die die aus der Differenzierung von Person, Gemeinschaft und Institution resultierenden Chancen zur Ausbildung einer hochindividualisierten Religiosität betont ${ }^{20}$. Aufgrund der Auflösung des einstmals engen $\mathrm{Zu}$ sammenhangs von Person und Institution bzw. Individuum und Gemeinschaft könne der Einzelne heute in einem nie dagewesenen Ausmaß über seine religiösen Orientierungen und Praktiken selbst bestimmen. Dadurch gewinne die individuelle Religiosität eine von den Kirchen und religiösen Gemeinschaften unabhängige Dynamik. Wenn auch die Kirchen in der Moderne an Einfluss verlieren, bedeute das daher keineswegs ein Rückgang der Bedeutung von Religion. Im Gegenteil. Religiosität und Kirchlichkeit stünden in einem inversen Verhältnis ${ }^{21}$.

3. Wettbewerbsforen: Auch hinsichtlich der Wirkung religionsinterner Wettbewerbsforen stehen sich in der Religionssoziologie unterschiedliche Auffassungen gegenüber. Peter L. Berger ${ }^{22}$ und Steve Bruce ${ }^{23}$ vertreten die These, religiöse Pluralisierung unterminiere »all taken-for-granted certainties« und führe zwangsläufig zur wechselseitigen Relativierung religiöser Geltungsansprüche ${ }^{24}$. Mit der Pluralisierung des Religiösen gehe seine Überzeugungskraft zurück. Die Gegenposition wird von den bereits erwähnten Vertretern der ökonomischen Markttheorie gehalten ${ }^{25}$ : Je pluralistischer der religiöse Markt sei und je mehr Konkurrenz zwischen den einzelnen religiösen Anbietern herrsche, desto stärker seien die einzelnen Religionsgemeinschaften herausgefordert, um ihre Anhänger zu werben und das Niveau ihrer religiösen Leistungen anzuheben. Religiöse Pluralisierung erhöhe die religiöse Vitalität. Dies gelte allerdings nur dann, wenn faire Wettbewerbsbedingungen gesichert seien und der Staat sich aus religiösen Angelegenheiten heraushalte.

20 Thomas Luckmann, Die unsichtbare Religion, Frankfurt a.M. 1991 (ursprünglich: ders., The Invisible Religion. The Problem of Religion in Modern Society, New York 1967); Grace Davie, Europe: The Exceptional Case. Parameters of Faith in the Modern World, London 2002; Hubert Knoblauch, Populäre Religion. Auf dem Weg in eine spirituelle Gesellschaft, Frankfurt a.M. u.a. 2009.

21 Davie, Europe: The Exceptional Case, S. 8.

22 Berger, The Heretical Imperative.

23 BRUCE, God is Dead.

24 Peter L. Berger, Postscript, in: Linda Woodhead (Hg.), Peter Berger and the Study of Religion, London u.a. 2001, S. 189-198, hier S. 194.

25 StARK / Finke, Acts of Faith; Laurence IANnACCONE, The Consequences of Religious Market Structure. Adam Smith and the Economics of Religion, in: Rationality and Society 3 (1991), S. 156-177; ders., Why Strict Churches are Strong, in: AJS 99 (1994), S. 1180-1212. 
Zur Beantwortung dieser Fragen greife ich aufStudien zurück, die ich gemeinsam mit Gergely Rosta angestellt und in dem kürzlich erschienenen Buch Religion in der Moderne: Ein internationaler Vergleich präsentiert habe ${ }^{26}$. Als empirisches Fundament unserer Analysen haben wir sowohl kirchliche als auch von staatlichen Ämtern erstellte Statistiken, sowohl öffentlich verfügbar repräsentative Bevölkerungsumfragen wie z.B. die World Value Survey (WVS) oder die Allgemeine Bevölkerungsumfrage der Sozialwissenschaften $^{27}$ als auch selbst erhobene Daten benutzt, so das von der VolkswagenStiftung geförderte Projekt »Church and Religion in an Enlarged Europe ${ }^{28}$ sowie die 2010 am Exzellenzcluster »Religion und Politik« der Universität Münster durchgeführte Studie »Wahrnehmung und Akzeptanz religiöser Vielfalt $\star^{29}$.

Um zu aussagekräftigen Ergebnissen zu gelangen, haben wir unter Heranziehung internationaler Bevölkerungsumfragen nicht nur ländervergleichende Analysen durchgeführt, sondern auch Einzelfallstudien. Zusammenhänge, die sich auf internationaler Ebene manifestieren, können sich aufgrund andersartiger Kontextbedingungen in verschiedenen Regionen unterschiedlich darstellen. Die Durchführung von Länderstudien erlaubt kontextsensible Analysen und kann davor bewahren, auf der internationalen Ebene gewonnene Ergebnisse vorschnell zu verallgemeinern. In den Einzelfallstudien haben wir uns mit dem religiösen Wandel in Westdeutschland, den Niederlanden, Italien, Russland, Polen, Ostdeutschland, den USA, Südkorea sowie - als einem international anzutreffenden Phänomen - der Pfingstbewegung auseinandergesetzt. Eingebettet sind diese Fallstudien in länderübergreifende Vergleiche, so dass die in den Einzelanalysen gewonnenen Einsichten noch einmal auf ihre Verallgemeinerbarkeit geprüft werden können. Einige der in den Einzelanalysen und Vergleichsuntersuchungen gewonnenen Einsichten seien hier präsentiert. Diese Einsichten sollen nicht zu einer religionssoziologischen Universaltheorie zusammengefasst werden,

26 Vgl. Detlef Pollack / Gergely Rosta, Religion in der Moderne. Ein internationaler Vergleich, Frankfurt a.M. u.a. 2015.

27 ALLBUS (Allgemeine Bevölkerungsumfrage der Sozialwissenschaften) (1996, 2002, 2012), Drei Wellen einer langfristig angelegten Umfrageserie zu Einstellungen, Verhaltensweisen und Sozialstruktur der Bevölkerung in der Bundesrepublik Deutschland. Datensatz. Köln: GESIS.

28 C \& R (2006): Church and Religion in an Enlarged Europe: Cumulated Codebook. European University Viadrina Frankfurt (Oder): Chair of Comparative Sociology of Culture/Frankfurt Institute for Transformation Studies (F.I.T.).

29 WARV (2010): Wahrnehmung und Akzeptanz religiöser Vielfalt: Repräsentative Bevölkerungsumfrage in Deutschland, den Niederlanden, Dänemark, Frankreich und Portugal. Datensatz. Münster: Universität Münster, Lehrstuhl für Religionssoziologie. 
sondern stellen Theorieelemente dar, die miteinander kombiniert werden können und auf diese Weise eher zu einer multi-paradigmatischen Theorieperspektive $^{30}$ als zu einem neuen Masternarrativ führen.

\section{Funktionale Differenzierung und Diffusion}

\subsection{Funktionale Differenzierung}

Häufig stehen Prozesse funktionaler Differenzierung in Spannung zur Integrationsfähigkeit von Religion und Kirche. In modernen Gesellschaften vermag Religion nicht mehr wie in früheren Gesellschaften Normen, Werte und Weltinterpretationen anzubieten, die für alle gesellschaftlichen Bereiche Gültigkeit beanspruchen können. Die Politik kann auf den Rückgriff auf religiöse Legitimationsformeln verzichten und stattdessen auf die Effektivität demokratischer Verfahren vertrauen. Auch die wissenschaftliche Analyse bedarf nicht der Unterstützung durch göttliche Offenbarung, sondern erzielt überzeugende Ergebnisse auf der Grundlage systematisch eingesetzter Methoden. In modernen funktional differenzierten Gesellschaften ist Religion nicht mehr die überwölbende Instanz, die alles zusammenhält, sondern nur noch eine gesellschaftliche Sphäre unter anderen.

In den westeuropäischen Ländern waren die Kirchen in den 1950er Jahren vielfach noch in der Lage, die Gesellschaft als Ganze zu durchdringen und die Relevanz des Christentums für alle gesellschaftlichen Sphären, für die Gestaltung einer sozial gerechten Marktwirtschaft wie für den Erhalt der Familie, für eine moralische Lebensführung wie für die Bewahrung des Weltfriedens zu plausibilisieren. Diese Fähigkeit hat seit den 1960er Jahren mehr und mehr nachgelassen. Sowohl im wirtschaftlichen als auch im politisch-öffentlichen, sowohl im kulturellen als auch im bildungspolitischen und erzieherischen Bereich nahm seit dieser Zeit die Eigendynamik der Einzelsysteme zu, was zu Leistungssteigerungen in allen Bereichen geführt hat: zur Erhöhung der Wirtschaftskraft, dem Ausbau des Sozialsystems, zur Explosion der Freizeit- und Konsumindustrie, der Erweiterung der politischen Partizipationsmöglichkeiten, der Verlebendigung der öffentlichen Debattenkultur sowie zum Anstieg des Bildungsniveaus. Mit diesen Ausdifferenzierungsprozessen verminderten sich die Chancen religiöser

30 Udo Kelle, Säkularisierung, Individualisierung oder religiöse Marktwirtschaft? Die vergebliche Suche nach einem Leitparadigma in der Religionssoziologie, in: Gerhard Wegner (Hg.), Gott oder die Gesellschaft? Das Spannungsfeld von Theologie und Soziologie, Würzburg 2012, S. 65-107, hier S. 94, 97. 
Organisationen und Gemeinschaften, das gesellschaftliche Leben und die einzelnen Sinnsphären von religiösen Gesichtspunkten her zu interpretieren, $\mathrm{zu}$ beeinflussen und zu integrieren.

\subsection{Distraktion}

Die Säkularisierungseffekte funktionaler Differenzierung treten aber nicht nur auf der Makroebene hervor, sondern auch auf der individuellen Ebene. Wie Norris und Inglehart und andere herausgearbeitet haben, korrespondiert die ökonomische und wohlfahrtsstaatliche Befriedigung von existentiellen Sicherheitsbedürfnissen mit einem Rückgang individueller Religiosität ${ }^{31}$. Dabei steht hinter der Abwendung von Religion und Kirche oft nicht eine bewusst vollzogene Wahl, sondern lediglich eine Aufmerksamkeitsverschiebung. Familiäre Unternehmungen, berufliche Verwirklichungsmöglichkeiten, Freundschaftsnetzwerke, Konsum- und Freizeitaktivitäten sind für viele schlichtweg wichtiger als die Beschäftigung mit religiösen Fragen oder die Beteiligung am kirchlichen Leben. Wenn der Einzelne nicht am Gottesdienst teilnimmt - das zeigt die Kirchenmitgliedschaftsuntersuchung der EKD von $2002^{32}$-, so hängt das vor allem damit zusammen, dass er am Sonntag anderes zu tun hat als zum Gottesdienst zu gehen. Demgegenüber spielen kircheninterne Gründe für die Absenz vom Gottesdienst, etwa schlechte Predigten oder störender Gesang, keine zentrale Rolle. Offenbar ist ihm anderes wichtiger als das Hören des Wortes Gottes und die Feier der heiligen Kommunion. Nicht Unzufriedenheit mit der Art und Weise, wie der Gottesdienst durchgeführt wird, scheint hier der zentrale Mechanismus zu sein, der die Nichtteilnahme am Gottesdienst erklärt, sondern Distraktion bzw. Attraktion durch nichtreligiöse Dinge.

Auch die immer wieder auftretende auffällige Diskrepanz zwischen der in Befragungen bekundeten hohen Bereitschaft, sich als regelmäßigen Gottesdienstbesucher zu bezeichnen, und der nachweislich deutlich geringeren tatsächlichen Partizipationsfrequenz weist darauf hin, dass hinter der Nichtteilnahme am Gottesdienst oft nicht eine bewusste Entscheidung gegen den Gottesdienst steht, sondern eine nicht intendierte Distraktion. In der Befragung gibt man an, jede Woche zur Kirche zu gehen, die kirchlichen Statistiken aber zeigen, dass die tatsächliche Zahl der Gottesdienstbesucher viel geringer ist als die Zahl der Teilnahmebekundungen. Offenbar versteht sich der Befragte selbst noch immer als regelmäßiger Kirchgänger, auch wenn er

31 Norris / Inglehart, Sacred and Secular.

32 KMU IV: Vierte EKD-Erhebung über Kirchenmitgliedschaft von 2002. Datensatz. Hannover: Sozialwissenschaftliches Institut. 
längst nicht mehr regelmäßig am Gottesdienst teilnimmt. Möglicherweise hat er sogar vor, zur Kirche zu gehen, tut es dann aber nicht. Die Abwendung von den kirchlichen Angeboten vollzieht sich hier also offenbar nicht als Ergebnis einer rationalen Wahl, sondern ergibt sich lautlos und unintendiert aus den vielfachen Alltagsbezügen, in die der Einzelne hineingestellt ist und die anscheinend schwerer wiegen als die Verbundenheit mit der Kirche. Möglicherweise sind weniger Einstellungsverschiebungen für Distanzierungen von der Kirche entscheidend als die Vielzahl von Handlungsgelegenheiten und Selbstverwirklichungsmöglichkeiten jenseits der Kirche, die mit der zunehmenden Verfügbarkeit über Ressourcen und der Ausweitung nichtreligiöser Angebote freilich steigen. Gewinnt die Abstandnahme von der kirchlichen Interaktion aber erst einmal handlungspraktische Dominanz, dann können mentale Distanzierungen durchaus die Folge sein.

\subsection{Diffusion}

Verbinden sich religiöse Identitäten mit nicht-religiösen, zum Beispiel mit politischen, wirtschaftlichen oder ethnischen Interessen (funktionale Diffusion), trägt das jedoch oft zur Stärkung von Religion und Kirche bei. Dieser Zusammenhang lässt sich gut am Fall der USA studieren, wo trotz einer strikten rechtlich-institutionellen Trennung von Staat und Kirche Religion und Politik im gesellschaftlichen Leben enger zusammenhängen als in den meisten westeuropäischen Ländern. Der Schulunterricht beginnt mit einem gemeinsamen Gebet, der Präsident spricht seinen Amtseid auf die Bibel, die Ein-Dollarnote enthält die Aufschrift »In God we trust«, und viele Amerikaner sind überzeugt, dass die USA eine heilige Mission in der Welt zu erfüllen haben und nicht nur im eigenen Land, sondern in der ganzen Welt für Freiheit und Demokratie eintreten müssen. In den USA denken mehr als doppelt so viele wie in Europa, dass nur Politiker, die an Gott glauben, für ein öffentliches Amt geeignet sind. Und die so denken, sind zugleich weitaus religiöser als die anderen. Doch nicht nur die Politik ist in den USA religiös stark durchdrungen, was in der Religionssoziologie seit Robert Bellah unter dem Stichwort Zivilreligion verhandelt wird, auch im Sport, in der Unterhaltungsmusik, in der Kunst oder im Gelderwerb spielen religiöse Motive, verglichen mit Europa, eine ungleich gewichtigere Rolle.

Der religiöse Aufschwung nach 1990 in Russland stellt ebenfalls vor allem eine Folge der Vermischung von religiösen und politischen Identitäten dar. Enttäuscht von der Duma, den politischen Parteien und einer von Korruption und Misswirtschaft geprägten Situation projiziert die Bevölkerung politische, soziale, moralische und nationale Erwartungen auf die RussischOrthodoxe Kirche, der sie ein Vertrauen entgegenbringt wie sonst nur noch 
dem Präsidenten. Dabei werden diese Hoffnungen und Erwartungen durch die in der russischen Geschichte tief verankerte Symphonie von Staat und Kirche bestärkt. Wer ein guter Russe ist, der ist orthodox, der glaubt an Gott, an Russland und an den heiligen Boden der Rus.

Ganz anders sah die Verbindung von Religion, Nation und Politik im kommunistischen Polen aus. Aber auch sie trug zur Stärkung der kirchlichen Bindungen bei. Der Besuch von Johannes Paul II. nach seiner Wahl zum Papst glich einem Triumphzug. Der Papst musste am kommunistischen Regime überhaupt keine Kritik üben, weder auf seiner Reise 1979 noch auf der von 1983, es reichte aus zu sagen, dass er die Nöte der Menschen in Polen kenne, ihr Gefühl des erlittenen Unrechts und der Erniedrigung, und dass der Mensch sich selbst, sein Wesen, sein Recht und seine Würde ohne Christus nicht begreifen könne, so wie es ausgeschlossen sei, die Geschichte der polnischen Nation ohne Christus zu verstehen - all das genügte, um das atheistische sozialistische Regime als unmenschlich und unpolnisch zu brandmarken. Wenn der Papst den Menschen zurief: »Habt keine Angst! Öffnet, ja reißt die Tore weit auf für Christus! « ${ }^{33}$, so konnte man diesen christlichen Weckruf vor dem Hintergrund der ausschließlichen Bindung von Humanität an den Christusglauben kaum anders deuten denn als Aufruf zum politischen Umsturz. Sein rein religiöser Aufruf war zu einer politischen Botschaft geworden. Religion und Politik waren nah aneinander gerückt. Das ist ein wichtiger Grund, warum die katholische Kirche aus der Konfrontation mit dem kommunistischen Regime letztendlich gestärkt hervorging.

Auch die Verkündung des Wohlstandsevangeliums und das auf ökonomische Besserstellung ausgerichtete kirchliche Engagement in den protestantischen Kirchen Südkoreas verdeutlichen, welch mobilisierende Kraft Religion entfalten kann, sofern sie sich mit nichtreligiösen Bedürfnissen und Interessen verbündet. Der Protestantismus galt in den Zeiten des rapiden wirtschaftlichen Aufschwungs in Südkorea seit den 1950er Jahren als Symbol der westlichen Moderne. Aus den protestantischen Gemeinden rekrutierte sich ein Großteil der nationalen Eliten. In den kirchlich getragenen Schulen und Universitäten erfuhren sie ihre Ausbildung. Die dort geknüpften Kontakte kamen ihrem Aufstieg zugute, der zugleich landesweite Ausstrahlungskraft entfaltete. Das Wirtschaftswachstum ging in Südkorea daher nicht zufällig einher mit der Verbreitung des protestantischen Christentums.

Wenn Religion mit Politik, mit nationalen Gefühlen, mit wirtschaftlichen Aufstiegsinteressen oder auch mit ästhetischen Erlebnissen verknüpft ist, kommt das ihrer Integrationskraft zugute. Die Attraktivität religiöser Gemeinschaften, Identitäten und Überzeugungen geht jedoch zurück, wenn

33 Ansprache von Johannes Paul II. am Beginn seines Pontifikats am 22. Oktober 1978, URL: <http://www.clerus.org/bibliaclerusonline/de/f4s.htm> (28.12.2017). 
die mit ihr verbundenen Sphären sich verselbstständigen. Infolge der Demokratisierungs- und Liberalisierungsprozesse in Irland, Spanien, Québec und anderen Ländern verlor die Kirche ihre Funktion als Ankerpunkt der nationalen Identität und durchlief innerhalb weniger Jahrzehnte einen dramatischen Prozess des Niedergangs. Nachdem die Katholiken in den USA in den 1960er Jahren denselben sozialen Status erlangt hatten wie die Mehrheit der Protestanten, brach der Messbesuch ein. Ebenso hatte auch in den Niederlanden die Entkopplung konfessioneller Zugehörigkeiten von ihrer Einbindung in politisch, sozial und alltagsweltlich geschlossene Milieus, die sich nach dem Zweiten Weltkrieg vollzog, die Auflösung konfessioneller Bindungen zur Folge.

\subsection{Funktionale Absorption}

Gleichzeitig ist es erforderlich, auch die Grenzen der Effekte funktionaler Diffusion ins Auge zu fassen, denn kommen sich Religion und Politik zu nahe, geht die Attraktivität religiöser Gemeinschaften und Organisationen zurück. In einem solchen Fall können religiöse Identitäten durch nichtreligiöse Funktionen aufgesaugt und intrinsische von extrinsischen Motiven überlagert werden. In den USA ist es die Verschwisterung von Religion und Politik, die nicht nur zu hohen religiösen Mobilisierungsraten beiträgt, sondern auch zu hohen Defektionsraten. Gerade die politisch konservative Rhetorik hochengagierter Evangelikaler wirkt auf viele Amerikaner abschreckend und motiviert sie dazu, sich von Kirche und Religion abzuwenden. Wenn Religion so eng mit radikalen politischen Positionen verbunden ist wie bei den Evangelikalen und religiöse Argumente in der Gefahr stehen, politisch instrumentalisiert zu werden, wollen sie mit Religion nichts mehr zu tun haben. Ihren Rückzug erklärend sagen sie »I’m not like them«.

In den postkommunistischen Ländern Mittel- und Osteuropas, in denen vor 1989 Religion eine eminent politische Rolle spielte, drängt heute eine Mehrheit auf die strikte Trennung von Kirche und Staat. Selbst im hochkatholischen Polen musste die Kirche einen beachtlichen Vertrauensverlust hinnehmen, als sie unmittelbar nach dem Zusammenbruch des Kommunismus versuchte, das Wahlverhalten der Gläubigen zu beeinflussen. Ebenso laufen die Sympathien auch in Deutschland gegen die Kirche, wenn der Eindruck entsteht, dass sie als quasi-politische Institution agiert. Und auch für Südkorea lassen sich die negativen Effekte einer Überidentifikation der Religion mit anderen gesellschaftlichen Bereichen aufzeigen. Was zunächst zum atemberaubenden Erfolg der protestantischen Kirchen beigetragen hatte - ihre Versprechungen von Gesundheit und Wohlstand -, das sollte sich langfristig als ein Hindernis für die weitere Steigerung ihres 
Erfolges erweisen. Für viele Mitglieder waren anscheinend nichtreligiöse Motive ausschlaggebend für ihren Übertritt zum Protestantismus, während sie intrinsische Motive nur unzureichend verinnerlicht hatten. Nachdem viele den sozialen Aufstieg geschafft hatten, verließen sie die Kirche wieder. Die Abwanderungsraten in den protestantischen Kirchen sind seit einigen Jahren jedenfalls so hoch wie in keiner anderen Religionsgemeinschaft Südkoreas.

Die Verknüpfung mit politischen, wirtschaftlichen, nationalen Interessen stärkt mithin die soziale Bindungsfähigkeit der Kirche, aber wenn sich Religion und andere Bereiche bis zur Unkenntlichkeit vermischen, besteht die Gefahr, dass sich die religiöse Identität im Nichtreligiösen auflöst, sowie die nicht minder große Gefahr, dass das Religiöse die nichtreligiösen Bereiche übermächtigt. Beide Formen der funktionalen Diffusion beeinträchtigen die gesellschaftliche Relevanz des Religiösen. Ebenso wird sie aber auch durch seine funktionale Isolation vermindert. Um die Wirksamkeit von Religion in den Prozessen der funktionalen Differenzierung zu beschreiben, könnte man sich des Bildes einer Parabel bedienen. Funktionale Überspezifikation schränkt ihre Wirksamkeit ein, aber auch funktionale Absorption. Eine Mittelposition zwischen funktionaler Spezifikation und funktionaler Diffusion scheint ihre soziale Relevanz hingegen zu begünstigen.

\section{Religiöse Individualisierung und Vergemeinschaftung}

\subsection{Verkopplung}

Treten die Konstitutionsebenen des Sozialen (vertikale Differenzierung) auseinander, so ist die Bindungsfähigkeit religiöser Gemeinschaften und Institutionen davon zumeist negativ betroffen. Religiöse Vorstellungen gewinnen an Überzeugungskraft, wenn der Einzelne sie mit anderen teilt, wenn er in kommunale, nachbarschaftliche, familiäre oder auch kirchliche Netzwerke eingebunden ist und so gemeinschaftliche und institutionelle Stützung erfährt. Schon die religiöse Sozialisation findet in der Familie statt. Wer als Kind religiös erzogen wurde, weist eine sehr hohe Wahrscheinlichkeit auf, sich auch als Erwachsener als religiöse Person zu definieren. Zugang zu religiösen Praktiken, Deutungen und Erfahrungswelten ohne kindliche Vorprägung finden hingegen nur wenige. Die Familie ist in Europa und den USA die entscheidende Instanz zur Vermittlung zwischen dem Einzelnen und den religiösen Gemeinschaften. Das gilt nicht nur für die Herkunftsfamilie, sondern auch für die Familie, die man selbst gegründet hat. Individuelle Religiosität ist stärker ausgeprägt, wenn Menschen verheiratet sind und Kinder haben. 
Auch die Einbindung des Einzelnen in das kirchliche Leben übt einen beachtlichen Einfluss auf seine Religiosität aus. Wer regelmäßig am Gottesdienst teilnimmt, sich an der Arbeit kirchlicher Kreise beteiligt und Kontakt zum Pfarrer hat, bekennt sich häufiger zum Glauben an Gott als derjenige, der an den unterschiedlichen Formen kirchlicher Kommunikation nicht teilhat. Das ist kein Zufall, denn der religiöse Glaube bezieht sich auf etwas Transzendentes, etwas Unanschauliches, das der kommunikativen Vergewisserung durch Gleichgesinnte und der sozialen Unterstützung durch religiöse Gemeinschaften und Institutionen bedarf. Zwar sagt in den westeuropäischen Gesellschaften eine Mehrheit, dass sie auch ohne Kirche gläubig sein könnte, aber wie tiefergehende Untersuchungen zeigen, besteht zwischen der Teilnahme am kirchlichen Leben und der individuellen Glaubensintensität ein sich wechselseitig bestärkendes Interdependenzverhältnis. Es ist daher nicht überraschend, dass kirchliche Bindungen bei hoher Akzeptanz von Individualisierungswerten wie Selbstbestimmung oder Hedonismus schwächer ausfallen als bei überdurchschnittlicher Bejahung von Altruismus-, Gemeinschafts- und Ordnungswerten. Ebenso stellen auch die Mitgliedschaft und das Engagement in Vereinen, Gemeinschaftsbewegungen und Projektgruppen wichtige Vermittlungsinstanzen zwischen dem religiösen Individuum und der Kirche dar. Religiöse Individualität und kirchliche Bindung sind auf diese Weise miteinander verkoppelt, auch wenn sie natürlich nicht zusammenfallen.

Offenbar stärkt es Religion, wenn sie auf unterschiedlichen Ebenen der Gesellschaft präsent ist und diese miteinander verkoppelt sind. Dann können religiöse Ideen und Praktiken sich in unterschiedlichen Sozialformen ausprägen und wechselseitig bestärken. Diese Effekte sind charakteristisch für Italien, wo sich charismatische und sozial engagierte Bewegungen an die kirchlichen Strukturen anlagern, kirchliche Ressourcen für ihre Zwecke benutzen und damit zugleich zur Attraktivität der katholischen Kirche beitragen. Ein ähnliches Prinzip ist aber auch in den protestantischen Gemeinden in Südkorea wirksam. Der missionarische Erfolg dieser Gemeinden beruht nicht nur auf der Anziehungskraft ihrer großen charismatisch inspirierten Gottesdienste, die die eigene Glaubensgemeinschaft als sozial mächtig erscheinen lassen, oder auf ihren Beziehungsnetzwerken in Politik und Wirtschaft, sondern auch auf der Arbeit kleiner Hauskreise mit ihren engen Solidarbeziehungen und effektiven Kontrollmöglichkeiten.

Natürlich gibt es im Grad der religiösen Individualisierung starke Unterschiede zwischen den Ländern. In Polen versteht sich mehr als die Hälfte der Bevölkerung als »religiös nach den Lehren der Kirche«. In den USA hingegen gehört individuelle Selbstbestimmung zur Definition des Religiös-Seins hinzu. Wohl in keinem anderen modernen Land fällt die Konversionsrate, also der Anteil derjenigen, die aufgrund individueller Entscheidung von 
einer Glaubensgemeinschaft in eine andere wechseln, so hoch aus wie in den USA. Insgesamt gesehen ist individuell gelebte Religiosität indes nicht dann am stärksten, wenn sie von sozialen Gemeinschaftsformen und religiösen Institutionen losgelöst vagabundiert. Vielmehr besitzt Religion auch in modernen, hoch individualisierten und kulturell pluralisierten Gesellschaften einen stark gemeinschaftlichen Charakter.

Hoch individualisierte Formen der Spiritualität und Esoterik sind daher in der Regel äußerst fluide, instabil und dünn. Sofern sich Menschen auf Formen von Esoterik, Okkultismus oder New-Age-Spiritualität einlassen, geht ihr Engagement mit einem hohen Grad an kontextueller Unabhängigkeit einher und korreliert tatsächlich positiv mit Individualisierungswerten. Gerade diese nichtchristlichen Formen der Religiosität sind jedoch nicht weit verbreitet und recht fragil, auch wenn die Neugier auf sie hoch ist. Mehrheitlich praktiziert ist in Europa hingegen ein mit anderen geteilter, relativ unbestimmt bleibender Glaube an Gott oder eine höhere Macht, der mit der oft unbefragten Mitgliedschaft in einer christlichen Kirche und gelegentlichem Kirchgang einhergeht. Believing without belonging - der Slogan der britischen Religionssoziologin Grace Davie, mit dem sie die typische Form des postmodernen Glaubens in Europa kennzeichnen wollte - ist nicht völlig ausgeschlossen, als ein empirisch auftretendes Phänomen jedoch ziemlich selten.

\section{2 Übermächtigung}

So sehr die Einbettung in eine übereinstimmende soziale Plausibilitätsstruktur religiösen Glauben bestärken kann, so sehr gilt doch aber auch: Wird die von Gemeinschaften ausgehende soziale Kontrolle so eng, dass der Einzelne sich in seiner Autonomie eingeschränkt fühlt, nimmt seine Neigung zu, sich von der Gemeinschaft zu distanzieren und sich gegen sie zu behaupten. Auch wenn es um die glaubensstärkenden Effekte der Einbindung der Gläubigen in religiöse Gemeinschaften geht, ist also nicht mit einer einlinigen Steigerung dieses Wirkungsmechanismus zu rechnen. Vielmehr müssen auch hier die Grenzen der Gültigkeit dieses Mechanismus bedacht werden. Insbesondere dann, wenn Kirche zur Herrschaftsinstitution wird, treten die hemmenden Effekte der institutionellen Einbindung des religiösen Individuums hervor. Sowohl in den versäulten konfessionellen Milieus der Niederlande mit ihren sich nach außen hin abschottenden und ihren intern stark reglementierenden Strukturen, als auch in den protestantischen Gemeinden Südkoreas, deren missionarischer Eifer offenbar auch zu Abstoßungsreaktionen führt, lassen sich diese Effekte beobachten. Die dramatischen Abbruchstendenzen der niederländischen Konfessionsmilieus seit Mitte des 20. Jahrhunderts sowie 
die hohen Defektionsraten im strengen Protestantismus Südkoreas legen von den ruinösen Wirkungen religiöser Überorganisation und Übermächtigung beredtes Zeugnis ab.

Allerdings sind die Wirkungen hochintegrierter, intoleranter religiöser Ordnungen nicht eindeutig. In weiten Teilen Osteuropas besitzen autoritäre Regime ein überdurchschnittlich hohes Religiositätsniveau ${ }^{34}$. Oft wenden sich die Individuen erst von der strukturell verfestigten kirchlichen Macht $\mathrm{ab}$, wenn sich die Gelegenheitsstrukturen erweitern und Spielräume für abweichendes Verhalten entstehen. In der Zeit davor scheinen die Bindungen an die autoritären Strukturen und an die geschlossenen Gemeinschaften hingegen relativ eng zu sein. Dies gilt beispielsweise auch für die katholische Kirche in Spanien, wo der Rückgang der Kirchenbindung erst einsetzte, nachdem das totalitäre Franko-Regime, zu dem die Kirche über lange Zeit enge Kontakte unterhalten hatte, zusammengebrochen war. Welche Wirkungen von hoch integrierten staatsnahen kirchlichen Ordnungen auf die individuelle Religiosität ausgehen und von welchen Faktoren deren kulturelle Unterstützung abhängt, bedarf weiterer religionssoziologischer Forschung.

\section{Religiöse Pluralisierung und Homogenisierung}

\subsection{Mehrheitskultur}

Im Gegensatz zu den Annahmen des ökonomischen Marktmodells zeigen viele empirische Untersuchungen der letzten Zeit, dass die religiöse Vitalität unter Bedingungen religiöser Pluralität nicht steigt, sondern fällt ${ }^{35}$. Dieser Zusammenhang lässt sich bereits bei einem flüchtigen Blick auf den religiösen Wandel Westeuropas entdecken, wo in vielen Ländern die einstige konfessionelle Homogenität in den letzten Jahrzehnten mehr und

34 Paul Froese, Religious Vitality in Monopoly Churches. The Unusual Case of the Former Soviet Union, Baylor University 2002 (Diss. masch.), S. 27f.

35 Mark Chaves / David E. Cann, Regulation, Pluralism, and Religious Market Structure. Explaining Religion's Vitality, in: Rationality and Society 4 (1992), S. 272-290; Daniel V. A Olson, Quantitative Evidence Favoring and Opposing the Religious Economies Model, in: Detlef Pollack / Daniel V. A. Olson (Hg.), The Role of Religion in Modern Societies, New York, NY u.a. 2008, S. 95-113; Volkhard Krech, What are the Impacts of Religious Diversity? A Review of the Methodological Considerations and Empirical Findings of a Research Project on Religious Pluralization in North Rhine-Westphalia, Germany, in: Religion 39 (2009), S. 132-149; Markus Hero/Volkhard Krech, Die Pluralisierung des religiösen Feldes in Deutschland. Empirische Befunde und systematische Überlegungen, in: Gert PiCKEL/Kornelia Sammet (Hg.), Religion und Religiosität im vereinigten Deutschland. Zwanzig Jahre nach dem Umbruch, Wiesbaden 2011, S. 28-41. 
mehr einer religiösen Vielfalt gewichen ist und sich die Bindungen an Religion und Kirche dennoch abgeschwächt haben.

Die lebendige Religiosität in den USA kann zu einem nicht unerheblichen Teil darauf zurückgeführt werden, dass der Grad der religiösen Pluralität weitaus geringer ist als allgemein angenommen. Nur etwas mehr als 5 Prozent der Amerikaner gehören nichtchristlichen Religionsgemeinschaften an - weniger als in Frankreich, Deutschland oder Großbritannien. Mehr als 20 Prozent sind konfessionslos - etwa so viel wie in Westdeutschland. Aber nahezu drei Viertel sind Mitglied einer christlichen Kirche. Die oft bewunderte religiöse Vielfalt der Vereinigten Staaten ist vor allem ein innerprotestantisches Phänomen. Gerade die protestantischen Kirchen aber erleben derzeit die stärksten Rückgänge.

Wie stark religiöse Gemeinschaften davon profitieren, wenn sie in der Mehrheit sind, zeigt ein Vergleich zwischen West- und Ostdeutschland. In Ostdeutschland sind die Konfessionslosen, die mehr als 70 Prozent der Bevölkerung ausmachen, deutlich weniger religiös als in Westdeutschland, wo sich ihr Anteil auf etwa ein Fünftel beläuft. Die Minderheitensituation der Kirchenmitglieder in Ostdeutschland wiederum hat indes keineswegs zu einer Intensivierung ihres kirchlichen Engagements geführt. Im Gegenteil. An den kirchlichen Rändern ist die religiöse Bindung teilweise sogar noch schwächer als in den Kirchen Westdeutschlands. So wie es offenbar overburnt areas gibt, durch die mehrfach Wellen der Erweckung gegangen sind und deren Religiositätsniveau durch Mobilisierungsanstrengungen nicht weiter angehoben werden kann, so legt das Beispiel Ostdeutschlands die Annahme nahe, dass es auch religiös ausgebrannte Gebiete gibt, die kaum noch zu geistlichem Leben zu erwecken sind.

Auch bei den evangelikalen und charismatischen Gruppierungen in Brasilien zeigt sich die hohe Abhängigkeit von der religiösen Mehrheitskultur. Dort unterscheiden sich die Evangelikalen und Pfingstler in ihrem religiösen Engagement und in ihren Glaubenseinstellungen vielfach nur wenig von denen der mehrheitlich katholischen Gesamtbevölkerung. Das steht in scharfem Gegensatz zu Europa, wo die Evangelikalen sich von den religiösen Einstellungen und Verhaltensweisen der Mehrheit stark abheben, zugleich aber nicht jenes hohe Religiositätsniveau erreichen wie die Charismatiker in Lateinamerika. Es dürfte daher die Annahme wohl nicht falsch sein, dass die charismatischen und evangelikalen Gruppen in Brasilien in ihrem religiösen Engagement durch die hochreligiöse Mehrheitskultur eine enorme Unterstützung erfahren, die den Evangelikalen in Europa, wo sie eine religiöse Ausnahmeerscheinung darstellen, fehlt. 


\subsection{Konflikt}

Die Wirksamkeit der jeweiligen konfessionellen Mehrheitskultur wird noch gesteigert, wenn sie sich als bedroht versteht. Sowohl in Polen als auch in Italien lässt sich beobachten, dass die zahlreichen gesellschaftlich diskutierten weltanschaulichen und politischen Konflikte dazu beitragen, die zentralen Werte und Ideen des Katholizismus in der Öffentlichkeit wachzuhalten. Durch Abgrenzung von vermeintlichen oder wirklichen Gegnern kann der konfessionelle Zusammenhalt gestärkt werden. Die Inszenierung eines solchen Konfliktes wirkt aber nur, wenn der Bestand der angeblich gefährdeten Kultur in der Bevölkerung tief verwurzelt ist. In Westdeutschland und vielen anderen ost- und westeuropäischen Ländern mit einem leidenschaftslosen Verhältnis zum Christentum lösen daher kulturelle Bedrohungsgefühle obschon nachweisbar - kaum derartige bestärkende Effekte auf religiöse Praktiken und Überzeugungen aus.

Dabei entfalten religiöse Konflikte vor allem dann eine besondere Mobilisierungskraft, wenn sie von einer hochmotivierten aggressiven Gruppe angeheizt werden. In den Niederlanden, in den USA und in Brasilien etwa zeigt sich, wie erfolgreich solche religiösen Minderheitsgruppen operieren können. $\mathrm{Ob}$ es sich nun um strenge orthodoxe Neocalvinisten wie in den reformierten Niederlanden des 19. Jahrhunderts, um politisch engagierte Evangelikale wie im mehrheitlich protestantisch geprägten Amerika oder um charismatische Gruppierungen in der einstigen katholischen Hochburg Brasilien handelt, jedes Mal sind die Minderheitsgruppen in der Lage, Anhänger von der Mehrheitskonfession abzuziehen und für ihre partikularistischen Ziele zu begeistern. Die von ihnen betriebene Abspaltung und die Eskalation des Konfliktmechanismus durch forcierte Abgrenzung nützen in diesem Falle ihnen, nicht aber der Mehrheitskonfession. Dabei erzielen die religiösen Minderheiten ihre Relevanzgewinne nicht nur durch aggressive Missionierungsstrategien, sondern auch dadurch, dass sie an die Mitgliedschaftsbestände der Mehrheitskonfession anknüpfen und auf ihren Sozialisationserfolgen aufbauen. Insofern lässt sich diese Form des religiösen Bedeutungsgewinns als Wachstum durch parasitäre Anlagerung bezeichnen. Die konfessionellen Mehrheitskulturen, so sehr sich die in ihnen geführten Diskurse auch wechselseitig bestärken, haben den konfliktbereiten kleinen Gruppierungen dann zuweilen nicht sehr viel mehr als die Bedeutung und Schwerkraft ihrer Tradition entgegenzusetzen - sofern sie von ihnen nicht lernen und neue Mobilisierungsstrategien entwerfen. 


\subsection{Exklusivität}

Die auf Konflikt und Abgrenzung beruhenden Missionserfolge steigen freilich in der Regel nicht linear an. In Südkorea stagniert, wie erwähnt, das Wachstum der aggressiv missionierenden protestantischen Kirchen und wird inzwischen durch Zuwächse gemäßigterer christlicher Gruppierungen, etwa der katholischen Kirche, übertroffen. In den Niederlanden brachen - auch darauf wurde bereits hingewiesen - die exklusiven und religiös angespannten Konfessionsmilieus in der Mitte des 20. Jahrhunderts sogar zusammen und wichen einer weithin säkularen Kultur. Und auch in Brasilien haben die enthusiastischen Pfingstbewegungen ihren Zenit bereits überschritten. Religiöse Gruppenkulturen, die auf Exklusion und Überformung aller Lebensbereiche setzen, scheinen unter den Bedingungen von funktionaler Differenzierung und religiöser Pluralisierung nur zeitlich begrenzt besonders erfolgreich sein zu können. Ihr Insistieren auf alleinige Gültigkeit und Allzuständigkeit ist mit Prozessen der weltanschaulichen und religiösen Pluralisierung nur schwer kompatibel und macht sie in pluralen, funktional differenzierten Gesellschaften besonders verletzbar.

Auch im Hinblick auf das Verhältnis von religiöser Pluralität und religiöser Vitalität scheint die Integrationsfähigkeit religiöser Gemeinschaften also dem Bild einer Parabel zu entsprechen. Sie wächst mit dem Maß religiöser Homogenität, kann aber durch ein Übermaß an Homogenität ebenso geschwächt werden wie durch ein Übermaß an Diversität, Konflikt und Exklusivität.

\section{Zurück nach Korea}

Auf welche Weise können die hier präsentierten Überlegungen angewandt werden, um den religiösen Aufschwung in Südkorea besser zu verstehen?

Zunächst einmal scheint dem Theorem der funktionalen Diffusion eine besondere Erklärungskraft zuzukommen. Die Entwertung der konfuzianischen Staatsreligion sowie die Diskreditierung des Buddhismus durch die japanische Kolonialherrschaft ebnete nach dem Zweiten Weltkrieg den Weg für den Aufstieg des Christentums, das damit zum Marker für Modernität wurde und darüber hinaus von vielen auch mit dem modernen koreanischen Nationalismus identifiziert wurde. Anziehend wirkte das Christentum aber auch aufgrund seiner Versprechungen von Wohlstand, Reichtum und sozialem Aufstieg, die durch die wirtschaftlichen und akademischen Erfolge der Protestanten eine eindrückliche Bestätigung erhielten.

Neben der Multifunktionalität des Christentums und seiner funktionalen Diffusion mit anderen gesellschaftlichen Sphären war aber auch ein 
Konfliktmechanismus am Werk. Der Zulauf zum Christentum wurde auch durch die nach dem Zweiten Weltkrieg ausbrechenden Konflikte zwischen dem Nord- und dem Südteil Koreas begünstigt, denn dadurch nahm die christliche Mission in Südkorea einen antikommunistischen Charakter an und bildete eine Allianz mit der südkoreanischen Staatsdoktrin.

Außerdem wurde der Aufschwung des Protestantismus auch durch seine netzwerkartige Strukturierung begünstigt. Über sie kann der Einzelne sein berufliches und persönliches Leben organisieren und nützliche Beziehungen aufbauen. So wie das Wachstum der Yoido Full Gospel Church vor allem auf der Arbeit der kleinen Hauskreise und Zellen beruhte, in die die Kirchenmitglieder eingebunden waren und deren Normen und Werten sie sich kaum entziehen konnten, so vermittelte sich die Zugehörigkeit zu den protestantischen Kirchen auch andernorts über gemeinschaftliche Netzwerke. In modernen Gesellschaften, die durch die zunehmende Divergenz der Konstitutionsebenen des Sozialen gekennzeichnet sind, nimmt die Integrationskraft des Religiösen zu, wenn das religiöse Individuum mit Strukturen auf der Mesoebene - Gemeinschaft, Organisation, Markt - verknüpft ist. Oben wurde dieser Zusammenhang als Verkopplung der Konstitutionsebenen bezeichnet.

Natürlich müssen zur Erklärung des religiösen Aufschwungs in Südkorea auch andere Faktoren herangezogen werden, etwa die Fähigkeit der christlichen Kirchen, die in die explodierenden Großstädte strömenden Menschen aufzufangen, ihnen Räume sozialer Anerkennung und Bestärkung anzubieten sowie caritative Einrichtungen oder sie mit effektiven Bildungsinstitutionen, mit Schulen und Universitäten zu versorgen. Auf jeden Fall sollte deutlich geworden, sein, dass Glaube und Spiritualität nicht allein das Ergebnis individueller Vorlieben und Abneigungen sind und auch nicht nur auf private Erfahrungen zurückgeführt werden können, sondern auch von gesellschaftlichen Bedingungen abhängen. 


\section{Historische ZUGÄNGE UND PeRsPeKtiven}




\title{
Christopher Voigt-Goy
}

\section{Naturwissenschaft als »Leitwissenschaft«?}

\author{
Zum Verhältnis von naturwissenschaftlicher Methode und \\ Religion in der Frühen Neuzeit
}

Einer der ersten Bestseller der Ideengeschichtsschreibung war John William Drapers History of the Conflict between Religion and Science. Das zuerst 1875 in New York gedruckte Buch des englischen Naturwissenschaftlers und Professors an der jungen New York University wurde schnell in fast alle westeuropäischen Sprachen übersetzt, oft wieder aufgelegt und später nachgedruckt. Drapers History ist von einer tiefen Empörung über die Verhältnisbestimmung von Glaube und Vernunft getragen, die wenige Jahre zuvor vom Ersten Vatikanischen Konzil in der Dogmatischen Konstitution »Dei Filius" (24. April 1870) promulgiert worden war ${ }^{1}$. Sie gilt Draper als weiterer Beweis für den weltgeschichtlichen Dauerkonflikt zwischen »Religion« und »Naturwissenschaft«, der in ihrem jeweiligen Wesen begründet liege. Gleichwohl deutet er den dogmatisch-kirchlichen Antimodernismus seiner Gegenwart als ein letztes Aufbegehren. Denn, und damit eröffnet Draper seine Schrift, die »intellektuelle Klasse " wende sich in Europa und Amerika im großen Stil vom öffentlichen religiösen Glauben ab, was unabsehbare Folgen auch für den privaten Glauben und die Politik haben werde. Sicher sei indes, dass im Zuge dieses Prozesses die "Naturwissenschaft» aus der Unterdrückung durch die "Religion" endgültig befreit und dadurch die ihr eigene Rationalität zum Wohl der Gesellschaft entfaltet werde:

The intellectual night which settled on Europe [...] is passing away; we live in the daybreak of better things. Society is anxiously expecting light, to see in what direction it is drifting. It plainly discerns that the track along which the voyage of civilization has thus far been made, has been left; and that a new departure, on an unknown sea, has been taken ${ }^{2}$.

2 John William Draper, History of the Conflict between Religion and Science, New York, NY 1875, S. viif. 
So einflussreich Drapers sogenannte »historische Konfliktthese « und durch sie genährte Hoffnungen waren und teilweise bis heute sind, so hat Drapers essentialistisch fixierte Sicht auf den Antagonismus von "Religion" und »Naturwissenschaften" in der aufkommenden Wissenschaftsgeschichtsschreibung relativ schnell an Plausibilität verloren ${ }^{3}$. Markanterweise geschah dies durch die seit den 1930er Jahren anhebende Forschung zu den Anfängen der modernen Naturwissenschaften in der "Scientific Revolution" des 17. und 18. Jahrhunderts ${ }^{4}$. Robert K. Mertons Studie Science, Technology and Society in Seventeenth Century England aus dem Jahr 1938 löste mit ihrer an Max Webers Protestantismusthese angelehnten Konstruktion eines engen Zusammenhanges zwischen Puritanismus und Institutionalisierung der modernen Naturwissenschaft in England einen produktiven Streit aus, der nach und nach zur Auflösung von Drapers Version der "historischen Konfliktthese « führte ${ }^{5}$. An ihre Stelle sind konfessionell und national differenzierte Bilder der frühneuzeitlichen Verhältnisbestimmung von »Religion" und »Naturwissenschaften" mit unterschiedlichen Harmoniegraden getreten $^{6}$. Diese Differenzierung weist jedoch auch darauf hin, dass sich in der Entwicklung der modernen Naturwissenschaften offensichtlich bestimmte Bruchlinien im Verhältnis zur »Religion« ausgebildet haben. Einer solchen Bruchlinie möchte ich im Folgenden nachgehen, nämlich der, die mit der Idee der kollaborativen experimentellen Naturforschung verbunden ist.

Der programmatische Gestalter dieser Idee war Francis Bacon ${ }^{7}$, der sie in der 1620 erschienenen Schrift Instauratio magna mit eben jener Lichtund Aufbruchsmetaphorik versah, die Draper zur Ausschmückung seiner "Konfliktthese" nach gut 250 Jahre ebenfalls benutzen sollte. Das zeigt schon das Titelkupfer von Bacons Schrift, die später unter dem Titel Novum Organum scientiarum verbreitet und berühmt wurde ${ }^{8}$. Worauf das Titelkupfer allerdings mit der Anführung von Dan 12,4 auch hinweist, ist, dass Bacons wissenschaftliche Aufklärungs- und Umbruchserwartungen - in deutlichem Unterschied zu Draper - religiös motiviert waren. "Denn der Mensch«, so hebt der Sympathisant der Puritaner zum Schlussakkord seiner

3 Vgl. Colin A. Russel, The Conflict of Science and Religion, in: Gary B. Ferngren (Hg.), Science and Religion. A Historical Introduction, Baltimore, MD 2002, S. 3-12.

4 Zur Einführung in den gegenwärtigen Forschungsstand vgl. John Henry, The Scientific Revolution and the Origins of Modern Science, New York, NY ${ }^{3} 2008$ sowie Steven ShapIN, Die wissenschaftliche Revolution, Frankfurt a.M. 1998.

5 Vgl. zu diesen Debatten I. Bernhard Cohen (Hg.), Puritanism and the Rise of Modern Science. The Merton Thesis, New Brunswick 1990.

6 Vgl. Shapin, Die wissenschaftliche Revolution, S. 158.

7 Vgl. zu Person und Werk Markku Peltonen (Hg.), The Cambridge Companion to Bacon, Cambridge 2006.

8 Vgl. Dieter GroH, Göttliche Weltökonomie. Perspektiven der Wissenschaftlichen Revolution vom 15. bis zum 17. Jahrhundert, Berlin 2010, S. 399f. Für das Folgende siehe auch die überzeugende Bacon-Interpretation a.a.O., S. 419-464. 
Programmschrift an, »ist durch den Sündenfall zugleich aus seinem Stand der Unschuld und von seiner Herrschaft über die Schöpfung gestürzt. Beide dieser Sachen jedoch können auch in diesem Leben teilweise wiederhergestellt werden; das erste durch Religion und Glaube, das letztere durch Künste und Wissenschaften «" Es ist dabei zu beachten, dass diese Aussage einen antifinalistischen Zug hat. Für Bacon bleiben die gewonnenen menschlichen Erkenntnisse in den Sphären der Religion einerseits und der Sphäre der Wissenschaften andererseits immer ergänzungsbedürftig bzw. ergänzungsfähig.

Vor diesem Hintergrund ist es offensichtlich sinnlos, von der auf Naturerkenntnis bezogenen Philosophie - dem eigentlichen Thema von Bacons Schrift - abschließende Antworten über die Natur zu erwarten. Deshalb ist die Naturerkenntnis für Bacon auch so zu organisieren, dass sie die Kenntnisse, facta, über die Natur immer weiter vermehrt. Dazu sind die beiden Methoden der Naturerschließung, die Bacon zur Verfügung stehen, so aufeinander abzustimmen, dass sie dieses Ziel erreichen können: Die vor allem in der Alchemie gepflegte experimentelle Methode einerseits sowie die in der Schule gepflegte mathematische Methode andererseits. In wechselseitiger Korrektur und kontrollierter Ausdehnung ihrer jeweiligen Bestimmungsbereiche integriert Bacon beide geläufigen Methoden zu seiner berühmten »induktiven Methode«, die er auch »Interpretation der Natur« nennt:

Jedoch unser Weg und unsere Methode [...] ist diese: dass wir nicht Werke aus Werken und Experimente aus Experimenten (wie Empiriker), sondern aus Werken und Experimenten Ursachen und Axiome und noch dazu aus Ursachen und Axiomen wiederum neue Werke und Experimente (wie rechtmäßige Interpreten der Natur) herausziehen ${ }^{10}$.

Dieser Erkenntnisprozess, der effektiv nur durch Kollaboration verschiedener Wissenschaftler zu verfolgen ist, eröffnet nach Bacon Gottes einzelne Schöpfungswerke, ohne freilich die Schöpfung jemals in toto zu erschließen. Zugleich - und das ist ein für den späteren Erfolg des Baconschen Konzepts schwer zu überschätzender Punkt - bekommt der Mensch durch die

9 Francis BACON, Neues Organon. Lateinisch-Deutsch, hg. von Wolfgang Krohn, Hamburg 1990, Bd. 2, S. 610/612 (Aphorismus II, 52): "Homo enim per lapsum et de statu innocentiae decidit, et de regno in creaturas. Utraque autem res etiam in hac vita nonnulla ex parte reparari potest; prior per rleigionem et fidem, posterior per artes et scientias«. Die deutsche Übersetzung in der Ausgabe von Krohn übersetzt irgendwarum »ex parte«, was als juristischer Begriff eine einseitige Wiedergutmachung durch eine Prozesspartei bezeichnet, mit »irgendwie«.

10 BACON, Neues Organon, Bd. 1, S. 241 (Aphorismus I, 117): „Verum via nostra et ratio [...] ea est; ut non opera ex operibus sive experimenta ex experimentis (ut empirici), sed ex operibus et experimentis causas et axiomata, atque ex causis at axiomatibus rursus nova opera et experimenta (ut legitimis Naturae Interpretes), extrahamus«. 
fortschreitende Erkenntnis technische Nutzanwendungen der Naturbeherrschung an die Hand, um die von Gott geforderte Lebensführung besser zum Wohl der Gesamtgesellschaft auszuüben. In seiner utopischen Spätschrift Nova Atlantis (1624/7) hat Bacon den Idealstaat »Bensalem» beschrieben, in dem die Forschungen und Ergebnisse des im »Haus Salomo «beheimateten wissenschaftlichen Ordens die ganze Gesellschaft informieren, durchdringen und beglücken ${ }^{11}$. »Erfindungen«, so hielt Bacon bereits im Novum Organum fest, »segnen und bringen Wohltaten, ohne irgendjemandem Schaden und Traurigkeit zuzufügen. Auch sind Erfindungen gleichsam neue Schöpfungen und Imitationen der göttlichen Werke ${ }^{12}$.

Bacons Programm der "scientia nova entfaltete seine historische Bedeutung nicht dadurch, dass es systematisch umgesetzt worden wäre. Es wirkte vielmehr durch selektive Anknüpfungen und eklektische Aneignungen produktiv fort, in denen eine schillernde Undeutlichkeit des Baconschen Programms schon früh zutage trat: Wie sind nämlich die durch die naturwissenschaftliche Methode hervorgebrachten "facta« als Gottes Schöpfungswerke zu identifizieren? Mit Blick auf die englische Verarbeitung des Baconschen Programms in der frühen Royal Society for Improving Natural Knowledge durch Robert Boyle, die französische in der Bewegung der »Enzyklopädisten« durch Denis Diderot und die deutsche in der Hamburger Physikotheologie durch Barthold Heinrich Brockes wird dieser Beitrag verschiedene argumentative Reaktionen auf diese Uneindeutigkeit skizzieren. Schließen wird er dann mit einigen zusammenfassenden Bemerkungen zu den theologischen Folgen, die sich aus den hier überblickten Konstellationen ergeben.

\section{Robert Boyle}

Bacons Schriften, Manuskripte und Ideen zirkulierten in England zunächst in Kreisen der hotter sort of protestants außerhalb und innerhalb der königlichen Bischofskirche. Von besonderer Bedeutung war der Kreis um Samuel Hartlib und Henry Oldenbourg, der international weitverzweigte, transkonfessionelle Kontakte aufrecht erhielt ${ }^{13}$. Bacons Wissenschaftsprogramm beförderte dabei vor allem eine grundsätzlich positive Rezeptionshaltung

11 Vgl. dazu Richard SAAGE, Bacons »Neu-Atlantis« und die klassische Utopietradition, in: Utopie kreativ 93 (1998), S. 57-69.

12 Bacon, Neues Organon, Bd. 1, S. 268 (Aphorismus I, 129): »[...] inventa beant, et beneficium deferunt absque alicujus injuria aut tristitia. Etiam inventa quasi novae creationes sunt, et divinorum operum imitamenta [...]«.

13 Einen glänzenden Einblick in diesen Kreis, seine Anliegen und Verzweigungen geben die Beiträge in: Mark Greengrass u.a. (Hg.), Samuel Hartlib and Universal Reformation. Studies in Intellectual Communication, Cambridge 1994. 
gegenüber anderwärts Entdecktem, Erfundenem und Experimentiertem. In nochmaliger religiöser Erhitzung erblickte man hier in den neuen Instrumenten der Naturforschung, wie dem Fernrohr, die Mittel, mit denen der Heilige Geist Gottes Schöpfung nun bekannt mache. John Wilkins' vehemente und durch Galileis Fernrohrbeobachtungen hervorgetriebene Verteidigung der neuen Astronomie aus dem Jahr 1640 harmonisierte nicht nur das heliozentrische Weltbild mit der biblischen Überlieferung ${ }^{14}$. Wilkins dachte darüber hinaus auch gerne darüber nach, wie es einst sein werde, wenn man zum Mond reisen und mit der dortigen Bevölkerung Handel treiben werde ${ }^{15}$. John Wilkins war wie Henry Oldenbourg Gründungsmitglied der 1660 ins Leben gerufenen Royal Society und mit Oldenbourg ihr erster Sekretär. Beide stehen exemplarisch für die in der Forschung mittlerweile kaum mehr bestrittene Prägung der frühen Royal Society durch den sogenannten »Puritanismus « ${ }^{16}$.

Allerdings setzte mit der Gründung eine gewisse religiöse Abkühlung sowie eine deutliche Ausrichtung des Wissenschaftsprogramms der Royal Society ein. Mit beidem passten die Gründer die junge Gesellschaft in die Gegebenheiten der anrollenden Restauration des englischen Königtums nach dem Bürgerkrieg und Interregnum an. Beides - Abkühlung und Ausrichtung - gehört zusammen. Wissenschaftsprogrammatisch trat die experimentelle Ermittlung empirischer »matter of facts « bzw. "phaenomena in den Vordergrund. Der Programmgestalter war Thomas Sprat, der schon 1667 die erste Geschichte der Royal Society publizierte, und zur Legitimation des Programms eben auf Bacon als Vorbild verwies:

The [...] new Philosophers, have been those, who have [...] propos'd to themselves the right course of slow, and sure Experimenting [...]. And of these, I shall onely mention one great Man, who had the true Imagination of the whole extent of this Enterprize, as it is now set on foot; and that is, the Lord Bacon. In whose Books there are every where scattered the best arguments, that can be produc'd for the defence of Experimental Philosophy; and the best directions, that are needful to promote it ${ }^{17}$.

14 John Wilkins, A Discourse Concerning a New World and Another Planet. In 2 Bookes, London 1640.

15 Ebd., Bd. 1, S. 240-242. Wilkins, der sich des fiktiven Zuschnitts dieses Gedankens bewusst ist, spielt hier auf die Schilderung der ersten englischen Mond-Utopie von Francis Godwin an, die unter dem Pseudonym Domingo Gonsales, eines katholischen Bischofs, erschien: Domingo Gonsales [Francis Godwin], The Man in the Moone, or A Discourse of a Voyage Thither, London 1638.

16 Vgl. die ausführliche Auseinandersetzung mit den sozialhistorischen und ideengeschichtlichen Hintergründen der Gründungsgeschichte unter Einbeziehung der einschlägigen Literatur bei GROH, Göttliche Weltökonomie, S. 558-627.

17 Thomas Sprat, The History of the Royal-Society of London. For the Improving of Natural Knowledge, London 1667, S. 35. 
Mit der Hervorhebung der Langsamkeit, Sicherheit und - wie Sprat ebenfalls noch anzuführen wusste - diskursiven Rationalität wurde die Naturforschung religionspolitisch dem Verdacht enthusiastischer Schwärmereien enthoben. Die experimentelle Praxis signalisierte weltanschauliche Neutralität in gesellschaftspolitischer Absicht: Sie empfahl sich über religiöse Gräben hinweg als integratives Gemeinschaftsprojekt ${ }^{18}$.

Der immer größer und religiös diffuser werdende Mitglieder- und Unterstützerkreis der Royal Society weist darauf hin, dass man in dieser Hinsicht erfolgreich war. Die trotz Privilegs ausbleibende finanzielle Unterstützung durch den König hatte daher keine weitreichenden ökonomischen Folgen und sicherte der Society - wiederum attraktivitätssteigernd - eine gewisse Unabhängigkeit, die auch nach der "Glorious Revolution « 1688/89 bestehen blieb. Der anhaltende Anstieg des Ansehens der Royal Society nach diesem abermaligen politischen Wandel war aber auch das Verdienst von Robert Boyle, der das Programm der Royal Society noch einmal nachjustierte. Hierfür entwarf er die naturwissenschaftliche Idealgestalt des "Christian virtuoso«. Boyles gleichnamige Schrift, in welcher der Rekurs auf Francis Bacon dauerhaft präsent ist, erschien im Jahr 1690 und trägt den Untertitel: »[...] shewing, that by being addicted to Experimental Philosophy, a Man is rather Assisted, than Indisposed, to be a Good Christian $\aleph^{19}$.

Es ist ein eingeschliffenes Urteil über den Experimentalphysiker und Chemiker Boyle, dass er auf der Grundlage des durch seinen Bekannten Isaac Newton geprägten mechanistischen Weltbildes den Beweis der Existenz Gottes zu führen gedachte - die »New Science« also zur Grundlage religiöser, christlicher Apologetik machte. Dieses Urteil ist richtig, aber differenzierungsbedürftig. Denn es lassen sich bei Boyle zwei systematisch nicht miteinander verbundene, spannungsvolle Gedankenreihen identifizieren:

Die eine Gedankenreihe ist nun in der Tat eine schließende Argumentation, die nun aber nicht auf die Existenz Gottes, sondern auf die Providenz Gottes bezogen ist. Konstitutiv für diese Argumentationsfigur sind für Boyle zwei »cartesianisch" genannte Prinzipien, nämlich (1.) dass die Bewegung der Materie nicht inhärent ist, sowie (2.) dass immaterielle Substanzen wirklich unterschieden von Körpern und von ihnen trennbar sind. Im ersten

18 Vgl. Paul B. Wood, Die philosophische Ausrichtung der Royal Society, in: Grundriss der Geschichte der Philosophie. Die Philosophie des 17. Jahrhunderts, Bd. 3/2: England, hg. von Jean-Pierre SchobInger, Basel 1988, S. 391-394, bes. S. 392. Zu den sozial- und politiktheoretischen Implikationen der Naturphilosophie im England des 17. Jahrhunderts vgl. auch Steven Shapin/Simon Schaffer, Leviathan and the Air-Pump. Hobbes, Boyle, and the Experimental Life, Princeton, NJ 1985.

19 Robert Boyle, The Christian Virtuoso, Shewing, that by Being Addicted to Experimental Philosophy, a Man is Rather Assisted, than Indisposed, to be a Good Christian. The First Part, [London]: In the Savoy 1690. 
Fall ist es nach Boyle unerfindlich, wie die Materie nicht nur in Bewegung gesetzt wird, sondern vor allem wie sie konstant in Bewegung gehalten wird $^{20}$. Im zweiten Fall ist es unerfindlich, wie Leben entsteht:

since I understand not, by what Physical Charm or Spell an Immaterial Substance can be allur'd into this or that Particular Embryo [...]; nor by what merely Mechanical Ty, or Band, an Immaterial Substance can be so durably (perhaps for 80 or 100 Years) joyn'd and united with a Corporeal ${ }^{21}$.

Beide Fälle sind aber - wie nun der wenig überraschende Schluss Boyles lautet - durch das unmittelbare providentielle Wirken Gottes zu erklären. Wichtiger als die Plausibilität dieser Argumentationsfigur ${ }^{22}$ ist für den hiesigen Zusammenhang ihre Stoßrichtung. Denn Boyles Gedankenreihe ist gegen vermeintliche und tatsächliche zeitgenössische »Materialisten « gerichtet, die der Materie weitreichende Qualitäten - etwa Selbstbewegungsfähigkeit oder eine vis viva - beilegen. Boyles Argumente nehmen ja ihren Ausgangspunkt nicht in der Bestimmung der Materie, sondern in den mit der Materie verknüpften Differenzen, zur »Kraft« einerseits, zur »Seele« andererseits.

Die andere Gedankenreihe nimmt bei Boyle erheblich mehr Raum ein. Sie wird in verschiedenen Variationen nachgerade redundant eingebläut und lautet: Die durch den naturforschenden Virtuosen mit Vernunft und Erfahrung sowie technischen Instrumenten ermittelten »matter of facts« verweisen bei ihrer richtigen Interpretation und Zusammenschau auf den göttlichen Welturheber:

That the consideration of the Vastness, Beauty, and Regular Motions, of the heavenly Bodies; the excellent Structure of Animals and Plants; besides a multitude of other Phaenomena of Nature [...] may justly induce him [...] to Conclude, That this vast, beautiful, orderly, and (in a word) many ways admirable System of things, that we call the World, was fram'd by an Author surpremely Powerful, Wise, and Good, can scarce be deny'd by an intelligent and unprejudic'd Considerer ${ }^{23}$.

20 Ders., The Christian Virtuoso, S. 34.

21 Ebd., S. 35.

22 Vgl. zur frühneuzeitlichen Schlagkraft besonders des zweiten Arguments von Boyle Winfried Schröder, Der Tod Gottes und die Neuzeit. Philosophiehistorische Anmerkungen zum Zusammenhang von Atheismus und Moderne, in: Christel GÄrtner u.a (Hg.), Atheismus und religiöse Indifferenz, Opladen 2003, S. 23-39, S. $30 \mathrm{f}$.

23 Boyle, The Christian Virtuoso, S. 14. 
Boyle ist in solchen Argumentationszusammenhängen von einer ganz und gar erstaunlichen Offenheit darüber, was für diese religiös-theologische Interpretation der "phenomena« vorausgesetzt ist, nämlich ein Gott gegenüber »well dispos'd mind « ${ }^{24}$. Das heißt umgekehrt: »And I deny not, [...] if the knowledge of Nature falls into the hands of a Resolved Atheist, or a Sensual Libertine, he may misemploy it to Oppugn the Ground, or Discredit the Practice, of Religion ${ }^{25}$. In solchen Ausführungen wird deutlich, dass die Interpretationsvoraussetzungen der natürlichen Phänomene als auf Gott verweisende sichtlich den Phänomenen selbst äußerlich bleiben. Die von der Naturforschung hervorgebrachten Erkenntnisse und Einsichten zwingen nicht - zumindest nicht in dieser Gedankenreihe - zur Annahme der Existenz Gottes. Insofern sind sie - mit Boyles Begriff der "Materie« gleichlautend - in gewisser Weise weltanschaulich neutral.

Dass Boyle diesen weltanschaulich neutralen Kern der "matter of facts" dadurch religiös in den Griff zu bekommen sucht, dass er nun nicht wie Bacon in diesen selbst das Schöpfungswerk Gottes erblickt, sondern in ihrer Zusammenstimmung, Aggregation und Prinzipienharmonie, dürfte deutlich geworden sein. Dabei war Boyle natürlich der Ansicht, dass es nur vernünftig und erfahrungsgemäß ist, aus diesen Umständen die Schlüsse zu ziehen, die

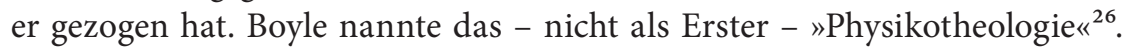
Wir werden noch sehen, welche Folgen sich aus Boyles in dieser Hinsicht durchaus wegweisender Theoriebildung ergaben. Zuvor blicken wir aber auf eine historische Konstellation, die unter anderen intellektuellen Dispositionen die experimentelle Naturforschung in den Spuren Bacons und bei Kenntnis Boyles und vor allem Newtons andere und erheblich kritischere gedankliche Optionen in der Verhältnisbestimmung von "Religion" und »Naturwissenschaft« eröffnete.

\section{Denis Diderot}

Der Begriff des »Baconianismus«, »Baconisme« wurde in Frankreich geprägt. Er findet sich - offenbar zuerst - als Stichwort im zweiten Band des berühmten Werks Encyclopédie ou Dictionnaire raisonné des sciences,

24 Ebd., S. 3.

25 Ebd., S. $6 f$.

26 Vgl. zur Begriffsgeschichte Peter HArrison, Physico-Theology and the Mixed Sciences. The Role of Theology in Early Modern Natural Philosophy, in: Peter A. Anstey / John A. Schneider (Hg.), The Science of Nature in the Seventeenth Century. Patterns of Change in Early Modern Natural Philosophy, Dordrecht 2005, S. $165-184$. 
des arts et des métiers aus dem Jahr $1751^{27}$. Der Verfasser des Artikels war der französische katholische Theologe Jean Pestré, dessen Pfründe als Abt eines südfranzösischen Klosters ihm sein Leben in Paris und seine intensive Mitarbeit an der Encyclopédie ermöglichte ${ }^{28}$. Der »Baconianismus « ist von vorneherein ein Programmbegriff, der im Kontext der Encyclopédie dem Ziel der Durchsetzung der »experimentellen Philosophie« dient, deren eigentliche Gallionsfigur für die Enzyklopädisten Isaac Newton ist. Der »Baconianismus« ist also eine Art Introduktionsmittel des »Newtonianismus« - und das mit Bedacht:

Denn Newtons mechanistisches Weltbild wurde weltanschaulich weithin mit Skepsis betrachtet - ein Ruf, den Newton nicht zuletzt Voltaire verdankte. Dessen Lettres philosophiques, zuerst englisch als Letters Concerning the English Nation 1733 publiziert und dann 1734 übersetzt, beinhalteten nämlich nicht nur das ausgiebige Lob einer an Empirie und Materie ausgerichteten, mithin durch Newton geformten Wissenschaft der Natur. Darüber hinaus sah es Voltaire auch als ein Lohn dieser Wissenschaft an, dass die englische Nation ökonomisch, politisch und in Sachen religiöser Toleranz zum Vorbild aller europäischen Gesellschaften aufgestiegen sei. Das löste natürlich und von Voltaire durchaus gewollt einen handfesten Skandal aus, der auch den Ruf nach entsprechenden Maßnahmen gegen den Autor umfasste ${ }^{29}$.

Jedoch reagierte die katholisch dominierte französische Wissenschaftspublizistik auf Newton auch differenzierter. Das lag unter anderem daran, dass der zentrale Advokat Newtons in der Académie des sciences, 1666 nach Vorbild der Royal Society gegründet, Anfang der 1730er Jahre - zeitgleich zu dem von Voltaire ausgelösten Skandal - einen weitbeachteten Erfolg verzeichnen konnte: Die Mathematiker und Astronomen Pierre Louis Moreau de Maupertuis und Jacques Cassini waren über die Frage nach der Form der Erde aneinander geraten ${ }^{30}$. Cassini, der als »Cartesianer « die mathematische Naturforschung der experimentellen Messung vorzog und Newtons Gravitationsgesetzen skeptisch gegenüber stand, hatte eine Berechnung vorgelegt,

27 [Jean Pestré], Art. Baconisme, in: Enc. Mis en ordre \& publié par M. Diderot, de l'Académie Royale \& des Belles-Lettres de prusse; \& quant à la Partie Mathematique, par M. d'Alembert, de l'Academie Royale des Sciences de Paris, de celle de Prusse, \& de la Societé Royale de Londres, Paris 1751-1780 (Reprint in 35 Bd., Stuttgart-Bad Cannstatt 1968-1995), Bd. 2 (1751), S. 8-10.

28 Vgl. zur Person Frank A. KAFker/Serena L. KAfker, The Encyclopedists as Individuals. A Biographical Dictionary of the Authors of the Encyclopédie, Oxford 1988, S. 304-306.

29 Vgl. zu diesem ganzen Streit Jonathan B. Shank, The Newton Wars and the Beginning of the French Enlightenment, Chicago, IL 2008, S. 295-321.

30 Vgl. in aller Kürze Henry, The Scientific Revolution, S. 112. 
derzufolge die Erde sich zu den Polen hin zuspitzt. Maupertuis konnte dagegen aufgrund von Messungen im Polarkreis und auf Grundlage der Newtonschen Mechanik zeigen, dass sie zu den Polen hin abflacht ${ }^{31}$.

In dieser Mischung aus weltanschaulichen Bedenken und wissenschaftlicher Anerkennung gegenüber Newton kam der Betonung Francis Bacons eine wichtige Funktion zu, mit der die Enzyklopädisten die »experimentelle Philosophie« salonfähig machen wollten. Der Artikel "Baconisme» deutet die Strategie an: Der hochgelobte Philosoph Bacon kommt vor allem als Zerstörer der aristotelischen Metaphysik in Betracht, der nun aber im Gegenzug vereinseitigend die Empirie betont habe. Ein Umstand, den niemand anderes als René Descartes, so Pestré, erkannt und korrigiert hat ${ }^{32}$. Vollends deutlich wird die Funktion Bacons, wenn man in den einleitenden, von Jean-Baptiste le Rond d'Alembert verfassten Essay für die gesamte Enzyklopädie blickt ${ }^{33}$ : Denn hier wird Bacon zwar als der zentrale Anreger einer kollaborativ organisierten empirischen Wissenschaft hervorgehoben. Doch seien die Probleme von Bacons einseitiger empirische Philosophie durch Descartes behoben worden, der nun aber wiederum einseitig der Geometrie als Mittel der Naturwissenschaft verfallen sei. Es war deshalb nach d'Alemberts Narrativ Newton, dem das Verdienst zukommt, aus beiden Quellen voll geschöpft zu haben und in ihrer ingeniösen Synthese das Verständnis der Naturwissenschaften auf die nächste Ebene gehoben zu haben. Bacon dient in dieser Erzählung dazu, Descartes in der Geschichte der »experimentellen Philosophie eine treibende und positive Rolle zuzuweisen. Und damit nicht genug: Denn im selben Atemzug wird von d'Alembert betont, dass bei Neuerungen in der Metaphysik Descartes deutlich vor Bacon Anerkennung zukommt ${ }^{34}$, wohingegen sich Newton vernünftigerweise mit metaphysischen Angelegenheiten erst gar nicht wirklich beschäftigt habe ${ }^{35}$. Vor diesem Hintergrund empfiehlt sich die »experimentelle Philosophie« à la Newton als religiös und politisch unverdächtig sowie als eine wissenschaftliche Option, die auch für die Anhänger Descartes' ergreifbar ist.

Es ist bekannt, dass solche Ausführungen in der Encyclopédie oft einen mindestens doppelten Boden haben, vor allem dann, wenn sie von den miteinander befreundeten Herausgebern verfasst wurden. Nur ist es wiederum zu einfach, wenn solche Ausführungen immer bloß als verkappte, dissimulierende Strategien einer wesentlich materialistischen, religionskritischen

31 Vgl. Shank, The Newton Wars, S. 323-357.

32 [Pestré], Art. Baconisme, S. 9.

33 Hier nach der deutschen Ausgabe: Jean le Rond D'AlEmBERT, Einleitung zur Enzyklopädie. Durchges. und mit einer Einleitung hg. von Günther MENsCHING, in: PhB 473, Hamburg 1997, S. 65-74.

34 D’Alembert, Einleitung, S. 70.

35 Ebd., S. 73. 
Grundeinstellung gelesen werden. Was d'Alembert mit dem unmetaphysischen Newton andeutet, hat einen Punkt für sich, der sich in der Lesart der Bacon-Newtonschen Vorstellung vom experimentellen Wissen finden lässt, wie sie einige Artikel der Herausgeber widerspiegeln. Noch einmal deutlicher herausgearbeitet ist dieser Punkt in dem Schriftchen De l'interprétation de la nature aus dem Jahr 1753, das von Denis Diderot verfasst wurde. Nicht nur im Titel spielt die Schrift auf Bacon an, sondern sie ist wie Bacons Novum Organum als Sammlung von Aphorismen gestaltet. Das wird mit der Veränderung des Titels in der späteren, leicht überarbeiteten Ausgabe Pensées sur l'interprétation de la nature (1754) noch einmal deutlicher hervorgehoben. Diderot bietet darin nicht weniger als das Programm der erneuten Erneuerung der Naturwissenschaft, wie sie sich die Enzyklopädisten vorstellen. Diderots Darlegungen haben zwei Schwerpunkte, die hier nacheinander kurz umrissen werden:

Der erste Schwerpunkt charakterisiert die Arbeitsweise der »experimentellen Philosophie« im Unterschied zur »rationalen Philosophie« bzw., gleichbedeutend damit, der »experimentellen Physik« im Unterschied zur »systematischen Philosophie«. Während die erste vom Einzelnen ausgehend in einem instrumentengestützten unendlichen Erkenntnisprozess begriffen ist, so strebt die zweite danach, abschließende Erklärungen für die einzelnen Naturphänomene zu finden. Die »experimentelle Philosophie« ist für Diderot also wesentlich durch den Baconschen methodischen Antifinalismus bestimmt: „Die experimentelle Philosophie weiß nicht, was bei ihrer Arbeit herauskommen wird, noch was bei ihr nicht herauskommen wird; aber sie arbeitet unerlässlich«. Langfristig erweist sie sich damit allerdings der »rationalen Philosophie« überlegen, wie Diderot unter Rekurs auf Newtons Experimente zur Brechung des Lichts anführt:

Die rationale Philosophie [...] erwägt die Möglichkeiten, entscheidet und hält plötzlich inne. Sie behauptet kühn: »Man kann das Licht nicht zerlegen«. Die experimentelle Philosophie hört zu und schweigt ihr gegenüber jahrhundertelang; dann zeigt sie ihr plötzlich das Prisma und sagt: »Das Licht ist zerlegbar ${ }^{36}$.

36 Denis Diderot, Zur Interpretation der Natur/Philosophische Grundsätze über Materie und Bewegung, Leipzig ${ }^{2}$ 1967, S. 41. Vgl. den kompletten Abschnitt [Denis Diderot], Pensées sur l'Interpretation de la nature, o.O. 1754, S. 54f.: »La philosophie expérimentale ne sçait ni ce qui lui viendra pas de son travail; mais elle travaille sans relâche. Au contraire la philosophie rationelle pése les possibilités, prononce \& s'arrête tout court. Elle dit hardiment, on ne peut décomposer la lumiere: la philosophie expérimentale l'écoute, \& se taît devant elle pendant des siécle entiers; puis tout à coup elle montre le prisme, \& dit, la lumiere de décompose«. 
Diesem methodisch-arbeitsorganisatorischen Antifinalismus korrespondiert - und das ist der zweite Schwerpunkt von Diderots Schrift - der immer hypothetische Status der Ergebnisse, welche die »experimentelle Philosophie» in ihrem unendlichen, korrekturoffenen Erkenntnisprozess hervorbring $t^{37}$. Diese Einsicht ist für Diderot jedoch den reflektierten »Interpreten« der Natur vorbehalten, die anders als die bloß empirischen "Beobachter«, also die einfältigen Phänomensammler, Schlussfolgerungen zu ziehen in der Lage sind. Just hier entfaltet die Bacon-Newtonsche Vorstellung der »experimentellen Philosophie« in Diderots Lesart ihr volles metaphysikskeptisches Potential: Der Naturinterpret

erhebt sich zur eigentlichen Wesenheit der Ordnung; er sieht ein, dass die bloße und die einfache Existenz eines empfindungsfähigen und denkenden Wesens in Verbindung mit irgendeiner Verkettung von Ursachen und Wirkungen nicht genügt, um ein absolutes Urteil über jene Wesenheit zu fällen; er macht also halt. Würde er noch einen weiteren Schritt machen, so würde er über die Natur hinausgehen ${ }^{38}$.

Dem wahren Interpreten ist die Erklärung von Endzwecken sowie Erstursachen der Natur also verwehrt. Eine grundsätzliche Ablehnung des Gottesgedankens ist das nicht. Es heißt allerdings für Diderot, dass die "natürliche Theologie« ein Oxymoron ist: "Sie bedeutet: die wichtigste theologische Wahrheit an das Schicksal einer Hypothese zu binden $\aleph^{39}$. Entsprechend massiv fällt Diderots Kritik an der »Physikotheologie« aus, die für ihn vor allem schlechte Dichtkunst ist: "Wie viele absurde Ideen, falsche Voraussetzungen und trügerische Begriffe sind in jenen Hymnen enthalten, die einige vermessene Verteidiger der Endursachen zur Ehre des Schöpfers zu dichten wagten! " $^{40}$. Nachgerade zynisch ist daran anknüpfend das »Gebet" formuliert, mit dem Diderot seine Aphorismensammlung beschließt - und über dessen literarische Qualität sich füglich streiten lässt ${ }^{41}$. Dass Dide-

37 Vgl. ders., Zur Interpretation, S. 43; ders., Pensées, S. 59f.

38 Ders., Zur Interpretation, S. 82; ders., Pensées, o.S. (zwischen S. 169 und 170): »[...] il s'éleve à l'essence même de l'ordre; il voit que la coexistence pure \& simple d'un être sensible \& pensant, avec un enchaînement quelconque de causes \& d'effets, ne lui suffit pas pour porter un jugement absolu; il s'arrête là; s'il faisoit un pas de plus, il fortiroit de la Nature«. Hierbei handelt es sich um eine Ergänzung zur Erstausgabe, weshalb im Druck die Seitenzahlen ausgelassen wurden, um die Paginierung der Erstausgabe 1753 nicht ändern zu müssen.

39 Ders., Zur Interpretation, S. 83; ders., Pensées, S. 170f.: „C'est substituer la conjecture de l'homme à l'ouvrage de Dieu; c'est attacher la plus importante des vérités au fort d'une hypothèse«.

40 Ders., Zur Interpretation, S. 84; ders., Pensées, S. 175: „Combien d'idées absurdes, de suppositions fausses, de notions chimériques dans ces Hymnes que quelques défenseurs téméraires des causes finales ont osé composer à l'honneur du Créateur?«.

41 Ders., Zur Interpretation, S. 91-92; ders., Pensées, S. 202-204. 
rot mit seiner im Ton schon hervorstechenden Kritik die zeitgenössische Rezeption seiner Schrift auf die zu erwartenden Bahnen allgemeiner öffentlicher Empörung lenkte, wusste er wohl. Nicht umsonst hatte er anonym und ohne Druckort veröffentlicht.

Diderot war sichtlich von anders disponiertem Geist als Robert Boyle, und insofern gibt er problemgeschichtlich Boyle auch Recht, dass die »experimentelle Philosophie« Bacon-Newtonscher Prägung in Händen Anderer andere, teils religionskritischere Konsequenzen haben kann. Allein, Diderots Schriftchen zeigt, dass dies ohne allzu große Anstrengungen möglich war. Es bedurfte dazu nicht einmal massiver weltanschaulicher Vorannahmen. Es reichte, an einem Faden des von Bacon ausgehenden Problembündels experimenteller Naturforschung zu ziehen, um die metaphysische Luft entweichen zu lassen. Die für Diderot sich daraus ergebende Alternative zur »Physikotheologie« war die Beschränkung des Interpreten auf den eben ihm zur Verfügung stehenden Möglichkeitsbereich der Naturerkenntnis. Die "New Science" differenzierte sich damit deutlicher als noch bei Bacon und bei Boyle als eigenständige Wissenssphäre aus. Mitnichten war damit aber die von Diderot kritisierte »Physikotheologie« religiös erledigt. Und das lag nicht daran, dass, wie Diderot vermutete, die Physikotheologen grundsätzlich keine Interpreten sondern bloße Beobachter der Natur waren.

\section{Barthold Heinrich Brockes}

Für das 18. Jahrhundert lässt sich von einer regelrechten physikotheologischen Bewegung sprechen, die Europa quer durch alle Konfessionen hindurch erfasste ${ }^{42}$. Sie widmete sich der experimentell »erweislichen« Harmonie von natürlichen Phänomenen und providentiellem Schöpfungsglauben christlicher Prägung. Endgültig ins Rollen gebracht hatte diese Bewegung der englische Theologe und Naturphilosoph der Royal Society William Derham mit seiner 1713 erschienenen Physico-Theology: or A Demontration of the Being and Attributes of God from the Works of Creation. Sie war aus einer Serie von »Boyle-Lectures« entstanden, also der Predigtreihe, die Robert Boyle zum Kampf gegen den Atheismus, den Deismus und die Freigeisterei gestiftet hatte. Fast ohne Unterbrechungen zogen diese Predigten das ganze 18. Jahrhundert hindurch die Bürger Londons jährlich wie ein Magnet nach St. Martin in the Field, St. Paul's oder nach St. Mary-le-Bow ${ }^{43}$. Die in der For-

42 Vgl. mit weiteren Literaturhinweisen Birgit BieHLER, Physikotheologie, in: Enzyklopädie der Neuzeit 9 (2009), Sp. 1175-1181, sowie Udo KrolzIK, Physikotheologie, in: TRE 26 (1996), S. 590-596.

43 Vgl. dazu Groh, Göttliche Weltökonomie, S. 628-640. Weiterhin: John J. Dahm, Science and Apologetics in the Early Boyle Lectures, in: ChH 39 (1970), S. 172-186. 
schung immer noch nicht überschaute Publikationsflut, die Derham auslöste, erstreckte sich auf alle möglichen Felder der Naturkunde und -beobachtung. Alphabetisch geordnet reicht sie von der »Akridotheologie«, die sich mit den Heuschrecken beschäftigt, bis zur »Testaceo-Theologia«, deren Gegenstand Muscheln und Schnecken sind ${ }^{44}$.

Durch die Popularität der Physikotheologie etablierten sich die experimentellen Naturwissenschaften im Bildungskanon des werdenden Bürgertums, das sich breit an der Bewegung beteiligte. Begünstigt wurde die bürgerliche Partizipationsmöglichkeit durch die erhöhte Verfügbarkeit erschwinglicherer Instrumente, vor allem des Mikroskops, dessen Vergrößerung schon durch die Kombination mehrerer günstiger Linsen immens gesteigert werden konnte ${ }^{45}$. Die Technikbegeisterung trug freilich auch dazu bei, dass die Validität von instrumentellen Naturbeobachtungen unter konkurrierenden Naturforschern bis weit in das 19. Jahrhundert hinein durch die Qualität der Instrumente begründet wurde. Der Anspruch auf mathematische Erweislichkeit blieb, auch aufgrund der Komplexität der nötigen Theorien, zunehmend den Eliten an den Akademien und in den Sozietäten vorbehalten. Die naturwissenschaftliche Bedeutung der physikotheologischen Bewegung ist daher in der Forschung durchaus umstritten. Doch war die Zuverlässigkeit der Beobachtungen zumindest so hoch, dass am Anfang des 19. Jahrhunderts die ersten naturkundlichen Schulbücher ihr Material aus physikotheologischen Werken bezogen, freilich unter Aussparung der theologisch-religiösen Textteile. Diese waren jedoch schon am Ende des 18. Jahrhunderts zunehmend in die Vorworte abgewandert ${ }^{46}$. Die Beschäftigung mit der Empirie verdrängte faktisch die physikotheologische Argumentation und trug damit ebenfalls zur Verselbstständigung der Naturwissenschaften als bürgerlicher Wissensform bei.

Hinsichtlich der argumentativen Qualität der in die gesellschaftliche Breite gehenden Bewegung werden Kritiker wie etwa Diderot nicht immer ganz Unrecht gehabt haben, da Tendenzen zu einer unmittelbaren Behauptung des Beweises Gottes anhand der Naturbeobachtungen durchaus kursierten. Allerdings lässt sich in der physikotheologischen Bewegung auch eine religiöse Deutung der naturwissenschaftlichen Beobachtungen und Ergebnisse erfassen, welche die bereits von Boyle in den Blick gerückte Verweisstruktur der Natur auf Gott vertiefte. Diese Vertiefung verdankte sich dem Einrücken ästhetischer Gefühlskategorien in den Religionsbegriff, eine

44 Paul Michel, Physikotheologie. Ursprünge, Leistungen und Niedergang einer Denkform, Zürich 2008, URL: <http://www.symbolforschung.ch/files/pdf/Michel_ Physikotheologie.pdf $>$ (01.10.2017), S. 4f.

45 Vgl. zur technischen Entwicklung in der Frühen Neuzeit Dieter GERLACH, Geschichte der Mikroskopie, Frankfurt a.M. 2009, S. 49-169.

46 Biehler, Physikotheologie, Sp. 1180. 
Entwicklung, die wiederum in England durch Anthony Ashley Cooper, den dritten Earl von Shaftesbury angestoßen worden war. Vermittelt durch die Überlegungen Joseph Addisons zum »Naturschönen« und "Naturerhabenen « im Spectator ${ }^{47}$ war einer der frühen deutschen Vertreter dieser Deutung Barthold Heinrich Brockes.

In Hamburg hatte sich über die kurzlebige, 1715 gegründete »Teutsch übende Gesellschaft« ein Zirkel von Freunden zusammengefunden, die eine physikotheologische Arbeitsgemeinschaft mit ganz eigener Arbeitsteilung umfasste $^{48}$ : Vor allem Johann Albert Fabricius übernahm die Sammlung und Aggregation physikotheologischen Naturwissens; er übersetzte auch Derham ins Deutsche ${ }^{49}$. Brockes hingegen, der den Spectator und später auch Shaftesbury übersetzte, verarbeitete dieses Naturwissen lyrisch in seinem von 1721 bis 1747 erschienenen Monumentalwerk Irdisches Vergnügen in Gott - ein Werk, das die Tradition der Naturbetrachtungen der lutherischen Erbauungsliteratur unter dem Eindruck vielfältiger geistiger Anregungen seiner Zeit umformend weiterführte ${ }^{50}$.

Für unseren Zusammenhang besonders wichtig ist dabei, wie bei Brockes die Naturbetrachtung den Natubetrachter aus seinem gewohnten, alltäglichen Weltverhältnis herausreißt. Dadurch treibt der Moment eine neue Affektion heraus, die nach Brockes das lyrische Ich erst dazu veranlasst, von »Schönheit«, ja von einem »Wunder« zu reden:

Als ich im Garten, jüngst durch dicke Erlen gieng,

Und mit geöffneter, darauf schnell geschlossn'er Hand,

Ein Sommer-Vögelchen, das flatternd floge, fieng,

Erstarrete mein Aug', es stutzte der Verstand,

Da ich dasselbige so schön, so Wunder-schön,

So herrlich ausgezieret, so reich an Farben fand ${ }^{51}$.

47 Vgl. Holger Steinmann, Absehen - Wissen - Glauben. Physikotheologie und Rhetorik 1665-1747, Berlin 2008, S. 127-149.

48 Vgl. Frank Kopitzsch, Sozietäten und Literatur in der Hamburger Aufklärung, in: Inge Stephan / Hans-Gerd Winter (Hg.), Hamburg im Zeitalter der Aufklärung, Hamburg 1989, S. 124-135, S. 124 f.

$49 \mathrm{Vgl}$. Sabine Volk-Birke, Naturwissenschaft, Philologie und Andacht. Johann Albert Fabricius' Übersetzung von William Derhams Astrotheology und Physicotheology, in: Johann Anselm STEIger (Hg.), Hamburg. Eine Metropolregion zwischen früher Neuzeit und Aufklärung, Berlin 2012, S. 827-844.

50 Vgl. zu den komplexen ideengeschichtlichen Hintergründen Hans-Georg KemPER, Aufgeklärter Hermetismus. Brockes’ »Irdisches Vergnügen in Gott « im Spiegel seiner Bibliothek, in: Monika Neugebauer-Wölk (Hg.), Aufklärung und Esoterik, Hamburg 1999, S. 140-178.

51 Barthold Heinrich Brockes, Auszug der vornehmsten Gedichte, aus dem von Herrn Barthold Heinrich Brockes in fünf Theilen herausgegebenen Irdischen Vergnügen in Gott, Hamburg 1738, S. 240 (»Der lehrende Schmetterling«). 
Die durch die vorgängige Unterbrechung hervorgerufene Bewunderung kann sich dabei am Reichtum der Natur - wie im zitierten Beispiel -, aber auch an der Harmonie und Nützlichkeit der Natur für den Menschen entzünden. Im Nachspüren nach der Quelle dieser affektiv entzündeten Bewunderung der Natur stößt das lyrisch Ich dann auch auf Gott als den Urgrund der Schönheit, es wird »Zu der Wunder Schöpfer « ${ }^{52}$ hingeführt. Für Brockes sind es aber nicht nur solche positiven, allerdings in der Natur "verborgenen" Empfindungen ${ }^{53}$, welche den nachspürenden Betrachter auf Gott hinlenken. Auch die Erfahrungen der bedrohlichen Natur und ihrer unfassbaren Unendlichkeit lösen solche religiös produktiven Unterbrechungen aus ${ }^{54}$ :

Als jüngst mein Auge sich in die Sapphirne Tieffe,

Die weder Grund, noch Strand, noch Ziel, noch End' umschrenckt,

Ins unerforschte Meer des holen Luft-Raums senckt,

[...] entsatzte sich mein Geist [...]

Und ich verlohr mich selbst. Dieß schlug mich plötzlich nieder,

Verzweiflung drohete der ganz verwirrten Brust:

Allein, o heylsams Nichts! glückseliger Verlust!

Allgegenwärt'ger Gott, in Dir fand ich mich wieder ${ }^{55}$.

Alle von Brockes verwendeten Motive der Naturbetrachtung sind in der physikotheologischen Literatur bekannt. Nur werden sie dort eben nicht bzw. nicht so betont durch das Nadelöhr des sich entsetzenden, erstarrenden, stutzenden und sich zu verlieren drohenden Ich geführt ${ }^{56}$. Doch eben das hat für das Verständnis der »Physikotheologie« erhebliche Folgen: Denn die Gottesempfindung dieses naturbetrachtenden »Ich" hängt weder wie Diderot meinte - an einer naturwissenschaftlichen Hypothese, noch ist sie zwangsweise - wie es bei Boyle immer vorausgesetzt ist - an einem letztlich substanzmetaphysisch grundierten Gottesbegriff mit all seinen Objektivitätsanmutungen ausgerichtet. Und sie ist erst recht nicht, wie Brockes seinen eigentlichen Gegnern, den »Pietisten«, entgegen hält, durch

52 Ders., Auszug, S. 310 (»Der Herbst $)$.

53 Vgl. nur ders., Auszug, S. 241 (»Der lehrende Schmetterling«): »Die zwar verborgene, doch unleugbare Spur/ Vom all-erfüllenden, allmächt'gen Wunder-Wesen [...]«.

54 Vgl. zu den Hintergründen auch Ruth GroH / Dieter GroH, Von den schrecklichen zu den erhabenen Bergen. Zur Entstehung ästhetischer Naturerfahrung, in: Dies., Weltbild und Naturaneignung. Zur Kulturgeschichte der Natur, Frankfurt a.M. ${ }^{2} 1996$, S. 92-149, bes. S. 128-134.

55 Brockes, Auszug, S. 477 (»Das Firmament«).

56 Vgl. auch zu den Sehtechniken in den Gedichten Brockes' Jörn STEIGerwald, Das göttliche Vergnügen des Sehens. Barthold Hinrich Brockes' Techniken des Betrachtens, in: Convivium. Germanistisches Jahrbuch Polen 2000, S. 9-42. 
Weltabgewandtheit geprägt ${ }^{57}$. Jedoch ist die von Brockes umrissene Konstellation einer gefühls- und empfindungsorientierten physikotheologischen Verhältnisbestimmung durch den »Betrachter«, der die Natur nicht erklärend interpretiert oder sie bloß empirisch beobachtet, durchgängig auf eine grundsätzlich religiöse, genauer: christliche Fundierung des Weltverhältnisses des Subjekts angewiesen. Damit wird bei Brockes nun noch einmal ein Problem deutlich, das die religiösen Folgen der Entwicklung der naturwissenschaftlichen Methode in der Frühen Neuzeit begleitete. Dieses Problem wird die abschließenden, zusammenfassenden Überlegungen bestimmen.

\section{Schlussbetrachtung}

Bis zum Ende des 18. Jahrhunderts stieg die experimentelle Naturforschung zu einem zentralen bürgerlichen Wissensfeld auf, an dessen intellektueller Eigenständigkeit kaum mehr gezweifelt wurde. Dieser Aufstieg war, wie an Francis Bacon deutlich wurde, von Anfang an mit leitwissenschaftlichen Ansprüchen versehen, die auch in der Folgezeit von den Vertretern der »New Science " geltend gemacht wurden. Allerdings ist es wichtig zu betonen, dass diese Ansprüche zunächst mit Blick auf andere Formen der Naturerklärung erhoben wurden, allen voran - wie Bacons Überlegungen zeigten - gegenüber der »bloß« mathematischen oder der alchemistischen. Eine gezielte und unmittelbare Kritik an der Religion war mit der Entwicklung der »New Science ursprünglich nicht intendiert. Gleichwohl war diese Entwicklung ebenfalls von Anfang an mit der Religionsthematik verwoben, da sie zum Umbau des aristotelisch eingefärbten Weltbildes führte, auf das auch die christlichen Traditionen seit dem Hohen Mittelalter abgestimmt waren. Insofern waren die aufkommenden Debatten über das Verhältnis von »Religion « und "naturwissenschaftlicher Methode» eine zwingende Folge des Aufstiegs und der Etablierung der »New Science« als eigenständigen Wissensfelds.

In den facettenreichen Verhältnisbestimmungen von »Religion" und »New Science« der Frühen Neuzeit dominierte, aufs Ganze gesehen, eine wechselseitige produktive Sympathie. Die von der Papstkirche im 17. Jahrhundert formulierten Denkverbote, für welche die Verurteilung Galileo Galileis ebenso berühmt wie exemplarisch ist, entfalteten in der Folgezeit selbst in katholisch dominierten Wissenschaftsmilieus wie dem Frankreichs keine dauerhafte Wirkung. Dafür waren die Vertreter der "New Science» sowie die an der neuen Naturerklärung Interessierten auch viel zu stark in

57 Vgl. Marc Chaprlak, B.H. Brockes' fröhliche Physikotheologie. Poetische Strategien gegen Weltverachtung und religiösen Fanatismus in der Frühaufklärung, Bielefeld 2015, S. 81. 
über- und transkonfessionelle Netzwerke eingebunden ${ }^{58}$. Und die ganz praktischen Leistungen der "New Science " haben, wie das Beispiel Maupertuis deutlich machte, zur wachsenden gesellschaftlichen Akzeptanz der neuen Wissenschaftspraxis das Ihre beigetragen. Das gilt sicher auch für die protestantischen Kontexte, in denen die »New Science» sich entfaltete. Allerdings wurde sie hier teils dynamisch von einer großen religiösen Begeisterung der Neuentdeckungen der Schöpfungen Gottes getragen, wie an der Entstehung der Royal Society zu sehen war. Allein, gerade im englischen Protestantismus mischte sich diese Begeisterung recht schnell mit dem Bemühen, die Akzep$\tan z$ der neuen Wissenschaftspraxis dadurch zu sichern, dass sie dem politischen Verdacht religiöser Heterodoxie bzw. kirchlichen Dissidententums enthoben und mit den theologischen Vorstellungen providentiellen Schöpfungsglaubens harmonisiert wurde.

Dieser wechselseitigen Sympathie von "Religion" und "New Science" gegenüber stellt die Hervorhebung der religiösen Folgenlosigkeit der naturwissenschaftlichen Arbeit durch die Enzyklopädisten in der Frühen Neuzeit eine Minderheitenmeinung dar. Eine Fehlinterpretation der ursprünglichen Grundgedanken der neuen Wissenschaftspraxis war diese Hervorhebung jedoch nicht. Denn mit der Betonung der immer hypothetischen Ergebnisse der Naturwissenschaften bei Diderot wurde die antifinalistische Intention, die schon Bacon der experimentellen Naturforschung eingeschrieben hatte, nur konsequent ausbuchstabiert. Nichtsdestoweniger war diese Betonung bei Diderot und den anderen Enzyklopädisten mit einem ganz anders gelagerten, weniger naturwissenschaftlichen als vielmehr gesellschaftspolitischen Führungsanspruch der "Interpreten" gegenüber den »Beobachtern« versehen - zugespitzt formuliert: mit einem Welterklärungsanspruch der "aufgeklärten« Intellektuellen, durch den die Enzyklopädisten sich normativ als religionskritische Elite von der ungebildeten »Masse« absetzten.

Diese religionskritische Haltung stand allerdings unter den akademisch-intellektuellen Eliten besonders im protestantischen Teil Europas im 18. Jahrhundert in Konkurrenz zu einem sich merklich ändernden Begriff und Verständnis der »Religion«. Schon Brockes operierte mit einem solchen veränderten Religionskonzept: Er konnte sich in ästhetisch-psychologischer Subjektivierung des (christlichen) Gottesgedankens den Ergebnissen der »New Science« bedienen, ohne für die religiöse Selbstexplikation des naturbetrachtenden (lyrischen) Ich auf Kategorien der Naturerklärung zurückgreifen zu müssen. In Brockes' Dichtungen tritt somit die bewusste Differenz zwischen religiöser Weltdeutung und wissenschaftlicher Welterklärung

58 Vgl. für das 17. Jh. nun die eindringliche Studie von Tina Asmussen, Scientia Kircheriana. Die Fabrikation von Wissen bei Athanasius Kircher, Affalterbach 2016. 
deutlich heraus, die sich schon in Boyles Vorstellung der "Physikotheologie» vorsichtig angekündigt hatte.

So wenig diese Differenz eine einfache Beseitigung von Problemen in der Verhältnisbestimmung von »Religion" und »Naturwissenschaft« bedeutete (und bedeutet) $^{59}$, so wird mit ihr doch der spezifisch neuzeitlich-moderne Zuschnitt dieser Probleme profiliert: Charles Taylor hat dafür den Begriff "spin " gebraucht, womit der dem Individuum eigene Standpunkt bezeichnet ist, den es in seiner sinnbehafteten Deutung einer von der Naturwissenschaft erschlossenen Welt einnimmt, die nicht notwendigerweise und von sich aus auf Transzendenz verweist ${ }^{60}$. Diesen neuzeitlich-modernen Zuschnitt hat bereits am Ende des 18. Jahrhunderts Friedrich Schleiermacher hervorgehoben, als er - auf einer anderen begrifflichen und theoretischen Klaviatur angesichts verschiedener Möglichkeiten von »Anschauungen « des »Universums « bemerkte: [...] welche von diesen Anschauungen des Universums ein Mensch sich zueignet, das hängt ab von seinem Sinn für das Universum, das ist der eigentliche Maßstab seiner Religiosität, ob er zu seiner Anschauung einen Gott hat, das hängt ab von der Richtung seiner Fantasie « ${ }^{61}$.

59 Vgl. zu den Folgedebatten jetzt auch Friedrich Wilhelm Graf, Kreationismus. Sechs Kapitel aus der Religionsgeschichte der Moderne, in: Ulrich BARTH u.a. (Hg.), Aufgeklärte Religion und ihre Probleme. Schleiermacher - Troeltsch - Tillich, Berlin u.a. 2013, S. 113-134.

60 Charles Taylor, A Secular Age, Cambridge u.a. 2007, S. 551-556.

61 Friedrich Schleier macher, Über die Religion. Reden an die Gebildeten unter ihren Verächtern (1799), hg. von Günter Meckenstock, Berlin u.a. 2000, S. 113. Vgl. zu Schleiermachers Begriff der »Fantasie« Christof Ellsiepen, Anschauung des Universums und Scientia Intuitiva. Die spinozistischen Grundlagen von Schleiermachers früher Religionstheorie, Berlin u.a. 2006, S. 396. 


\section{Politische Ideologien und ihre säkularisierende Wirkung - das Beispiel Russland im 20. und 21. Jahrhundert}

\section{Vom »Verschwinden« und Wiederaufstieg der Russisch-Orthodoxen Kirche}

Als ich im Jahr 1986 mein Studium der Osteuropäischen Geschichte begann, lag es für mich nicht auf der Hand sich mit Fragen der Orthodoxie oder der Bedeutung von Religion in den Kontexten der Geschichte des Zarenreiches oder der Sowjetunion zu beschäftigen. Mich interessierte seinerzeit der Fortgang der Perestroika unter Michail Gorbatschow. Und in diesem Lichte studierte ich auch die Oktoberrevolution von 1917: Welche Irrwege waren eingeschlagen worden? Wie ließ sich die Sowjetunion umbauen? Dass bei meiner ersten Reise nach Russland eine Kirche wie die Kazaner Kathedrale auf dem Leningrader Nevskij-Prospekt als Museum für die Geschichte des Atheismus fungierte, erschien mir als Kuriosum. Als Ergebnis nahm ich den Umstand als gegeben hin, dass die Orthodoxie als lebensweltlich bedeutsamer Faktor fast verschwunden war und wohl ganz verschwinden würde. Der Gottesdienst war eine Angelegenheit weniger alter Frauen mit Kopftüchern.

Ein Hauptseminar meines späteren Doktorvaters Peter Nitsche zur Geschichte der Russisch-Orthodoxen Kirche im Millenniumsjahr 1988 erschien uns hochinteressant, aber auch ein wenig entlegen. Als wir 1989 auf einer vom ihm veranstalten Exkursion das Danilov-Kloster in Moskau besuchten, das nach 1917 als Regenschirmfabrik und Gefängnis gedient hatte, nun aber dem Patriarchen Pimen I. zurückgegeben worden war und bis heute als Amtssitz des Patriarchen fungiert, sah ich keine Renaissance orthodoxen Glaubens und keine Renaissance einer Partnerschaft von Staat und Kirche. Aber in den 1990er und 2000er Jahren erlebte ich bei meinen Besuchen und Aufenthalten in Russland wie Religion als Glaube und als Argument an Bedeutung (zurück-)gewann. Die alten und neuen Kirchen füllten sich, die Präsidenten Jelzin, Medwedew und vor allem auch Putin traten gemeinsam an hohen orthodoxen Feiertagen, aber auch geschichtspolitisch bedeutsamen Gedenktagen auf und demonstrierten einen Schulterschluss zwischen Staat und Kirche. Ob es sich bei alldem um eine tiefgehende Re-Christianisierung Russlands auf der Ebene der Individuen handelt, muss offen bleiben. Die Präsenz der Orthodoxen Kirche im öffentlichen Raum ist kein zwingender Beleg dafür. 
Es sei jedoch darauf hingewiesen, dass nicht nur die Orthodoxie eine Renaissance erlebt. Auch andere Religionen, die im Russländischen Imperium Lebenswelt und Miteinander prägten, treten wieder verstärkt nach außen - man denke an den Islam in Tatarstan oder vor allem im Kaukasus ${ }^{1}$, aber auch an den Buddhismus in Burjatien. Das wären, ebenso wie deren Verflechtungen im postsowjetischen Raum, eigene Themen. Ich beschränke mich hier auf die Orthodoxie in Russland und der Sowjetunion.

Ausgehend von diesen persönlich motivierten Beobachtungen sollen im folgenden Wegmarken der russischen Geschichte erörtert werden, die zu der Annahme - und auch meiner Annahme - beitrugen, dass auch in Russland die Moderne, in diesem Fall eine totalitäre Moderne ${ }^{2}$, wenn schon nicht zu einer Säkularisierung, so doch zu einer Entchristlichung geführt habe.

\section{Die sowjetische Erfahrung}

Blickt man auf die Geschichte Russlands im 20. und zu Beginn des 21. Jahrhunderts, so bilden auch für die Geschichte der Orthodoxie jene Einschnitte, die für Eric Hobsbawm das kurze 20. Jahrhundert markierten, wesentliche Einschnitte - das Revolutionsjahr 1917 und der Zusammenbruch der Sowjetunion mit der Perestroika Michail Gorbatschow 1985-1991. Mit dem Revolutionsjahr 1917 begann sich nicht nur das Verhältnis von Staat und Kirche zu verändern, nach dem Oktober begann ein Kampf gegen die Religion generell und gegen die Orthodoxie im Besonderen, der darauf zielte, die Religion aus der sukzessive errichteten Modernisierungsdiktatur zu verbannen. Mit dem Sturz der zarischen Autokratie endete zunächst aber die Organisation der orthodoxen Kirche als Staatskirche. Peter der Große hatte Anfang des 18. Jahrhunderts im Rahmen seiner »Revolution von oben« das Patriarchenamt abgeschafft und mit dem Synod eine kollektive Leitung eingerichtet. Viel ist darüber diskutiert worden, ob die Kirche darüber zu einer »handmaiden of the state" geworden sei $^{3}$. Im Ergebnis stilisierten sich Zaren wie Alexander III., oder der nach dem Zusammenbruch der Sowjetunion nach längerer Diskussion im Jahre 2000 heiliggesprochene Nikolaus II., als orthodoxe Autokraten, die ihren Staat - trotz der imperialen Realität von Multireligiosität und Multiethnizität - als orthodox grundiert begriffen und darin von Vordenkern einer konservativen Orthodoxie, wie dem Oberprokuror

1 Sofie Bedford u.a., Islam im postsowjetischen Kaukasus. Von Sunniten, Schiiten, Sufis und Salafisten, in: Osteuropa 7-10 (2015), S. 71-92.

2 Stefan Plaggenborg, Experiment Moderne. Der sowjetische Weg, Frankfurt a.M. 2006.

3 Gregory Freeze, Handmaiden of the State? The Church in Imperial Russia Reconsidered, in: JEH 36/1 (1985), S. 82-102. 
Konstantin Pobedonoscev bestärkt wurden ${ }^{4}$. Sie überdeckten, dass es auch innerhalb des hohen und niederen Klerus eine weitgespannte Diskussion über einen künftigen Weg der Orthodoxie gab. Extrem nationalistische und antisemitische Positionen, wie die eines Johann von Kronstadt ${ }^{5}$, standen nach der Revolution von 1905 Gruppen gegenüber, die eine Erneuerungstheologie befürworteten, für die orthodoxe Kirche eine Trennung vom Staat forderten, eine Sozialdoktrin formulieren wollten oder darüber nachdachten, was Sozialismus und Orthodoxie verbinden könnte.

Die provisorische Regierung unterstützte nach dem Sturz des Zaren Nikolaus II. die Einberufung eines großen Landeskonzils, das von sich aus eine Lösung vom Staat einleitete, in dem es nach zwei Jahrhunderten wieder einen Patriarchen wählte, welches aber auch davon ausging, die Orthodoxie müsse die Leitreligion für eine gesellschaftliche Ordnung im postzarischen Russland bleiben 6 .

Die Oktoberrevolution bedeutete hier einen radikalen Einschnitt. Das Dekret »Über die Gewissensfreiheit, die kirchlichen und religiösen Vereinigungen « vom 20. Januar (2. Februar) 1918, das als das Dekret »Über die Trennung der Kirche vom Staat und der Schule von der Kirche« in die Geschichte eingegangen ist, legte die Grundsätze der sowjetischen Religionspolitik fest ${ }^{7}$. Sie hatte ihren Ausgangspunkt in Lenins Überzeugung, dass die Religion Opium für das Volk sei ${ }^{8}$. Sie zielte in erster Linie auf die Russisch-Orthodoxe Kirche (ROK), in der man eine Stütze der zaristischen Autokratie und des antisowjetischen Widerstandes sah. Das Dekret stellte einen massiven Eingriff sowohl in den Besitz, als auch in die Leitungs- und Organisationsstruktur der ROK dar, womit man das Ende der Orthodoxie in Russland überhaupt herbeizuführen hoffte. Über diesen Rahmen hinaus bestand seine Intention darin, andere, nichtorthodoxe und nichtchristliche Religionsgemeinschaften auszuschalten.

Der Bolschewismus als säkulare religiöse Bewegung zeigte sich damit in erbarmungslosem Kampf gegen die Religionsgemeinschaften und ihre Hierarchien zugleich. Religion, so die Bolschewiki, war ein Aspekt aus der

4 Noch immer instruktiv Gerhard Simon, Konstantin Petrovič Pobedonoscev und die Kirchenpolitik des Heiligen Sinod 1880-1905, Göttingen 1969.

5 Walter Laqueur, Der Schoß ist fruchtbar noch. Der militante Nationalismus der russischen Rechten, München 1995, S. 76-83.

6 Günther Schulz, 1914-1918 als kirchengeschichtlicher Einschnitt in Russland, in: ZThK 97/1 (2000), S. 18-45.

7 Helmut Altrichter u.a. (Hg.), Die Sowjetunion. Von der Oktoberrevolution bis zu Stalins Tod, Bd. 2: Wirtschaft und Gesellschaft, München 1987, S. 49-51; siehe auch Otto Luchterhandt, Der Sowjetstaat und die Russisch-Orthodoxe Kirche. Eine rechtshistorische und rechtssystematische Untersuchung, Köln 1976, S. 32-34.

8 Ausgeführt in einer Schrift von 1905 über Religion und Soziologie Vladimir Il'ič LenIn, Über die Religion. Eine Auswahl, Berlin/Ost, S. 39-44. 
dunklen Vergangenheit, und sie wurde als feindliche Kraft ausgemacht. Die mit erzieherischen ebenso wie mit administrativ repressiven Mitteln zu bekämpfen sei. Die Systematik, mit der nach und nach gegen alle ihre Erscheinungsformen vorgegangen wurde, hatte offensichtlich damit zu tun, dass der Bolschewismus als Glaubenssystem keine Konkurrenz dulden konnte. Hierin sollten sich die totalitären Ansprüche des Bolschewismus und Stalinismus zeigen.

Eine erste Phase des Kirchenkampfes 1921-1923 richtete sich in erster Linie gegen die Hierarchen der wichtigsten christlichen Kirchen - so auch der russisch-orthodoxen. In der zweiten Phase seit 1927 standen die Aktivitäten der sogenannten Gottlosen-Bewegung im Vordergrund. Ihre Angriffsobjekte waren Geistliche aller Religionen. Dabei ging es schon nicht mehr um die Diskreditierung der geistlichen Hierarchen, sondern um die Auslöschung religiöser Überzeugung und Glaubenssysteme in der Bevölkerung. Die Gottlosen-Bewegung war ein Teil des zweiten revolutionären Aufbruchs im Übergang zu Kollektivierung und Planwirtschaft, des sogenannten Kulturfeldzuges mit seiner revolutionären Inbrunst und seinem Himmel stürmenden Pathos. Alle Institutionen der Russisch-Orthodoxen Kirche verfügten vor der Revolution über mehr als 3.000.000 Hektar Grund und Boden; die 1253 Klöster allein über 1.000.000. 1921 wurden etwa 827.000 Hektar konfisziert ${ }^{9}$. Die Trennung von Kirche und Staat in bolschewistischer Lesart entsprach in mancher Hinsicht dem Modell der Französischen Revolution. Das Familienrecht wurde säkularisiert. Die Religionsgemeinschaften, so eben auch die Orthodoxe Kirche, wurden aus dem Bildungswesen verdrängt. Ihr Eigentum einschließlich der Kirchen und Klöster unterlag der Nationalisierung, auch wenn es zum Teil zur Nutzung wieder zurückgegeben wurde. Die wichtigsten Aggressionsobjekte der Bolschewiki waren zunächst die orthodoxen Kirchen in Russland, aber auch Kirchen in der Ukraine, in Georgien und Armenien. Dagegen sahen Teile der Parteiführung in den Altgläubigen und in den Sekten des russisch-orthodoxen Spektrums sowie in den zumeist übernationalen protestantischen Freikirchen eher vorübergehende Verbündete ${ }^{10}$.

9 Zahlen bei Dietrich Beyrau, Petrograd, 25. Oktober 1917. Die russische Revolution und der Aufstieg des Kommunismus, München 2001, S. 82.

10 Siehe die nach Konfessionen und Religionen geordneten Beiträge in Christoph Gassenschmidt u.a. (Hg.), Politik und Religion in der Sowjetunion 1917-1941, Wiesbaden 2001; sowie Eberhard Müller, Opportunismus oder Utopie? V.D. Bonč-Brunevič und die russischen Sekten vor und nach der Revolution, in: JGO 35 (1987), S. 509-533. 
Die ROK gab sich zunächst strikt antibolschewistisch. Die Revolutionäre galten als Wahnsinnige, die man aufrief, ihr satanisches Tun einzustellen. Die Militanz der Bolschewiki und ihres Anhangs ist aber kaum allein mit der politisch oft genug kompromittierten Bestellung der Kirche und dem bolschewistenfeindlichen Sendschreiben des Patriarchen Tichon zu erklären, der schließlich das Anathema verhängen sollte ${ }^{11}$. Die Revolutionäre der ersten Generation bildeten politisch und weltanschaulich den radikalen Flügel der säkularisierten Intelligenzija-Gegenkultur, wie sie seit den 1860er Jahren unter den wechselnden Vorzeichen von Populismus und Marxismus, von Materialismus und Positivismus in Wissenschaft und Kultur bereits hegemoniale Positionen besetzt hatten ${ }^{12}$. Der Kampf gegen die als überkommen geltende Orthodoxe Kirche war schon vor dem Roten Oktober common sense - nicht nur bei den Bolschewiki.

Umgekehrt tat sich die Amtskirche schwer, die Rolle eines Dialogpartners wahrzunehmen. Zudem hatte sich die Orthodoxe Kirche schon vor 1917 mit den Phänomenen der Moderne schwer getan. Es gelang ihr kaum, unter den Handwerkern und der Arbeiterschaft in den Fabriken und Arbeiter-Stadtteilen der Großstädte Fuß zu fassen. Um Dietrich Beyrau zu zitieren:

Die Geschichte der Intelligenz und der Arbeiterbewegung mit ihrer sympathischen Hingabe an Wissenschaft und Aufklärung war zu einem erheblichen Teil die Geschichte einer manchmal militanten Distanzierung von alten Autoritäten und Traditionen. Dies scheint im gleichen Maße für sozialistische und später bolschewistische Milieus unter den Christen zu gelten ${ }^{13}$.

Nach der Enteignung und einer ersten offenen, wenig organisierten Verfolgung von Geistlichen wurden öffentlichkeitswirksam in spektakulären Aktionen Reliquienschreine und Gräber von Heiligen und Märtyrern geöffnet. Diese sollten unter Hinzuziehung von Fotografen und Experten den Nachweis des Betrugs an den Gläubigen erbringen. Besonderes Aufsehen erregte die Öffnung der Schreine Alexander Newskijs, des Bezwingers des Deutschen Ordens, und Sergejs von Radonesch, des Begründers des Sergej Troize Lavras. 1923 plante man bereits in Moskau ein rotes Kloster der Götter der Welt ${ }^{14}$.

11 Wolfgang Heller, Die Russische Orthodoxe Kirche 1917-1941, in: Gassenschmidt, Politik und Religion, S. 13-46, hier S. 39.

12 Beyrau, Petrograd, S. 84.

13 Zitat: Ebd., S. 84.

14 Jakov N. ŠčAPov, Russkaja pravoslavnaja cerkov’ i kommunističeskoe gosudarstvo 1917-1941. Dokumenty i fotomaterialy, Moskau 1996, S. 63. 
Die Initiative, der Orthodoxen Kirche wie auch bürgerlichen Kreisen im Zusammenhang mit der Hungersnot von 1921-22 einen weiteren Schlag zu versetzen, ging von der Geheimpolizei GPU unter Leitung von Felix Dzeržinskij aus. Sie hatte fast ein Monopol auf die Verfügung über die Kirche und ihren bisher schon beschlagnahmten Besitz ${ }^{15}$.

Es waren aber vor allem Lenin und Trotzki, die unter dem Schirm der Hungerhilfe einen regelrechten Krieg gegen die kirchliche Hierarchie in Gang setzten ${ }^{16}$. Dabei standen mehrere Aspekte und Optionen im Vordergrund. Die Kirche sollte als Institution entmachtet werden. In den Worten Lenins: »Wir sollten gerade jetzt der reaktionären (Schwarzhundert-) Geistlichkeit einen entscheidenden schonungslosen Kampf liefern, so dass sie dies im Laufe mehrerer Jahrzehnte nicht vergisst ${ }^{17}$. Obwohl Patriarch Tichon schon zuvor den Verkauf kirchlicher Wertgegenstände, die im Gottesdienst nicht notwendig seien, für die Hungerhilfe genehmigt hatte, forderte das Dekret vom 23. Februar 1922 auch die Ablieferung geweihter Geräte. Dabei hegten Lenin und Trotzki völlig übertriebene Erwartungen, was von der Kirche zu holen sei. Es sollten nur wenige Millionen Goldrubel werden. Über Ausmaß und Umfang des Widerstands, den gläubige Christen in Stadt und Land gegen diese Plünderung der Kirchen leisteten, wird anhaltend gestrit$\operatorname{ten}^{18}$. Während orthodoxe Kirchenhistoriker argumentieren, der umfassende Widerstand zeige, dass Russland in seinem Kern ein orthodoxes Land geblieben sei und bleiben würde, konstatierten Historiker, die sich mit den zwanziger Jahren beschäftigten, eine erstaunliche Apathie gegenüber der bolschewistischen Kampagne, die sicher auch einer allgemeinen Müdigkeit nach Weltkrieg, Revolution und Bürgerkrieg geschuldet war.

Als Widerstand gegen die Bolschewiki manifest wurde, wurden Prozesse gegen den Klerus angestrengt, auch dort wo sich dieser gar nicht gewehrt hatte. Hierbei fällten die Gerichte auch viele Todesurteile. Zu den prominentesten Opfern gehörte Wenjamin, der Metropolit von Petrograd. Die wichtigsten Prozesse steuerte das Politbüro; es gab Urteile vor und entschied über ihren Vollzug. Diese Prozesse sollten auch das Vorspiel bilden, um gegen den Patriarchen selbst vorzugehen ${ }^{19}$.

Tichon wurde 1922 verhaftet und in die Lubjanka verbracht. Danach wurde er im Moskauer Donskoi-Kloster interniert. Eine bolschewistisch do-

15 Hier kam es zu Konflikten mit Bauern, die meinten Land und Besitz der Kirche stünde ihnen zu.

16 Und zum folgenden Paul Gabel, And God Created Lenin. Marxism and Religion in Russia 1917-1929, Amherst 2005, S. 200-217; Aleksej N. KAšEvarov, Pravoslavnaja rossijskaja cerkov i sovetskoe gousudarstvo (1917-1922), Moskava 2005, S. 221-249.

17 Zitiert nach Beyrau, Petrograd, S. 85.

18 ŠČAPOV, Russkaja pravoslavnaja cerkov'i kommunističeskoe gosudarstvo, S. 123-129.

19 Gaebel, And God Created Lenin, S. 218-231. 
minierte allrussische Kirchenversammlung setzte ihn ab und enthob ihn aller geistlichen Ämter. In Tichons Namen, der das Annathema gegen die Bolschewki verhängt hatte, wurde eine Reueerklärung veröffentlicht, deren Echtheit in Kirchenkreisen angezweifelt wird. Sein Tod im Jahr 1925 gab zu Vermutungen über eine Vergiftung Anlass. Sein Testament, in dem er zur Aussöhnung mit dem neuen Regime aufrief, gilt als Fälschung ${ }^{20}$.

In einer Frage hatte der Patriarch bis zu seinem Tod zähen Widerstand geleistet. Es ging um die Anerkennung der sogenannten lebendigen Kirche: Eine weitere Option der Partei und des Geheimdienstes hatte darin bestanden, die Hierarchie der ROK durch Spaltung zu sprengen. Dem Geheimdienst war es gelungen, eine ganze Reihe von Geistlichen für sich zu gewinnen oder zu erpressen, um gegen den Patriarchen mobil zu machen und sich als Erneuerer der Kirche zu konstituieren. Unter Anleitung der GPU und der im Oktober 1922 gebildeten »Antireligiösen Kommission beim Zentralkomitee« nutzte die Partei das Potenzial teils tatsächlich reformorientierter, teils erpressbarer Geistlicher, um ein sozialismusfreundliches Gegengewicht zum Patriarchen und zu seinem Anhang zu schaffen ${ }^{21}$. Sobald die Spaltung der Kirche erreicht sei, sollte die sogenannte lebendige Kirche ihrerseits zersetzt werden. 13 von 150 Bischöfen stellten sich der lebendigen Kirche zu Verfügung. 1927 sollten die Erneuerer (obnovlency) zwar 84 Bistümer besetzt haben, konnten aber nur einen Bruchteil der Geistlichen der Gemeinden kontrollieren: Der höhere Klerus war leichter unter Druck zu setzen, als die Gemeinden und die Priester vor Ort, die ohnehin als liženzy, als überflüssige Menschen, bereits schweren Schikanen unterlagen ${ }^{22}$. Sie hatten bereits seit der Oktoberrevolution das Wahlrecht verloren und waren damit mit ehemaligen Adligen und Fabrikbesitzern in eine Kategorie eingeordnet. In den ersten Jahren waren karnevaleske Umzüge, die die Revolution feiern und deren Gegner verhöhnen sollten, an der Tagesordnung. Popen wurden herabwürdigend dargestellt und ganz im Sinne ihrer rechtlichen Kategorisierung als Vertreter der Ausbeuterklasse dargestellt, die in der Diktatur des Proletariats der Verächtlichmachung anheim gegeben wurden ${ }^{23}$.

20 Zu Tichon Vladimir V. Lobanov, Patricharch Tichon i sovetskaja vlast' 1917-1925, Moskau 2008.

21 Aleksandr Mazyrin, Dokumenty Central'nogo archiva FSB Rossii o sekretnoj dejatel'nosti GPU-OGPU protiv pravoslavnoj cerkvi na Ukraine v 1920-e gg, in: Otečestvennye archivy 4 (2014), S. 59-69.

22 Beyrau, Petrograd, S. 86f.

23 Gaebel, And God Created Lenin, S. 170-173, sowie jetzt: Julia Röttjer, Gab es eine "religiöse Neue Ökonomische Politik« in der frühen Sowjetunion? Die Antireligiöse Kommission des Zentralkomitees und die russisch-orthodoxe Kirche, in: Religionsgeschichtliche Studien zum östlichen Europa. Festschrift für Ludwig Steindorff zum 65. Geburtstag, hg. von Martina Thomsen, Stuttgart 2017, S. 225-240. 
Nach der großen Welle der Repressalien von 1922 bemühte man sich seit 1923 um weniger provozierende Kampagnen. Karnevals- und Festumzüge, in denen auch die Geistlichkeit karikiert wurde ${ }^{24}$, und Straßendemonstration mit antikirchlicher Ausrichtung sollten in Zukunft unterbleiben. Der rote Festkalender sollte Alternativen zum christlichen Festkalender bieten. Für ihn wurden genaue Regeln festgelegt. Statt Ostern wurde nun die Implementierung eines rituellen Frühlingsfestes versucht. Mit symbolisch hoch aufgeladenen Ritualen wurde der 1. Mai gefeiert - als Sinnbild für revolutionäres Heldentum und kämpferische Romantik.

Auch die Bolschewiki kamen ohne kultische Handlungen nicht aus. Trotzki sah durchaus deren Potenzial, wie er in seinen Schriften zu Fragen des Alltags darlegte ${ }^{25}$. In seiner Schrift Schnaps, Kirche und Kino maß er der Religion und dem Alkohol gleichermaßen opiatische und sedierende Wirkung zu. Er zeigte sich aber auch von den Eindruck gebietenden Elementen der orthodoxen Liturgie angetan, in der alle Register zur Überwältigung gezogen würden. Von den medialen und kultischen Überwältigungsstrategien, so Trotzki, könne man einiges lernen und das Kino sei das geeignete Medium, um auch auf dem Lande präsent zu sein.

Seit 1922 veröffentlichten Parteiaktivisten in Zeitschriften oder Serien wie Religion als soziales Übel. In dieser Zeit verfasste auch Emeljan Jaroslavskij, dem Sandra Dahlke eine brillante Dissertation gewidmet hat, seine ersten Broschüren, die sich um eine materialistische Deutung von Religion bemühten. Wie die Götter und Göttinnen geboren werden, wie sie leben und sterben oder die Bibel für Gläubige und Nichtgläubige - solche Bücher von Jaroslavskij wurden noch bis in die 1970er Jahre des vorigen Jahrhunderts verlegt. Emeljan Jaroslavskij gehörte zu den aktiven, wenn auch immer etwas im Hintergrund bleibenden intellektuellen Aktivisten der Gottlosen-Bewegung, die auch einen erheblichen Einfluss in der Antireligiösen Kommission beim ZK, dem Zentralkomitee der Russischen Kommunistischen Partei, besaßen. Er repräsentierte jenen Typus des gebildeten Revolutionärs, der sich vom Parteiaktivisten Leninscher Prägung zum Parteisoldaten Stalins wandelte. Sein populärer Schreibstil musste ihn in Stalins Augen zu einem geeigneten Kandidaten gemacht haben, um ihn in jene Kommissionen aufzunehmen, welche den kurzen Lehrgang der KPdSU verfasste, in dem 1938 auch kurz und knapp dargelegt wurde, was von der Religion zu halten $\mathrm{se}^{26}$.

24 Hierzu zum Beispiel Julia Röttjer, Die Stadt als Bühne. Orte bolschewistischer Massenfeste, in: Markus Ackeret u.a. (Hg.), Sankt Petersburg. Schauplätze einer Stadtgeschichte, Frankfurt a.M. u.a. 2007, S. 211-226.

25 Leo Trotzki, Fragen des Alltagslebens, Essen 2001.

$26 \mathrm{Zu}$ Jaroslavskij umfassend Sandra DAHLKe, Individuum und Herrschaft im Stalinismus. Emel'jan Jaroslavskij (1878-1943), München 2010. 
Wie groß war der Erfolg der Antireligiösen Propaganda? Weltkrieg, Revolution, Bürgerkrieg mögen einem Prozess der Entkirchlichung und der Säkularisierung vor allem in der städtischen Bevölkerung sowie einer Pluralisierung der Volksfrömmigkeit Vorschub geleistet haben. Die antireligiöse Propaganda hatte hieran sicher nur einen geringen Anteil, auch wenn sie mit Aufwand betrieben wurde. Sie wurde nicht nur medial breit aufbereitet, in Schulen und Hochschulen wurde Marxismus-Leninismus als obligatorisches Unterrichtsfach eingeführt. Die Vermittlung wissenschaftlicher Erkenntnisse hatte zusätzlich religiöse Vorstellungen zu widerlegen. Zudem publizierte man speziell der Religion gewidmete Broschüren und Zeitschriften, während die Kirchen keinerlei Papierzuteilungen erhielten ${ }^{27}$.

Seit 1921 gab es die Zeitung Der Gottlose. Seit 1922 erschien die Zeitung Der Gottlose an der Werkbank und seit 1926 die Zeitschrift Der Antireligiöse. All diese Organe wurden von Emeljan Jaroslvaskij geleitet. Der Gottlose hatte in seinen besten Zeiten Auflagen von bis zu 500.000 Exemplaren. Gleichzeitig entstanden Vereine der Atheisten, die allerdings erst 1928/29 zu einer Massenbewegung wurden und 1930 angeblich bis zu zwei Millionen Mitglieder besaßen ${ }^{28}$.

Im Zuge des Übergangs zum ersten Fünfjahrplan und zur Kollektivierung bildete die seit 1929 in "Verband der militanten Gottlosen« umbenannte Parteiorganisation eine Art von Mobilisierungsreserve, die wie der Komsomol für den Kampf gegen alle Religionen eingesetzt werden konnte ${ }^{29}$. Am 8. April 1929 verkündete der Rat der Volkskommissare ein neues Gesetz über religiöse Vereinigungen. Dieses Gesetz legte für die nächsten Jahrzehnte die rechtlichen Grundlagen für die Gemeinden fest. Sie hatten sich von lokalen Sowjetbehörden registrieren zu lassen. Vor Ort hatten sich mindestens 20 Gläubige zusammen zu schließen, um eine Gemeinde zu gründen und ein Gottes- oder Gebetshaus mieten zu können. Karitative und wirtschaftliche Aktivitäten blieben verboten, religiöse Unterweisung wurde auf spezielle Kurse beschränkt, die der Zustimmung des Kommissariats für Inneres bedurften. Die Religionsgemeinschaften existierten rechtlich nur auf lokaler Ebene. Kurz nach der Bekanntgabe des Gesetzes wurde beim Zentralkomitee der Partei eine interministerielle ständige Kommission für Religionsfragen (Kultkommission) gegründet.

27 Aleksandr Mazyrin, Antireligiöse Politik des sowjetischen Staates unter Lenin und Stalin und Reaktionen der Russisch-Orthodoxen Kirche, in: Forum für Osteuropäische Zeit- und Ideengeschichte 19/2 (2015), S. 11-26, hier S. 15f.; 18f.

28 John S. Curtiss, Die Kirche in der Sowjetunion, München 1953, S. 197-206.

29 Ausführlich Daniel Peris, Storming the Heavens. The Soviet League of the Militant Godless, Ithaca NY 1998. 
In den Städten war die neue Militanz ein Teil des sogenannten Kulturfeldzuges, auf dem Land ein Teil der Entpolitisierung und Kollektivierung und zugleich ein Versuch, ein zentrales Element der Bauernkultur zu zerstören ${ }^{30}$. Die Gotteshäuser auf dem Land stellten nicht nur religiöse Zentren, sondern auch Orte sozialer Gemeinschaft und Bildung dar. Von einem besonderen Symbolwert waren hierbei die Glocken, die zum Objekt der bolschewistischen Begierde wurden. Sie läuteten nicht nur zum Gottesdienst, sie signalisierten auch Gefahr bei Bränden, riefen das Dorf zu wichtigen Anlässen zusammen, manchmal auch zum Aufruhr. Sie waren das Symbol der Dorfgemeinschaft. In der Schließung der Kirchen und Gotteshäuser, mit der Vertreibung und Verbannung oder Verhaftung von Geistlichen und der Abnahme von Glocken manifestierte sich die Besetzung des Dorfes durch die proletarische Diktatur und damit der groß angelegte Versuch, einen säkularen atheistischen Staat durchzusetzen. Im Zuge der Kollektivierung 1929/30 entbrannte nun wirklich ein heftiger Kampf um die Gotteshäuser ${ }^{31}$. Besonders symbolträchtig war ein Vorfall in einem Dorf im Westen Russlands. Dort wurden Ikonen aneinandergereiht und erschossen; jede Ikone war mit der Aufschrift versehen, dass der auf ihr dargestellte Heilige wegen Sabotage der Kollektivierung zum Tode verurteilt worden sei. Bis 1933 wurden 385.000 Glocken requiriert. Insgesamt 37 Tonnen Metall, die so erbeutet wurden, wurden zum Teil für die Münzprägung oder symbolträchtig für die Ausschmückung der soeben errichteten zentralen Lenin-Bibliothek in Moskau genutzt.

1936, bei der Bekanntgabe der Stalin-Verfassung, wurden den Gläubigen in den Artikeln 124 und 125 Rechte zugestanden, die formal erlaubten, ihren Glauben zu leben und Glaubensfreiheit zu beanspruchen ${ }^{32}$. Diese Freiheit existierte einerseits nur auf dem Papier. Die Ergebnisse der Volkszählung von 1937 andererseits, in der sich über die Hälfte der Bevölkerung zu einer Religionsgemeinschaft bekannte, lassen aber erkennen, dass die Parteiführung um Stalin mit den Resultaten der antireligiösen Politik nicht zufrieden sein konnte. Es beunruhigte, dass der Zulauf zu den Religionsgemeinschaften stark blieb und dass die Gottlosen-Bewegung faktisch in sich zusammengefallen war.

Von den 1917 existierenden über 73.000 Kirchen sollen nach der Revolution 42.000 geschlossen worden sein; von den 1937 noch verbliebenen 30.000 Gotteshäusern seien immer noch ca. 20.000 aktiv gewesen. Vor dem

$30 \mathrm{Zu}$ Stalin und dem Ende der sogenannten religiösen NEP umfassend Ivan. A. KURLJANDSKIJ, Stalin, vlast' religija, Moskau 2011, S. 233-431.

31 Sandra DAhlke, Kampagnen für Gottlosigkeit. Zum Zusammenhang zwischen Legitimation, Mobilisierung und Partizipation in der Sowjetunion der zwanziger Jahre, in: JGO 50/2 (2002), S. 172-185.

32 Peter Hauptmann u.a. (Hg.), Die Orthodoxe Kirche in Russland. Dokumente ihrer Geschichte (860-1980), Göttingen 1988, S. 748. 
Ausbruch des Zweiten Weltkrieges kam es noch einmal zu zahlreichen Schließungen von Gotteshäusern. 1939/40 befanden sich die meisten der noch aktiven orthodoxen Kirchen in den soeben annektierten Gebieten Polens und Rumäniens; die Anzahl der Geistlichen war von einst über 50.000 um 1917 auf einige 100 zurückgegangen. Der größte Teil von ihnen dürfte abgeschworen, sich in Haft oder Verbannung befunden haben oder ermordet worden sein. Immerhin war das erste Konzentrationslager in der Sowjetunion die Klosterinsel Solovki im Weißen Meer. Die dort lebenden Mönche konnten gleich als Häftlinge vor Ort bleiben. Nach dem Zusammenbruch der Sowjetunion wurden viele dieser ermordeten Geistlichen $\mathrm{zu}$ den sogenannten neuen Märtyrern, die der Orthodoxen Kirche bei ihrem Neustart neuen Sinn verleihen sollten. Selbstbehauptung trotz Bedrückung und Verfolgung wurde eines der Hauptnarrative nach 1988/1991.

Die Haltung des sowjetischen Staates gegenüber der Orthodoxen Kirche änderte sich mit dem 22. Juni $1941^{33}$. Nach dem Überfall der Deutschen Wehrmacht auf die Sowjetunion rief der Metropolit Sergeij noch am selben Tag - und damit mehr als eine Woche vor Stalin - in einem Rundbrief an alle Hirten und Gläubigen seiner Kirche zum Kampf gegen die Eindringlinge auf. Die Kirche veranstaltete Sammlungen unter den Gläubigen und trug erhebliche Summen zu einem Verteidigungsfond bei, mit dem Waffen für die Rote Armee finanziert wurden. Insbesondere wurde aus den Spenden eine Panzerkolonne finanziert, die in Anlehnung an den Sieger über die Tataren 1380 Dimitri Donskoj genannt wurde. Eine Fliegerstaffel namens Alexander Newskij, benannt nach dem bereits bekannten Bezwinger der Schweden und des Deutschen Ordens, wurde ebenfalls durch Spenden der Gemeinden finanziert. Die Reaktion des Metropoliten wirft ein bezeichnendes Licht auf die Beziehung zwischen Staat und Kirche in der russischen Tradition. Der Gesamtstaat hatte die Kirche fast bis zur völligen Vernichtung verfolgt und zerstört, im Falle der äußeren Bedrohung stellte sie sich jedoch sofort und vorbehaltlos auf seine Seite ${ }^{34}$. Der Staat seinerseits akzeptierte die kirchliche Unterstützung, und die aktiven Versuche, die Existenz der Kirche unmöglich zu machen wurden eingestellt. 1943 kam es zu einer historischen Begegnung zwischen drei Bischöfen und Stalin, bei der die Kirche die Erlaubnis erhielt, nach 18 Jahren Vakanz einen neuen Patriarchen zu wählen. Die Behörden ermöglichten der Kirche auch eine Reihe von bisher nicht zugelassenen Aktivitäten. Sie konnte die Zeitschrift des Moskauer Patriarchats sowie einige Bücher publizieren und auch wieder eine Einrichtung zur Priesterausbildung

33 Nach Meinung von I. A. Kurlandskij freilich schon mit dem Ende des »Großen Terrors« 1939 KURLANDSKiJ, Stalin, S. 532-549.

34 Mazyrin, Antireligiöse Politik, S. 23-25. 
eröffnen $^{35}$. Die Kirche hatte größere Handlungsmöglichkeiten oder, wie Thomas Bremer es formulierte, »im Vergleich zur Zeit unmittelbar vor dem Krieg hatte sie überhaupt Handlungsmöglichkeiten ${ }^{36}$.

Im Zusammenhang mit der Entstalinisierung, die unter Nikita Chruschtschow nach 1956 begann, wurde wieder ein schärferer Kurs gegenüber der Kirche eingeschlagen. Er betraf insbesondere das annektierte Baltikum. Die antireligiöse Politik des neuen starken Mannes, der ganz in vermeintlich atheistischen Kategorien dachte, in deren Kontext er auch den Personenkult um Stalin stellte, bildete vielleicht auch einen Ausgleich zu den Falken, die dem 1953 gestorbenen Führer nachtrauerten ${ }^{37}$. Stalin hatte trotz des Terrors bei vielen Menschen hohes Ansehen genossen, zum einen als Sieger des Zweiten Weltkrieges, zum anderen aber auch als jemand, unter dem Ordnung geherrscht hatte ${ }^{38}$. Eine Rücknahme des säkular-religiösen Personenkultes und anderer Elemente der Stalinschen Politik wurde daher von einem antikirchlichen Kurs begleitet, der gleichsam eine Rückkehr zu den Prinzipien eines Leninschen Atheismus darstellen sollte ${ }^{39}$. So wurden mit den späten 1950er und frühen 1960er Jahren wiederum zahlreiche Gemeinden, Kirchen und Klöster geschlossen, darunter das Kiewer Höhlenkloster. 1960 ließ Chruschtschow gar das Priesterseminar in Sagorsk schließen. Bischöfe, die zu aktiv waren, wurden in den Ruhestand versetzt ${ }^{40}$. Der Staat versuchte die Kirche auch zu unterwandern. Agenten des Geheimdienstes wurden ins Priesterseminar geschleust, und man versuchte Priester zur Zusammenar-

35 Thomas Bremer, Kreuz und Kreml. Kleine Geschichte der orthodoxen Kirche in Russland, Freiburg 2007, S. 130-132; sowie CurTiss, Die Kirche in der Sowjetunion, S. 274-286.

36 Bremer, Kreuz und Kreml, S. 132; manche Historiker sehen einen Anstieg von Repressionen aber bereits nach dem Kriegsende 1945 Tatiana A. Chumachenko, Church and State in Soviet Russia. Russian Orthodoxy from World War II. to the Khrushchev Years. Edited and Translated by Edwad E. RosLof, London 2002, S. 101113; 1948 begann etwa eine Offensive insbesondere gegen Sekten KuRLJANDSKIJ, Stalin, vlast' religija, S. 550-560.

37 Jan Kusber, Gewandeltes Herrscherbild, veränderte Inhalte. Von Stalin zu Chruščev, in: ZfG 9 (2008), S. 743-754.

38 So die Interpretation von Bremer, Kreuz und Kreml, S. 133. Siehe auch: Ulrike Hunn, Beten für Stalin? Die Russische Orthodoxe Kirche im Jahr 1953, in: Religion \& Gesellschaft in Ost und West 40 (2012), H. 6, S. 18-20.

39 Nathanial Davis, A Long Way to Church. A Contemporary History of Russian Orthodoxy, Boulder ${ }^{2} 2003$, S. 33-45; Inese RUNCE, »Ich hätte predigen können, aber ich habe es nicht getan«. Die Tagebücher katholischer Priester in Sowjetlettland, in: Svetlana Bogojavlenska u.a. (Hg.), Tradition und Neuanfang. Forschungen zur Geschichte Lettlands an der Wende vom 20. zum 21. Jahrhundert, Münster 2014, S. 131-144.

40 Dimitry V. Pospielovsky, A History of Soviet Atheism in Theory, and Practice, and the Believer, Bd. 1: A History of Marxist-Leninist Atheism and Soviet Anti-Religious Policies, New York, NY 1987, S. 84. 
beit mit dem Geheimdienst zu bewegen ${ }^{41}$. In Russland hat es nach dem Ende des Kommunismus keine Öffnung der Geheimdienstarchive gegeben, aus einzelnen Dokumenten ist aber bekannt, dass einige Bischöfe nicht nur Informationsgespräche mit KGB-Mitarbeitern geführt haben, sondern selbst Angehörige des Dienstes waren ${ }^{42}$. Das kirchliche Leben konsolidierte sich langsam, wenn auch auf niedrigem Niveau. Der Preis war eine unterwanderte Kirche, die sich in der Umarmung des Staates mit einer marginalisierten Existenz zufriedengab.

Zugleich waren die Zeiten Chruschtschows und seines Nachfolgers Leonid Breschnew jene Jahre, die heute von vielen als die goldene Zeit der Sowjetunion erinnert wird. In der Tat, nach Stalins Tod nahm die Gewalt $\mathrm{ab}$, sie verschwand als ubiquitäres Phänomen. Die Diktatur wandelte sich und trug mit dem Ausbau der sozialen Sicherungssysteme, der fortgesetzten Urbanisierung und De-Agrarisierung Züge der Variante einer Entwicklung der Moderne, die bei weitem nicht allen, aber doch vielen Sowjetbürgern zusagte. Es entwickelte sich eigentlich erst auf dem Fundament der Stalinschen Gewalt und aus ihr heraus, ein »Soviet way of life«, der einerseits dazu führte, dass »Bolshevik speak« - d.h. die immer gleichen Propagandaphrasen - als leer empfunden wurde, andererseits aber auch dazu, dass wohl erst in den sechziger und siebziger Jahren die große Welle der Säkularisierung über und durch das Land ging. Die Kirche in der Koexistenz hatte unter den Bedingungen des entwickelten und sozial befriedeten sozialistischen Staates weniger anzubieten, als im Widerstand gegen das System in den zwanziger und dreißiger Jahren, als die Reihen sich geschlossen und die Strukturen der Untergrundkirche fest geworden waren. Es war gerade im Jahre 1988, dem Jahr des Millenniums, nicht abwegig zu glauben, dass, nachdem auch Ideologie und Personenkult nicht mehr verfingen, die Sowjetunion und damit Russland ein weitgehend säkularisierter Staat seien. In den Jahren des Zusammenbruchs der UdSSR und um das Millennium herum agierte die ROK mehr als vorsichtig, um sich in der erwarteten neuen Situation zu orientieren $^{43} .1990$ erschien es in der Sowjetunion als völlig unkritisch, ein liberales Gesetz über Religionsfreiheit zu verabschieden ${ }^{44}$. Der säkulare Staat hatte sich durchgesetzt und auch die Ersatzreligion einer erstarrten und damit zerfallenden Religion war im Untergang begriffen.

41 Stefan Plaggenborg bezeichnete diese Methoden als stalinistisch Plaggenborg, Experiment Moderne, S. 214; siehe auch Jurij V. Geras'KIN, Iz istorii chruščevskogo nastuplenia na Russkuju pravoslavnuju cerkov', in: Novyj istoričeskij vestnik 19 (2009), S. 71-79.

42 Yevgenia Albats, The State Within a State. The KGB and its Hold on Russia - Past, Present, and Future, New York, NY 1994, S. 46.

43 Zur Kooperation zwischen KGB und Kirchenhierarchen Davies, A Long Way, S. 99-103.

44 Bremer, Kreuz und Kreml, S. 193. 


\section{Kirche und Staat in postsowjetischer Zeit}

1917 hatte die Kirche von sich aus mit dem Landeskonzil den Weg der Distanznahme vom Staat gewählt, um sich zu erneuern. Nach 1991 konnte die Re-Christianisierung des Landes nicht ohne die Hilfe des Staates gelingen. In der Phase der Orientierungslosigkeit der Jelzin-Jahre, war das Land nicht arm an Sinnstiftungsangeboten religiöser, spiritueller, esoterischer oder ideologischer Art. Die krudesten Zivilisationsmodelle wurden als ebenso zukunftsträchtig angeboten, wie ideologische Versatzstücke aus dem 19. Jahrhundert. Es war das Jahrzehnt der evangelikalen Freikirchen in Russland; es war auch das Jahrzehnt, in dem der Buddhismus nicht nur im Fernen Osten sehr starken Zulauf erhielt. Es war aber schließlich auch das Jahrzehnt, in dem der Islam offen als gesellschaftlich-religiöse Kraft an der Peripherie in Erscheinung trat und auf das Zentrum zurückzuwirken begann.

Laut russischer Verfassung von 1993 ist Russland ein säkulares Land. Doch die Trennung von Kirche und Staat gerät auf beiden Seiten zuweilen in Vergessenheit; sie wurde von Seiten der ROK bewusst vergessen gemacht. Nach dem Zusammenbruch der Sowjetunion war die Kirche die einzige gesellschaftliche und geistige Institution, die auch Panzer für den Tschetschenienkrieg segnen ließ - ein Garant des Zusammenhalts. Die RussischOrthodoxe Kirche bot sich dem Staat an und die Regierungen begannen sie in unterschiedlichem Ausmaß zu nutzen. Der Staat nutzte die Kirche vor allem als Herrschaftsinstrument und als Bühne für einen traditionsbewussten Nationalismus.

Die Wahl Wladimir Putins zum Präsidenten des Landes wurde 2000 in einem Gottesdienst gefeiert. Auch sein Nachfolger Dmitrij Medwedew ließ sich vom Patriarchen segnen, wenn auch sein Glaubensbekenntnis weniger inbrünstig ausfiel. Unterdessen ist es üblich geworden, dass der oberste Patriarch - seit 2009 Kirill - bei allen wichtigen politischen Anlässen neben den Staatsmännern auftritt. Wenn Geschäftsleute etwas Gutes tun wollen, stiften sie in der Provinz eine Kirche, sodass das Uniforme der Wohnstädte der sowjetischen Moderne nun durch pittoreske, historisierende Kirchenneubauten aufgelockert wird. Die von Stalin für den nie gebauten Palast der Sowjets gesprengte Christ-Erlöser-Kathedrale, die mit viel Aufwand an den Ufern der Moskva wiedererbaut wurde, stand Pate für eine ganze Reihe von auch typologisch sehr ähnlichen Nachfolgebauten.

Doch der reale Einfluss der Kirche bleibt begrenzt. Der Staat hilft ihr nur, wenn es dem eigenen Vorhaben nutzt. Der jahrelange Wunsch der orthodoxen Priester nach religiösem Pflichtunterricht in der Schule wurde bisher nicht erfüllt. Zu sehr muss die russische Führung auf die Balance mit anderen 
Konfessionen und Religionen achten ${ }^{45}$. Putin besuchte etwa demonstrativ die neue Zentralmoschee im September 2015. Also nutzt die Kirche andere Plattformen. Der Patriarch hat einen YouTube-Kanal geschaltet. Seit 2005 geht der russisch-orthodoxe Fernsehsender Spas (Rettung) auf Sendung, mittlerweile rund um die Uhr.

Für ihre geistige Führung Russlands nutzt die Kirche die Geschichte auf ihre Weise, indem sie an die "großen Errungenschaften" von Russlands Vergangenheit erinnert, um diese für seine Zukunft $\mathrm{zu}$ mobilisieren, wie Jutta Scherrer in den letzten Jahren mehrfach überzeugend dargetan hat ${ }^{46}$. Beschworen wird immer wieder die byzantinische »Symphonie« der weltlichen und geistlichen Macht sowie die Idee von »Moskau, dem Dritten Rom«. Seit einer Reihe von Jahren wird die Auffassung vom »kanonischen Territorium« angeführt (Alexej II. sprach sogar vom »kanonischen Territorium Eurasiens«), die den nationalen Anspruch der orthodoxen Kirche untermauert und den »Proselytismus« unterbindet. In der auf dem Landeskonzil im Jahre 2000 verabschiedeten Sozialdoktrin der Orthodoxen Kirche - der ersten ihrer Art überhaupt - wird zwar auf die unterschiedlichen Zielsetzungen von Kirche und Staat hingewiesen, doch zugleich an den »Patriotismus des orthodoxen Christen « appelliert, der sich »in der Verteidigung des Vaterlands gegen den Feind, in der Arbeit zum Wohle der Heimat, im Einsatz für das öffentliche Leben einschließlich der Teilnahme an den Angelegenheiten der Staatsverwaltung äußert ${ }^{47}$.

Bezeichnenderweise war die Kirche auch bei der Findung des neuen »Tags der nationalen Einheit« maßgeblich beteiligt, mit dem Putin 2005 den bislang arbeitsfreien 7. November (den ehemaligen Gedenktag an die Oktoberrevolution) ablöste: der Sieg einer russischen Volkswehr über die katholischen Polen am 4. November 1612, welche den Kreml besetzt hielten, womit die Zeit der Wirren (smuta) beendet wurde, an den seit 1649 als Fest der wundertätigen Ikone der Gottesmutter von Kazan im Kirchenkalender erinnert worden war. Das Ende der »Wirren« und die Wiedergeburt eines starken russischen Zentralstaats mit dem Herrschaftsbeginn der Romanows konnte geschichtspolitisch als Argument und zur Sinnstiftung genutzt werden. Sie entsprachen den auf Kontinuität und Einheit der russischen Geschichte

45 Seine Rede zur Eröffnung der neuen Moschee Vladimir Putin, Traditional Islam is an Integral Part of Russia’s Spiritual Life, in: Russias Mufties Council, URL: <http:// www.muslim.ru/en/articles/137/13878/> (22.09.2016).

46 Jutta Scherrer, Kirche und Identität im postsowjetischen Russland, in: Ost-West. Europäische Perspektiven, hg. von Renovabis u.a., URL: <https://www.owep.de/ artikel/71/kirche-und-identitaet-im-postsowjetischen-russland $>$ (22.09.2016).

47 Zitiert nach Risto SaArinen, Die neuesten Soziallehren der Kirchen und ihr europäisches Umfeld, in: Heinz DuchHardt u.a. (Hg.), Die europäische Integration und die Kirchen. Akteure und Rezipienten, Göttingen 2010 (VIEG Beiheft 85), S. 89-106, hier S. 99. 
ausgerichteten Wertvorstellungen Putins, und die Analogie zur Gegenwart war offensichtlich, in der eine neue Frontstellung zum Westen zu Tage tritt, in der auch eine Front zwischen Orthodoxie und vor allem dem Katholizismus gedacht wird ${ }^{48}$.

In den Identitätsdiskurs der Kirche schreibt sich auch das zivilisatorische Paradigma (civilizacionnyj podchod $k$ istorii) ein, das auf die vermeintliche Bedrohung durch die Globalisierung mit der Singularität der orthodoxen russischen Kultur antwortet. Bereits 1992 war mit der Kulturologie (kul'turologija) eine neue akademische Disziplin dazu geschaffen worden, Sinn- und Wertvorstellungen aus den Traditionen der russischen Geschichte und Kultur wieder lebendig zu machen und diese als Pflichtfach Schülern und Studenten zu übermitteln ${ }^{49}$. Die Kulturologie hatte auch die Religion als formatives Element der Kultur rehabilitiert und im Falle Russlands die "orthodoxe Ethik" und, mit ihr verbunden, die Vorstellung von einem "orthodoxen Raum" der russischen Kultur oder Zivilisation propagiert (beide Termini werden synonym gebraucht).

Die russische Identität wird von der Kirche dem Individualismus, Liberalismus und Säkularismus des Westens gegenübergestellt. Unter dem Schlagwort "russische Idee" gilt die sobornost' - der russische Gemeingeist (wörtlich »Konziliarität«) - als erster Wert der orthodoxen Eigenständigkeit Russlands. Die Abgrenzung vom Westen veranlasste die Kirche etwa auf dem Russischen Volkskongress 2006 dazu, sich von dem westlichen Konzept der Menschenrechte abzugrenzen und es als »Beleidigung religiöser und nationaler Werte«, darzustellen, wie es der damals für die Außenbeziehungen des Moskauer Patriarchats verantwortliche Metropolit Kirill formulierte. »[...] Orthodoxe Gläubige können nicht schweigen, wenn ihnen fremde Normen aufgezwungen werden, die den Grundlagen des orthodoxen Glaubens widersprechen ${ }^{50}$.

»Das Säkularisationsprojekt ist ausgeschöpft. Es raubt dem Volk seine Lebenskraft, es ist nicht bereit die Menschen zu motivieren, und sie der Selbstaufopferung zu lehren $\aleph^{51}$, erklärte der ehemalige Leiter der Synodalabteilung

48 Ulrich Schmid, Technologien der Seele. Vom Verfertigen der Wahrheit in der russischen Gegenwartskultur, Berlin 2015, S. 188-210; Rudolf ProKsCHI, Russischorthodoxe Kirche. Glaube und herrsche, in: ZEIT Geschichte 3 (2015), URL: <http:// www.zeit.de/zeit-geschichte/2015/03/russisch-orhtodoxe-kirche-wladimir-putinkreml-kommunismus/komplettansicht> (19.09.2016).

49 Jutta Scherrer, Kulturologie. Russland auf der Suche nach einer zivilisatorischen Identität, Göttingen 2003, S. 93.

50 Evangelischer Pressedienst, Orthodoxe Menschenrechte. Die Russische Kirche grenzt sich von westlichen Werten ab, in: Evangelische Kirche in Deutschland, URL: <https://archiv.ekd.de/aktuell/060418_orthodoxe_menschenrechte. html $>$ (08.04.2019).

51 Ende 2015 wurde er entlassen und übt seither Kritik am Patriarchen Kirill. Corey Flinthoff, In Russia, A High-Ranking Orthodox Priest Is Sacked - And Hits Back, 
für Wechselbeziehungen zwischen der Kirche und der Gesellschaft, Erzpriester Vsevolod Čaplin auf einer Konferenz in Moskau, die dem Thema der Beziehung zwischen der Religion und dem Staat gewidmet war ${ }^{52}$.

Für viele Russen gilt die Aussage: »Russe gleich orthodox«. Nach Angaben des russischen Meinungsforschungsinstituts WZIOM bekennen sich etwa 75 Prozent der 143 Millionen Einwohner im Land zum russisch-orthodoxen Glauben. Etwa fünf Prozent derer, die sich als solche bezeichnen, sind nicht getauft. Der Anteil aktiver Kirchgänger liegt bei maximal zehn Prozent der Bevölkerung. Bei vielen gilt die Aussage, russisch-orthodox zu sein, allerdings nicht als Bekenntnis zur Religiosität, sondern zur russischen Kultur. Sie verstehen die Religion als nationale Tradition, ohne wirklich gelebte Alltags-Religiosität - auch wenn kaum ein Russe auf eine Ikone im Haus, Auto oder im Portemonnaie verzichtet, und sei sie nur im Spielkartenformat ${ }^{53}$.

Die Bilanz der orthodoxen Kirche in Russland seit dem Zusammenbruch der Sowjetunion ist beeindruckend: Fast 20.000 Kirchen wurden unter dem letzten Patriarchen Alexeij II. neu errichtet oder wieder aufgebaut. 1988 zählte die Russisch-Orthodoxe Kirche weniger als 7.000 Pfarreien und um die 20 Klöster, 2007 waren es 26.600 Pfarreien und 652 Klöster. 2012 sprachen die Russen in Umfragen der Orthodoxen Kirche das zweitgrößte Vertrauen zu - nach dem Präsidenten. Selbst der russische Kommunistenchef Gennadij Sjuganov zeigt sich seit einigen Jahren als bekennender orthodoxer Christ und lobt die Religion als konstitutives Element russischen Seins ${ }^{54}$. Ein Drittel seiner Parteimitglieder gelten als gläubig.

\section{Schluss}

So bleibt zusammenfassend festzuhalten, dass das Säkularisierungsprojekt der Bolschewiki an seinem totalitären Zugriff gescheitert ist. Das postmoderne Russland mit seinem autoritären Regime unter Putin setzt auf die Orthodoxie. Ist aber Russland deshalb ein re-christianisiertes Land? Ein

in: Parallels. Many Stories, One World, URL: <http://www.npr.org/sections/parallels/2015/12/26/461047919/in-russia-a-high-ranking-orthodox-priest-is-sacked-andhits-back> (21.09.2016).

52 Die Russische Kirche äußert sich gegen die Säkularisierung der Gesellschaft, in: Bogoslov.ru. Wissenschaftlich-Theologisches Portal, URL: <http://de.bogoslov.ru/ text/414158/index.html> (27.11.2015).

53 Inna Hartwich, Die Rolle der Religion in Russland. Von Atheisten zu gläubigen Christen, in: Bundeszentrale für politische Bildung, URL: <http://www.bpb.de/internationales/europa/russland/47992/religion? $\mathrm{p}=$ all $>$ (27.11.2015).

54 Russland. Patriarch Kirill verleiht Kommunistenführer Sjuganov Kirchenorden, in: Institut G2W. Ökumenisches Forum für Glauben, Religion und Gesellschaft in Ost und West, URL: <https://g2w.eu/news/987-russland-patriarch-kirill-verleiht-kommunistenfuehrer-sjuganov-kirchenorden> (21.09.2016). 
Land, das als Gegenbeispiel für den viel beschriebenen Zusammenhang von Moderne und Säkularisierung gelten kann? Mir scheint es im Jahr 2016 vor allem ein Land zu sein, in dem die Kirche zur Hilfsabteilung Derjenigen wird, die die Vision eines national-konservativen Russland haben, das zwar in technologischer und alltagsweltlicher Hinsicht modern sein will, aber Phänomene, die als Auswüchse der Moderne begriffen werden, zugleich geißelt. In den medialen Strategien, die zur Verwirklichung dieser Vision verwandt werden, ist man auf der Höhe des »Fortschritts«, auch wenn die legitimatorischen Versatzstücke, zu denen auch die Beschwörung der Heiligen Rus' zählt, ausschließlich auf eine aus der Vergangenheit resultierenden Größe orientiert sind ${ }^{55}$. Und die derzeitige Vision, angeboten von Staat und Kirche, trifft auf Akzeptanz.

55 Jan Kusber, Die Nation und Geschichtspolitik im öffentlichen Raum. Das Beispiel Russlands im 19. und am Beginn des 21. Jahrhunderts, in: Luise Gütr u.a. (Hg.), Wo bleibt die Aufklärung? Aufklärerische Diskurse in der Postmoderne, Stuttgart 2013, S. 315-332. 


\section{Perspektiven AUf SÄKUlarisierung IN DER GEGENWART}




\title{
Manfred Sing
}

\section{Der Islam als Kontrastfolie in der Säkularisierungsdebatte}

\author{
Ein mehrfaches Missverständnis?
}

Muslime werden in der europäischen Öffentlichkeit heutzutage oftmals auf ihre Religionszugehörigkeit reduziert und als relativ einheitlich angesehen, nämlich als religiös definierbare und auch gläubige Gruppe. Durch diese Vereinheitlichung bildet »der« Islam nicht nur einen natürlichen Gegenspieler zum Säkularismus, sondern Säkularisierungsprozesse unter Muslimen und Differenzen zwischen ihnen bleiben grundsätzlich unterbelichtet.

Der folgende Beitrag problematisiert derartige Sichtweisen und zwei daraus resultierende Schieflagen: zum einen warnen nicht mehr nur Rechtspopulisten vor einer »Islamisierung « Europas, ja vor deren »dritter Welle« (nach der Schlacht von Poitiers 732 und von Wien 1683)' ; zum anderen werden politische und soziale Probleme von der Migration bis zur politischen Gewalt pauschal dem Islam als Religion zugerechnet. Das Pew-Institut in Washington etwa errechnete auf Grundlage einer hohen Geburtenrate, es werde bis 2070 weltweit mehr Muslime als Christen geben²; und für Deutschland prognostizierten Islamgegner eine muslimische Mehrheit bis Mitte des 21. Jahrhunderts, wobei sie eine jährliche Zuwachsrate des muslimischen Bevölkerungsteils von mehr als sechs Prozent voraussetzten'3. Während sich der Schwund christlicher Kirchen daraus ergibt, dass als Christ nur gezählt wird, wer getauft ist und einer Kirche angehört, gibt es für Muslime keine

1 Vgl. die Analyse bei Maurits S. Berger, The Third Wave. Islamization of Europe, or Europanization [sic] of Islam?, in: Journal of Muslims in Europe 2 (2013), S. 115136; Thijl Sunier, Beyond the Domestication of Islam in Europe. A Reflection on Past and Future Research on Islam in European Societies, in: Journal of Muslims in Europe 1 (2012), S. 189-208.

2 Pew Research Center, The Future of World Religions. Population Growth Projections, 2010-2050, URL: <http://www.pewforum.org/2015/04/02/religiousprojections-2010-2050> (13.01.2017).

3 Michael Blume, Wird Deutschland islamisch? - Zahlen, Fakten \& Prognosen (24.11.2007), URL: <http://www.blume-religionswissenschaft.de/pdf/WirdDeutsch landislamischBadBollBlume2007.pdf> (14.12.2016); ders., Islam in Deutschland 2030 - Erstellung einer begründeten Prognose, URL: <http://www.blume-religions wissenschaft.de/pdf/Islam_in_Deutschland_Prognose_2030_Seminarbericht.pdf > (14.12.2016); Riem Spielhaus, Muslime in der Statistik. Wer ist Muslim und wenn ja wie viele?, Berlin 2013, URL: <https://mediendienst-integration.de/fileadmin/ Dateien/Muslime_Spielhaus_MDI.pdf> (30.12.2016). 
derartige Differenzierung: Muslim ist man in solchen Statistiken unabhängig von der Gläubigkeit oder einer Verbandszugehörigkeit, es genügt, wenn man selbst oder die Familie aus einem Land stammt, in dem mehrheitlich Muslime leben ${ }^{4}$. Auf diese Weise taxierte das Bundesamt für Migration und Flüchtlinge 2009 die Zahl der Muslime in Deutschland auf 3,4 bis 4,3 Millionen, also auf rund fünf Prozent der Bevölkerung. Beim Zensus 2011 gaben indes nur 1,9 Prozent freiwillig an, dem sunnitischen, schiitischen oder alevitischen Islam - so die eingeschränkte Vorauswahl - anzugehören; mehr als 17 Prozent der nicht-christlichen Befragten machten von ihrem Recht Gebrauch, keine Religion zu nennen ${ }^{5}$.

Solche Ungenauigkeiten folgen nicht allein aus einer statistischen Unschärfe. Vielmehr sind überhaupt nur etwa 20 Prozent der Muslime in Deutschland in einem religiösen Verein oder einer Gemeinde aktiv, bei Sunniten (22 Prozent) deutlich mehr als bei Schiiten und Aleviten (zehn Prozent) ${ }^{6}$. Auch wenn der Religionsmonitor der Bertelsmann-Stiftung 49 Prozent der Muslime als "religiös« einstufte ${ }^{7}$, bleibt die Frage nach den Kriterien, der Tiefe und Bedeutung der Gläubigkeit. In einer Studie der Deutschen IslamKonferenz von 2009 gaben nur 33,9 Prozent der Befragten an, täglich zu beten (nicht aber unbedingt fünf Mal), wohingegen es die Mehrheit anders hielt und nur mehrmals in der Woche (9,4 Prozent), einmal in der Woche (9,7 Prozent), ein paar Mal im Monat (8,1 Prozent), ein paar Mal (15,3 Prozent) oder nie (20,4 Prozent) betete ${ }^{8}$. Nach einer Studie des Europäischen Parlaments bekennt sich nur etwa ein Drittel der geschätzten 15 Millionen Muslime in der EU aktiv zum Glauben'. Eine Umfrage von WIN/Gallup International in 57 Staaten kam im Jahre 2012 zu dem Ergebnis, dass sich in Saudi-Arabien fünf Prozent aller Bürger als »Atheisten« bezeichneten,

4 Siehe Michael Blume, Die Islamisierung fällt aus - Anmerkungen zur globalen Religionsdemografie und -soziologie (17.05.2016), URL: <http://scilogs.spektrum.de/ natur-des-glaubens/die-islamisierung-faellt-aus-anmerkungen-zur-religionsdemografie-und-soziologie> (13.12.2016); ders., Stiller Rückzug statt Islamisierung, in: Qantara.de (06.12.2016), URL: <https://de.qantara.de/inhalt/mythos-von-der-nichtsaekularisierung-von-muslimen-stiller-rueckzug-statt-islamisierung?nopaging> (13.12.2016).

5 Spielhaus, Muslime in der Statistik, S. 7. Für Christen, deren Zahl sich auf 53,2 Millionen beläuft, war die Angabe der Konfessionszugehörigkeit verpflichtend.

6 Mathias Rohe, Der Islam in Deutschland. Eine Bestandsaufnahme, München 2016, S. 119.

7 Riem Spielhaus, Germany, in: Jocelyne Cesari (Hg.), The Oxford Handbook of European Islam, Oxford 2015, S. 104-157, hier S. 116.

8 Rohe, Islam in Deutschland, S. 89.

9 Felice Dassetro u.a., Islam in der Europäischen Union, Was steht für die Zukunft auf dem Spiel? (erstellt vom Europäischen Parlament, Ausschuss für Kultur und Bildung), Brüssel Mai 2007, URL: <http://www.europarl.europa.eu/RegData/etu des/etudes/join/2007/369031/IPOL-CULT_ET\%282007\%29369031_DE.pdf> (07.12.2016), S. iii und 8 . 
19 Prozent gaben an, sich selbst "nicht als religiöse Person« zu betrachten. Unter Italienern lag diese Quote lediglich bei 15 Prozent, obwohl in SaudiArabien, wie in fünf anderen arabischen Staaten, Apostasie strafbar ist ${ }^{10}$. In derselben Umfrage drückten 22 Prozent der befragten Araber religiöse Zweifel aus - ein Wert, der über demjenigen in Südasien und Lateinamerika lag (17 respektive 16 Prozent). Während arabische Regierungen diese Zahlen herunterzuspielen versuchten, werden sie von westlichen Massenmedien zumeist ignoriert, gehen beide Seiten doch davon aus, dass Religiosität unter Muslimen etwas unhinterfragt Gegebenes sei. Dass atheistische Tendenzen zum Teil als Reaktion auf islamisch legitimierte Terrorakte - in den vergangenen Jahren deutlich sichtbarer wurden, liegt unter anderem daran, dass sich Gleichgesinnte in den sozialen Netzwerken abseits direkter staatlicher Zugriffsmöglichkeiten organisieren und austauschen ${ }^{11}$.

Was die Geburtenrate und die damit zusammenhängende "youth bulge«These anbelangt, nach der ein Übermaß an »zornigen, jungen Männern« für Gewalt, Krieg und Terror verantwortlich zeichne, so belegen die verfügbaren Daten, dass seit den 1960er Jahren auch in islamischen Staaten die Kinderzahl abnimmt und in einigen Ländern wie Iran und der Türkei unter die Bestandserhaltungsgrenze gefallen ist (d.h. zwei Geburten pro Frau). Auch in Westeuropa gleichen sich die Geburtenraten an den Durchschnitt der jeweiligen Mehrheitsgesellschaft an, wobei nicht Muslime, sondern Religiöse generell eine Ausnahme bilden, weil sie unabhängig von ihrer Religionszugehörigkeit mehr Kinder bekommen als ihre säkularen Nachbarn ${ }^{12}$. Die

10 Brian Withaker, The Rise of Arab Atheism, in: New Humanist (25.06.2016), URL: $<$ https://newhumanist.org.uk/articles/4898/the-rise-of-arab-atheism> (02.12.2016); ders., Arabs without God. Atheism and Freedom of Belief in the Middle East, North Charleston, SC 2014; Ahmed Benchemsi, Invisible Atheists. The Spread of Disbelief in the Arab World, in: The New Republic (24.04.2015), URL: <https://newrepublic. com/article/121559/rise-arab-atheists $>$ (02.12.2016).

11 Gerichtsverfahren gegen islamkritische Blogger oder körperliche Angriffe auf sie erregen zwar die Aufmerksamkeit der Medien, werden aber in der Regel als Einzelfälle dargestellt, etwa die Verurteilung Raif Badawis 2013 in Saudi-Arabien, die Ermordung säkularer Blogger in Bangladesch und des Atheisten christlicher Herkunft Nahed Hattar in Jordanien oder das Verschwinden von fünf pakistanischen Bloggern. Siehe dazu Aljazeera, Fourth Secular Bangladesh Blogger Hacked to Death (08.08.2015), URL: <http://www.aljazeera.com/news/2015/08/fourth-secular-bangladesh-blogger-hacked-death-150807102408712.html> (16.01.2017); Ulrich ScнмID, Ein Mord erschüttert die jordanische Ruhe, in: NZZ (27.09.2016), URL: <http://www. nzz.ch/international/nahost-und-afrika/unruhige-levante-ein-mord-erschuettertdie-jordanische-ruhe-ld.118857> (16.01.2017); Silke DitTrich, Kritische Stimmen spurlos verschwunden (15.01.2017), URL: <https://www.tagesschau.de/ausland/ blogger-pakistan-105.html> (16.01.2017).

12 Michael Blume, Werden Deutschland, Europa islamisch? Haben Muslime grundsätzlich mehr Kinder?, in: SciLogs (04.01.2010), URL: <http://scilogs.spektrum. de/natur-des-glaubens/werden-deutschland-europa-islamisch-haben-muslimegrunds-tzlich-mehr-kinder> (14.12.2016). 
Schweizer Volkszählung von 2000 ergab, dass eingebürgerte Musliminnen weniger Kinder (1,73 Kinder pro Frau) haben als ihre ausländischen Glaubensschwestern (2,49 Kinder pro Frau). Ein Vergleich der österreichischen Volkszählungen von 1981 und 2001 zeigt, dass in allen »Konfessionen" ein Rückgang zu verzeichnen war - islamisch (von 3,09 auf 2,34 Kinder pro Frau), katholisch (von 1,7 auf 1,32 Kinder pro Frau), evangelisch (von 1,51 auf 1,21 Kinder pro Frau) und konfessionslos (von 1,12 auf 0,86 Kinder pro Frau $)^{13}$. Die Bevölkerungswissenschaftler Courbage und Todd argumentieren auf Grundlage solcher Daten, dass die zunehmende Bildung von Frauen mit einer abnehmenden Geburtenrate korreliere und beides zusammen eine wichtige Rolle in Säkularisierungs- und Demokratisierungsprozessen spiele, an die sich auch die so genannte islamische Welt angeschlossen habe $e^{14}$.

Für mehrere arabische Staaten haben Umfragen schon vor den arabischen Aufständen 2011 ergeben, dass die Zustimmung zur Demokratie im weltweiten Vergleich hoch bis sehr hoch ausfiel und nur gering bis mäßig von der Variablen »islamische Religiosität« abhing ${ }^{15}$. Wenn demnach die Vereinbarkeit von Islam und Demokratie weniger problematisch erscheint, als allgemein angenommen, so variieren hier doch Eigen- und Außenwahrnehmung erheblich ${ }^{16}$.

Dass ein islamischer Einfluss auf Politik, Recht und Wirtschaft zweifellos vorhanden, wenn auch begrenzt ist, zeigt sich zum Beispiel daran, dass ausgerechnet die Muslimbrüder 2013 die erste gewählte zivile Regierung in Ägypten stellten, diese aber nach anderthalb Jahren vom Militär gestürzt wurde; oder dass das zinsfreie, "Scharia-konforme« Finanzsystem selbst in islamischen Ländern nur auf zehn Prozent Marktanteil kommt und auch in Saudi-Arabien noch immer mehr als die Hälfte der Finanztransaktionen im herkömmlichen Bankensektor abgewickelt werden - auch wenn sich islamisches Banking weltweit zweistelliger Wachstumsraten erfreut und inzwischen zum Portfolio herkömmlicher europäischer Banken gehört ${ }^{17}$; oder dass unter den 56 Staaten, die der Organisation Islamischer Staaten angehören, der

13 Ebd. In Deutschland werden solche Daten nicht erhoben.

14 Youssef Courbage/Emmanuel TodD, Die unaufhaltsame Revolution. Wie die Werte der Moderne die islamische Welt verändern, München 2008.

15 Siehe etwa Mark Tessler, Islam and Democracy in the Middle East. The Impact of Religious Orientations on Attitudes Toward Democracy in Four Arab Countries, in: Comparative Politics 34 (2002), S. 337-354; Amaney Jamal/ders., The Democracy Barometers. Attitudes in the Arab World, in: Journal of Democracy 19 (2008), S. 97-110.

16 Dazu Reinhard Schulze, Die dritte Unterscheidung. Islam, Religion und Säkularität, in: Wolfgang Lienemann / Walter Dietrich (Hg.), Religionen - Wahrheitsansprüche - Konflikte. Theologische Perspektiven, Zürich 2010, S. 147-205.

17 Thomas Thiel, Die zinslose Ökonomie - Eine sichere Bank?, in: FAZ (01.05.2012), URL: <https://www.faz.net/aktuell/feuilleton/islamic-banking-die-zinslose-oekonomie-11736495.html?printPagedArticle=true\#pageIndex_0> (14.12.2016); Gian 
Islam nur in etwa der Hälfte als Staatsreligion gilt und die schariatrechtlich begründeten hadd-Strafen für religiöse Grenzüberschreitungen - etwa das Auspeitschen bei unehelichem Geschlechtsverkehr oder Amputationen bei Diebstahl - nur in einem Dutzend von ihnen im Strafrecht verankert sind. Mit anderen Worten: Vielerorts koexistieren säkulare und islamische Logiken, um politisches, ökonomisches und rechtliches Handeln zu begründen.

Angesichts der Statistiken zur Religiosität und zum Lebensstil sowie des komplizierten Beziehungsgeflechts von Religion zu Politik, Recht, Wirtschaft und Gesellschaft stellt sich daher die Frage, warum Muslime generell als Sonderfall in der Säkularisierungsdebatte behandelt werden. Im folgenden Beitrag argumentiere ich gegen diese Sonderbehandlung, unabhängig davon, ob die Säkularisierungsthese modernisierungstheoretisch oder funktionalistisch begründet wird, ob ihre universale Anwendbarkeit kritisch hinterfragt oder postkolonial dekonstruiert wird. Ich schlage vielmehr vor, das Säkulare als Teil eines wirkmächtigen Bezeichnungs- und Klassifikationsschemas $\mathrm{zu}$ verstehen, das notwendigerweise »Religion « - also auch »Islam « in seiner Varianzbreite - mitproduziert ${ }^{18}$. Wenn somit das Säkulare und Religiöse untrennbar aneinandergekoppelt sind, so lässt sich die Politisierung des Religiösen ebenso wie die religiöse Aufladung des Politischen als Folge der ambivalenten Transformationsprozesse verstehen, die konstitutiv für die Ausbildung des »immanent frame ${ }^{19}$ in der säkularen Moderne waren. Zum anderen verschiebt sich die Perspektive weg von der Frage, ob ein Begriff wie Säkularisierung religiöse, soziale und politische Phänomene - und deren Entflechtung, Trennung oder Koppelung - analytisch präzise erfasst, hin zu der Frage, wie Akteure das Schema »Säkular versus Religiös« bei Interessenskollisionen nutzen, um Claims abzustecken, zu artikulieren und zu entscheiden $^{20}$. In den Blick kommt daher derjenige Klassifikationsprozess, durch den Handlungen, Institutionen sowie Lebens- und Denkweisen als »religiös« oder »säkular« eingeteilt werden. Hinterfragt wird jedoch, warum ein solcher Klassifikationsprozess auch eine eigenständige Kategorie des »Islamischen « erzeugt, die entweder dem »Religiösen «, jedoch unterschieden vom Christentum, zugerechnet wird oder gar etwas Drittes bildet, das sich prinzipiell gegen die religiös-säkulare Klassifikation sperrt.

Maria Piccinelli, Development and Perspectives of Islamic Economics (Banking and Finance) in the West, in: Roberto Toтtoli (Hg.), Routledge Handbook of Islam in the West, London u.a. 2015, S. 411-425.

18 Hierzu Russell T. McCutcheon, »They Licked the Platter Clean«. On the Co-Dependency of the Religious and the Secular, in: Method and Theory in the Study of Religion 19 (2007), S. 173-199.

19 Nach Charles Taylor, A Secular Age, Cambridge 2007.

20 McCutcheon, »They Licked the Platter Clean«, S. 178. 
Im Folgenden untersuche ich das Verhältnis des Islams zum religiössäkularen Schema in drei Schritten, indem ich zwischen »Säkularisierung «, »Säkularität« und »Säkularismus « unterscheide. Zunächst gebe ich einen Überblick über die Säkularisierungsdebatte und ihre Bezüge zum Islam; darauf aufbauend beschäftige ich mich zuerst mit der Entstehung säkularer Ordnungen in Nationalstaatsbildungsprozessen und dann mit den rezenten Diskussionen zum Thema »Islam in Europa «, in denen säkulare Normen und säkularistische Positionen verhandelt werden. Der Begriff »Säkularisierung « soll hierbei denjenigen gesellschaftlichen und intellektuellen Differenzierungsprozess bezeichnen, durch den Religion überhaupt erst als Religion von Politik und Kultur abgrenzbar wird und religiöse Autoritätsund Geltungsansprüche in einen Teilbereich gesellschaftlicher Ordnung verwiesen werden, was sich in Europa in ganz unterschiedlichen Arrangements (staatskirchlich, religionsneutral, laizistisch, atheistisch) niedergeschlagen hat. Der Begriff "Säkularität« bezieht sich im Folgenden primär auf staatliche Arrangements, also säkulare Ordnungen, in denen die Toleranz für plurale Lebensentwürfe und der Platz für religiöse Institutionen in der Gesellschaft ausgehandelt und im besten Fall auch garantiert werden. Unter "Säkularismus" werden Weltanschauungen zusammengefasst, die klare Trennlinien zwischen Religion einerseits und Politik sowie Staat andererseits befürworten oder zu etablieren versuchen und von religiösen Fragestellungen in politischen und gesellschaftlichen Debatten weitestgehend absehen.

Der Überblick über die Theoriedebatte zur Säkularisierungsthese soll die offen oder verdeckt verhandelten Klassifikationsprobleme in Bezug auf den Islam deutlich machen. Die Beschäftigung mit Nationsbildungsprozessen dient als Gegenargument zu der Annahme, Nationsbildungsprozesse seien als rein säkularisierende Phänomene aufzufassen und säkulare Ordnungen seien mehr oder weniger gewaltsam gegen Religion und speziell gegen den Islam durchgesetzt worden. Vielmehr wird gezeigt, dass für Prozesse der Nationsbildung ein Homogenisierungsstreben grundlegend ist, in dem einerseits Religionen eine Rolle spielen, andererseits religiöser Pluralismus wie er für multireligiöse und multiethnische Gesellschaften typisch ist - oftmals als Problem erscheint. Anhand ausgewählter Beispiele von Nationsbildungsprozessen in mehrheitlich islamischen Gesellschaften wird dargelegt, dass die Kategorien »Nation«, »Ethnie«, »Sprache« und »Religion« in einem spannungsreichen und dynamischen Verhältnis zueinanderstanden, was bis in die Gegenwart nachwirkt. Anhand der rezenten Debatten in Westeuropa wird sodann dargestellt, dass Verächter, Kritiker und Verteidiger staatlicher Säkularität, die von einer Unverträglichkeit zwischen Islam und säkularer Ordnung ausgehen, ihre Argumente oftmals auf unzulängliche Vorstellungen von Islam und Säkularität gründen. Demgegenüber wird die Integration 
islamischer Religionsgemeinschaften in säkulare Rechtsordnungen als ein zäher Verhandlungsprozess mit durchaus gegenläufigen Tendenzen auf verschiedenen Ebenen beschrieben.

\section{Islam und Säkularisierungsthese}

Die These eines universal gültigen Säkularisierungsprozesses - also die Annahme, dass Religion im privaten wie öffentlichen Bereich weltweit zunehmend an Bedeutung verliere, - haben Geistes- und Sozialwissenschaftler seit einigen Jahren einer umfassenden Revision unterzogen, nicht zuletzt seit der öffentlich zelebrierten Konversion des US-amerikanischen Soziologen Peter L. Berger in diesem Punkte ${ }^{21}$. Die starke Variante der Säkularisierungsthese, die von einem allgemeinen Bedeutungsverfall des Religiösen ausging, hat dadurch an Überzeugungskraft verloren ${ }^{22}$, so dass heute auch Anhänger der Säkularisierungsthese wie Karel Dobbelaere Säkularisierung primär als funktionale Differenzierung definieren und den schwindenden Einfluss religiöser Institutionen sowie abnehmende individuelle Religiosität nur als sekundären Effekt ansehen ${ }^{23}$. Während diese kritische Überprüfung zu einer produktiven Verunsicherung des Selbstbildes vom säkularen Westen beigetragen hat, war die Debatte für islamische Kontexte weniger produktiv. Sie führte nicht zur Verunsicherung herkömmlicher Differenz-Narrative, sondern verharrte weiter in bipolarer Stagnation und verstärkt diese teilweise sogar. Auch wenn sich daher in der Säkularismusdebatte manche, vormals als schroff wahrgenommenen Gegensätze abgeschwächt haben - wie etwa derjenige zwischen dem säkularen Europa und den religiösen USA oder derjenige zwischen dem Westen und dem Rest der Welt -, so hat sich in Bezug auf

21 Berger vertrat die Säkularisierungsthese in den 1960er und 1970er Jahren, erklärte aber seit den 1990ern, dass sie eigentlich schon Ende der 1970er widerlegt war und niemals viel empirische Substanz besaß. Siehe Peter L. Berger, The Sacred Canopy. Elements of a Sociological Theory of Religion, New York, NY 1967; ders., The Heretical Imperative. Contemporary Possibilities of Religious Affirmation, New York, NY 1979; ders., Sociology. A Disinvitation?, in: Society 30 (1992), S. 12-18; ders., Secularism in retreat, in: The National Interest 46 (1996), S. 3-12. Siehe auch Charles T. Mathewes, An Interview with Peter Berger, in: Hedgehog Review 8 (2006), S. 152-161, URL: <http://www.iasc-culture.org/THR/archives/ AfterSecularization/8.12PBerger.pdf> (30.11.2016). Allgemein zur Debatte um die Säkularisierungsthese siehe William H. Swatos, Jr./Kevin J. Christiano, Secularization Theory. The Course of a Concept, in: Sociology of Religion 60 (1999), S. 209-228.

22 Siehe etwa Rodney Stark, Secularization R.I.P., in: Sociology of Religion 60 (1999), S. 249-273; José Casanova, Public Religions in the Modern World, Chicago, IL 1994.

23 Karel Dobbelaere, Towards an Integrated Perspective of the Process Related to the Descriptive Concept of Secularization, in: Sociology of Religion 60 (1999), S. 229-247. 
den angeblich säkularisierungsresistenten Islam wenig geändert. Geändert hat sich lediglich die Art und Weise, wie der Islam als Kontrastfolie beschrieben wurde. Zwar bildet der Islam ein zentrales Element für das Narrativ von der »Rückkehr der Religion" und mithin auch für Umformulierungen der Säkularisierungsthese - in Bergers Fall etwa weg von der »Säkularisierung" hin zur »De-Säkularisierung« und »Pluralisierung« des Religiösen. Der Islam selbst jedoch bleibt ein theoretischer und praktischer Fremdkörper in diesen Narrativen. Vielmehr wird er als »dramatic challenge « für europäische Gesellschaften gesehen, und muslimische Versuche, Tradition und Moderne $\mathrm{zu}$ verbinden, erscheinen als $» \mathrm{a}$ question of life-and-death importance ${ }^{24}$. Diese mit dramatischem Effekt vorgetragene Sonderstellung des Islams ist beileibe kein Einzelfall. Aus dem Umstand, dass zumindest der sunnitische Zweig des Islams über keine zentrale kirchenartige Instanz verfügt, haben sowohl muslimische als auch nicht-muslimische Autoren über die Jahrzehnte und intellektuellen Moden hinweg gefolgert, dass der Islam entweder keine Trennung weltlicher und spiritueller Macht »kenne« oder ihrer nicht bedürfe, oder sie haben die Nützlichkeit des Vergleichs mit dem Christentum oder die Anwendbarkeit des Konzepts "Säkularisierung" gänzlich in Abrede gestellt.

Vier wesentliche Problemlagen, die heute im Zusammenhang mit säkularen Gesellschaftsordnungen diskutiert werden, treffen jedoch ebenfalls auf den Islam als Religion, auf Gesellschaften mit muslimischer Mehrheitsbevölkerung und auf Muslime als Minderheiten zu. Erstens lassen sich Prozesse funktionaler Differenzierung auch in "islamischen « Staaten wie Saudi-Arabien, Pakistan oder Iran beschreiben, selbst wenn diese sich als Gegenentwurf zum westlichen Staatsmodell verstehen. Die Ausdifferenzierung sozialer Felder, darunter eines religiösen, wirft generell die Frage nach dem Ort des Religiösen in der Gesellschaft neu auf; einerseits werden die Ansprüche religiöser Institutionen begrenzt und von der Aufgabe gesamtgesellschaftlicher Integration entlastet, andererseits aber vervielfältigen sich religiöse und religionsartige Phänomene und diffundierten auch in nicht-religiöse Bereiche $^{25}$. Zweitens stellt sich die Frage, inwiefern Religion Teil des privaten Bereichs oder des öffentlichen Raums ist und ob sich beide Sphären trennscharf voneinander scheiden lassen ${ }^{26}$. Drittens steht zur Debatte, welche Rolle religiöse Moralvorstellungen für die persönliche Lebensführung und

24 Siehe Mathewes, An Interview with Peter Berger.

25 Hierzu Gaetano Romano, Religion und soziale Ordnung - wie viel Multikulturalität braucht die Gesellschaft?, in: Martin Baumann/Samuel M. Behloul (Hg.), Religiöser Pluralismus. Empirische Studien und analytische Perspektiven, Bielefeld 2005, S. 223-240.

26 Nilüfer Göle / Ludwig Ammann (Hg.), Islam in Sicht. Der Auftritt von Muslimen im öffentlichen Raum, Bielefeld 2004. 
Entscheidungsfindung des Einzelnen haben ${ }^{27}$. Und viertens sind im »säkularen Zeitalter« die Menschen grundsätzlich vor die Wahl gestellt, zu glauben oder nicht zu glauben, wobei sie für keine Option Selbstverständlichkeit reklamieren können, weil beide begründungspflichtig geworden $\operatorname{sind}^{28}$.

Wenn in Bezug auf den Islam dennoch eine Differenzbehauptung dominiert, so speist sich diese aus verschiedenen Quellen. Die vier wichtigsten wissenschaftlichen Herangehensweisen, mit denen der Gegensatz von Islam und Säkularisierung behauptet wird, sollen hier kurz rekapituliert werden: Für Vertreter der Modernisierungstheorie und Säkularisierungsthese war bis in die 1970er Jahre hinein ausgemacht, dass auch im Nahen und Mittleren Osten die Bindekraft der Religion nachlasse und moderne demokratische Gesellschaften im Entstehen seien. Auch wenn der Gegensatz von Islam und Säkularismus vorausgesetzt wurde, so wurde er doch als einer verstanden, der im Schwinden begriffen sei. Man verwies auf die säkularen Modernisierer von Mustafa Kemal in der Türkei bis zu Gamal 'Abd al-Nasser in Ägypten ${ }^{29}$.

Die Iranische Revolution 1978/79, die Ermordung des ägyptischen Präsidenten Anwar al-Sadat 1981 und der Aufschwung islamischer Bewegungen, der vielerorts zu verschärften Debatten über die Islamisierung von Staat, Gesellschaft und Recht führte, erschütterten nicht nur die modernisierungstheoretischen Gewissheiten, sondern trugen maßgeblich dazu bei, über eine Rückkehr der Religion(en) und des Islams zu spekulieren ${ }^{30}$. Wenn nun vermehrt Zweifel an der Gültigkeit der Säkularisierungsthese für nicht-europäische Gesellschaften angemeldet wurden, so wandte sich die wissenschaftliche Kritik einerseits gegen die Art und Weise einer autoritären Säkularisierung, wie sie im Nahen und Mittleren Osten praktiziert worden sein, und andererseits gegen den Wert der Säkularisierungsthese an sich. Daraus haben sich drei Formen der Säkularisierungskritik ergeben, die den Gegensatz zwischen Islam und Säkularisierung eher noch stärker akzentuierten, als es Modernisierungstheoretiker zu tun pflegten.

Zum einen wird nun, wenn neuerdings wieder darüber diskutiert wird, wie sehr auch in Europa und den USA Religion und Politik miteinander verwoben sind, die Differenz des Islams darauf zurückgeführt, dass dort Religion

27 Siehe am Beispiel bioethischer Fragen Manfred SING, Sacred Law Reconsidered. The Structural Similarity of Islamic and Western Bioethical Discourses, in: JRE 36 (2008), S. 97-121.

28 TAYLOR, Secular Age.

29 Siehe zum Beispiel Manfred Halpern, The Politics of Social Change in the Middle East and North Africa, Princeton, NJ 1963; Niyazi Berkes, The Development of Secularism in Turkey, Montreal 1964.

30 James Gelvin, Secularism and Religion in the Arab Middle East. Reinventing Islam in a World of Nation-States, in: Derek R. Peterson / Darren R. Walhof (Hg.), The Invention of Religion. Rethinking Belief in Politics and History, New Brunswick u.a. 2002, S. 115-130. 
und Politik mit Gewalt getrennt worden seien. Wiederum wird auf die erste Riege der Modernisierer verwiesen, nun aber argumentiert, dass viele Muslime Säkularismus »als Ideologie autoritärer Regierungen« wahrnehmen, »die ihn gegen die eigene Gesellschaft durchsetzen « ${ }^{31}$, so die Formulierung der Islamwissenschaftlerin Gudrun Krämer. Säkularisierung werde mithin als Mittel der »Kolonisierung und Entfremdung « ${ }^{32}$ verstanden; diese Ablehnung »des säkularen Prinzips « müsse erstaunen, da sich doch längst »reale Prozesse der Säkularisierung ${ }^{33}$ in Politik, Recht, Wirtschaft, Bildung und Kultur finden ließen. Der Publizist Navid Kermani erklärte 2015 in seiner Rede zur Verleihung des Friedenspreises des Deutschen Buchhandels in diesem Sinne, das Problem des Islams sei »vielleicht [...] weniger die Tradition als vielmehr der fast schon vollständige Bruch mit dieser Tradition, der Verlust des kulturellen Gedächtnisses, seine zivilisatorische Amnesie ${ }^{34}$. »Alle Völker des Orients« hätten »durch den Kolonialismus und durch laizistische Diktaturen eine brutale, von oben verordnete Modernisierung erlebt $\aleph^{35}$. Mit Verweis darauf, dass der Shah 1936 Soldaten ausschwärmen ließ, um Frauen das Kopftuch vom Kopf zu reißen, behauptete Kermani: „Anders als in Europa, wo die Moderne bei allen Rückschlägen und Verbrechen doch als ein Prozess der Emanzipation erlebt werden konnte und sich über viele Jahrzehnte und Jahrhunderte vollzog, war sie im Nahen Osten wesentlich eine Gewalterfahrung. Die Moderne wurde nicht mit Freiheit, sondern mit Ausbeutung und Despotie assoziiert ${ }^{36}$.

Nach dieser Sichtweise bedeutete die Säkularisierung weniger einen Kulturkonflikt zwischen Europa und dem Orient, als vielmehr eine selbstzerstörerische Transformation, in der zuerst der Islam um seine vielfältige Kultur gebracht wurde, worauf dessen radikale Vertreter sich dann mangels besseren Wissens gegen den Westen wandten. Im Grunde bekämpft sich auf diese Weise die Moderne selbst. Eine gewaltsame Säkularisierung wird so auch für ihre Gegner in die Verantwortung genommen, wie in den Worten der Religionswissenschaftlerin Karen Armstrong, nach denen Fundamentalismus in »symbiotischem Verhältnis « mit der Säkularisierung lebe

31 Gudrun KräMER, Der rechte Glaube und der Rechtsstaat, in: Berliner Zeitung (24.09.2013), URL: <http://www.berliner-zeitung.de/islam-der-rechte-glaube-undder-rechtsstaat-3834560> (22.12.2016); dies., Arabische Welt will keinen Staat ohne Religion (September 2013), URL: <https://www.uni-muenster.de/Religion-undPolitik/aktuelles/2013/sep/PM_Religion_und_Staat_im_Islam.html $>$ (22.12.2016).

32 Dies., Zum Verhältnis von Religion, Recht und Politik. Säkularisierung im Islam, in: Hans Joas / Klaus WiegandT (Hg.), Säkularisierung und die Weltreligionen, Frankfurt a.M. 2007, S. 172-193, hier S. 177.

33 KräMer, Arabische Welt.

34 Navid Kermani, Über die Grenzen - Jacques Mourad und die Liebe in Syrien, URL: $<$ http://www.friedenspreis-des-deutschen-buchhandels.de/819312> (27.12.2016).

35 Ebd.

36 Ebd. 
und umso extremer werde, je grausamer und gewalttätiger diese auftrete: $»$ When we look with horror upon the travesty of Isis, we would be wise to acknowledge that its barbaric violence may be, at least in part, the offspring of policies guided by our disdain $\aleph^{37}$. Während damit die Interventionen westlicher Staaten zu säkularen Handlungen umgedeutet werden, erscheinen die Vergewaltigung, Versklavung und Tötung Andersgläubiger durch den »Islamischen Staat« als bloße Reaktion darauf, als fundamentalistische, weil anti-säkulare Praxis.

Die zweite Form der jüngeren Säkularisierungskritik beschreibt Säkularismus einerseits als einen für nicht-christliche Religionen problematischen Kulturimport und behauptet andererseits, die Präsenz von Muslimen in Europa bringe eine Krise europäischer Identität und Säkularität sowie einen latent vorhandenen Rassismus zum Vorschein ${ }^{38}$. Diese oftmals als postkolonial apostrophierte Säkularisierungskritik argumentiert, dass der sich selbst als säkular verstehende Westen nicht-westliche Kulturen zu nicht-säkularen Religionen umgeschrieben und dadurch als defizitär ausgewiesen habe. Der Verweis auf die europäischen, christlichen und nationalstaatlichen Wurzeln des Säkularismus soll dabei zeigen, dass das Begriffspaar »religiös / säkular«, dessen beide Seiten zugleich voneinander getrennt als auch aufeinander bezogen seien, kein neutrales, sondern ein sehr voraussetzungsvolles Konstrukt sei. Saba Mahmood argumentiert etwa, dass sich die Anwendung säkularer Prinzipien im Nahen und Mittleren Osten nachteilig auf religiöse Minderheiten ausgewirkt habe, weil es dadurch möglich oder zumindest einfacher geworden sei, religiöse Minderheiten zu definieren, zu kontrollieren und bei Bedarf auszugrenzen ${ }^{39}$. Der Anthropologe Talal Asad schreibt: »If the secularization thesis no longer carries the conviction it once did, this is because the categories of politics and religion turn out to implicate each other more profoundly than we thought, a discovery that has accompanied our growing understanding of the powers of the modern nation-state $~^{40}$.

$\mathrm{Da}$ in solchen postkolonialen Kritiken ein universaler Religionsbegriff ebenso wie ein universaler Säkularisierungsprozess angezweifelt wird, tritt der Gegensatz zwischen Islam und säkularer Welt in anderem Gewande

37 Karen Armstrong, The Myth of Religious Violence, in: The Guardian (25.09.2014), URL: <https://www.theguardian.com/world/2014/sep/25/-sp-karen-armstrongreligious-violence-myth-secular $>$ (27.12.2016).

38 Siehe etwa Luca Mavelli, Europe's Identity Crisis, Islam in Europe, and the Crisis of European Secularity, in: Roberto Toтtoli (Hg.), Routledge Handbook of Islam in the West, London/New York 2015, S. 185-197.

39 Siehe Saba Manmood, Religious Difference in a Secular Age. A Minority Report, Princeton, NJ 2016.

40 Talal AsAD, Formations of the Secular. Christianity, Islam, Modernity, Stanford, CA 2003, S. 200. 
neu zu Tage $e^{41}$. Diese Problematik trifft auch auf Talal Asads Interventionen $\mathrm{zu}$, weil in ihnen die permanente Gegenüberstellung von Islam und Westen einen konstitutiven Platz einnimmt ${ }^{42}$. So kritisiert er beispielsweise die moderne Rechtsentwicklung in Ägypten als eine teils von außen induzierte, teils von innen betriebene Flickschusterei, die die islamische Tradition grundsätzlich deformiert habe ${ }^{43}$. In dieser Argumentation dient das säkulare Europa nicht nur als äußerer Bezugspunkt; vielmehr nimmt die Stellung von Muslimen in Europa einen zentralen Stellenwert ein, weil Asad zeigen will, dass und wie sehr der Säkularisierung eine Tiefengrammatik zu eigen sei, die auf einfachen Gegensätzen zu islamischen Praktiken basiere, Kulturkämpfe gegen Muslime ermögliche und als Herrschaftsinstrument gegenüber Muslimen eingesetzt werde: »Muslims are clearly present in secular Europe and yet in an important sense absent from it ${ }^{44}$. Auch verweist Asad darauf, dass in den Säkularisierungsnarrativen weitgehend ausgeblendet werde, dass die Begegnung mit dem nicht-europäischen Anderen säkulare Ordnungsvorstellungen überhaupt erst denkmöglich gemacht habe und dass sich in nichteuropäischen Kulturen ebenfalls nichtreligiöse Diskurse ausdifferenziert hätten. Er führt diesen Gedanken aber nicht konsequent aus - wahrscheinlich deshalb, weil er sich den Begriff des Säkularen nicht über eine islamische Vorgeschichte aneignen möchte, in der, wie sich zeigen ließe, Säkularität und Säkularismus in nuce analog zum Christentum angelegt wären ${ }^{45}$.

Die dritte Form der Säkularisierungskritik versteht sich ebenfalls als Kritik an Prozessen der Säkularisierung, Modernisierung oder Verwestlichung, fokussiert aber auf die Globalisierung des Religionsbegriffs. In einer »Protestantisierung « der Weltreligionen ${ }^{46}$ wird nun die Ursache dafür gesehen, dass es zwar zu einer globalen Angleichung im Religionsverständnis, nicht aber zu einem Bedeutungsverlust des Religiösen gekommen sei. Diese

41 Siehe etwa die Kritik bei Arvind-Pal S. MAndair / Markus Dressler, Introduction. Modernity, Religion-Making, and the Postsecular, in: Markus Dressler/ArvindPal S. Mandair (Hg.), Secularism and Religion-Making, Oxford u.a. 2011, S. 3-36, hier S. 18.

42 Siehe Sindre Bangstad, Contesting Secularism/s. Secularism and Islam in the Work of Talal Asad, in: Anthropological Theory 9 (2009), S. 188-208, hier S. 189, 193-195, 197, 201.

43 AsAd, Formations, S. 205-256, Kapitel: "reconfigurations of law and ethics in colonial Egypt «. Freilich stellt sich bei dieser Argumentation die Frage, ob sich dies nicht von der Entwicklung jeder Rechtstradition sagen ließe, die den Bezug zu ihren (imaginären) Quellen herzustellen sucht, auch wenn sie sich davon entfernt.

44 Ebd., S. 159.

45 Walter Roтнholz, Rudimente einer Theorie der Säkularisierung im Islam, in: ZRGG 49 (1997), S. 244 und 253.

46 Reinhard Schulze, Islam und Judentum im Angesicht der Protestantisierung der Religionen im 19. Jahrhundert, in: Lothar GALL/Dietmar Willoweit (Hg.), Judaism, Christianity, and Islam in the Course of History. Exchange and Conflicts, München 2011, S. 287-306. 
These wertet einen wenig beachteten religiösen Transfer- und Übersetzungsprozess gegenüber den Globalisierungsprozessen säkularer Art auf. Angesichts der kolonialen und globalen Expansion Europas hätten sich Muslime in ihren Reformbestrebungen (selektiv) eine "protestantische Schablone « ${ }^{47}$ zu eigen gemacht - etwa Verinnerlichung des Glaubens, Schriftprinzip und Geschichtlichkeit der Offenbarung. Obgleich dieser Theoriestrang die Vergleichbarkeit religiöser Erneuerungsbewegungen herausstreicht und islamische Radikalität nicht monokausal auf islamische Wurzeln zurückführt, sondern deren "Protestantisierung « hervorhebt, bleibt er in der Konsequenz ambivalent. Zum einen simplifiziert er Transformationsprozesse auf eine Schablone, die ein monolithisches »Protestantisches" mitdenkt und Beeinflussung als Einbahnstraße versteht. "Under conditions of globalization, world religions do not only draw upon their own traditions but also increasingly upon one another «, schreibt indes José Casanova und weiter: »Inter-civilizational encounters, cultural imitations and borrowings, diasporic diffusions, hybridity, creolization, and transcultural hyphenations are all part and parcel of the global present $~^{48}$. Zum anderen kann dieser Ansatz als Erklärungsmuster gleichwohl für eine angeblich ausgeprägte Tendenz des Islams zur Radikalisierung verwendet werden. Da der Protestantismus mit Selbstreflexion sowie der Distanzierung von der eigenen christlichen Tradition verknüpft ist, stellt sich eine alte Frage neu, die bereits Anfang des 20. Jahrhunderts der Religionsphilosoph Ernst Troeltsch abschlägig beantwortete, nämlich ob Muslime fähig seien, nicht nur den Bezug zu ihren Quellen herzustellen, sondern auch über diesen hinauszugehen ${ }^{49}$.

Die drei Formen der Säkularisierungskritik machen deutlich, dass Fragen nach dem Verhältnis von Religion und Politik und nach der gesellschaftlichen Relevanz des Religiösen in sinnvoller Weise kaum losgelöst von anderen Problemstellungen wie Antikolonialismus, Nationalstaatsbildung, Identitätskonstruktion und Herrschaftsweise behandelt werden können. Paradoxerweise gingen Entkolonialisierung und Nationalstaatsbildung im 20. Jahrhundert mit einer zunehmend stärkeren ökonomischen und politischen Einbindung von islamischen Gesellschaften in das globale System

47 Johann Büssow, Re-imagining Islam in the Period of the First Modern Globalization. Muhammad 'Abduh and His Theology of Unity, in: Liat Kozma (Hg.), A Global Middle East. Mobility, Materiality and Culture in the Modern Age, 1880-1940, London 2015, S. 273-320.

48 José Casanova, Rethinking Secularization. A Global Comparative Perspective, in: Hedgehog Review 8 (2006), S. 7-22, hier S. 17, URL: <https://www.uef.fi/documents/661547/931509/03_Casanova_Secularization.pdf/c30fd487-a56c-4478-9eb3$5 \mathrm{~d} 336626 \mathrm{bc0b}>(05.04 .2019)$.

49 Zur Debatte zwischen Troeltsch und Carl Heinrich Becker siehe Cornelia Essner / Gerd Winkelhane, Carl Heinrich Becker (1876-1933), Orientalist und Kulturpolitiker, in: WI 27 (1988), S. 154-177. 
einher. In den Säkularisierungskritiken wird die Widersprüchlichkeit dieser Transformationen oft nicht deutlich genug hervorgehoben, was an folgenden Tendenzen augenfällig wird:

1. So wird das Säkularisierungspotenzial im Islam oftmals anhand des Auftretens fundamentalistischer Bewegungen vermessen, obwohl weder Fundamentalismus noch politische Gewalt ein Proprium des Islams sind.

2. Die praktische Säkularisierung wird dem idealisierten Bild eines säkularen Europa gegenübergestellt, obwohl es innerhalb und zwischen europäischen Gesellschaften erhebliche Unterschiede gibt, was die individuelle, institutionelle und soziale Rolle von Religion anbelangt.

3. Säkularisierung wird als etwas von außen Kommendes, den Islam Deformierendes vorgestellt, obwohl sich in islamischen Herrschaftsbereichen ab etwa dem 10. Jahrhundert n. Chr. faktisch eine Differenzierung zwischen der politischen und religiösen Sphäre feststellen lässt.

4. Unklar bleibt, ob Säkularisierung Ergebnis eines gesellschaftlichen Prozesses oder politischen Handelns ist. Der Prozesscharakter der Säkularisierung bildet jedenfalls einen eigentümlichen Gegensatz zu der anscheinend besonders ausgeprägten säkularisierenden oder de-säkularisierenden Handlungsmacht, wie sie muslimischen Akteuren zugeschrieben wird.

Besonders der letztgenannte Punkt hat erhebliches Irritationspotenzial. So fordern islamische Denker und Bewegungen seit knapp 100 Jahren und verstärkt seit den 1970er Jahren eine Islamisierung von Politik, Recht und Wirtschaft in Staaten mit islamischer Mehrheitsbevölkerung. Bereits die Forderung zeigt jedoch, dass den Islamisierungsbefürwortern die herrschenden Verhältnisse verweltlicht erscheinen - während ihre intellektuellen Opponenten diese für nicht säkular genug halten ${ }^{50}$. Zudem kann die paradoxe Obsession von Islamisierungsbefürwortern mit dem modernen Staat, der eine Islamisierung legalistisch - also die Gesetze Gottes gegen den eigenen Souveränitätsanspruch - durchsetzen soll, als Ausdruck eines kompletten Selbstwiderspruchs ${ }^{51}$ oder auch einer »unbewussten Säkularisierung « ${ }^{52}$ gesehen werden. Anders gesagt: auch wenn seit den 1970er Jahren verstärkt von einer »Re-Islamisierung« des öffentlichen Raumes gesprochen wird, was an islamischen Zeichen und Symbolen und der Betonung eines islamischen

50 Siehe Alexander Flores, Die innerislamische Diskussion zu Säkularismus, Demokratie und Menschenrechten, in: Werner Ende / Udo Steinbach (Hg.), Der Islam in der Gegenwart, München 2005, S. 620-634; ders., Säkularismus und Islam in Ägypten. Die Debatte der 1980er Jahre, Berlin u.a. 2012.

51 Wael HallaQ, The Impossible State. Islam, Politics, and Modernity's Moral Predicament, New York, NY 2013.

52 Rothholz, Rudimente, S. 251f. 
Lebensstils festgemacht wird, so stellt sich angesichts fehlender statistischer Erhebungen über längere Zeiträume hinweg doch die Frage, ob damit jenseits eines Anstiegs demonstrierter Frömmigkeit und religiös gewandeter Politik auch ein abnehmender Grad der zuvor erreichten Säkularisierung gemeint ist, also eine De-Säkularisierung.

Des Weiteren ist in Staaten mit muslimischer Mehrheit die Religionsfreiheit oftmals eingeschränkt, insbesondere was den Wechsel weg vom Islam und die negative Religionsfreiheit betrifft; zudem sind religiöse Minderheiten meist benachteiligt ${ }^{53}$. Beides stellt zwar einen schwerwiegenden staatlichen Eingriff in persönliche Freiheiten dar. Dieser Eingriff ist aber abgesehen davon, dass er auch dem Säkularismus selbst angelastet wurde $(\text { siehe oben })^{54}$ - wenig aussagekräftig für soziale Säkularisierungsprozesse oder allgemein für »Säkularisierung im Islam《; genau genommen illustriert er, anders als häufig argumentiert wird, weder den »Dominanzanspruch des Islam $\aleph^{55}$ noch die »Bindekraft religiöser Normen und religiöser Zugehörigkeit « ${ }^{56}$, sondern lediglich ein Streben nach politischer Legitimation und sozialer Homogenisierung, das in Teilen der betroffenen Gesellschaften selbst auf Kritik stößt. Auch das im selben Zusammenhang oft vorgetragene Argument, der Islam sei mit seinen alles wenn nicht überragenden, so doch übertönenden Moscheen »eine öffentliche Religion par excellence « ${ }^{57}$, klammert die durch Regierungshandeln bewirkten säkularen Transformationen im Dienste des Islams aus. So pflastert die saudische Regierung seit Jahren Mekka mit Wolkenkratzern, Shopping-Malls und Luxushotels für die jährliche Pilgerfahrt zu und geht dabei nicht nur rücksichtslos mit dem archäologischen Erbe des Frühislams um, sondern hat auch den Charakter der Stadt so verändert, dass Kritiker sagen, »naked capitalism has usurped spirituality as the city's raison d'être «"

Gegen die direkten oder indirekten Differenzbehauptungen zum Islam ist daher einzuwenden, dass Säkularität und Säkularisierung weder aus der islamischen Tradition heraus gänzlich unverständlich sind, noch völlig unerwartet über die Muslime hereingebrochen sind. Zwar säkularisierte sich die kemalistische Türkei in atemberaubendem Tempo; doch setzte sie damit lediglich den tiefgreifenden Veränderungsprozess fort, der im Osmanischen

53 Siehe etwa Martin Forstner, Das Menschenrecht der Religionsfreiheit und des Religionswechsels als Problem der islamischen Staaten, in: Kanon 1 (1991), S. 105-186.

54 Mahmood, Religious Difference.

55 Siehe Krämer, Zum Verhältnis von Religion, Recht und Politik, S. 191.

56 Ebd., S. 189.

57 Ebd., S. 190.

58 Siehe etwa Jerome TAYLOR, Mecca for the Rich. Islam's Holiest Site »Turning into Vegas", in: The Independent (24.09.2011), URL: <http://www.independent.co.uk/ news/world/middle-east/mecca-for-the-rich-islams-holiest-site-turning-into-vegas2360114.html> (29.12.2016). 
Reich seit der Tanzimat-Periode (1839-1876) begonnen hatte. Auch erklären die christlichen Ursprünge des Säkularismusbegriffs oder die protestantischen des Religionsbegriffs weder die globale Relevanz der Säkularisierung noch die praktischen Probleme und Differenzen in der globalen Anwendung $^{59}$, zumal sich Säkularisierung ja auch gegen das christliche Establishment richtete. Die schärfste anti-religiöse Variante des Säkularismus, der militante Atheismus in der Sowjetunion, traf Moschee- genauso wie Kirchengemeinden $^{60}$. Während Protestanten und Katholiken im Bolschewismus eine Apotheose des Säkularismus und Materialismus und damit eine gottlose Bedrohung der christlichen Sozial- und Moralordnung sahen ${ }^{61}$, war der Islam im Vergleich dazu konzilianter gegenüber dem Kommunismus und bildete keine aktive Opposition aus - trotz vergleichbarer Verheerungen $^{62}$. Das Verhältnis zwischen Islam und Kommunismus wurde vielmehr als "a growing process of give and take ${ }^{63}$ beschrieben, denn Zentralasien wurde Mitte des 20. Jahrhunderts zum technologisch am weitesten entwickelten Teil der islamischen Welt ${ }^{64}$. Kommunistische Parteimitglieder aus Zentralasien konnten dennoch als selbsterklärte, nämlich »ethnisch" markierte Muslime auftreten ${ }^{65}$. Im sowjetischen Kontext, so ließe sich folgern, war das »Islamische« leichter zu integrieren als das Christliche.

Daher lässt sich von einer »Familienähnlichkeit« (Wittgenstein) der Probleme, Handlungen und Konflikte sprechen, die sich Muslimen wie Nichtmuslimen im Umgang mit dem »säkularen Prinzip« stellen. Ausgehend von dieser Perspektive lassen sich die vier diskutierten theoretischen Ansätze als Thesen in je eigener Sache lesen. Wenn Vertreter der Modernisierungstheorie den Bedeutungsverfall des Religiösen prognostizierten und die Säkularisierung auch im Islam am Werk sahen, so legitimierten sie damit zugleich eine sozialwissenschaftliche Gesellschafts- und Geschichtsbetrachtung. Kritiker dieser Sichtweise werten hingegen die Bedeutung des Religiösen auf. Ihre Gegenrede von der autoritären Durchsetzungen eines kulturell »fremden" Säkularen evoziert nicht nur Verständnis für staatlich verfolgte Religionen, deren Eigensinn und Widerständigkeit gegenüber der Moderne, sondern

59 Vgl. Bangstad, Contesting, S. 194.

60 Siehe zum Beispiel Dimitry V. Pospielovsky, A History of Soviet Atheism in Theory, and Practice, and the Believer, 2 Bde., New York, NY 1987/88.

61 Paul Hanbrink, European Protestants Between Anti-Communism and Anti-Totalitarianism. The Other Interwar Kulturkampf?, in: Journal of Contemporary History (2017), S. 1-22, hier S. 3, URL: <https://doi.org/10.1177/0022009417704894> (04.08.2017).

62 Paul Froese, »I am an Atheist and a Muslim«. Islam, Communism, and Ideological Competition, in: JChS 47 (2005), S. 473-501, hier S. 498.

63 Ebd., S. 487.

64 Ebd.

65 Ebd., S. 497. 
schreibt Säkularisierungsprozess und -these in eine Geschichte des Kulturverfalls ein und dockt so an eine wirkmächtige Gegenthese $\mathrm{an}^{66}$.

Was José Casanova über den angeblichen religiös-säkularen Sonderstatus Europas oder der USA schreibt, je nach dem, von welcher Seite man schaue $^{67}$, lässt sich jedoch cum grano salis auch auf den Islam übertragen: Es handelt sich dabei um eine problematische Verallgemeinerung, die der Perspektive geschuldet ist. Weder ist der Islam die Ausnahme vom Säkularisierungsprozess noch die Speerspitze des religiösen Revivals, weder der Gegenentwurf zu Europa noch zu den USA. Da es verschiedene individuelle Antworten, gesellschaftliche Pfadabhängigkeiten und wandelbare politische Kontexte gibt, lässt sich keine einheitliche »islamische « Antwort auf komplexe soziale Transformationsprozesse skizzieren und einer "westlichen" gegenüberstellen.

\section{Religion und Nationsbildung}

Über die Trennung von Religion und Politik und die Vereinbarkeit von Islam und säkularer Ordnung wird unter Muslimen - Rechtsgelehrten, Politikern und Intellektuellen - vor allem seit Beginn des 20. Jahrhunderts kontrovers diskutiert ${ }^{68}$. Dass hierbei recht unterschiedliche Ansichten vertreten wurden, die man zum Beispiel als »liberal«, »konservativ«, »traditionalistisch« oder "salafistisch « klassifizieren kann, ist ebenso offenkundig wie trivial und vielfach beschrieben ${ }^{69}$. Wie erwähnt, sehen viele muslimische Gelehrte seien es Traditionalisten oder Reformer und nicht zuletzt »die Ingenieure des dschihad $\aleph^{70}$ - islamische Gesellschaften durch einen wie auch immer

66 Siehe allgemein Arthur Herman, The Idea of Decline in Western History, New York, NY 1997; zum Islam Thomas BAuer, Die Kultur der Ambiguität. Eine andere Geschichte des Islams, Berlin 2011.

67 Casanova, Rethinking Secularization, S. 17.

68 Flores, Die innerislamische Diskussion; ders., Säkularismus und Islam.

69 Dale F. Eickelman / James P. Piscatori, Muslim Politics, Princeton, NJ 1996; John Esposito/John O. Voll, Makers of Contemporary Islam, New York, NY 2001; Charles Kurzman (Hg.), Liberal Islam. A Sourcebook, New York u.a., NY 1998; ders. (Hg.), Modernist Islam, 1840-1940. A Sourcebook, Oxford 2002; Roxanne L. Euben/Muhammad Q. Zaman (Hg.), Princeton Readings in Islamist Thought. Texts and Contexts from Al-Banna to Bin Laden, Princeton, NJ 2009; Gerhard BöwERING u.a. (Hg.), The Princeton Encyclopedia of Islamic Political Thought, Princeton, NJ 2012; John L. Esposito, Rethinking Islam and Secularism, in: ARDA Guiding Papers Series 2010, URL: <http://www.thearda.com/rrh/papers/guidingpapers.asp> (28.12.2016).

70 Diego Gambetta/Steffen Hertog, Engineers of Jihad. The Curious Connection between Violent Extremism and Education, Princeton, NJ 2016. 
definierten Säkularismus bedroht und plädieren für eine Re-Islamisierung. Im Folgenden sollen nun nicht etwa die Argumente derjenigen prominenten Intellektuellen und Religionsgelehrten - etwa der Ägypter 'Alī 'Abd al-Rāziq und Muḥammad Sa'īd al-'Ašmāwī, des gebürtigen Sudanesen Abdullahi al-Naim oder des Rektors der Großen Moschee in Paris Dalil Boubakeur rekapituliert werden, die in den 1920er und 1970er Jahren oder in der Gegenwart säkulare oder laizistische Gesellschafts- und Herrschaftsvorstellungen islamisch rechtfertigten. Eine solche Darstellung würfe die Frage auf, warum diese Positionen nicht von allen Gelehrten geteilt werden und ob sie einem "authentisch" verstandenen Islam entsprechen. Sie suggerierte zudem, dass es zwei relativ stabile säkulare und anti-säkulare Lager gebe und dass der Ausgang des Kampfes zwischen ihnen das Schicksal des Islams bestimme. Im Folgenden soll stattdessen ein anderer Weg eingeschlagen und hervorgehoben werden, dass unterschiedliche Positionen zur Rolle der Religion maßgeblich mit den Problemen der Staats- und Nationsbildung in multireligiösen Gemeinschaften zusammenhängen. Die Nationsbildung ist hier nicht als ein säkularisierender Prozess zu verstehen, sondern als dynamisches Ringen zwischen ethnischen, religiösen und nationalen Kräften, das nicht selten zu eigentümlichen Mischungsverhältnissen führte.

Für den indischen Subkontinent hat Ashis Nandy gezeigt, dass sich eine politische Hierarchie des Säkularismus herausgebildet habe, je nach dem, in welchem Verhältnis Politiker zur Religion stünden ${ }^{71}$. An der Spitze rangierten diejenigen Politiker, die weder öffentlich noch privat Gläubige seien (z.B. Jawaharlal Nehru), gefolgt von denen, die nach außen hin nicht als Gläubige erscheinen wollten, aber privat durchaus aufrichtige Gläubige waren (z.B. Indira Gandhi). Daneben gebe es jene Politiker, die öffentlich als gläubig in Erscheinung träten, aber privat wenig bis nichts für Religion übrig hätten; zu dieser Kategorie zählt Nandy Mohammed Ali Jinnah (gest. 1946), der die Sache des Islams und des Staates Pakistan ergriff, obwohl er persönlich ein Agnostiker war, sowie Vinayak Damodar Savarkar (gest. 1966), der die hindu-nationalistische Ideologie (Hindutva) entwickelte, obwohl er Atheist war. Am unteren Ende der Säkularismushierarchie befänden sich diejenigen Politiker, die sowohl öffentlich als auch privat als religiös auftraten (z.B. Gandhi). Obwohl sich Gandhi positiv auf die vormoderne religiöse Toleranz in Indien - und damit auf eine Toleranz jenseits des säkularen Rahmens - bezog und sagte, er sei gleichzeitig ein Hindu, Muslim, Sikh und Christ, und diese plurale Identität auch Andersgläubigen zubilligte, wurde er von Hindu-Nationalisten erschossen - »in the name of secular statecraft.

71 Ashis Nandy, The Politics of Secularism and the Recovery of Religious Tolerance, in: Alternatives XIII (1988), S. 177-194. 
They said so explicitly and declared Gandhi to be an enemy of the nascent Indian nation-state $\ll^{72}$.

Nandy möchte anhand dieses säkular-religiösen Rankings demonstrieren, dass die säkulare Ordnung in Indien nicht funktioniere. Er argumentiert grundsätzlich, dass der politische Säkularismus auf dem Subkontinent weder zur Beseitigung der Religion und Ethnizität aus der Politik noch zu einer größeren Toleranz zwischen Religionen und Ethnien geführt habe ${ }^{73}$. Dieser Einwand ist zum Teil zwar durchaus berechtigt; deswegen jedoch, wie Nandy es tut, einen Abgesang auf die säkulare Ordnung anzustimmen, obwohl diese die politische Realität Indiens maßgeblich mitbestimmt, heißt, die säkularen Versprechen (Trennung von Religion und Politik, Toleranz) zwar für bare Münze zu nehmen, sie aber in Indien für nicht einlösbar zu erklären. Anders herum wird ein Schuh daraus: Im Versuch, Religion politischen Regelungsmechanismen zu unterwerfen, stellen sich Machtfragen, Rechtsfragen und Fragen nach der politischen Legitimation ebenso wie nach einer Definition von Religion neu, nicht nur in Indien. Die Ermordung Gandhis durch Hindu-Nationalisten - oder auch die Benachteiligung von religiösen Minderheiten - allein einer fehlgesteuerten Säkularisierung anzulasten, greift zu kurz, weil es in allen existierenden säkularen Ordnungen variable Grenzverläufe und Überlappungen zwischen dem Politischen und dem Religiösen gibt. Die Kritik an der destruktiven Gewalt des Säkularen, die Nandy im Einklang mit Mahmood und Asad formuliert, arbeitet oft mit dem letztbegründenden Verweis auf die »säkularen Religionen" Nationalsozialismus und Stalinismus, die jeglichen originär religiösen Furor bei weitem übertroffen hätten ${ }^{74}$. In diesen Beispielen wie auch im Fall der Hindu-Nationalisten stellt sich jedoch die Frage, wie viel religiöse oder quasi-religiöse Aufladung in säkularen Ideologien steckt. Das scheinbar schlichte Argument über die dem Säkularismus innewohnende Gewalt wirft somit direkt die kaum lösbare Frage nach einer verbindlichen Definition des Religiösen auf; es verweist ferner darauf, dass der Säkularismus - im Versuch, eine Trennung zwischen dem Politischen und Religiösen zu etablieren - erst die potentiell »religiösen" Tatbestände hervorruft, über deren Definition und Einhegung seine Vertreter und Gegner politisch und rechtlich streiten.

Der Fall der Hindu-Nationalisten zeigt ferner, dass Religion und Nation gemeinschaftsbildende Ordnungsvorstellungen sind, die sowohl miteinander konkurrieren als auch sich gegenseitig stützen können. Unabhängig davon, ob die religiöse Sphäre als privat oder öffentlich, als eng, weit oder nahezu

72 Ebd., S. 193.

73 Ebd., S. 183.

74 Talal Asad, Genealogies of Religion. Discipline and Reasons of Power in Christianity and Islam, Baltimore, MD u.a. 1997, S. 236; zur Kritik siehe BAngstad, Contesting, S. $199 f$. 
allumfassend gedacht wird, kann Religion sowohl im Dienste der Nation als auch gegen sie angerufen werden, je nach dem, wer religiöse Ansprüche zu welchem Zweck und unter welchen Bedingungen geltend macht. Gegen die Vorstellung, Nationalismus lasse sich als rein säkulares Phänomen auffassen, skizziert Rogers Brubaker verschiedene historiographische Ansätze, mit denen sich das besondere Verhältnis zwischen Religion und Nation besser bestimmen lässt ${ }^{75}$. Neben den Fällen, in denen sich eine Konfession oder Religion als kulturelle Ressource im Nationsbildungsprozess beschreiben lässt oder in denen sich zeigen lässt, dass die politische Sprache von religiösen Mythen und Metaphern durchdrungen ist, finden sich auch Beispiele, in denen Akteure eigenständige Forderungen - etwa auf Repräsentation oder Autonomie - im Namen der Religion formulieren, analog zu Forderungen im Namen von Nation, Ethnie oder Rasse. Ob jenseits der Verflechtung religiöser und politischer Sprache auch von einem eigenständigen Typus eines "religiösen Nationalismus" gesprochen werden kann, sieht Brubaker eher skeptisch, muss uns an dieser Stelle jedoch nicht weiter interessieren. Entscheidend ist seine Sicht auf das Spannungsverhältnis zwischen Nation und Religion im Nationsbildungsprozess. Im Versuch, nationale Homogenität herzustellen, haben sich die multireligiösen und multiethnischen Gesellschaften des globalen Südens erhebliche, oft bis heute ungelöste Probleme eingehandelt, die nicht aus einem Mangel an Säkularisierung, sondern aus dem Versuch sozialer Homogenisierung entstanden sind.

Diese Problematik lässt sich anhand der Entwicklungen in der Türkei, in Pakistan und Algerien demonstrieren - anhand der Nachfolgestaaten zweier islamischen Reiche und des am längsten kolonisierten islamischen Landes. Trotz aller Unterschiede weisen diese Länder ähnliche Phasen der Staatsgründung auf:

1. der Zusammenbruch eines multireligiösen, multiethnischen Staatsgebildes sowie die islamische Mobilisierung in der Unabhängigkeitsbewegung und damit einhergehend der Massenexodus von Nicht-Muslimen;

2. eine säkularisierende Politik nach der nationalen Unabhängigkeit sowie die Entstehung ethnischer und religiöser Gegenbewegungen, die sich im und gegen den neuen Staat formierten ${ }^{76}$.

75 Rogers Brubaker, Religion and Nationalism. Four Approaches, in: Nations and Nationalism 18 (2012), S. 2-20.

76 Die Problematik ist mit diesen drei Beispielen natürlich nicht erschöpfend behandelt. Die folgenden Ausführungen stützen sich auf Sener AктURк, Religion and Nationalism. Contradictions of Islamic Origins and Secular Nation-Building in Turkey, Algeria, and Pakistan, in: Social Science Quarterly 96 (2015), S. 778-806; vgl. auch Kamal Soleimani, Modern Islamic Political Thought, »Islamism« and Nationalism, in: Journal of Humanities and Cultural Studies 2/1 (2017), S. 1-14. 
Als das Osmanische Reich, eine der längsten Herrscherdynastien der Welt (1299-1922), 1918 kapitulierte, wurde Anatolien in britische, französische, italienische und griechische Besatzungszonen aufgeteilt und Istanbul unter eine multinationale Besatzung gestellt. Der Unabhängigkeitskrieg (1919-1923) wurde in der gesamten islamischen Welt mit Sympathie verfolgt. 1920 gaben 153 muslimische Religionsgelehrte ein Rechtsgutachten (fatwā) heraus, in dem der Unabhängigkeitskrieg als ǧihäd bezeichnet und damit zur religiösen Pflicht erklärt wurde. Auch das Parlament verabschiedete eine Erklärung an die islamische Welt, in der zur Unterstützung für den Kampf gegen die Entente aufgerufen wurde. Während in spätosmanischer Zeit auch Nicht-Muslime Abgeordnete waren, bestand das neue Parlament in Ankara aufgrund eines neuen Wahlgesetzes nur noch aus 337 Muslimen, darunter waren 23 Prozent Religionsgelehrte. Die beiden Parlamentssprecher waren die Führer des sunnitischen Mevlevi- und des heterodoxen Bektashi-Ordens. Die ethnische und sprachliche Vielfalt - Albaner, Araber, Kurden, Lazen, Tscherkessen, Zaza usw. - war den Kämpfern bewusst; stets war die Rede von Muslimen, die eine Nation bildeten. Nach dem Sieg und dem Rückzug der griechischen Truppen vollzog sich ein Massenexodus von einer Million Christen; zudem wurde ein Bevölkerungsaustausch von Christen in der Türkei (außerhalb Istanbuls) mit Muslimen in Griechenland vorgenommen. Nach Auflösung des Parlaments dominierte im 1923 neu gewählten Parlament Mustafa Kemals Republikanische Volkspartei (CHP) als einzige zugelassene Partei, die die Türkei in einen laizistischen Staat verwandelte. Innerhalb von fünf Jahren erfolgten zahlreiche Reformen und Verbote ${ }^{77}$, wie etwas das Verbot aller religiöser Orden. Parallel dazu entfiel die frühere Anerkennung ethnischer Diversität. Türkisch wurde nicht nur einzige offizielle Sprache; wer eine andere Sprache, auch jenseits offizieller Anlässe, benutzte, wurde bestraft. 1932 wurde sogar der Gebetsruf auf Türkisch verpflichtend.

Im Kampf um die Unabhängigkeit Britisch Indiens sah sich ein Teil der Muslime, die sich als Nachfahren des Sultanats von Delhi (1206-1526) und des Mogulreiches (1526-1858) verstanden, auf verlorenem Posten gegenüber der großen hinduistischen Mehrheit. Mohammed Ali Jinnah und die von ihm geführte Muslimliga distanzierten sich in den 1930er Jahren zunehmend vom Indischen Nationalkongress, nachdem sie damit gescheitert waren, eine Garantie politischer Rechte für Muslime nach der Unabhängigkeit zu erwirken. Jinnah verfolgte nun die Zwei-Nationen-Theorie, der zufolge die Religion der ausschlaggebende Faktor sei, der indische Muslime und Hindus zu

77 Abschaffung des Kalifats, des Ministeriums für islamisches Recht, des islamischen Kalenders, der arabischen Schrift, religiöser Stiftungen und islamischer Schulen; Hutpflicht für Männer, Verlegung des Feiertags auf Sonntag. 1926 wurden das Schweizer Bürgerrecht und das italienische Strafrecht eingeführt, 1928 wurde der Satz über den Islam als Staatsreligion aus der Verfassung gestrichen. 
je einer eigenen Nation mache. Nach der Teilung des Subkontinents 1947 kam es mit 17 Millionen zum größten Bevölkerungsaustausch der Geschichte. Im unabhängigen Pakistan blieben die säkularen Gesetze Britisch Indiens zunächst in Kraft, da man sich nicht darauf einigen konnte, was einen islamischen Staat ausmachte; hierbei wirkten sich auch Differenzen zwischen Sunniten und Schiiten aus, da in der Muslimliga eine Gruppe ismailitischer Schiiten um Jinnah eine wichtige Rolle spielte. Erst 1956 wurde die Verfassung der »Islamischen Republik« erlassen. Das zur Nationalsprache erhobene Urdu war vor allem die Sprache der gebildeten Auswanderer aus Indien, während es 90 Prozent der Bevölkerung nicht als erste Sprache benutzten; weit mehr Menschen hatten Bengali als Muttersprache.

In Französisch-Algerien gab es eine große Kluft zwischen einem Zehntel der Bevölkerung, das die französische Staatsbürgerschaft besaß (zumeist Ausländer, Christen und Juden), und den restlichen vorwiegend muslimischen 90 Prozent. Selbst bei Konversion war es ungewiss, ob Muslime die Staatsbürgerschaft erhalten würden; ihre Zahl wird auf 2000 geschätzt. Im Gegensatz dazu erhielten algerische Juden ab 1870 das Recht, die französische Staatsbürgerschaft zu erwerben. Die Unabhängigkeitsbewegung, von Arabern und Berbern gemeinsam geführt, formierte sich ab den 1930er Jahren und bediente sich eines islamischen Diskurses. Traumatisches Ereignis war das Massaker von Sétif am 8. Mai 1945, in dessen Folge die französische Armee im Zuge ihrer »Aufstandsbekämpfung « tausende Zivilisten, deren genaue Anzahl unbekannt ist, tötete. Ab 1954 entbrannte ein zunehmend brutal geführter Krieg zwischen der Befreiungsbewegung (FLN) sowie dem französischen Militär und den Siedlern. Hatte der Zensus von 1960 noch etwas mehr als eine Million Nicht-Muslime gezählt, so verließen diese sogenannten Pieds-Noirs innerhalb weniger Jahre nach der Unabhängigkeit 1962 das Land. In dem Einparteienstaat, der sich als sozialistisch definierte, begann eine Arabisierungspolitik ${ }^{78}$, die nicht nur die berberische Sprache aus dem öffentlichen Leben verbannte, sondern der auch alle wichtigen berberischen Politiker zum Opfer fielen, die entweder marginalisiert, verhaftet oder getötet wurden. Ideologisch stützte sich das Regime auf einen Mix aus Sozialismus und Islam, der sich sowohl gegen die traditionellen Gelehrten als auch gegen frühere Kampfgefährten richtete, die einen Staat auf islamischen Prinzipien gründen wollten.

In allen drei Staaten entstanden nach der Unabhängigkeit Gegenbewegungen, die sich auf Religion oder Ethnie beriefen. In der Türkei kam es in den 1920er und 1930er Jahren zu sunnitischen und kurdischen Aufständen, wobei der vorläufige Höhepunkt der Dersim-Aufstand 1937/38 war, in

78 Arabisch wurde, als Algerien 1875 zum integralen Teil Frankreichs erklärt wurde, zur Fremdsprache erklärt. 
dessen Verlauf türkische Soldaten mindestens 13.000 Kurden töteten. 1950 erfolgte der Übergang zur Mehrparteien-Demokratie, wobei die oppositionelle Demokratische Partei die Wahl gewann, da sie die Stimmen der meisten religiösen und kurdischen Wähler auf sich vereinen konnte. Als erste Entscheidung führte die neue Regierung den arabischen Gebetsruf wieder ein. Auch das islamische Erziehungswesen wurde gesetzlich neu geregelt, was es erlaubte, islamische Gymnasien zu eröffnen. Nachdem sich 1970 die erste islamische Partei gegründet hatte, wurden vier islamische Parteien nacheinander vom Staat wegen anti-säkularer Aktivitäten verboten. Nach dem Militärputsch 1980 kam es zur offenen Konfrontation mit der kurdischen Arbeiterpartei PKK (1984-1999), in deren Verlauf 35.000 Menschen das Leben verloren haben sollen. Seit 2002 bildet die islamische Partei für Gerechtigkeit und Aufschwung (AKP) bei allen Parlamentswahlen die stärkste Kraft. Sie lockerte den türkischen Laizismus weiter; unter anderem wurde das Kopftuchverbot an Universitäten und in Behörden aufgehoben. Anknüpfend an Reformen der Vorgängerregierung, wurden kulturelle Rechte der Kurden gestärkt, etwa die Erlaubnis für kurdischen Sprachunterricht und Rundfunksendungen auf Kurdisch. Trotz der Verhaftung Abdullah Öcalans (1999) und einer Waffenstillstandserklärung der PKK blieb der Kurdenkonflikt jedoch weiterhin ungelöst und hat sich zuletzt wieder verschärft - auch aufgrund der Entwicklungen in den Nachbarstaaten Syrien und Irak. Nach 2011 und besonders nach einem gescheiterten Putschversuch im Juli 2016 legte die AKP-Regierung den begonnen Demokratisierungsprozess auf Eis, agierte zunehmend autoritär und repressiv und schreckte auch vor Massenverhaftungen und -entlassungen nicht zurück ${ }^{79}$.

In Pakistan kam es 1971 zum Bürgerkrieg, als die westpakistanische Elite, die Militär und Staatsverwaltung dominierte, den Wahlsieg der Bengali Awami League nicht anerkannte. Der Konflikt kostete 100.000 Menschen das Leben und führte zur Abspaltung Bangladeschs. Danach ging die Elite daran, Rest-Pakistan zu islamisieren: 1974 verbot das Parlament die Ahmadiyya, eine islamische Sondergruppe; wenig später wurden auch die haddStrafen, Scharia-Gerichtshöfe sowie islamisch begründete Steuern (zakāt, $u \check{s} r$ ) eingeführt. Trotzdem kam Pakistan nicht zur Ruhe, weil sich die Elite aus dem Punjab mit Gleichberechtigungsforderungen anderer Ethnien (Balutschen, Paschtunen, Sindhis und Mohajir) konfrontiert sieht, während sich sunnitische Täter durch die Islamisierungspolitik darin bestärkt fühlen, Gewalt gegen Minderheiten (Schiiten und Christen) anzuwenden ${ }^{80}$.

79 Siehe etwa Günter Seufert, Nach dem Putschversuch in der Türkei (18.07.2016), URL: <https://www.swp-berlin.org/kurz-gesagt/nach-dem-putschversuch-in-dertuerkei> (09.11.2017).

80 Siehe dazu etwa Frederike BögE, Im Zangengriff der Mullahs, in: FAZ (09.02.2015), 
In Algerien formierte sich die Gegnerschaft gegen die staatliche Politik in der Kabylei und von islamischer Seite bereits in den 1960er Jahren, wurde aber massiv unterdrückt. Bei den ersten freien Parlamentswahlen 1991 kamen diese Konflikte offen zum Vorschein, da die Islamische Heilsfront (FIS) im ersten Wahlgang 188 von 231 Parlamentssitzen und die von Berbern unterstützte Front Sozialistischer Kräfte (FFS) in der Kabylei (25) jeweils mehr Sitze erlangten als die FLN (15). Nach der Intervention durch das Militär und der Annullierung der Wahlergebnisse folgte ein zehnjähriger Bürgerkrieg mit 160.000 Toten. Die Berbersprache Tamazigh wurde erst 2002 als Nationalsprache und 2016 auch als Amtssprache anerkannt.

In allen drei Nationsbildungsprozessen konnte weder das proto-nationale, islamische noch das staatlich-säkulare Homogenisierungsstreben die ursprünglich vorhandene religiöse und ethnische Pluralität bewahren. In allen drei Fällen kam es zu Bürgerkriegen, im Falle Pakistans ging sogar die Einheit des Landes verloren. Die islamische Mobilisierung im Zuge der Unabhängigkeitsbewegung konnte zwar die Differenzen zwischen den Ethnien überbrücken und sie vorübergehend zu einer »islamischen Nation« zusammenschweißen, führte aber zum Exodus vieler Nichtmuslime. Mit dem Sieg der Unabhängigkeitsbewegung erübrigte sich die islamische Mobilmachung, wodurch das einigende Band zwischen den Ethnien geschwächt wurde. Da der Islam zudem als transterritoriale Religion allein keine nationale Einheit stiften konnte, trat nun eine säkulare Staatsvorstellung in den Vordergrund, die eindeutig eine ethnische Gruppe und ihre Sprache präferierte und dadurch die Bevölkerung weiter ethnisch und sprachlich zu homogenisieren versuchte, nachdem sie sie zuvor schon religiös homogenisiert hatte. Beide religiöse ebenso wie staatliche - Homogenisierungsbestrebungen versuchten das Prinzip des europäischen Nationsmodells zu kopieren, wirkten sich aber auf Teile der Bevölkerung exkludierend aus. Konfrontiert mit dauerhaften ethnischen Separationsbewegungen war es daher durchaus ratsam, dass die Eliten im Laufe der Zeit wieder stärker den islamischen Charakter des Landes betonten, was sich jedoch nachteilig auf religiöse Minderheiten und säkulare Intellektuelle auswirkte.

Diese drei Beispiele sollen zwei verbreitete Narrative relativieren. Zum einen gibt es die These, die oftmals kursorisch auf den Islam verweist, dass sich - nach einem Säkularisierungsschub in den 1960er Jahre - im letzten Drittel des 20. Jahrhunderts ein religiöses Erwachen ereignet habe, das geradezu als De-Säkularisierung bezeichnet werden könne. Mit Blick auf die genannten Beispiele lässt sich indes argumentieren, dass in mehrheitlich islamischen Gesellschaften das gesamte 20. Jahrhundert von einem einmal

URL: <http://www.faz.net/aktuell/politik/ausland/asien/in-pakistan-verfolgenislamisten-religioese-minderheiten-13407053.html> (31.12.2016). 
stärkeren, ein andermal schwächeren national-religiös-ethnischen Ringen durchzogen war, das, einem eigenen Rhythmus folgend, maßgeblich durch Probleme der Entkolonialisierung und Nationsbildung bestimmt war und daher je nach Ort zeitlich variierte.

Zum anderen existiert die These, wonach in Europa Religionskriege zum Westfälischen Frieden (1648) und damit zur Trennung von Religion und Politik, also zur Säkularisierung, geführt hätten - eine Erfahrung, die etwa dem Islam fehle. Gegen dieses Narrativ hat unter anderem der Religionssoziologe José Casanova eingewandt, dass der Westfälische Frieden lediglich die Territorialisierung von Religion und die Konfessionalisierung von Politik hervorgebracht habe; in der Schweiz, Deutschland und Holland sei es nur unabsichtlich zu einem religiösen Pluralismus gekommen ${ }^{81}$. Bestimmend für die europäischen Staats- und Gesellschaftsvorstellungen sei vielmehr die Idee der Homogenität gewesen, die im Zeitalter des Nationalismus von der Religion auf die Gesellschaft insgesamt übertragen worden sei. In diesem Sinne belegen die drei Beispiele, dass die Schwierigkeiten im Nationsbildungsprozess nicht einem islamischen Spezifikum geschuldet sind, sondern an die Probleme anknüpfen, die in nationalistischen Homogenisierungsvorstellungen angelegt sind und die sich von Europa aus im 20. Jahrhundert weltweit verbreiteten. Carl Schmitt illustrierte sein Diktum von 1923, zur Demokratie gehöre »notwendig erstens Homogenität und zweitens - nötigenfalls - die Ausscheidung oder Vernichtung des Heterogenen ${ }^{82}$, zustimmend mit dem Hinweis einerseits auf die $»$ radikale Aussiedlung der Griechen« und die »rücksichtslose Türkisierung« der Türkei und andererseits auf die Einwanderungsgesetzgebung Australiens, die »unerwünschten Zuzug fernhält«. Da laut Schmitt sich Gleichheit seit dem 19. Jahrhundert auf »nationale Homogenität« gründe, zur Gleichheit aber »auch immer Ungleichheit « ${ }^{83}$ gehöre, höre eine Demokratie nicht auf Demokratie zu sein, wenn sie einen Teil der vom Staate beherrschten Bevölkerung ausschließe und somit auch Menschen umfasse, die »in irgendeiner Weise ganz oder halb entrechtet ${ }^{84}$ seien. Denn »die politische Kraft einer Demokratie« zeige sich gerade darin, »daß sie das Fremde und Ungleiche, die Homogenität Bedrohende zu beseitigen oder fernzuhalten weiß«. Das

81 José Casanova, Die religiöse Lage in Europa, in: Joas / Wiegandt (Hg.), Säkularisierung, S. 322-357.

82 Siehe hier und im Folgenden, soweit nicht anders angemerkt, Carl Sснмітт, Zur geistesgeschichtlichen Lage des heutigen Parlamentarismus, Berlin 2010 [Erstauflage 1923], S. 14.

83 Ebd., S. 15.

84 Ebd. 
Erbe dieses Denkens findet sich heute nicht nur in den krisenhaften Entwicklungen in mehrheitlich islamischer Gesellschaften, sondern auch in der Zuwanderungsdebatte in Europa.

\section{Islam im säkularen Europa}

In den europäischen Gesellschaften - seien sie laizistisch wie in Frankreich, religionsneutral wie in Deutschland oder staatskirchlich wie in England, Dänemark oder Griechenland - hat sich trotz der Unterschiede im Detail eine historisch gewachsene Koexistenzpragmatik zwischen den christlichen Kirchen und dem Staat herausgebildet, wobei weder die Grenzen noch die Verflechtungen zwischen beiden Seiten unveränderlich sind. Diese historisch gewachsene Ordnung kann jedoch nicht einfach auf islamische Gemeinden, Vereine oder Verbände in Europa übertragen werden ${ }^{85}$. Vielmehr stellt sich die Frage, wie sie fortgeschrieben werden soll, damit Muslime ihre Religionsfreiheit in angemessener Weise entfalten können ${ }^{86}$.

Der Sinn einer säkularen Ordnung besteht nach heutigem Rechtsverständnis nicht darin, Religion aus dem öffentlichen Raum zu verdrängen, sondern einen möglichst großen Freiraum für religiöse Pluralität und religiöse Überzeugungen zu gewährleisten. Auch wird den Gläubigen kein Bekenntnis zu Demokratie oder zur säkularen Ordnung abverlangt, selbst wenn dies im Sinne des Miteinanders wünschenswert wäre; der Staat ${ }^{87}$ ist gegenüber religiösen Überzeugungen weitgehend indifferent, solange sich die Gläubigen im Glaubensvollzug, also ihrem praktischen Handeln, an Recht und Gesetz halten ${ }^{88}$. Da bei Sicherheitsbedenken jedoch die staatliche Religionsneutralität hinter dem Schutzbedürfnis der Bevölkerung zurücksteht, ist in den vergangenen Jahren insgesamt der Druck auf islamische Vereine gewachsen,

85 Nahziel ist, den jüngsten Grundsatzurteilen zufolge und dem Gleichheitsgrundsatz folgend, eine Annäherung an den Status der Kirchen, wobei die Messlatte weniger auf Höhe der Großkirchen als auf Höhe kleinerer christlicher und anderer Religionsgemeinschaften liegt, siehe RoHE, Islam in Deutschland, S. 178.

86 Siehe dazu den Band Lothar HäBERLE / Johannes Hattuer (Hg.), Islam - Säkularismus - Religionsrecht. Aspekte und Gefährdungen der Religionsfreiheit, Heidelberg 2012, und speziell den Beitrag von Stefan Magen, Neutralität und negative Religionsfreiheit im staatlich verantworteten öffentlichen Raum, in: HäBERLE / HATTLER, Islam - Säkularismus - Religionsrecht, S. 95-109.

87 Siehe dazu auch den Beitrag in diesem Band von Michael Germann, Säkularisierung und Religion in der Perspektive des Religionsverfassungsrechts, S. 187.

88 Siehe etwa Lothar Häberle / Johannes Hattler (Hg.), Einführung, in: Dies. (Hg.), Islam - Säkularismus - Religionsrecht, S. 1-4; Dieter GRIMM, Grundgesetzlich irrelevant, in: FAZ (22.04.2016), URL: <http://www.faz.net/aktuell/feuilleton/de batten/islam-vs-grundgesetz-debatte-ueber-religionsfreiheit-14191706.html> (09.11. 2017). 
sich und ihre Mitglieder als verfassungskonform zu präsentieren. Aus der Frage, wie der Islam institutionell in die säkulare Ordnung integriert werden kann, hat sich daher sowohl auf islamischer als auch auf staatlicher Seite Handlungsbedarf ergeben. Zum einen bildeten sich islamische Organisationen neu, um mit dem Staat zu kooperieren, zum anderen sind die Staaten selbst zu Akteuren im religionspolitischen Feld geworden und haben Gremien geschaffen, in denen Muslime repräsentiert sind und über die Integration des Islams diskutiert wird ${ }^{89}$. Diese Form der Anerkennungspolitik geht mit Regulierungs-, Disziplinierungs- und Homogenisierungsmechanismen einher, da den Muslimen ein Zuwachs an Rechten in Aussicht gestellt wird, wenn sie sich zusammenschließen, in die säkular-liberale Matrix einfügen und unter die Obhut staatlicher Verwaltung begeben ${ }^{90}$. Die Selbstrepräsentation der anzuerkennenden Subjekte innerhalb hegemonialer Strukturen tastet jedoch bestehende Asymmetrien nicht direkt an. Vielmehr wird sie zum Preis eines »Wucherns der Diskurse über Muslime ${ }^{91}$ und einer fortgesetzten Anrufung und Selbstanrufung von Muslimen erkauft. Durch die Logik einer Sicherheitspartnerschaft werden die Prozesse der Regulierung, Zähmung und Vereinheitlichung - und damit auch die Unterscheidung zwischen legitimer und illegitimer Religionsausübung - an die Muslime selbst delegiert.

Was an der heutigen Präsenz von Muslimen in Europa jedoch ins Auge sticht, ist ihre Heterogenität in nahezu jeder Hinsicht. Nirgendwo sonst auf der Welt gibt es eine derartige Vielfalt islamischer Glaubensgruppen, die sich nicht nur intern - in Hinblick auf ihre religiösen, nationalen, sprachlichen, kulturellen und politischen Eigenheiten - unterscheiden, sondern auch in jedem europäischen Land auf andere Rahmenbedingungen stoßen und auf eine andere Geschichte zurückblicken. Innerhalb der EU beispielsweise ist die Verteilung von Muslimen sehr ungleich (Durchschnitt: vier Prozent) und weist ein starkes Stadt-Land-Gefälle auf. In den Niederlanden machen Muslime etwa sechs Prozent der Bevölkerung aus (2011), in Amsterdam und Rotterdam hingegen 28 respektive 37 Prozent ${ }^{92}$. Mehrere Untersuchungen belegen erhebliche Unterschiede im Glauben je nach Alter,

89 Hierzu Jocyline CESARI, Introduction, in: Dies. (Hg.), Handbook of European Islam, S. 1-15, hier S. 7.

$90 \mathrm{Zu}$ den Aporien von Anerkennung und Selbstrepräsentation siehe Schirin AmIRMoazami, Die "muslimische Frage « in Europa. Politische Aporien der Anerkennung unter liberal-säkularen Bedingungen, in: Philipp Hubmann u.a. (Hg.), Politische Aporien. Akteure und Praktiken des Dilemmas, Wien u.a. 2016, S. 111-133, sowie dies., Wer spricht für wen - und warum? Zur Anerkennung, Authentizität und Repräsentation von Muslimen unter liberal-säkularen Bedingungen, in: BERTELsMANn STIfTung (Hg.), Vielfältiges Deutschland. Bausteine für eine zukunftsfähige Gesellschaft, Gütersloh 2014, S. 357-377.

91 Amir-Moazami, Wer spricht für wen und warum, S. 362; sie spricht in Anlehnung an Michel Foucault auch von »diskursiver Explosion«, ebd., S. 360.

92 Berger, The Third Wave, S. 121. 
Konfession, Region oder Herkunfts- und Aufnahmeland ${ }^{93}$. Selbst in einer mittleren deutschen Kleinstadt finden sich heute leicht Muslime aus 27 Nationen mit fünf unterschiedlichen islamischen Vereinen, wobei ein Drittel der Muslime die deutsche Staatsbürgerschaft besitzt, aber nur ein Fünftel in einem der islamischen Vereine organisiert ist ${ }^{94}$. Diese Heterogenität zeigt, dass Muslime nicht a priori ein Kollektiv bilden, sondern erst durch Fremdund Selbstbeschreibung, durch statistische Erhebungen, Forschungsprojekte und Islamkonferenzen seit den 1990er Jahren dazu gemacht worden sind ${ }^{95}$. Die islamischen Verbände wiederum leiten ihren Vertretungsanspruch aus solch staatlichem und nicht-staatlichem Handeln ab. Allerdings bietet sich auf organisatorischer Ebene weiterhin kein einheitliches Bild. Die Vielfalt reicht von lokalen Moscheevereinen zu nationalen und europaweiten Dachverbänden. Während manche Gruppen vom Verfassungsschutz beobachtet werden, nähren andere durch intransparente Strukturen Zweifel an ihrer finanziellen und politischen Unabhängigkeit - vor allem gegenüber der Türkei und Saudi-Arabien ${ }^{96}$; aus solchen Gründen gerät die Institutionalisierung der Kooperation mit dem Staat, wie jüngst in Niedersachsen, immer wieder ins Stocken ${ }^{97}$. Wieder andere Gruppierungen verstehen sich als »europäische Muslime « - allen voran die bosnischen Muslime ${ }^{98}$ - oder positionieren sich als »integrierte« und »friedliche« Muslime - so wie etwa die Ahmadiyya

$93 \mathrm{Zu}$ Deutschland siehe Rohe, Islam in Deutschland, S. 80-95 und Spielhaus, Germany, S. 109-124. Zu europäischen Ländern siehe Berger, The Third Wave, S. 121-123, und Cesari (Hg.), Handbook of European Islam.

94 So das Beispiel der 44.000-Einwohner-Stadt Bad Kreuznach bei Jörn Thielmann, Muslime in Rheinland-Pfalz, in: Friedrich Kahlenberg / Michael Kissener (Hg.), Kreuz - Rad - Löwe. Rheinland-Pfalz. Ein Land und seine Geschichte, Bd. 2, Mainz 2012, S. 614-617, hier S. 615f.

95 Vgl. Spielhaus, Germany, S. 106. Zu den Islamkonferenzen als Ausdruck von Herrschaftstechnik siehe Schirin Amir-Moazami, Dialogue as Governmental Technique: Managing Gendered Islam in Germany, in: feminist review 98 (2011), S. 9-27, sowie dies., Pitfalls of Consensus-Oriented Dialogue. The German Islam Conference (Deutsche Islamkonferenz), in: Approaching Religion 1 (2011), S. 2-15.

96 Dies betrifft sowohl konservative als auch liberale Vereine, siehe Susanne Schröter, Streit um DITIB. Ein undurchsichtiges Spiel, in: FAZ (20.08.2016), URL: <https://www.faz.net/aktuell/feuilleton/debatten/streit-um-ditib-einundurchsichtiges-spiel-14394916.html?printPaged Article=true\#pageIndex_0> (23.01.2017), sowie Daniel BAx, Ateş und saudische Vereinsfinanzierung. Der Feind meines Feindes, in: taz (30.10. 2017), URL: <http://www.taz.de/!5456830> (09.11.2017).

97 Reinhard Bingener, Islamverträge in Niedersachsen vor dem Aus, in: FAZ (19.01.2017), URL: <http://www.faz.net/aktuell/politik/inland/vertraege-mit-islamverbaenden-in-niedersachsen-vor-dem-aus-14698908.html> (23.01.2017).

98 Xavier Bougarel, Bosnian Islam as »European Islam«: Limits and Shifts of a Concept, in: Aziz Al-Azmen / Effie Fok as (Hg.), Islam in Europe. Diversity, Identity and Influence, Cambridge 2007, S. 96-124; Samuel M. Behloul, Negotiating the »Genuine« Religion. Muslim Diaspora Communities in the Context of the Western Understanding of Religion, in: Journal of Muslims in Europe 1 (2012), S. 7-26. 
Muslim Jamaat, die 2013 in Hessen und 2014 in Hamburg als erste muslimische Gruppierung in Deutschland den Status einer »Körperschaft des öffentlichen Rechts« zugesprochen bekam.

Bewusst integratives Verhalten indes schließt Anfeindungen nicht aus, wie etwa die Aufregung um einen Ahmadiyya-Stand auf dem »Weihnachtsmarkt der Nationen« im hessischen Rüdesheim am Rhein zeigt. Auf dem Stand sollten pakistanische Spezialitäten verkauft werden, doch aufgrund von Pöbeleien und Drohanrufen durch Marktbesucher, die den Stand als Versuch einer "Islamisierung « verstanden, wurde er nach wenigen Tagen geschlos$\operatorname{sen}^{99}$. Das Beispiel zeigt pars pro toto den schmalen Grat zwischen Integrationsaufforderung und Islamisierungsvorwurf. In dem Maße, wie Integration die Sichtbarkeit islamischer Differenz erhöhen kann, kann gerade auch ein Mitwirken an der »europäischen Leitkultur ${ }^{100}$ als Problem gedeutet werden. Indem die schwammige Aufforderung zur »Integration « zwischen der Ablehnung einer muslimischen Parallelgesellschaft und der Warnung vor einer Islamisierung changiert, kann sie jede sichtbare Form islamischer Präsenz als Beispiel fehlgeschlagener Integration brandmarken.

Unter anderem mit Blick auf den Kruzifix-Beschluss ${ }^{101}$ von 1995 argumentieren sogenannte Islamkritiker häufig, der westliche Säkularismus schaffe einen Freiraum, in den ein politisierter Islam vorstoßen könne ${ }^{102}$. Während hier die säkulare Rechtsordnung als Einfallstor für eine Islamisierung des

Jutta Schwiddessen, Muslimischer Info-Stand auf dem Rüdesheimer Weihnachtsmarkt sorgt für Aufregung, in: Wiesbadener Tagblatt (29.11.2016), URL: <http:// www.wiesbadener-tagblatt.de/lokales/rheingau/ruedesheim/muslimischer-infostand-auf-dem-ruedesheimer-weihnachtsmarkt-sorgt-fuer-aufregung_17504819. htm> (07.12.2016); Wiesbadener Tagblatt, Ahmadiyya-Gemeinde schließt ihren Stand auf dem Rüdesheimer Weihnachtsmarkt (03.12.2016), URL: <http://www. wiesbadener-tagblatt.de/lokales/rheingau/ruedesheim/ahmadiyya-gemeindeschliesst-ihren-stand-auf-dem-ruedesheimer-weihnachtsmarkt_17514758.htm> (07.12.2016). Der Stand wurde etwa auf dem islamfeindlichen Blog »Politically Incorrect" als Zeichen einer "kulturell-geistigen Selbstaufgabe« gewertet, siehe Michael Stürzenberger, Rüdesheim. Ahmadiyya auf Weihnachtsmarkt, URL: <http://www.pi-news.net/2016/12/ruedesheim-ahmadiyya-auf-weihnachtsmarkt> (07.12.2016).

100 Eine Begriffsprägung von Bassam TiBI, Europa ohne Identität? Die Krise der multikulturellen Gesellschaft, München 1998.

101 Das Bundesverfassungsgericht konkretisierte damit Regeln für die staatliche Neutralitätspraxis, indem es die Bayrische Volksschulordnung für verfassungswidrig erklärte, nach der in jedem Klassenzimmer das Anbringen eines Kreuzes vorgeschrieben war. Auf die Zahl der aufgehängten Kreuze in bayrischen Klassenzimmern hatte das Urteil praktisch keine Auswirkung, Heribert Prantl, 20 Jahre Kruzifix-Urteil. Aufstand der Aufgeregten, in: Süddeutsche Zeitung (19.08.2015), URL: <http://www.sueddeutsche.de/politik/jahre-kruzifix-urteil-aufstand-deraufgeregten-1.2613635> (09.12.2016).

102 Siehe die Veröffentlichung auf dem AfD-nahen Blog »Die Freie Welt« des Instituts für Strategische Studien Berlin, Islamische Welt: Säkularismus vollends geschei- 
Abendlandes missverstanden wird, kritisieren manche muslimischen Stimmen den Säkularismus als anti-islamisches Steuerungsinstrument. Sie beklagen nicht nur eine zunehmende "Islamophobie« in europäischen Gesellschaften, sondern bemängeln, wie etwa auch Talal Asad, dass der auf einem europäischen und christlichen Universalismus basierende Säkularismus Muslime benachteilige: „Europe [...] is ideologically constructed in such a way that Muslim immigrants cannot be satisfactorily represented in it ${ }^{103}$; Muslime könnten nur als »religiöse Minderheit" mit minderen Rechte auftreten, nicht aber als "a minority in a democratic state that consists only of minorities ${ }^{104}$. Einer dritten Sichtweise zufolge erscheint Säkularität als kultureller Wert Europas, den es gegen eine Verwässerung zu verteidigen gelte. Hierbei wird oftmals die Forderung erhoben, der organisierte Islam müsse da er keine Trennung zwischen Politik und Religion kenne - sich erst einmal reformieren, um "Religion" in einem europäischen Sinne zu werden; erst dann dürfe er darauf hoffen, in die säkulare Ordnung aufgenommen zu werden. Besonders im Zuge verschiedener terroristischer Anschläge seit $2001 \mathrm{nahm}$ die Islamkritik auch durch Autoren islamischer Herkunft stark $\mathrm{zu}$, und es gründeten sich in mehreren europäischen Ländern Vereinigungen von "Ex-Muslimen «, die sich als liberal und säkular verstehen. Problematisch erscheint diese Selbstbeschreibung für die hier zu verhandelnde Thematik deshalb, weil sie suggeriert, dass nur ein Muslim, der keiner mehr sei, säkular sein könne ${ }^{105}$.

In dieser Diskussion benutzen unterschiedliche Seiten verschiedene Vorstellungen von »Säkularität« und»Säkularismus«, um je eigene politische Interessen zu artikulieren. Sie stellen sich sowohl die säkulare Ordnung als auch den Islam als einen Containerbegriff vor. Die säkulare Ordnung erscheint als ein Container mit »falschem « Inhalt, weil sie entchristianisiert und kulturell entkernt werde, weil sie zutiefst christlich und anti-islamisch geprägt sei oder weil sie Gefahr laufe, aufgeweicht zu werden. Der Islam erscheint ebenfalls als ein Container, der entweder als Ganzes eingegliedert, auf Abstand gehalten oder reformiert werden müsse. Bei der konkreten Kooperation zwischen dem

tert? Der politische Islam verdrängt den Säkularismus (27.04.2016), URL: <http:// www.freiewelt.net/reportage/islamische-welt-saekularismus-vollends-gescheitert-10066582> (27.12.2016).

103 Asad, Formations, S. 159. Er hat vor allem die Situation im laizistischen Frankreich im Blick, ebd., S. 175-177.

104 Ebd., S. 178.

105 Siehe hierzu Nimet ŞEKER, Ist der Islam ein Integrationshindernis? - Essay, in: Aus Politik und Zeitgeschichte (23.03.2011), URL: <http://www.bpb.de/apuz/33389/ ist-der-islam-ein-integrationshindernis-essay> (02.12.2016). Zur Kritik »liberaler« Beliebigkeit siehe Ali Mete, »Liberaler Islam«. Ein Projekt voller Fragezeichen, in: IslamiQ (12.11.2017), URL: <http://www.islamiq.de/2017/11/12/liberaler-islam-einprojekt-voller-fragezeichen $>$ (13.11.2017). 
Staat und den Religionen stellt sich jedoch nicht die Wahl, ob »der« Islam als Partner akzeptiert wird, genauso wenig wie übrigens »das « Christentum ${ }^{106}$; vielmehr wird geprüft, welche Organisationen konkret die strukturellen und inhaltlichen Eigenschaften einer Religionsgemeinschaft oder einer - rechtlich besser gestellten - Körperschaft öffentlichen Rechts erfüllen.

Dass es sich bei der institutionellen Integration des Islams in die säkulare Ordnung um einen zähen Aushandlungsprozess handelt, belegt etwa das Beispiel des Islamunterrichts an Schulen und Universitäten in Deutschland. Die deutsche Politik debattierte seit einem entsprechenden Beschluss der Kultusministerkonferenz von 1984 über die Einrichtung eines islamischen Religionsunterrichts an staatlichen Schulen. Seit der Jahrhundertwende liefen in mehreren Bundesländern Modellversuche, ehe in den vergangenen Jahren in acht Bundesländern Religionsunterricht mit verschiedenen islamischen Kooperationspartnern eingerichtet wurde. Für die islamische Religionslehrerausbildung wurden 2012 an fünf universitären Standorten vom Bund finanzierte Abteilungen für islamische Theologie gegründet ${ }^{107}$. Trotzdem wurde im November 2017 das Ansinnen zweier großer Islam-Verbände, islamischen Religionsunterricht unter eigener Regie an den Schulen Nordrhein-Westfalens anzubieten, durch das Oberverwaltungsgericht Münster in zweiter Instanz abschlägig beschieden ${ }^{108}$. Nach dem Gerichtsurteil erfüllen beide Großverbände nicht die Merkmale einer Religionsgemeinschaft im Sinne des Grundgesetzes ${ }^{109}$. Daher besteht nun unter Muslimen die Befürchtung, das Urteil könne weit reichende Folgen haben, da bestehende Kooperationen mit staatlichen Stellen in allen Bundesländern auf den Prüfstand kommen könnten ${ }^{110}$. Obwohl das Bundesverwaltungsgericht schon in der Revisionsverhandlung von 2005 gewarnt hatte, dass sich in Mitgliederstruktur und Dachverbandsarbeit originär religiöse Kompetenz zeige müsse, nicht nur Fachkompetenz in Jugend- und Bildungsarbeit oder religionspolitisches Engagement, versäumten es beide Verbände in den folgenden zwölf Jahren,

106 Vgl. RoHe, Islam in Deutschland, S. 152.

107 Siehe ebd., S. 288-293.

108 Der Zentralrat der Muslime in Deutschland und der Islamrat für die Bundesrepublik Deutschland hatten schon 1998 gegen das Land auf Einrichtung eines islamischen Religionsunterrichts geklagt; an der 2012 vom Land geschaffenen und bis 2019 laufenden Übergangslösung in 230 Schulen wirken sie nur über einen Beirat mit.

109 Nach dem Urteil (Aktenzeichen: 19 A 997/02) mangelt es beiden Vereinen an »Sachautorität und -kompetenz für identitätsstiftende religiöse Aufgaben« sowie an der »realen Geltung« der in Anspruch genommenen religiöse Autorität in der gesamten Gemeinschaft bis hinunter zu den Moscheegemeinden, siehe Oberverwaltungsgericht NRW, Kein Anspruch auf Einführung islamischen Religionsunterrichts (09.11.2017), URL: <http://www.ovg.nrw.de/behoerde/presse/pressemitteilungen/ 50_171109/index.php> (10.11.2017).

110 Siehe den Blog-Eintrag von Murat Kayman, Woran es gelegen hat (11.11.2017), URL: <http://murat-kayman.de/2017/11/11/woran-es-gelegen-hat> (13.11.2017). 
dementsprechende Veränderungen vorzunehmen. Ein früherer DİTİBFunktionär urteilt deshalb, der Ausgang des Rechtsstreits sei nicht etwa »durch antimuslimischen Rassismus [...] entschieden worden«, sondern »die Folge ganz erheblichen persönlichen und institutionellen Unvermögens auf muslimischer Seite «111.

Dass in langwierigen Aushandlungsprozessen oft gegenläufige Tendenzen zum Tragen kommen können, zeigt sich auch daran, dass heute restriktivere rechtliche Leitlinien für Anträge auf Unterrichtsbefreiung (Schwimmunterricht für Mädchen, Sexualkundeunterricht), die in den 1990er Jahren noch großzügig gehandhabt wurden, gelten, während etwa in der KopftuchDebatte die Entscheidungen zunehmend liberaler ausfielen ${ }^{112}$. Im Konflikt um die Lehrerin Fereshta Ludin, der das Land Baden-Württemberg 1998 die Einstellung in den staatlichen Schuldienst mit Verweis auf ihr Kopftuch verweigerte, hatte das Bundesverfassungsgericht noch 2003 dem Gesetzgeber zugebilligt, religiöse Symbole bei verbeamteten Lehrkräften zu verbieten. Hatten daraufhin acht Bundesländer entsprechende Gesetze erlassen, so präzisierte das Gericht 2015, dass ein pauschales Verbot unverhältnismäßig sei ${ }^{113}$.

Das Beispiel der Kopftuch-Urteile verdeutlicht, dass die säkulare Ordnung politisch-legal auf Freiheit ausgerichtet und daher offen für Diversität ist, während es jedoch oftmals kulturell-religiöse Vorbehalte von Seiten der Mehrheitsgesellschaft gibt ${ }^{114}$. Weitere Beispiele für diesen Konflikt sind die Geschlechtertrennung und die Vermeidung des Händeschüttelns zwischen Angehörigen verschiedenen Geschlechts. Beides stellt einen Konflikt dar zwischen dem Umstand, dass die politisch-legalen Freiheiten eine solche Praxis erlauben, und dem Gefühl, dass das nicht die normale Art ist, wie "wir« hier miteinander umgehen. So machte zum Beispiel die Schulbehörde in Basel-Land 2016 das Händeschütteln unter Strafandrohung zur Pflicht, nachdem zwei Schüler aus Syrien ihrer Lehrerin diese Art der Begrüßung verweigert hatten ${ }^{115}$.

In der öffentlichen Debatte wird die Problematik der Ausgestaltung der säkularen Ordnung permanent mit den so genannten »Integrationsproble-

111 Ebd.

112 Siehe zu diesen Beispielen RoHe, Islam in Deutschland, S. 211 und 197-199.

113 Siehe den Beschluss (1 BvR 471/10, 1 BvR 1181/10) vom 27.01.2015 sowie Bundesverfassungsgericht, Ein pauschales Kopftuchverbot für Lehrkräfte in öffentlichen Schulen ist mit der Verfassung nicht vereinbar, Pressemitteilung 14/2015 (13.03.2015), URL: <https://www.bundesverfassungsgericht.de/SharedDocs/Pressemitteilungen/DE/2015/bvg15-014.html> (09.11.2017).

114 Berger, The Third Wave, S. 123f.

115 AFP, Muslimische Schüler müssen ihrer Lehrerin die Hand schütteln, in: FAZ (25.05.2016), URL: <http://www.faz.net/aktuell/gesellschaft/muslimische-schuelermuessen-lehrerin-hand-schuetteln-14252518.html> (23.12.2016). 
men« vermengt, also mit einer Reihe politischer, sozialer, kultureller und sicherheitspolitischer Fragen, die kollektiv Muslimen zugeschrieben werden. Wie Muslime individuell zu Staat und Gesellschaft stehen, wird über »Werte«, »Einstellungen« und »Normen« statistisch abgefragt; die dabei gewonnen und häufig als problematisch bewerteten Ergebnisse färben wiederum auf die juristisch und politisch ganz anders gelagerte Frage ab, wie die Integration islamischer Gemeinschaften in die säkulare Ordnung zu bewerkstelligen sei. Als typisches Beispiel für die Vermengung beider Perspektiven dürfen der Besteller, die ARD-Dokumentation und die Aussagen des Journalisten Constantin Schreiber gelten, der sich, obwohl er nichts Verfassungsfeindliches zu hören bekam, »ernüchtert« und »beunruhigt« über »konservative« und "antidemokratische « Freitagspredigten in 13 von ihm besuchten Moscheen zeigte ${ }^{116}$. Ihm zufolge predige »niemand «Integration, stattdessen seien »Abgrenzung und die Bewahrung der eigenen Identität« zentrale Botschaften $^{117}$. An diesen Aussagen verblüfft nicht alleine, wie wenig Predigten als eigenständige religiöse Redeweise verstanden, wie sehr sie politisch und dadurch auch teilweise falsch gedeutet und wie umstandslos sie auf den Zustand des Islams in Deutschland hochgerechnet werden ${ }^{118}$. Noch mehr erstaunt, wie Prozesse der Abgrenzung und Identitätswahrung lediglich als muslimisches Verhalten problematisiert werden, ohne spiegelbildliche Prozesse in großen Teilen der Mehrheitsgesellschaft in Rechnung zu stellen ${ }^{119}$, zu denen auch Journalisten selbst mit ihren »Moschee-Reports $«{ }^{120}$ beitragen. Gegen einen Moschee-Bau in Köln etwa demonstrierten Gegner 2008 mit

116 Siehe Constantin Schreiber, »Gott allein ist der Gesetzgeber« (31.03.2017), URL: <http://www.zeit.de/gesellschaft/zeitgeschehen/2017-03/inside-islam-constantinschreiber-moscheen-freitagspredigten> (09.11.2017). Zum Besteller siehe ders., Inside Islam. Was in Deutschlands Moscheen gepredigt wird, Berlin 2017. Zur ARDDokumentation $»$ Der Moschee-Report« (28.03.2017) siehe URL: <https://www. tagesschau.de/multimedia/video/video-273349.html> (05.04.2019).

117 Ders., »Niemand predigt Integration« (30.03.2017), URL: <http://www.zeit.de/ 2017/14/islam-constantin-schreiber-moscheen-predigt-imame > (09.11.2017).

118 Zur umfangreichen Kritik an diesen Aussagen siehe beispielhaft Canan TopçU, Outside Islam, in: al-Qantara (05.04.2017), URL: <https://de.qantara.de/inhalt/ constantin-schreibers-moscheereport-outside-islam> (09.11.2017).

119 Repräsentative Umfragen weisen für alle EU-Staaten starke Vorbehalte in der Bevölkerung gegenüber Muslimen aus. In Deutschland etwa stimmten in einer Allensbach-Umfrage von 200683 Prozent der Befragten der Aussage zu, der Islam sei fanatisch, 62 Prozent hielten ihn für rückwärtsgewandt, 71 Prozent für intolerant, 60 Prozent für undemokratisch und 91 Prozent für frauenunterdrückend. Siehe dazu Heiner Bielefeldt, Das Islambild in Deutschland, in: Thorsten Gerald SchneIders (Hg.), Islamfeindlichkeit. Wenn die Grenzen der Kritik verschwimmen, Wiesbaden ${ }^{2} 2010$, S. 173-206, hier S. 174.

120 Als journalistische Vorläufer für Schreibers Moschee-Report dürfen UndercoverBerichte gelten, wie sie die BBC und Channel 4 (»Undercover Mosque «) schon in den Jahren 2005 beziehungsweise 2007 über britische Moscheen sowie das dänische Fernsehen TV2 im Jahre 2016 über dänische Moscheen sendeten. Weil es in den 
der Parole »Gegen Türkisierung und Islamisierung. Köln darf nicht Istanbul werden ${ }^{121}$. Allein schon die anhaltende Debatte darüber, ob der Islam denn zu Europa "gehöre ${ }^{122}$, verschiebt die Frage nach islamischer Teilhabe auf die Ebene eines wesenhaften Kulturgegensatzes. Trotz ihrer physischen Präsenz, so lautet der Subtext dieser Debatte, "gehörten« Muslime kulturell eigentlich nicht nach Europa, sondern bedrohten es sogar.

Kontrafaktisch ist dieser Subtext, weil Umfragen zufolge die Mehrheit der Muslime in Europa die politisch-legale Grundordnung, also demokratische und säkulare Institutionen, begrüßt und Gewalt für eine hehre Sache ablehnt, zum Teil sogar deutlicher als die Mehrheitsbevölkerung ${ }^{123}$. Vergleichende Untersuchungen belegen zudem, dass sich Migranten in ihrem Verhalten und ihren Einstellungen an die Mehrheitsgesellschaft annähern. Sunniten, die sich nach eigener Einschätzung als »hochreligiös« einstufen, unterscheiden sich deutlich voneinander, je nach dem, ob sie in der Türkei oder in Deutschland leben ${ }^{124}$. In der Türkei stieß die Heirat Homosexueller bei ihnen ebenso wie bei "Mittelreligiösen" auf weniger Toleranz (12 respektive 33 Prozent) als bei der hoch- und mittelreligiösen sunnitischen Vergleichsgruppe in Deutschland (40 respektive 60 Prozent), während sich bei "nicht und wenig Religiösen" kein Unterschied zwischen der Türkei und Deutschland (je 67 Prozent) abbildete ${ }^{125}$. Auch sind im Vereinsleben Muslime aktiver als Angehörige anderer Religionen. Mehr als die Hälfte aller Muslime über 16 Jahre sind in einem deutschen Verein, nur vier Prozent ausschließlich in einem rein herkunftsbezogenen Verein (etwa: türkischer

heimlich gefilmten Beiträgen gelang, radikale Äußerungen von einigen Imamen aufzunehmen, schlugen diese Reports jedoch noch deutlich höhere Wellen in der Öffentlichkeit als die ARD-Dokumentation.

121 Thorsten Gerald Schneiders, Einleitung, in: Ders. (Hg.), Islamfeindlichkeit, S. 9-15, hier S. 12.

122 Stephan Detjen, »Der Islam gehört zu Deutschland«. Geschichte eines Satzes (13.01.2015), URL: <http://www.deutschlandfunk.de/der-islam-gehoert-zudeutschland-die-geschichte-eines-satzes.1783.de.html?dram:article_id=308619> (16.01.2017). Es lässt sich zudem fragen, warum diese Frage gerade jetzt, da Muslime in Europa sichtbar geworden sind, diskutiert wird und welche Funktionen sie erfüllt, siehe Schirin Amir-Moazami, Dämonisierung und Einverleibung. Die "muslimische Frage" in Europa, in: Maria do Mar Castro Varela/Paul Mecheril, Die Dämonisierung der Anderen. Rassismuskritik der Gegenwart, Bielefeld 2014, S. 21-39, hier S. 23f.

123 Mathias RoHe, Islam und säkularer Rechtsstaat: Grundlagen und gesellschaftlicher Diskurs, in: Aus Politik und Zeitgeschichte (23.03.2011), URL: <http://www.bpb.de/ apuz/33391/islam-und-saekularer-rechtsstaat-grundlagen-und-gesellschaftlicherdiskurs? $\mathrm{p}=$ all $>$ (27.12.2016).

124 Ders., Islam in Deutschland, S. 84f.

125 Die Zustimmungswerte unter katholischen und evangelischen Christen sowie Konfessionslosen liegen bei 70, 78 und 87 Prozent. 
Kulturverein) aktiv ${ }^{126}$. In den islamischen Jugendkulturen Europas wiederum vereinen sich Performanz, Popkultur und die Kommerzialisierung von Religion, was ein kulturell hybrides Phänomen darstellt ${ }^{127}$.

Kontrafaktisch ist der genannte Subtext auch deshalb, weil die Anwesenheit von Muslimen in Europa keineswegs neu ist. So standen Gebiete von einem Dutzend der momentan 28 EU-Staaten im Laufe der Geschichte unter arabischer, maurischer oder osmanischer Herrschaft. Auf der iberischen Halbinsel herrschten Muslime 800 Jahre, in Südosteuropa 500 Jahre lang. Als Bewohner sind Muslime ähnlich lange in Europa beheimatet, in Litauen und Polen sind es mehr als 600 Jahre. In deutschen Landen ist eine größere muslimische Präsenz zwar eher jüngeren Datums, doch erste Kontakte reichen bis in die Zeit Karls des Großen zurück, und schon ab dem 16. Jahrhundert waren vereinzelt muslimische Gefangene zugegen, arbeiteten in verschiedenen Berufen, konvertierten und heirateten teils sogar in adlige Familien ein ${ }^{128}$.

Der Verweis auf die soziale und historische Verwurzelung von Muslimen in Europa entfaltet in der Öffentlichkeit in der Regel nur geringe Überzeugungskraft. Nicht nur, weil der Subtext von der Fremdheit des Islams hohe Plausibilität und Affekt gestützte Zustimmung genießt, sondern auch, weil islam- und religionskritische Akteure in ihrem Kulturkampf gegen eine so genannte »Überfremdung « die Säkularität der Rechts-, Staats- und Gesellschaftsordnung als Argument benutzen, um das Recht auf kulturell-religiöse Eigenheiten auszuhebeln. Das erfolgreiche Schweizer Referendum von 2009 gegen den Minarettbau war insofern vielsagend, weil es damals gerade einmal vier Moscheen mit Minaretten in der Schweiz gab. 2012 entbrannte nicht nur in Deutschland eine Debatte über die Beschneidung von Knaben, nachdem ein Urteil des Landgerichts Köln den Eingriff als rechtswidrig eingestuft hatte $^{129}$. Unterschiedliche Politiker schlagen immer wieder ein Verbot des

126 Rohe, Islam in Deutschland, S. 112; Peter Carstens, Viel mehr Muslime als gedacht, in: FAZ (24.06.2009), URL: <https://www.faz.net/aktuell/politik/inland/ neue-studie-viel-mehr-muslime-als-gedacht-1813914-p2.html?printPagedArticle= true\#pageIndex_1> (20.12.2016).

127 Julia Gerlach, Zwischen Pop und Dschihad. Muslimische Jugendliche in Deutschland, Bonn 2006; Sunier, Beyond the Domestication, S. 198f; Gritt KLInKHammer, Islamic Style - die Sichtbarkeit "unsichtbaren" Islams, in: Dorothea LÜDDECKENS u.a. (Hg.), Die Sichtbarkeit religiöser Identität. Repräsentation - Differenz - Konflikt, Zürich 2013, S. 111-136.

128 Michael Borgolte, Der Islam als Geburtshelfer Europas, in: Aus Politik und Zeitgeschichte (23.03.2011), URL: <http://www.bpb.de/apuz/33398/der-islam-alsgeburtshelfer-europas? $\mathrm{p}=$ all $>(27.12 .2016)$.

129 Rohe, Islam in Deutschland, S. 192-194. Ende des Jahres 2012 sorgte der Bundestag per Gesetz für die Klarstellung, dass es sich nicht um eine Körperverletzung handele. Für die Debatte über Deutschland hinaus siehe Nilüfer GöLE, Europäischer Islam. Muslime im Alltag, Berlin 2016, S. 232-237. 
Gesichtsschleiers (»Burka-Verbot») vor, wie es seit 2011 in Frankreich praktiziert wird und vom Europäischen Gerichtshof 2016 gebilligt wurde, durch den algerischen Millionär Rachid Nekkaz aber auch ad absurdum geführt wird, weil dieser die selten ausgestellten Bußgelder von 150 Euro $^{130}$ für die »Burka-Trägerinnen« bezahlt ${ }^{131}$. Ein Burkini-Verbot in mehreren französischen Mittelmeer-Gemeinden, das das Zeigen nackter Haut am Strand im Juli 2016 zu einem laizistischen Wert erhob, wurde einen Monat später vom Obersten Verwaltungsgericht gekippt.

Solche Verbotsdebatten haben einen ambivalenten Charakter. Zum einen sorgen sie tatsächlich in einer Reihe von Punkten - vom Moscheebau über das islamische Schlachten bis zum Bestattungswesen - für rechtliche Klärung und damit auch für Rechtssicherung auf islamischer Seite. Zum anderen haben sie eine »irritierende Ähnlichkeit« ${ }^{132}$ mit Streitthemen, die in Bezug auf das Judentum im 19. Jahrhundert aktuell waren (Synagogenbau, Kippa-Tragen, Schulbesuch), und beziehen daher oft auch konkret das Judentum mit ein. Sie bedienen somit eine $»$ Desintegrationsindustrie ${ }^{133}$, die nicht nur eine Stigmatisierung des Islams bewirkt, sondern generell das Recht von Minderheiten auf Andersartigkeit in Abrede stellt.

\section{Ausblick}

Weder der Umstand, dass Muslime oft auf ihre Religionszugehörigkeit reduziert und per se als gläubig wahrgenommen werden, noch der Umstand, dass politische Gewalttäter sich auf den Islam berufen, belegt einen Mangel an Säkularisierung oder gar eine Umkehr von Säkularisierungsprozessen unter Muslimen. Wie andere mehr oder weniger Gläubige auch, sind Muslime in den säkularen »immanent frame« (Taylor) der Moderne geworfen, in dem Glaube und Religion begründungsbedürftig geworden sind. Dies zwingt den einzelnen zu einer Auseinandersetzung mit der religiösen Tradition, zu eigener Reflektion und im besten Fall zu einem offenen Dialog mit dem »anderen«. Folglich stellen sich auch für Muslime Fragen nach der persönlichen, ethischen, sozialen und politischen Bedeutung von Religion unter modernen Umständen neu. Die Antworten darauf fallen individuell und

130 Siehe zum rechtlichen Hintergrund den Beitrag in diesem Band von Germann, Säkularisierung und Religion in der Perspektive des Religionsverfassungsrechts, S. 201.

131 Petra Sorge, Der Laizismus ist eine gewaltvolle Ideologie, in: Cicero (10.12.2015), URL: <http://cicero.de/weltbuehne/algerier-bekaempft-burka-verbot-frankreichein-freiheitsfeindliches-intolerantes-europa-der> (20.12.2016).

132 GöLE, Europäischer Islam, S. 230.

133 Rohe, Islam in Deutschland, S. 167 unter Berufung auf den Migrationsforscher Klaus Bade. 
kontextgebunden sehr unterschiedlich aus, vom übersteigerten Glauben bis zum Unglauben, vom Rückzug auf traditionelle Werte bis zum politischen Aktivismus. Die Heterogenität islamischer Lebenswelten, wie sie sich heute in Europa darstellt, ist daher kein Irrweg, sondern Folge unterschiedlicher Erfahrungen und widersprüchlicher Prozesse wie Globalisierung und Individualisierung. Einerseits hat sich der Islam durch Migration und Vernetzung zu einer globalen Marke entwickelt, die lokale Kulturen vereinnahmen, wenn nicht einebnen kann. Andererseits bleibt der Islam weiterhin durch interne Vielfalt gekennzeichnet ${ }^{134}$, die auch offen für unorthodoxe und individualistische Praktiken ist.

Deshalb kann es nur als Missverständnis bezeichnet werden, dass »der" Islam in der Säkularisierungsdebatte in verschiedenen wissenschaftlichen Ansätzen als Kontrastfolie herhalten muss. Gleiches gilt für Klassifikationsschemata des »Säkularen« und »Religiösen«, die eine eigenständige Kategorie des "Islamischen" hervorbringen und dieses einerseits dem Religiösen zuordnen, aber vom Christlichen scheiden, oder es andererseits, mangels Säkularität, als der binären Klassifikation enthoben behandeln. Diese Fehlklassifikation basiert darauf, dass innerislamische Differenzen ebenso wie säkularisierende Prozesse zu wenig Beachtung finden, angefangen von Daten zur Religiosität und zum Lebensstil über die begrenzte Bindekraft religiöser Institutionen bis hin zur Koexistenz säkularer und religiöser Logiken, die in Politik, Recht, Wirtschaft und Gesellschaft in »islamischen« Staaten herrscht. Selbst im Falle selbsterklärter Feinde des Säkularismus ist zu diskutieren, inwiefern eine säkulare Ordnung ihre Gegner zu tolerieren hat und inwiefern diese mit ihrer Gewalt- und Staatsfixiertheit einer »unbewussten Säkularisierung ${ }^{135}$ Vorschub leisten.

Mit Blick auf drei Nationsbildungsprozesse in mehrheitlich islamischen Gesellschaften wurde weiter argumentiert, dass krisenhafte politische Entwicklungen nicht durch die fehlende Trennung von Staat und Religion oder durch die gewaltsame Durchsetzung einer säkularen Ordnung gegen den Islam erklärt werden können. Problematisch wirkte sich vielmehr ein nationales Homogenisierungsstreben aus, in dem der Islam eine ambivalente Rolle spielte. Während er in der Phase nationaler Mobilisierung vereinheitlichend und ausgrenzend zugleich wirkte, wurde er nach der Unabhängigkeit sowohl von oppositionellen als auch von staatlichen Akteuren benutzt; in Folgekonflikten nach der Unabhängigkeit bildete er jedoch nur eine von mehreren Komponenten, mit denen Akteure ihre je eigenen Interessen im Namen von Nation, Ethnie, Religion oder Konfession artikulierten.

134 Siehe etwa Sadik Hamid, Sufis, Salafis and Islamists. The Contested Ground of British Islamic Activism, London u.a. 2016.

135 Rothнolz, Rudimente, S. 251f. 
In der Debatte um den Islam in Europa wurden drei problematische Container-Verständnisse ausgemacht, mit denen der Islam als Antipode der säkularen Ordnung ausgewiesen wird: Verächter der Säkularität argumentieren, Muslime nützten eine wenig wehrhafte säkulare Ordnung als Einfallstor zur Islamisierung; Kritiker sehen Muslime durch Säkularismus strukturell ausgegrenzt; und übereifrige Verfechter der säkularen Ordnung fürchten, diese sei durch islamische Forderungen auf Gleichstellung in ihren Grundfesten gefährdet.

Ein Blick auf die Rechtsprechung sowie auf bestehende Kooperationen zwischen staatlichen und islamischen Partnern weist die Integration islamischer Verbände in die säkularen Rechtsordnungen Europas hingegen als störungsanfälligen Verhandlungsprozess aus, bei dem in den vergangenen Jahrzehnten gleichwohl Fortschritte erzielt wurden. Erkauft sind diese Fortschritte zum Preis einer Mitwirkungspflicht in hegemonialen Strukturen, einer Angleichung heterogener Organisationen an das Vorbild christlicher Kirchen, einer "Diskurs-Wucherung" zum Thema Islam in Politik und Medien sowie der Interferenzen aus den Bereichen der Sicherheits-, Migrations- und Integrationspolitik. Richterlich gekippte Verbote, konträre politische Initiativen sowie wandelbare rechtliche Grenzziehungen zeigen, wie sehr demokratische Gesellschaften darum kämpfen, freiheitliche Grundlagen, eine Offenheit für Veränderungen, sowie legale und kulturelle Ambivalenzen auszubalancieren. Während Muslime und islamische Vereine um ihr Selbstverständnis und ihren Platz in einer pluralistischen Gesellschaft ringen, besteht für europäische Gesellschaften die Herausforderung darin, sich gleichzeitig gegen islamisch begründeten Terrorismus wappnen, islamische Kooperationspartner anerkennen und die Grundlagen der säkularen Ordnung kritisch reflektieren zu müssen. Vor diesem Hintergrund betreffen die Aushandlungsprozesse zum Islam weder allein das religiöse Feld, noch vollziehen sie sich in einem herrschaftsfreien Raum. Es dürfte aufgrund dieser Gemengelage ein schwer aufzulösendes Spezifikum sein, dass mit den vorherrschenden Anerkennungsgesten Asymmetrien verbunden sind und fortgeschrieben werden, die sich etwa in der einseitigen Betonung von Integrationsdefiziten bei Muslimen oder der konditionalen Akzeptanz muslimischer Gesprächspartner zeigen. Die offen zu Tage tretenden Asymmetrien verweisen auf ein tieferliegendes Problem, sind sie doch nur ein - vielleicht besonders prägnantes - Beispiel für Ein- und Ausschlussmechanismen gegenüber marginalisierten Gruppen in liberal-säkularen Gesellschaften. Hier zeigt sich exemplarisch, wie politisch-rechtliche, religiöse, soziale, kulturelle, rassische und räumliche Formen gesellschaftlicher Ausgrenzung und Stigmatisierung ineinandergreifen und mit Politiken der Inklusion legitimiert und verwaltet 
werden ${ }^{136}$. Um dies zu thematisieren und bestenfalls auch zu ändern, müsste in Politik und Medien an die Stelle der oftmals obsessiven »Diskurs-Wucherungen« über Muslime freilich »die Bereitschaft treten, sich grundlegender mit den Ausschlussmechanismen liberaler Gesellschaften auseinanderzusetzen, anstatt liberale Freiheiten als neutrale Basis unbefragt vorauszusetzen ${ }^{137}$.

136 Siehe aus historischer Perspektive etwa Lutz RaphaEL, Grenzen von Inklusion und Exklusion. Sozialräumliche Regulierung von Armut und Fremdheit im Europa der Neuzeit, in: JMEH 11 (2013), S. 147-167.

137 Amir-Moazami, Wer spricht für wen, S. 374. 


\title{
Glaube durch Denken ins Gespräch bringen und zum "Tisch des Lebens« (Joseph Ratzinger) einladen
}

\author{
Phänomene des Säkularismus als Ansporn für kirchliche \\ Selbstreflexion und theologische Konzentration
}

\section{Zu einer Revitalisierung der Deutungskategorie des »Säkularismus«}

Wenn man von einer »Säkularisierung « und ihren empirischen Phänomenen spricht, kann man diesen Begriff nicht verwenden, ohne auf die Herkunft und Funktionsdynamik der sogenannten »Säkularisierungsthese« als hinterfragbares Wissenschaftsparadigma einzugehen. Systematische Theologie, Theologiegeschichte und darauf rekurrierende lehramtliche Äußerungen der Kirchen zu einer vermeintlichen oder tatsächlichen Verweltlichung in und außerhalb der Kirche kommen nicht umhin, sich die Herkunftsorte dieser Begriffswelten in der Wissenschaftsgeschichte der Soziologie zu vergegenwärtigen. Darauf macht Karl Gabriel aufmerksam: "Die Grundzüge der Säkularisierungsthese sind damit tief in die Ursprünge der Soziologie an der Wende vom neunzehnten zum zwanzigsten Jahrhundert eingelassen. Sie macht einen Teil der disziplinären Identität des Faches aus «"

Dementsprechend kündigt sich in den letzten Jahrzehnten des 20. und 21. Jahrhunderts interdisziplinär die Achtsamkeit darauf $\mathrm{an}^{2}$, dass es sich hier um eine Wissenschaftsthese handelt, die ihre eigene Realitätsbasis breitenwirksam mit erschuf ${ }^{3}$, ohne jedoch Religiosität, auch als öffentlichkeitswirksamen Faktor, flächendeckend zum Schweigen bringen zu können.

1 Karl Gabriel, Von der Postsäkularität zu den multiplen Modernen und Säkularitäten, in: George Augustin (Hg.), Die Strahlkraft des Glaubens. Identität und Relevanz des Christseins heute, Freiburg 2016, S. 165-186, hier S. 168.

2 Zu methodischen Unschärfen des Säkularisierungsparadigmas Jürgen Habermas, Religion in der Öffentlichkeit der "postsäkularen« Gesellschaft, in: Ders., Nachmetaphysisches Denken II. Aufsätze und Repliken, Berlin 2012, S. 308-327, hier S. 312; sowie Ulrich RuH, Säkularisierung als Interpretationskategorie. Zur Bedeutung des christlichen Erbes in der modernen Geistesgeschichte, Freiburg u.a. 1980, S. 352.

3 Beschrieben im Anschluss an Hermann Lübbe bei Gregor Maria Hoff, Ein anderer Atheismus. Spiritualität ohne Gott?, Kevelaer 2015, S. $35 f$.

4 Gabriel, Von der Postsäkularität, S. 170. 
Eine von der akademischen Hochkultur zu Unrecht übersehene Nische ist die vielfältige Religiosität in der Popularkultur, in deren Medien unbefangen religiöse Motive und Fragen durchgespielt werden ${ }^{5}$.

Da die Säkularisierungsthese sowohl in der Soziologie als auch in der Theologie besprochen wird, ist zu beachten, dass sie je nach Disziplin mit anderen parallelen Fragenkreisen mit behandelt wird: Nämlich in der Theologie im Zusammenhang mit unterschiedlichsten Spielarten des Atheismus. Darauf wird dieser Beitrag später zurückkommen. In der Soziologie wird hingegen die Parallele zu Debatten über Modernisierungsprozesse gezogen. Weil sich in der Postmoderne weitere Modernisierungsschübe ereignen, ermöglicht ein differenzierter Blick auf solchermaßen polyphone Modernisierungsverläufe Karl Gabriel, das Theoriedesign von »multiplen Modernen « vorzustellen?. Damit verbindet er im Anschluss an Monika WohlrabSahr die Redeweise von "multiplen Säkularitäten ${ }^{8}$, um zu erklären, warum äußere gesellschaftliche Umstände nicht die einzigen Faktoren für individuelle Glaubenshaltungen sind. Folglich kann die theologische Deutung der Gegenwart von unzureichenden pessimistischen Diagnosen entlastet werden, meint Karl Gabriel: "So weit in der Kirche und ihrer Pastoral ein Säkularisierungsbewusstsein vorherrschend ist, sollte es der Überzeugung weichen, dass die Zukunft von Religion und Kirche nicht gesellschaftlich vorentschieden, sondern offen ist «?.

Statt mit Schlagworten zu operieren, müsste also mit bedachtsamem Augenmerk abgewogen und diskutiert werden, mahnt der Gegenwartsautor Tomáš Halík ${ }^{10}$. Atheistische Äußerungen zielen, wenn auch zuweilen unwissentlich, nicht immer auf eine völlige Verneinung der Existenz Gottes, sondern auf bedenkliche Gottesbilder. Diese Unterscheidung verbietet es Gläubigen und Theologen, Formen von Atheismus und Säkularisierung in einer

5 Ebd., S. 173 sowie Terry Eagleton, Der Tod Gottes und die Krise der Kultur. Aus dem Englischen von Ulrike Strerath-Bolz, München 2015, S. 11. Dazu, dass manche »[...] Wissensbestände der Gegenwart [...]« durch die zeitgenössische Theologie übersehen werden, vgl. Hans-Joachim SANDER, Sieben Fehlanzeigen - Oder: Wie man der gefährlichen Profession und kritischen Berufung der Theologie ausweichen kann, in: Rainer Bucher u.a. (Hg.), Was fehlt? Leerstellen der katholischen Theologie in spätmodernen Zeiten. Ein Experiment, Würzburg 2015, S. 89-96, hier S. 91. Merkmale eines neuen Polytheismus behandeln Hubert Dreyfuss u.a., Alles, was leuchtet. Wie große Literatur den Sinn des Lebens erklärt. Aus dem Amerikanischen von Yvonne BADAL, Berlin 2005, S. 322f.

6 Gabriel, Von der Postsäkularität, S. 177.

7 Ebd., S. 178.

8 Ebd., S. 180.

9 Ebd., S. 184.

10 Das folgende nach Tomáš Halík, Prolog: Der tote Gott. Die Rede des tollen Menschen, in: Anselm GrüN u.a (Hg.), Gott los werden? Wenn Glaube und Unglaube sich umarmen, Münsterschwarzach 2016, S. 7-20, hier S. 18. 
oberflächlichen Wertung als »Gottlosigkeit« zu brandmarken. Im Unterschied zu einigen Theologen um die Mitte des 20. Jahrhunderts sieht sich die intellektuelle Auseinandersetzung heute nicht mehr nur mit einem kämpferischen Atheismus konfrontiert ${ }^{11}$, oder mit einem edelmütigen, humanistischen Idealen verhafteten Agnostizismus, sondern steht einem argumentativ weniger fasslichen Phänomen gegenüber: Eine Haltung, die den Glauben deswegen nicht bekämpft, weil er keine Wahrnehmung und keinen Streit mehr wert ist. Diese Haltung bezeichnet Tomáš Halík als "Apatheismus « ${ }^{12}$. Daneben bilde sich ein nicht weniger nicht-streitbarer "Etwasismus « ${ }^{13}$, ein Zugeständnis, dass es schon irgendeine Art von höherer Macht geben würde.

Daher erwähnt Tomáš Halík ${ }^{14}$ den Vorschlag eines begrifflichen Ausweges aus der Säkularisierungstheorie, den seinerzeit der evangelische Theologe Friedrich Gogarten vorgeschlagen hatte, nämlich die Deutungskategorie des Säkularismus.

Im 19. Jahrhundert war das Nomen »secularism « als Selbstbezeichnung von Gruppierungen gewählt worden, die eine bewusst kirchenferne, innerweltliche, materialistische Daseinsweise propagierten ${ }^{15}$. Friedrich Go-

11 Manuel Schlögl sieht allerdings einen Zusammenhang zwischen dem jüngsten akademischen Atheismus und populären Strömungen. Er verwendet hierfür den Begriff des »Atmosphärischen«, der schon, wie in Kap. 2 dieses Artikels gezeigt werden wird, bei Michael Schmaus eine Rolle spielte: »Der Neue Atheismus stellt die argumentative, mediale Speerspitze eines selbst schwer greifbaren, atmosphärischen Atheismus in der westlichen Welt dar, [...] « (Manuel SchlögL, Mystik - Atheismus - Dunkle Nacht. Johannes vom Kreuz und Therese von Lisieux im Gespräch mit dem neuzeitlichen Atheismus, Regensburg 2013, S. 69).

12 Tomáš Halík, Mit der Hypothese Gott - oder ohne sie, in: Grün u.a. (Hg.), Gott los werden?, S. 57-76, hier S. 57. Auch die empirische Religionspädagogik berichtet, dass "[...] religiöse Fragen an Streitwert verloren haben «, weil ein »Vielleicht- und irgendwie-Gott« nicht mehr zum Disput reizt (Rudolf ENGLERT u.a., Innenansichten des Religionsunterrichts. Fallbeispiele, Analysen, Konsequenzen, München 2014, S. 130). Das Verschwimmen des Gottesbildes und des konfessionellen Bewusstseins tragen so zu einem Verlust an Bedeutsamkeit in Emotion und Diskurs bei. Dies erschwert es der Forschung, zu validen Deutungen der gegenwärtigen Spiritualität zu gelangen. Das beklagen schon 1969 Thomas M. Gannan und George W. Traub, The Desert and the City. An Interpretation of the History of Christian Spirituality, London 1969, S. 251.

13 Halík, Mit der Hypothese Gott - oder ohne sie, S. 65. Empirische Daten untermauern den Befund, dass die »[...] Vorstellung eines unpersönlichen höheren Wesens [...]« zunehmend an Attraktivität gewinnt (So Detlef Pollak, Säkularisierung - Konzept und empirische Befunde, in: Hans G. Kippenberg u.a. (Hg.), Europäische Religionsgeschichte. Ein mehrfacher Pluralismus, Bd. 1, Göttingen 2009, S. 61-86, hier S. 78).

14 Halík, Mit der Hypothese Gott - oder ohne sie, S. 66; sowie Rémi Brague, Die religiöse Ermöglichung des öffentlichen Raums, in: Jeremiah Alberg/Daniela KöDER (Hg.), Habitus fidei - Die Überwindung der eigenen Gottlosigkeit. Festschrift für Richard Schenk OP zum 65. Geburtstag, Paderborn 2016, S. 79-86, hier S. 86.

15 So Ulrich RuH, Säkularisierung, Säkularisation, Säkularismus. 1. Terminologie, 2. Geistesgeschichtlich, in: ${ }^{3}$ LThK 8, Sp. 1467-1469, hier Sp. 1467; ferner Rémi BRAGUE, Die Frage nach Gott vor dem Hintergrund der Säkularisierurg, in: Justinus 
garten brachte den Begriff des Säkularismus ins Spiel, um Wertungen der unterschiedlichen Folgen einer Säkularisierung vorzunehmen, die als reformatorische Errungenschaft in der Entwicklung des Christentums zu sehen sei. Das reformatorische Grundvertrauen im sola fide habe nach Gogarten insofern die Säkularisierung induziert, als der Mensch nicht mehr vor Gott auf seine menschlichen Werke pochen könne und er ihnen so keine numinose Wertigkeit zuweisen könne ${ }^{16}$. Die Rechtfertigung allein aus Glauben lässt den Glaubenden innerweltliches Gelingen als Geschenk sehen, das aber ohne strikteste Bezüglichkeit auf Gott kein Anzeiger und Garant von Heil sein könne. So wird einerseits der weltliche Bereich als rein weltlicher Bereich schärfer vom religiösen abgegrenzt, aber andererseits gerade aus der reformatorische Abgrenzung von weltlicher und geistlicher Gewalt noch deutlicher auf Gott bezogen:

Der Unterschied dieser beiden Gestalten der Säkularisierung besteht darin, daß die Säkularisierung, wie sie vom Glauben verstanden wird, ihren Sinn aus dem Verhältnis empfängt, in dem der Glaubende zu Gott steht. Und zwar in einem Verhältnis, wie es allein durch den Glauben möglich ist ${ }^{17}$.

Von einer solchen Säkularisierung unter dem Horizont Gottes, die zur Reinigung des Gottesverständnisses beiträgt, will Gogarten einen Säkularismus unterschieden wissen, der nur noch um Innerweltliches kreist und es so vergötzt. Denn die erste Form der Säkularisierung wird zum Anwalt eines noch tragfähigeren Gottesbildes. Statt eines ausgedachten, für die Immanenz verzweckten Gottes wird Raum geschaffen für den durchaus unbequemen christlichen Gott:

Jene von dem religiösen Denken als sich immer weiter verbreiteten Atheismus verurteilte Entgöttlichung der Welt und Gottlosigkeit des Menschen dieser Welt könnten neben allem anderen, was sie sonst sein mögen, auch die Möglichkeit bedeuten, daß infolge der Säkularisierung der Welt und des durch sie bewirkten Verschwindens des von jenem religiösen Denken gedachten Gottes aus dieser sich der Raum öffnet für Gott, wie er im Unterschied zu jenem dem wahrhaft christlichen Glauben entspricht und wie dieser allein ihn zu erkennen vermag ${ }^{18}$.

C. Pech / Camillo Kardinal Ruini (Hg.), Quellen - Auslegungen - Perspektiven. Internationale theologische Reflexionen der Premio-Ratzinger-Preisträger, Regensburg 2015, S. 237-257, hier S. 245.

16 Friedrich Gogarten, Die Frage nach Gott. Eine Vorlesung, Tübingen 1968, S. 173.

17 Ebd., S. 169.

18 Ebd., S. 160. 
$\mathrm{Zu}$ einem ähnlichen Urteil, dass zu einer Klärung des christlichen Gottesbildes »kritischer Atheismus hilft «" ${ }^{19}$, gelangt gegenwärtig Tomáš Halík:

Der Hauptfeind des christlichen Glaubens ist also nicht der Atheismus - im Sinne der Ablehnung bestimmter religiöser Vorstellungen und Theorien -, sondern der Aberglaube, die Idolatrie, der Götzendienst; diese hat der biblische Glaube immer als Lästerung, als Sünde gegen den Glauben abgelehnt. Der kritische Atheismus kann eine ikonoklastische Rolle einnehmen, er kann ein Verbündeter des Glaubens sein in dessen Kampf gegen Karikaturen und Ersetzungen, [... $]^{20}$.

Ein solcher Ersatz Gottes in innerweltlichen Wertigkeiten und Wertgegenständen, deren Bedeutung quasi religiös aufgeladen wird, ist nach Gogarten als Säkularismus zu kritisieren. In Konsumgesellschaften wird er zum Beispiel im »Shoppen « zelebriert, um den Preis der Exklusion von weniger kaufkräftigen Bevölkerungssegmenten und um den Preis der Ichschwächung ${ }^{21}$ durch die Überbewertung äußerer Statussymbole und durch die Persönlichkeitsdiffusion zwischen Berufsdruck und Freizeitstress ${ }^{22}$. Konsumismus wird so nicht nur Lebensstil, sondern eine Weltanschauung, der nicht-banale Wirklichkeitsauffassungen, wie zum Beispiel die einer religiösen Entscheidung, nicht mehr zugänglich sind ${ }^{23}$.

\section{Theologische Diagnosen vor dem Zweiten Vatikanum}

Angesichts einer solchen Umformung von Lebensstilen untersuchten katholische Autoren schon in der ersten Hälfte des 20. Jahrhunderts nicht nur die intellektuelle Ebene der Säkularität, sondern das entsprechende gesellschaftliche Klima, die »Atmosphäre «"

Dabei gelingt es Michael Schmaus, eine empathische Wahrnehmung der Gegenwartskultur in die traditionelle Lehre von den Tugenden und Schwierigkeiten im geistlichen Leben einzuordnen:

19 Halík, Prolog: Der tote Gott, S. 18. Vgl. zu einer Parallelaussage bei Joseph Ratzinger SCHLÖGL, Mystik - Atheismus - Dunkle Nacht, S. 63.

20 Halík, Mit der Hypothese Gott - oder ohne sie, S. 69.

21 Vgl. die Warnungen bei Wolfgang Schmidbauer, Jetzt haben, später zahlen. Die seelischen Folgen der Konsumgesellschaft, Reinbeck bei Hamburg 1995.

22 Vgl. die Analysen von Matthew B. Crawford, Die Wiedergewinnung des Wirklichen. Eine Philosophie des Ichs im Zeitalter der Zerstreuung. Aus dem Amerikanischen von Stephan Gebauer, Berlin 2016, S. $298 f$.

$23 \mathrm{Zu}$ diesen Zusammenhängen Thomas Ruster, Wandlung. Ein Traktat über Eucharistie und Ökonomie, Ostfildern 2006, S. 75-78.

24 Michael Schmaus, Katholische Dogmatik, Bd. 1, München ${ }^{6} 1960$, S. 247. 
In der Gegenwart hat die Trägheit des Herzens, welche für die Überzeugung von Gott lebensgefährlich ist, eine besondere, bisher kaum vorhandene Form angenommen, nämlich die Form der völligen Gleichgültigkeit und Abgestumpftheit. Sie ist geboren aus der Teilnahmslosigkeit des von der Härte und Betriebsamkeit des alltäglichen Lebens überbeanspruchten und daher übermüdeten menschlichen Herzens ${ }^{25}$.

Feinfühlig erklärt er spirituelle Wirkungszusammenhänge im Rückgriff auf Beobachtungen bei Augustinus: Christus rückt uns Menschen sozusagen auf den Leib, während Gott verborgen bleibt. Doch gerade dieser »Annäherungsversuch« des Gott-Menschen Christus weckt umso größeren Widerstand bei uns ${ }^{26}$.

Josef Pieper stellt die methodische Frage, wie plausibel aus persönlichen Erfahrungen eine Theorie abgeleitet werden kann ${ }^{27}$. Der Ausgang von dem praktischen individuellen Erleben gehört von jeher zur Methodik geistlicher Theologie, erscheint aber angesichts der Situation in Moderne und Postmoderne noch dringlicher ${ }^{28}$.

Während Joseph Ratzinger quer durch sein Lebenswerk die Metaphorik des Öffnens durch Gottes Offenbarungshandeln betonen wird, erwägt Pieper die psychologische Frage nach der Offenheit der menschlichen Seele für eine mögliche Erfahrung Gottes ${ }^{29}$. Dabei entdeckt er dasselbe Phänomen religiöser Erfahrung und Nicht-Erfahrung wie Michael Schmaus: Das Gefühl, dass der christliche Gott sich entfernt habe, entsteht gerade dadurch, dass der Mensch vor seiner Nähe erschreckt und zurückweichen will ${ }^{30}$. Verborgenheit Gottes wird von Pieper und Schmaus als Beziehungsangst des Menschen entlarvt, wobei diese religiöse Beziehungsangst dadurch geadelt ist, dass sie sehr wohl vermutet, wie überbordend die Nähe Gottes sein könnte, wenn man sie zulassen würde ${ }^{31}$.

25 Ebd., S. 257. Vgl. seine Hinweise auf »Unruhe« und »Erschöpfung« als verbreitetes Phänomen ebd., S. 269. Jahrzehnte später warnen Ärzte, dass chronischer Schlafmangel die Urteilsfähigkeit und Entscheidungsfähigkeit minimiert (und so auch die Tiefenmotivierung für eine Religion oder Weltanschauung verschleiern kann; vgl. hierzu Arianna Huffington, The Sleep Revolution, London 2016, S. 9).

26 Schmaus, Katholische Dogmatik, S. 258.

27 Josef PIEPER, Über die Schwierigkeit, heute zu glauben, in: Ders., Über die Schwierigkeit, heute zu glauben. Aufsätze und Reden, München 1974, S. 11-24, hier S. 13.

28 Leider rekurriert Pieper nicht auf eine Hermeneutik der "Lebenswelt", wie sie die Phänomenologie damals und heute zu entwerfen versucht (vgl. Frank Vogelsang, Die Rede von Gott in einer offenen Wirklichkeit. Phänomenologisch-hermeneutische Untersuchungen nach Merleau-Ponty, Ricœur und Waldenfels, Freiburg u.a. 2016, S. 29f.).

29 Pieper, Über die Schwierigkeit, heute zu glauben, S. 15.

30 Ebd., S. 18.

31 Vgl. zu diesem Phänomen in der spirituellen Theologie des Hochmittelalters Marianne Schlosser, Statim factus bonus theologus oder Vom Nutzen des Zwei- 
Infolgedessen geht Josef Pieper auf Phänomene der Entsakralisierung im innerchristlichen Bereich ein ${ }^{32}$. Der Bereich des Sakralen werde zugänglich durch Poesie und Kunst, insofern sie Überschwang und Fülle vermitteln ${ }^{33}$.

Auch Romano Guardini und Eugen Biser erkennen als einen Schnittpunkt in der Wechselwirkung von Säkularisierung und Religion die Schwierigkeiten und Krisen auf dem Weg des gott-suchenden Menschen. Mithin sprechen sie nicht von der Säkularisierung und dem Säkularismus als einem glaubensfeindlichen Außenphänomen, sondern als einem Element christlicher Binnenerfahrung.

Freilich urteilt Romano Guardini, dass sich erst zu seiner Zeit der Atheismus zu einem Breitenphänomen entwickelt habe ${ }^{34}$. Hierbei differenziert er zwischen verschiedenen Formen eines zeitgenössischen Atheismus je nach den gesellschaftlichen Schichten ${ }^{35}$. Dieses Vorgehen, das man heute milieusensibel nennen würde, kombiniert er mit der Analyse von milieuübergreifenden Merkmalen des Atheismus. Von ihm aber erhofft er eine Chance für das Christentum: In der Auseinandersetzung zwischen Atheismus und Kommunismus kann der Glaube seiner selbst sicherer werden ${ }^{36}$. Der Glaube kann wachsen, indem er sich selbst prüft und durch Gewissenserforschung klärt, wo er zum Nichtglauben Anstoß gegeben hat: »[...] immer ist es auch eine Schuld des Glaubens, die den Unglauben zu verantworten hat ${ }^{37}$.

Umgekehrt können in der Auseinandersetzung um die Wahrheitsfrage neue Chancen erwachsen, »[...] Räume neuer Verkündigung $[\ldots] \aleph^{38}$. Dennoch werden keine eindimensionalen Perspektiven entwickelt. Vielmehr warnt Guardini vor eindeutigen Prognosen. Stattdessen fordert er eine wachsame Glaubensverantwortung: "So darf man sagen, der Glaube, der heute geleistet werden muß, sei un-naiv, reflektiert, beständiger kritischer Prüfung ausgesetzt $\aleph^{39}$.

fels. Thomas von Aquin über den Apostel Thomas, in: Jeremiah Alberg / Daniela KöDER (Hg.), Habitus fidei. Die Überwindung der eigenen Gottlosigkeit, Paderborn 2016, S. 281-295, hier S. 285.

32 Josef Pieper, Sakralität und »Entsakralisierung«, in: Ders., Über die Schwierigkeit, heute zu glauben, S. 25-61, hier S. 30.

33 Ebd., S. 54.

34 Romano Guardini, Der Glaube in unserer Zeit, in: Ders., Sorge um den Menschen, Bd. 1, Mainz u.a. ${ }^{4} 1988$, S. $93-115$, hier S. 96.

35 Ebd., S. 98.

36 Ebd., S. 96.

37 Ebd., S. 102. Ähnlich votiert jüngst Gregor Maria Hoff, Die atheistische Gegenwart des Konzils und die Gegenwart des Konzils im Horizont neuer atheistischer Diskurse. Eine pastorale Herausforderung, in: Diakonia 46/3 (2015), S. 159-165, hier S. 161.

38 Guardini, Der Glaube in unserer Zeit, S. 115.

39 Ebd., S. 113. 
Gleichwohl warnt Eugen Biser die Theologie vor einer »[...] intellektuellen Panik $[\ldots] \ll^{40}$ angesichts des Atheismus. Vielmehr müsse man jenen stärker $»[\ldots]$ in das Interessenfeld der Theologie rücken $[\ldots] \ll^{41}$. Denn seine Argumente können als $»[\ldots]$ Aporien des theologischen Gedankens $[\ldots] \ll^{42}$ interpretiert werden, als Aporien, die die systematische Theologie seiner Meinung nach noch klarer aussprechen sollte. Dabei kritisiert er, dass man Gott zu sehr als statisches Sein dargestellt habe, statt seine inkarnatorische Gegenwart, das dynamische »descendit de coelis $\aleph^{43} \mathrm{zu}$ schildern.

Pikanterweise distanzierte sich Hans Urs von Balthasar später über Jahrzehnte hinweg mehrfach ${ }^{44}$ von seinem aufschlussreichen Beitrag aus dem Jahr 1956, Die Gottesfrage des heutigen Menschen. Grund für diese Distanzierung ${ }^{45}$ dürfte sein damaliges Verständnis von Öffnung der Kirche sein, das er bald durch die Betonung der Kirche als eines schützenden hortus conclusus $^{46}$ relativierte. 1956 fällt jedoch auch bei ihm das Stichwort »offen«, allerdings weitaus unspezifischer als im offenbarungstheologisch-soteriologischen Ansatzpunkt Ratzingers, eher allgemein auf den Liebesimpetus Jesu und seiner Kirche gemünzt: »Aber dies hindert nicht, daß der Ur-Sinn der `Gründung` Jesu mit ihrer Hierarchie, ihren Sakramenten und vielfachen Einrichtungen das zur Welt hin offene Reich bleibt « ${ }^{47}$.

Denn die Liebe Jesu Christi »[...] macht [...] an den Grenzen der Kirche nicht halt, ja sie kennt als Liebe diese Grenze gar nicht; es ist ihr Wesen, sie zu übersteigen und damit das Wesen der Kirche selbst zu offenbaren $\aleph^{48}$.

40 Eugen Biser, Atheismus und Theologie, in: Joseph Ratzinger (Hg.), Die Frage nach Gott, Freiburg 1973, S. 89-115, hier S. 90.

41 Ebd., S. 107.

42 Ebd.

43 Ebd., S. 109.

44 Vgl. Hans Otmar Meuffels, Einbergung des Menschen in das Mysterium der dreieinigen Liebe. Eine trinitarische Anthropologie nach Hans Urs von Balthasar, Würzburg 1991, S. 24.

45 Möglicherweise handelt es sich dabei um eine innere Spannung im Denken von Balthasars, die er nach außen hin glätten wollte. Denn bereits in einer Monographie aus den Jahren 1946/47 sprach er statt von einer Öffnung der Kirche auf die zu erlösende Welt hin von einer »[...] Ablehnung jeder Synthese von Welt und Christentum [...] «, (Hans Urs von Balthasar, Von den Aufgaben der Katholischen Philosophie in der Zeit, Neuausgabe, Einsiedeln 1998, S. 11), weil sich das »[...] Reich Christi [...] mit aller Klarheit und Schärfe von dieser Welt absetzt [...]« (ebd., S. 10).

46 Vgl. Rebecca Milena Fuchs/Bertram Stubenrauch, „Weder Umarmung noch Getto!«. Theologische Debatten um die Justierung des Verhältnisses von Kirche und Welt seit Gaudium et Spes, in: MThZ 63 (2012), S. 205-217, hier S. 211.

47 Hans Urs von Balthasar, Die Gottesfrage des heutigen Menschen, Wien u.a. 1956, S. 211.

48 Ebd., S. 211. 
Das sind Worte, die gegebenenfalls integralistisch missverstanden werden könnten, als ob die Kirche die säkulare Welt nach und nach in sich aufsöge, so dass Säkularität nur ein vorrübergehendes Phänomen wäre. Durchaus könnten aber diese Worte ebenso die Dialogbereitschaft mit anderen Weltanschauungen fördern. Auf jeden Fall weisen diese Sätze, die von Balthasar kein Jahrzehnt später ${ }^{49}$ relativiert haben wollte, auf eine weniger bekannte Seite von Balthasars hin, die weitere Untersuchungen wert wäre.

Durch den Grundansatz in seiner frühen Schrift Die Gottesfrage des heutigen Menschen, einem Grundansatz von einer dynamischen Liebe Jesu und einer dynamischen Wirksamkeit der Kirche in die säkulare Welt hinein, deckte von Balthasar dort auch Dynamiken in der Entwicklung des Gottesbildes auf. Er begründet dies topologisch: Für Gott wurden jeweils bestimmte Wirklichkeitsbereiche aufgespart, die die Menschen dann durch eigene Wirksamkeit für sich eroberten ${ }^{50}$. Jene menschlichen Konstruktionen wurden nach und nach jeweils säkularisiert. Daher müsse der Christ, so der frühe von Balthasar, den jeweiligen Zeitstil eines Gottesbildes von innen her erfassen können:

So hat auch das Gottesbild unserer Zeit einen Stil, und der Christ müsste ihn erkennen und sich in ihm auszudrücken wissen. Und dies nicht eigentlich von außen, diplomatisch und apologetisch, sondern von innen: als das Kind dieser Zeit, das teilhat an der Lage, an Not und Reichtum der Epoche, $[\ldots]^{51}$.

Diese Mahnung des frühen, in dieser Facette heute weniger bekannten von Balthasar erinnert an die bekannten Eingangsworte von $»$ Freude und Hoffnung, Trauer und Angst" der pastoralen Konstitution des Zweiten Vatikanums, Gaudium et Spes ${ }^{52}$. Die existentielle Anteilnahme an den realen Lebensverhältnissen der Menschen ist der Grundakkord der Konstitution, die in ihren Kapiteln 19 bis 21 die kirchliche Stellungnahme zum Atheismus reformuliert.

49 1965, so Meuffels, Einbergung des Menschen, S. 24.

50 Von Balthasar, Die Gottesfrage, S. 138.

51 Ebd., S. 137.

52 Gaudium et Spes (GS), Kap. 1: »Freude und Hoffnung, Trauer und Angst der Menschen von heute, besonders der Armen und Bedrängten aller Art, sind auch Freude und Hoffnung, Trauer und Angst der Jünger Christi« (zitiert nach: Karl Rahner/ Herbert Vorgrimler, Kleines Konzilskompendium. Sämtliche Texte des Zweiten Vatikanums, Freiburg ${ }^{22} 1990$, S. 449-552, hier S. 449). 


\section{Kernaussagen zum Atheismus in der Konstitution Gaudium et Spes (GS 19-21) des Zweiten Vatikanums}

Manuel Schlögl erinnert daran, dass die Kapitel 19 bis 21 der Konzilsdeklaration Gaudium et Spes des Zweiten Vatikanums, promulgiert 1965, immer noch eine entscheidende Argumentationsbasis von katholischer Seite für die Einschätzung und das Gespräch mit Atheismus und Säkularismus sind ${ }^{53}$. Während die Kapitel 19 und 20 verschiedene Erscheinungsweisen und Entstehungsursachen des Atheismus erwähnen, erzählen etliche weitere Passagen in Gaudium et Spes von den Gefährdungen der Menschenwürde durch den Säkularismus ${ }^{54}$. Indem die Pastoralkonstitution so exemplarisch ihre eigene hermeneutische Anweisung, "[...] nach den Zeichen der Zeit zu forschen [...] (GS 4) befolgt, ermuntert sie den Leser zu einer eigenständigen Fortschreibung ihrer Analysen der Gegenwartskultur (GS 91). Zudem werden die einzelnen Gläubigen dadurch in die Pflicht genommen, dass sie zur Gewissenserforschung angehalten werden, inwieweit sie selbst "[...] das wahre Antlitz Gottes und der Religion eher verhüllen als offenbaren« (GS 19). Mag auch der Säkularismus »[...] durch [...] einseitige Zuwendung zu den irdischen Wirklichkeiten, den Zugang zu Gott erschweren [...]«(GS 19), so wird dennoch die Theodizeefrage mit ihrem »[...] heftigen Protest gegen das Übel in der Welt [...] « (GS 19) als Tiefenproblematik nicht verschwiegen.

Eine ihrem Wesensauftrag gemäße Distanzierung vom Atheismus könne die Kirche nur »[...] voll Schmerz [...]« (GS 21) vornehmen. Nach dieser einleitenden Tonlage geht es jedoch in dem Kapitel 21 von Gaudium et Spes vor allem um eine religiöse Selbstbesinnung der Kirche. Hierzu wäre eine Auseinandersetzung mit den Tiefenmotiven des Atheismus als Arbeitsauftrag an die Theologie gefordert ${ }^{55}$. Jedoch wird das »[...] Gewicht der Fragen [...] « (GS 21) nur kurz gewürdigt, um dann einen Kernpunkt der dialogischen Lehre des Zweiten Vatikanums, von dem aus etliche Konzilsdokumente konzipiert sind, anzuführen: Die Menschenwürde kann nur verteidigt werden, wenn ihr Wurzelgrund in der Berufung des Menschen zur Gottesgemeinschaft anerkannt wird. Dieser Grundsatz leitete bereits in Kapitel 19 von Gaudium et Spes die Stellungnahme zum Atheismus ein. Hier nimmt sich nun die Kirche vor, diese Kernbotschaft in Wort und Tat klarer darzustellen. Um dieser Selbstverpflichtung nachkommen

53 Schlögl, Mystik - Atheismus - Dunkle Nacht, S. 60.

54 Zum Beispiel in GS 27, 47, 56.

55 GS 21: »Jedoch sucht die Kirche die tiefer in der atheistischen Mentalität liegenden Gründe für die Leugnung Gottes zu erfassen und ist im Bewußtsein vom Gewicht der Fragen, die der Atheismus aufgibt, wie auch um der Liebe zu allen Menschen willen der Meinung, daß diese Gründe ernst und gründlich geprüft werden müssen«. 
zu können, bedarf die Kirche einer steten Erneuerung, Reformation ${ }^{56}$. Die Konzilsväter fügten dieser Selbstverpflichtung einen Rekurs auf die dogmatische Konstitution über die Kirche des Zweiten Vatikanums hinzu, auf das Kapitel 8 aus Lumen Gentium. Dies hat einen tiefen Sinn: In Lumen Gentium 8 (LG 8) wird die Kirche als realitas complexa bezeichnet, als »[...] eine einzige komplexe Wirklichkeit, die aus menschlichem und göttlichem Element zusammenwächst«. So steht sie von ihrem Wesen her »[...] in einer nicht unbedeutenden Analogie [...]« (LG 8) zu Jesus Christus als GottMenschen solidarisch in den Realitäten der Welt, um Christus gegenwärtig sein zu lassen, ohne eine partielle, sekundärursächliche »[...] Autonomie der irdischen Wirklichkeiten [...]« (GS 36) zu schmälern.

Diese Bezugnahme auf das achte Kapitel von Lumen Gentium ist ein Hinweis darauf, dass der Dialog mit der säkularen Welt weniger in theistischer Apologetik zu führen ist, sondern von christologischen und ekklesiologischen Gedankengängen aus, die es ermöglichen, die scheinbare Säkularität zu ihrer Eigentlichkeit im Getragen-Sein durch Gott zurück zu holen. In diesem Sinn erhält die Theologie einen Arbeitsauftrag im Dienst der steten Kirchenreform, den Bertram Stubenrauch so beschreibt: »Es bleibt keine andere Möglichkeit als die, immer wieder neu eine Art ekklesiologischer Inventarisierung vorzunehmen und sozusagen nach der eisernen Ration zu fragen, von der die Kirche als komplexe gott-menschliche Wirklichkeit lebt $\ll^{57}$.

Auf die mithin erkenntnisleitende Frage »[...] nach der eisernen Ration [...] « werden wir weiter unten eingehen, um das Desiderat einer »theologischen Konzentration« zu thematisieren. Hierbei sollte nicht übersehen werden, dass in der Perspektive des Zweiten Vatikanums der Dialog mit der säkularen Welt nicht nur rein fundamentaltheologisch geleistet werden kann, sondern dass die Dogmatik in einer stringenten Zusammenschau ihrer Einzeltraktate von der Inhaltlichkeit des Glaubens aus ins Feld geführt werden muss. Die Ermunterung zu einer tatkräftigen Praxis, in der »[...] Glaubende und Nichtglaubende [...]« Hand in Hand »[...] zum richtigen Aufbau dieser Welt, in der sie gemeinsam leben, zusammenarbeiten [...]« (GS 21),

56 GS 21: „Das Heilmittel gegen den Atheismus kann nur von einer situationsgerechten Darlegung der Lehre und vom integren Leben der Kirche und ihrer Glieder erwartet werden. Denn es ist Aufgabe der Kirche, Gott den Vater und seinen menschgewordenen Sohn präsent und sozusagen sichtbar zu machen, indem sie sich selbst unter Führung des Heiligen Geistes unaufhörlich erneuert und läutert«.

57 Bertram Stubenrauch, Kirchenreform aus römisch-katholischer Sicht, in: Uwe Swarat / Thomas SöDIng (Hg.), Heillos gespalten? Segensreich erneuert? 500 Jahre Reformation in der Vielfalt ökumenischer Perspektiven, Freiburg 2016, S. 307-313, hier S. 312. 
versteht sich vom Horizont eines Glaubens her, der den Sohn Gottes als Gefährten eines jeden Menschen sieht, unabhängig von seiner expliziten Weltanschauung ${ }^{58}$.

\section{Mahnung zur kirchlichen Selbstreflexion aus dem Primat des Logos heraus bei Ratzinger}

Von folgenden ontologischen und ekklesiologischen Grundstrukturen aus, die sein Denken lebenslang prägen, argumentiert Joseph Ratzinger:

Sein $^{59}$ versteht er als gestuft. Daher verwendet er den Begriff des Primates in einer Vielfalt: Als Primat des Logos, als Primat der Freiheit ${ }^{60}$, als Primat der Gnade, als Primat des Gebetes, als Primat der Innerlichkeit. Da die Wirklichkeit für ihn durch Wertigkeiten strukturiert ist, ereignet sich Kirche innerhalb einer solchermaßen strukturierten Wirklichkeit: Kirche und damit ebenso der kirchliche Glaube ${ }^{61}$ haben von innen und außen griffige, aber keinesfalls abgeschottete Konturen: Kirche entsteht durch eine doppelte Selbstüberschreitung von innen und von außen her. Gott bricht in sie ein, in ihre Innerlichkeit. Durch ein solches Eintreten Gottes in die Innerlichkeit der Kirche, durch das ihre Innerlichkeit von Gott geschaffen wird, kann sie sich nach außen zu den Noch-Nicht Gläubigen erweitern.

Dieses Geschehnis der Öffnung entspricht dem Wesen des Logos, des Sohnes Gottes, der zu den Menschen gesandt ist, indem er ganz für den Sendungswunsch des Vaters offen ist. Der Logos ist nicht nur derjenige, der -

58 GS 22: »Denn er, der Sohn Gottes, hat sich in seiner Menschwerdung gewissermaßen mit jedem Menschen vereinigt. Mit Menschenhänden hat er gearbeitet, mit menschlichem Geist gedacht, mit einem menschlichen Willen hat er gehandelt, mit einem menschlichen Herzen geliebt «.

59 Der Ansatz Ratzingers bei einem starken Seinsbegriff steht im Gegensatz zu Vattimos Entfaltung eines schwachen Seins als Entsprechung zur Säkularisierung (Gianni Vattimo, Glauben - Philosophieren [Credere di credere]). Aus dem Italienischen übersetzt von Christiane Schultz, Stuttgart 1997, S. 67: „Erneut ist es erforderlich, auf den Parallelismus zwischen Theologie der Säkularisierung und Ontologie der Schwächung zurückzugreifen«).

60 Joseph Ratzinger, Einführung in das Christentum. Vorlesungen über das Apostolische Glaubensbekenntnis, München 1968, S. 121.

61 Der »Primat des Besonderen vor dem Allgemeinen« trägt nicht nur die Person als Höchstwert, sondern findet sich ebenso in der Inhaltlichkeit des Glaubens, der von Personen geglaubt wird. Der Zusammenhang der Glaubensgeheimnisse, der nexus mysteriorum bedingt seine griffige Konturiertheit in Entsprechung zu den jeweiligen Vorrangigkeiten, Primaten (vgl. ebd. S. 124). Deswegen können Glaubensgeheimnisse korrelativ zu zwischenmenschlichen Erfahrungen in Bezug gesetzt werden, $»[$...] durchsichtig [...] auf uns hin« (ebd., S. 147). Glaubensinhalte ohne Konturen und Textur auffassen zu wollen als »etwas völlig Unbestimmbares", führt zur Aussageleere (ders., Die neuen Heiden und die Kirche, in: JRGS 8/2, S. 1143-1158, hier S. 1146). 
gemeinsam mit dem schöpferischen Geist - öffnet, sondern er ist zugleich causa exemplaris eines für die Wahrheit offenen Daseins: »[...] wieder wird das Sein begriffen als schlechthinniges Geöffnetsein ohne Vorbehalt ${ }^{62}$.

Die Öffnung der Kirche ${ }^{63}$ darf daher nach Ratzinger nicht als Menschenwerk missverstanden werden. Öffnung der Kirche ist zunächst Werk Gottes, indem er durch sein Wirken in der Kirche eine nur von ihm herzustellende Dialektik von innen und außen schafft. Gott bricht immer wieder in die von Menschen gebauten Kirchenmauern ein, um die Kirche für weitere Menschen zu öffnen. Da die Gnadenontologie Ratzingers auf der metaphysischen Tradition aufruht, dass zwischen Denken und Sein kein unüberbrückbarer Graben besteht, kann er die ekklesiologische Dialektik des Außen-Innen und das Bild des Öffnens durch Gott ebenso auf der Ebene der geistigen Auseinandersetzungen ins Spiel bringen.

Ratzinger formuliert zwar eine ähnliche Anfrage an die Leistungsfähigkeit der Theologie angesichts des Atheismus wie andere Autoren um die Mitte des 20. Jahrhunderts und heute: »Wieso hat sich die klassische Theologie angesichts dieser Vorgänge als so wehrlos erwiesen? Wo liegen die Schwachstellen, an denen sie unglaubwürdig wurde « ${ }^{64}$ ? Doch seine Antwort zielt primär auf einen anderen Ansatzpunkt als den einer Verfeinerung der rein menschlichen theologischen Denkbemühungen, der Methode und der Argumentationstechniken. Stattdessen beschreibt er Offenbarung als ein soteriologisches Geschehen der Gegenwart, in dem sich das Wort Gottes durch Selbstauslegung zeigt und so den Verstand des Menschen therapiert. Es ist der Geist Gottes, der »[...] den Kerker unserer Theorien aufbricht, mit deren Gitterstäben wir uns selbst gegen dieses Kommen Gottes in unser Leben absichern wollen $\aleph^{65}$.

Nur weil der Glaube empfangender, da von dem offenbarenden Gott dargebotener Glaube ist, der sich lebendig fortentwickelt, nur deshalb ist er dann in der Lage, im Dialog von Glaube und Vernunft, von Theologie und Philosophie, als Heilmittel der Vernunft wirksam zu werden.

62 Ders., Einführung in das Christentum, S. 148.

63 Vgl. zum Wortfeld des "Öffnens « in der Freiburger Rede von Papst Benedikt XVI. im September 2011: Fuchs / STUBENRAUCH, »Weder Umarmung noch Getto!«, S. 207.

64 Joseph Ratzinger, Glaube - Wahrheit - Toleranz. Das Christentum und die Weltreligionen, Freiburg 2003, S. 106. Als Studienanfänger empfand Ratzinger die Notwendigkeit einer solchen Selbstbesinnung der Theologie: »Wir waren fortschrittlich. Wir wollten die Theologie von Grund auf erneuern und damit auch die Kirche neu und lebendiger gestalten" (Benedikt XVI., Letzte Gespräche, mit Peter Seewald, München 2016, S. 101).

65 Ratzinger, Glaube - Wahrheit - Toleranz, S. 109. 
So gelangt Ratzinger zu der folgenden bekannten Formel, die seinen Gesprächspartner Jürgen Habermas beeindruckte ${ }^{66}$ : Die Vernunft wird ohne den Glauben nicht heil, aber der Glaube wird ohne die Vernunft nicht menschlich ${ }^{67}$.

In dieser Doppelformel zeigt sich, dass Ratzinger ebenso die Dialektik von innen und außen wie die Dialektik von Glaube und Vernunft als stets wechselseitige Einwirkung versteht. Diese wechselseitige Dialektik von Glaube und Vernunft hat Folgen für die Inkarnation des Glaubens im Leben der Menschen in Nüchternheit und Bodenständigkeit, wehrt aber auch einem verengten, inhumanen Begriff von Logos und Vernunft. Der Logos Gottes ist schöpferischer Geist, creator Spiritus ${ }^{68}$. Der menschliche Geist ist Ratzinger, dem Kenner der augustinischen theologia cordis, keinesfalls dürre ratio, sondern gefühlvoll in seiner antwortenden Spontaneität ${ }^{69}$. Dies begründet Ratzinger nicht nur aus anthropologischen Erwägungen, sondern aus der Tiefe seines Seinsbegriffes heraus, in dem das Herz zum Logos gehört, da es das »Maß des Seins « ist ${ }^{70}$. Darum duldet Joseph Ratzinger letztlich keinen Gegensatz zwischen theologischer Theorie und pastoraler Praxis: »Am Punkt scheinbar äußerster Theorie tritt das äußerst Praktische zutage; im Reden von Gott wird sichtbar, was der Mensch ist; [...] « ${ }^{71}$.

Bei seinen konkreten Forderungen nach einer Selbstreflexion der Kirche leuchtet Ratzinger nicht als Gegenpol den Säkularismus außerhalb der Kirche aus, sondern eine Verweltlichung im Innenraum der Kirche ${ }^{72}$. Hierbei

66 Jürgen Habermas äußert in ders. / Joseph RATZINGER, Dialektik der Säkularisierung. Über Vernunft und Religion, mit einem Vorwort hg. von Florian Schuller, Freiburg u.a. 2005, S. 31: »Aus der Asymmetrie der epistemischen Ansprüche lässt sich eine Lernbereitschaft der Philosophie gegenüber der Religion begründen, und zwar nicht aus funktionalen, sondern - in Erinnerung ihrer erfolgreichen sheglianischen Lernprozesse - aus inhaltlichen Gründen«.

67 Ratzinger, Glaube - Wahrheit - Toleranz, S. 110.

68 Ders., Europa in der Krise der Kulturen, in: Marcello Pera / ders., Ohne Wurzeln. Der Relativismus und die Krise der europäischen Kultur, Augsburg 2005, S. 62-84, hier S. 79f.: "Das Christentum muß sich immer neu darauf besinnen, daß es Religion des Logos ist. Es ist Glaube an den Creator Spiritus, an den Schöpfergott, von dem alles Wirkliche stammt. Das sollte heute auch seine schöpferische Kraft sein«.

69 Zur Diskussion um den Logosbegriff Ratzingers, der als Dialog vom Logos Gottes mit dem des Menschen geschildert wird, vgl. Heiko Nüllmann, Logos Gottes und Logos des Menschen. Der Vernunftbegriff Joseph Ratzingers und seine Implikationen für Glaubensverantwortung, Moralbegründung und interreligiösen Dialog, Würzburg 2012, S. 415-425.

70 Joseph Kardinal Ratzinger, Öffnet die Türen für Christus und fürchtet euch nicht, Silvesterpredigt 1978, Beilage zu Nr. 2 (1979) des Amtsblattes für das Erzbistum München und Freising, S. 14.

71 Ratzinger, Einführung in das Christentum, S. 150.

72 Ders., Warum ich noch in der Kirche bin, in: JRGS 8/2, S. 1169-1185, hier S. 1170: »[...] die Kirche erlischt in den Seelen und sie zerfällt in den Gemeinden«. 
beruft er sich auf seine eigenen Erfahrungen im pastoralen Dienst ${ }^{73}$. Heute handle es sich "[...] um eine Kirche, in deren Herzen das Heidentum lebt ${ }^{74}$. Der Unglaube getaufter Christen müsse fast schon als »Normalfall $\aleph^{75}$ angenommen werden. Auf rein menschlicher Ebene soll darauf mit kameradschaftlichem Takt reagiert werden:

[...] der Christ soll gerade auch ein fröhlicher Mensch unter Menschen sein können, ein Mitmensch, wo er nicht Mitchrist sein kann. Und ich meine, er sollte im Verhältnis zu seinem ungläubigen Nachbarn gerade und zu allererst Mensch sein, ihnen also nicht mit fortwährenden Bekehrungsversuchen und Predigten auf die Nerven fallen ${ }^{76}$.

Eine Selbstbesinnung der Kirche, vollzogen im liturgischen Gebet und in der theologischen Lehre, wird nach Ratzinger zur Folge haben, dass manche Verflechtungen mit der Welt aufgegeben werden müssen: "Es wird der Kirche auf die Dauer nicht erspart bleiben, Stück um Stück von dem Schein ihrer Deckung mit der Welt abbauen zu müssen und wieder das zu werden, was sie ist: Gemeinschaft der Glaubenden « ${ }^{77}$. Bei aller frohgemuten Offenheit für die Mitmenschen sei insbesondere bei der Sakramentenspendung als dem innersten Motor der Kirche eine Selbstbescheidung angebracht:

Es muss wieder klar werden, dass Sakramente ohne Glaube sinnlos sind, und die Kirche wird hier allmählich und in aller Behutsamkeit auf einen Aktionsradius verzichten müssen, der letztlich eine Selbsttäuschung und eine Täuschung der Menschen einschließt ${ }^{78}$.

Hier empfiehlt Ratzinger einen »[...] Primat der Überzeugung, des Glaubens vor dem bloßen Sakramentalismus «"

Andererseits verschweigt er nicht, dass gerade die Symbolik des eucharistischen Gastmahls Signum für die prinzipielle Offenheit Gottes für alle Menschen ist. Deshalb habe die Kirche auch in Zeiten der Säkularisierung »[...] diese Einladung, diese offene Geste der Platzanbietung am Tisch

73 Benedikt XVI., Letzte Gespräche, S. 112-114. Von dieser Kontextualisierung her kann bestritten werden, dass die Eingangspassage eines seit 1958 umstrittenen Aufsatzes einen Vorwurf gegen den Protestantismus darstelle (Ratzinger, Die neuen Heiden und die Kirche, S. 1143: „Dieses dem Namen nach christliche Europa ist seit rund vierhundert Jahren zur Geburtsstätte eines neuen Heidentums geworden, das im Herzen der Kirche selbst unaufhaltsam wächst und sie von innen her auszuhöhlen droht $\lll)$.

74 Ratzinger, Die neuen Heiden und die Kirche, S. 1143.

75 Ebd., S. 1144.

76 Ebd., S. 1150f.

77 Ebd., S. 1148.

78 Ebd., S. 1149.

79 Ebd., S. 1148. 
Gottes, weiterzugeben $\aleph^{80}$. Darum führt Joseph Ratzinger das eschatologische Gleichnis vom Gastmahl (Lk 14,14-24) an als Hoffnungsbild gegenüber einem Säkularismus innerhalb und außerhalb der Kirche:

Dieses Evangelium ist zunächst in sehr radikalem Sinne Frohbotschaft, wenn es erzählt, dass am Ende der Himmel vollgestopft wird mit allen, die man nur irgendwie auftreiben kann; mit Leuten, die gänzlich unwürdig sind, die im Verhältnis zum Himmel blind, taub, lahm, Bettler sind. Also ein radikaler Gnadenakt, und wer wollte bestreiten, dass nicht auch etwa all unsere modernen europäischen Heiden von heute auf diese Weise mit in den Himmel hineinkommen können ${ }^{81}$ ?

\section{Konturen einer theologischen Konzentration in der Gegenwart}

Im gegenwärtigen philosophischen Diskurs erprobt man ein »[...] volles Aufklärungsprogramm, welches nicht auf Religionskritik eingeengt ist, sondern auf die denkende Resondierung von Religion abzielt ${ }^{82}$.

Auf Seiten der Theologie benannte schon 1949 Hugo Rahner die Notwendigkeit einer »Gewissenserforschung unserer eigenen Christlichkeit ${ }^{83}$.

Die dazu nötige Ausübung einer Glaubensvernunft gehört nach Ratzinger zu einer Kernaufgabe der Kirche in der Gegenwart:

Es ist eine Aufgabe der Kirche heute, den Streit um die Vernunft des Glaubens oder des Unglaubens neu in Gang zu bringen. Der Glaube ist nicht gegen die Vernunft, sondern Anwalt ihrer Größe, wie Papst Johannes Paul II. in seiner Enzyklika über Fides et ratio leidenschaftlich dargelegt hat. Das Ringen um die neue Gegenwart der Vernunft des Glaubens sehe ich als eine vordringliche Aufgabe der Kirche in unserem Jahrhundert $\mathrm{an}^{84}$.

Ausgehend vom Primat des Logos spitzt Ratzinger diesen Grundgedanken zu auf eine $»[\ldots]$ innere Korrespondenz von Christentum und Aufklärung « ${ }^{85}$. Freilich hat eine solche Grundposition zur Folge, dass die Theologie

80 Ebd.

81 Ebd., S. 1157.

82 Ludwig NagL, Religion als optionaler Handlungshorizont, in: Marie Luise Raters (Hg.), Warum Religion? Pragmatische und pragmatistische Überlegungen zur Funktion von Religion und Leben, Freiburg u.a. 2015, S. 127-152, hier S. 128.

83 Hugo Rahner in seinem Vorwort zu Henri de Lubac, Die Tragödie des Humanismus ohne Gott. Feuerbach - Nietzsche - Comte und Dostojewski als Prophet, Salzburg 1950, S. 7-11, hier S. 11.

84 Joseph Ratzinger, Die Kirche an der Schwelle des 3. Jahrtausends, in: JRGS 8/2, S. 1243-1254, hier S. 1248f.

85 Ders., Europa in der Krise der Kulturen, S. 79. 
Schwachpunkte atheistischer Geisteshaltungen kritisieren darf, sei es in der argumentativen Stichhaltigkeit oder bezüglich des existentiellen Ernstes. So beklagt zum Beispiel Alois Maria Haas ein lediglich »[...] abstraktes Kokettieren im Hell-Dunkel zwischen Theismus und A-Theismus [...] $\ll^{86}$.

Ähnlich formuliert Hans Maier den Auftrag der Christen zur Verteidigung der Vernunft nach allen Seiten hin:

Vielleicht ist es so, daß heute, im Strudel eines neuen Irrationalismus, die Christen die Pflicht haben, auch die Substanz der Aufklärung weiterzutragen, sie zu verteidigen gegen die Abdankung des Intellekts und gegen einen irrlichternden Subjektivismus ${ }^{87}$.

Dem pflichtet Johanna Rahner in einer neueren Stellungnahme bei ${ }^{88}$. HansJoachim Sander stellt darüber hinaus zur Diskussion, ob nicht gar Säkularität als unverzichtbare Bedingung fungiere, um den Ort Gottes zu entdecken, da der Theologe aus einer säkularen Umwelt heraus zu sprechen habe:

Wo Säkularität nicht ist, kann ein Evangelium bestenfalls verehrt werden, aber da kann nicht mit ihm gearbeitet werden [...]. Wer Gott als Lebensressource in der Geschichte einschätzen will, muss sich säkular verorten und um die Weite dieses Raumes wissen, [...] Ohne Säkularität ist die Lokalisierung Gottes nicht möglich; [...] Diese Lokalisierung fehlt mir, weil man die säkularen Verhältnisse als Problemlagen sieht, die einem gegenüberstehen. Dabei steht man mitten drin, wenn man auf Gott trifft ${ }^{89}$.

Dies ist als ein methodisches Postulat von Sander aufzufassen, über dessen Prämissen und über dessen Tauglichkeit in Theorie und pastoraler Praxis zu verhandeln wäre.

86 Alois Maria HaAs, Das Verhältnis von Atheismus und Mystik - eine Skizze, in: Katja Thörner/Martin Thurner (Hg.), Religion, Konfessionslosigkeit und Atheismus, Freiburg 2016, S. 77-109, hier S. 95. Ebd., S. 109 weist Haas noch einmal abschließend darauf hin, dass die jeweilige Weltanschauung von einem spezifischen Habitus getragen ist.

87 Hans Maier, Gottesfinsternis? Zur Lage von Glaube und Kirche in einer nachchristlichen Gesellschaft, in: Stephan Pauly (Hg.), Der ferne Gott in unserer Zeit, Stuttgart u.a. 1988, S. 20-32, hier S. 25.

88 Johanna Rahner, Glaubenskrise? - Gotteskrise? - Kirchenkrise? Versuch einer aktuellen Standortbestimmung, in: Dies. / Andrea STRÜBIND (Hg.), Begegnungen Entgegnungen. Beiträge zur modernen Gottesfrage, kontextuellen Theologie und Ökumene. Festgabe für Ulrike Link-Wieczorek zum 60. Geburtstag, Leipzig 2015, S. $93-109$, hier S. 98.

89 Hans-Joachim SANDER, Sieben Fehlanzeigen - Oder: Wie man der gefährlichen Profession und kritischen Berufung der Theologie ausweichen kann, in: Rainer Bucher / Renate Oxenknecht-Witzsch (Hg.), Was fehlt? Leerstellen der katholischen Theologie in spätmodernen Zeiten: ein Experiment, Würzburg 2015, S. 89-96, hier S. 95. 
Denn einen gegensätzlichen hermeneutischen Standpunkt, der der Theologie zu einem frischen Blick auf ihre Kernfragen verhelfen könnte, hatte bereits Henri de Lubac als einer der geistigen Wegbereiter des Zweiten Vatikanums eingenommen. Damit sich das Christentum seines Wesens vergewissern kann und jenes eingängig seinen Zeitgenossen nahebringen kann, bedarf es intensiver und vorurteilsfreier theologiegeschichtlicher Forschungen:

Bevor das Christentum für die heutige Generation angepaßt dargeboten werden kann, muß es um jeden Preis erst wesenhaft es selbst sein [...]. Die Hauptanstrengung besteht also darin, das Christliche in seiner Fülle und Reinheit wiederzufinden. [...] Aber wie anders fände man das Christliche wieder, als indem man zu seinen Quellen zurücksteigt, es in der Zeit seiner alles sprengenden Lebenskraft ergreift ${ }^{90}$ ?

Auf der Ebene der systematischen Theologie müssen sodann die wechselseitigen Reaktionen von Fundamentalismus, Relativismus und Universalismus ausgeleuchtet und in ein neues Verhältnis gesetzt werden, um sowohl Dogmatizismus, als auch Simplifizierung und unsachgemäße Anbiederei $\mathrm{zu}$ vermeiden. Ein solches fundamentaltheologisches Programm umreißt Klaus Müller:

Teils müssen sie (die Theologen) geschlossene Universalismen, die nichts anderes als Fundamentalismus sind, aufbrechen, teils müssen sie gegen die Versuchung des Relativismus, der so bequem und konfliktfrei daher kommt, aber nur getarnter Fundamentalismus ist, eine Dimension des Universalen wiedergewinnen, in der allein so etwas wie eine vernunftgeleitete Begründung von letzten Bindungen gedacht werden $k_{a n n}{ }^{11}$.

Die Versuche einer Entthronung des Christentums durch Säkularismus und Atheismus brachten es seinem eigenen Wesenskern näher. Diesen Schluss zieht Charles Taylor: »The Gospel was always meant to stand out, unencumbered by arms. We have now been able to turn a little closer to this ideal with a little help from our enemies ${ }^{22}$. In diesem Wesenskern des Christen-

90 Henri de Lubac, Glaubensparadoxe, übertragen von Hans Urs von Balthasar, Einsiedeln 2015, S. 30f.

91 Klaus MüLler, Glauben und Wissen oder: Das Christentum auf dem Areopag der Philosophie, in: Johann Reikerstorfer / Josef Kreiml (Hg.), Suchbewegungen nach Gott. Der Mensch vor der Gottesfrage heute, Frankfurt a.M. 2007, S. 105-122, hier S. 122.

92 Charles Taylor, A Catholic Modernity?, in: Ders., Dilemmas and Connections. Selected Essays, Cambridge u.a. 2014, S. 167-187, hier S. 171 f. 
tums sind Glaubenstatsachen und gelebte Nächstenliebe eins, konvergierend in der Ebenbildlichkeit zu Gott: »Our being in the image of God is also our standing among others in the stream of love, which is that facet of God's life we try to grasp, very inadequately, in speaking of the Trinity « ${ }^{93}$.

93 Ebd., S. 185. 


\section{Matthias Felder und Frank Mathwig \\ Bekennen und Säkularisierung}

Zur gesellschaftlichen Verortung der Kirche aus reformierter Sicht

\section{Einleitung}

Die Schweiz sei »eines der am stärksten säkularisierten Länder Europas«, äußerte kürzlich der Berner Theologe Matthias Zeindler im Rahmen der Reformationsfeierlichkeiten ${ }^{1}$. Die Bemerkung lässt sich als eine Art Zustandsbericht über den Säkularisierungsdiskurs im schweizerischen Protestantismus lesen, für den drei Merkmale kennzeichnend sind:

1. Die Säkularisierungsthese hat erst sehr spät kirchliche Aufmerksamkeit erhalten. Beispielhaft dafür steht die Ökumenische Kirchengeschichte der Schweiz von 1994, in der der Säkularisierungsbegriff - neben einer einleitenden Bemerkung zur wirtschaftlichen Entwicklung im Nachkriegseuropa - lediglich an zwei Stellen auftaucht: einerseits im Zusammenhang der Absetzbewegung der Freikirchen und Gemeinschaften gegenüber den säkularistischen und ökumenischen Tendenzen in den Landeskirchen und andererseits in dem Versuch des Zusammenrückens der beiden großen Konfessionen als Reaktion auf die fortschreitende Entkirchlichung in den 1960er bis 1980er Jahren².

2. Die Säkularisierungsthese ist umstritten, nicht weil die Realität ihrer Symptome bezweifelt würde, sondern weil die Meinungen über deren Ursachen und Wirkungen weit auseinandergehen.

3. Eine Diskussion über Phänomene, die typischerweise dem Säkularisierungsparadigma zugerechnet werden, findet zwar inzwischen auch in den Kirchen statt, aber nach wie vor jenseits der Theologie. Säkularisierungszumutungen werden als pragmatische Aufgaben ekklesialer Organisation ernstgenommen, nicht aber als ekklesiologische Herausforderung im Blick auf das kirchliche Selbstverständnis.

1 Matthias Zeindler, Helvetia semper reformanda. Die Schweiz - ein nach- und vorreformatorisches Land, in: vice-versa 2 (2015), S. 6.

2 Lukas Vischer u.a. (Hg.), Ökumenische Kirchengeschichte der Schweiz, Freiburg u.a. 1994, S. 299, 307 f. 
Spannend ist das Thema Säkularisierung im schweizerischen Kontext weniger im üblichen Sinne als gesellschaftlicher Phänomenkomplex, der die Kirchen auf dem falschen Fuß erwischt, sondern mehr im Blick auf das eigentümlich kirchliche Desinteresse an einer theologisch-ekklesiologischen Reflexion. Zwei Thesen stehen zur Diskussion: 1. Die lange Abwesenheit einer kirchlichen Säkularisierungsdebatte ist weder zufällig noch ein theologisches Desiderat, vielmehr resultiert sie aus einer von langer Hand vorbereiteten und fest etablierten ekklesiologischen Grundentscheidung im 19. Jahrhundert. Und 2. Die das kirchliche Selbstverständnis des schweizerischen Protestantismus über lange Zeit kennzeichnende Säkularitätsvergessenheit bewirkt eine pragmatisch motivierte Säkularitätsversessenheit, in deren Folge die Säkularisierungsthese sukzessive den traditionellen Platz der Ekklesiologie okkupiert und deren Funktion übernimmt. Insofern bildet die Ekklesiologie - nicht nur hier, sondern grundsätzlich - den theologischen Lackmustest für die der reformatorischen - und erst recht der reformierten - Theologie gerne attestierte Affinität zu Moderne und Säkularisierung.

Im Folgenden sollen ausgewählte Aspekte kirchlicher Praxis auf ihre theologischen Bezüge, Voraussetzungen und Konsequenzen hin befragt werden. Der Referenzrahmen »kirchliche Praxis« ist in dem weiten Sinne zu verstehen, wie er traditionell in der spezifisch reformierten Verhältnisbestimmung von Kirche und Staat als »Königsherrschaft Christi« zum Ausdruck kommt. Zwei Experimentierfelder bieten sich an: einerseits die schweizerisch-reformierte Haltung gegenüber dem kirchlichen Bekenntnis und ihre Auswirkungen auf das kirchliche Selbstverständnis als Volkskirche (im bewussten Gegensatz zur Bekenntniskirche). Und andererseits - aus umgekehrter Perspektive - die expliziten und impliziten Wechselbeziehungen zwischen Staat und Kirche in gesellschaftspolitischen Zusammenhängen. Unsere Überlegungen schließen an die in den Studien von Campiche et al. begründete Zurückhaltung gegenüber einer Übertragung der internationalen Säkularisierungsdiskurse auf die Schweiz an ${ }^{3}$. Allerdings sprechen nicht nur historische, politische und soziologische Faktoren für den Sonderfall Schweiz, sondern auch binnentheologische und binnenekklesiologische Argumente, die die soziologische Außensicht teilweise bestätigen und plausibilisieren.

3 Vgl. Alfred Dubach / Roland J. CAmpiche (Hg.), Jeder ein Sonderfall. Religion in der Schweiz, Basel 1993; Roland J. Campiche, Die zwei Gesichter der Religion. Faszination und Entzauberung, Zürich 2004. 


\section{2. »Sonderfall« Schweiz?}

Im Nationalen Forschungsprogramm 58 »Religionsgemeinschaften, Staat und Gesellschaft« wird Säkularisierung als »die abnehmende Bedeutung der Religion auf gesellschaftlicher und individueller Ebene « bezeichnet ${ }^{4}$ und bedient sich bekannter Verlustrhetoriken, die bereits Hans Blumenberg als zweifelhaftes juristisches Enteignungsmodell, Thomas Luckmann als Fehlkonstruktion und Charles Taylor als religiöse Subtraktionsgeschichte kritisiert haben 5 . Je nachdem als Rationalisierungs-, Privatisierungs-, Ausdifferenzierungs-, Deinstitutionalisierungs-, Pluralisierungs- oder Mischvariante postuliert, erhält das »master narrative von Niedergang und Dechristianisierung $\aleph^{6}$ eine normative, negativ besetzte Pointe ${ }^{7}$. Dabei bleibt wesentlich unklar, was eigentlich auf dem Spiel steht, was also mit den auf der Verlustliste notierten Phänomenen und Beobachtungen kirchlich oder lebensweltlich verloren geht.

Der an der Georgetown-Universität in Washington lehrende Religionssoziologe José Casanova hat immer wieder den Pauschalisierungen und Entkontextualisierungen im Säkularisierungsdiskurs widersprochen. Bekannt ist seine These vom Sonderstatus der westeuropäischen Säkularisierung:

Die drastische Säkularisierung Westeuropas ist vielmehr in globaler Perspektive als Ausnahme erkennbar, für die es nur wenige Parallelen andernorts gibt [...]. Der Zusammenbruch der moralischen Autorität und der Plausibilitätsstrukturen einiger

4 NFP 58, Die Religiosität der Christen in der Schweiz und die Bedeutung der Kirchen in der heutigen Gesellschaft. Forschungsresultate aus ausgewählten Projekten des Nationalen Forschungsprogramms »Religionsgemeinschaften, Staat und Gesellschaft«, Themenheft IV, November 2011, S. 10, URL: <http://www.nfp58.ch/files/ downloads/NFP58_Themenheft04_DE.pdf> (25.07.2018).

5 Vgl. Hans Blumenberg, Die Legitimität der Neuzeit. Erneuerte Ausgabe, Frankfurt a.M. ${ }^{6} 2012$, S. 1-134; dazu Daniel Weidner, Säkularisierung, in: Robert BuCH / Daniel Weidner (Hg.), Blumenberg lesen. Ein Glossar, Berlin 2014, S. 245-259; Thomas Luckmann, Die unsichtbare Religion, Frankfurt a.M. 1991, S. 179; Charles TAYLOR, Ein säkulares Zeitalter. Aus dem Englischen von Joachim Schulte, Frankfurt a.M. 2009, S. 889.

6 Benjamin Ziemann, Säkularisierung, Konfessionalisierung, Organisationsbildung. Dimensionen der Sozialgeschichte der Religion im langen 19. Jahrhundert, in: ASozG 47 (2007), S. 485-508, hier S. 491 im Anschluss an David NAsh, Reconnecting Religion with Social and Cultural History. Secularization's Failure as a Master Narrative, in: Cultural and Social History 1 (2004), S. 302-325.

7 Zur Kritik dieser Verlustgeschichte vgl. die brillante Analyse von Ingolf U. DAlferth, Religionsfixierte Moderne? Der lange Weg vom säkularen Zeitalter zur post-säkularen Welt, in: Denkströme. Journal der Sächsischen Akademie der Wissenschaften 7 (2011), S. 9-32. 
der europäischen Nationalkirchen ist so außergewöhnlich, dass wir eine bessere Erklärung brauchen als den bloßen Verweis auf allgemeine Modernisierungsprozesse ${ }^{8}$.

Einzigartig sei die Entwicklung in Europa, »weil dort der Säkularismus als eine teleologische Theorie der Religionsentwicklung aus der aufklärerischen Religionskritik hervorging und obsiegte. Diese Religionskritik [...] macht aus europäischen Säkularisierungstheorien mehr als Deskriptionen sozialer Prozesse; sie sind vielmehr kritische Genealogien der Religion und normative Teleologien, für die der Niedergang der Religion das Ziel der Geschichte ist «?. Drei Aspekte stehen im Zentrum:

[1.] die kognitive Kritik der Religion als eines primitiven, prärationalen Weltbilds, das durch den Fortschritt der Wissenschaft und des rationalen Denkens überwunden würde; [2.] die politische Kritik kirchlich verfasster Religion als einer Verschwörung von Herrschenden und Priestern um das Volk unwissend und unterdrückt zu halten, was durch den Fortschritt der Volkssouveränität und demokratische Freiheiten überwunden würde; [und 3.] die humanistische Kritik an der Idee von Gott selbst als einer menschlichen Selbstentfremdung und als einer selbstverleugnenden Projektion menschlicher Wünsche und Absichten auf eine jenseitige Welt ${ }^{10}$.

Die drei Kritiken gelten in unterschiedlichen Ausprägungen für alle sozialen Bewegungen und politischen Parteien in Europa, aber auch für die diese Phänomene reflektierenden Säkularisierungstheorien selbst. "Die Annahme, dass eine Gesellschaft desto areligiöser werde, je moderner sie sei, wurde in Europa zu einer Selbstverständlichkeit - in der Religionssoziologie, aber auch bei der Bevölkerung « ${ }^{11}$. Die nach dem Zweiten Weltkrieg einsetzende Institutionalisierung der Wohlfahrtsstaaten in Westeuropa trat verstärkend hinzu, »insofern diese eine Übertragung der kollektiven Identifikation von der imaginären Gemeinschaft der Nationalkirche oder der Konfession auf die imaginäre Gemeinschaft des Nationalstaats zur Folge hatte « ${ }^{12}$. Die modernen wohlfahrtsstaatlichen Regimes adoptieren also die kommunitären, sozialkohäsiven Impulse und Funktionen von den christlichen Kirchen und ihren Institutionen.

8 José Casanova, Die religiöse Lage in Europa, in: Hans Joas/Klaus Wiegandt (Hg.), Säkularisierung und die Weltreligionen, Frankfurt a.M. ${ }^{2} 2007$, S. 322-357, hier S. 333; vgl. ders., Beyond European and American Expertionalisms. Towards a Global Perspective, in: Grace Davie u.a. (Hg.), Predicting Religion, Aldershot 2003, S. 17-29; ders., Public Religions in the Modern World, Chicago, IL u.a. 1994.

9 Casanova, Die religiöse Lage, S. 337.

10 Ebd., S. 338.

11 Ebd.

12 Ebd., S. 338f. 
Weniger bekannt ist, dass Casanova darüber hinaus der Schweiz eine gewisse Sonderstellung in Europa einräumt:

Im allgemeinen sind [...] katholische Länder stärker religiös als protestantische oder gemischte Länder (wie Westdeutschland und die Niederlande), obwohl die Schweiz (ein gemischtes und traditionell ähnlich wie Holland »versäultes « Land) am oberen Ende der europäischen Religionsskala zu platzieren ist, mit Raten, die - was Glaubenseinstellungen betrifft - denen des katholischen Österreich und Spaniens ähneln und - was Kirchenbesuch und Konfessionsbindung angeht - Polen und Irland nahekommen. [...] Was die Schweiz betrifft, haben die kantonale Struktur und in gewissem Masse die Neutralität und provinzielle Isolation vom übrigen Europa die schweizerischen Kirchen vor ähnlichen säkularisierenden Folgen bewahrt ${ }^{13}$.

Die These von der relativ stabilen Kirchenbindung - bei der Casanova auf statistische Daten aus den 1990er Jahren zurückgreift - ist von der Realität längst überholt. Die zweite These vom Einfluss der politischen Strukturen der Schweiz - die der Religionssoziologe allerdings nicht weiter ausführt verdient dagegen eine vertiefte Betrachtung, denn sie hat einige gewichtige Beobachtungen auf ihrer Seite.

1. Auf protestantischer Seite hat es im strengen Sinne niemals eine nationale Schweizer Kirche gegeben. Reformierte Kirchen begegnen angesichts ihrer kantonalen Organisation stets im Plural. Entsprechend vielfältig und differenziert fallen auch die Wahrnehmungen von Säkularisierungsphänomenen aus.

2. Die wohlfahrtsstaatliche Entwicklung setzte in der Schweiz verzögert ein und war kaum durch das staatliche Interesse motiviert, sich der Loyalität der Arbeiterschaft zu versichern. Die sozialkohäsive Funktion staatlicher Sozialpolitik war weniger stark ausgeprägt und Sozialdemokratie und Gewerkschaften waren weder »aktive Säkularisierungsagenten« (Benjamin Ziemann) noch eine "alternative culture« (Vernon L. Lidtke) wie im deutschen Kaiserreich ${ }^{14}$.

13 Ebd., S. 323, 339. Der Autor bezieht sich dabei auf empirische Befunde von Andrew M. Greely, Religion in Europe at the End of the Second Millenium, New Brunswick, NJ 2003, der auf Daten der European Values Studies von 1981, 1990 und 1995 sowie des International Social Survey Program von 1991 und 1998 zurückgreift.

14 Das gilt auch für Leonhard Ragaz und die religiösen Sozialisten oder Karl Barth während seiner Safenwiler Zeit; vgl. dazu einführend und mit einschlägigen Literaturhinweisen Robert BARTH, Leonhard Ragaz (1868-1945), in: Wolfgang LiENEManN / Frank Mathwig (Hg.), Schweizer Ethiker im 20. Jahrhundert. Der Beitrag theologischer Denker, Zürich 2005, S. 9-31 und Wolfgang Lienemann, Karl Barth (1886-1968), in: Ebd., S. 33-56. 
3. Die politische Kritik an einer machtpolitischen Kollaboration von Staat und Kirche spielt in der reformierten Schweiz - wenn überhaupt - nur eine untergeordnete Rolle. Die Staat-Kirchen-Verhältnisse - und auch hier muss im Plural gesprochen werden - weisen bis heute eine erstaunliche Vielfalt, Uneinheitlichkeit und bisweilen Uneindeutigkeit auf. Die von Ulrich Barth aus lutherischer Sicht vertretene These, dass Demokratisierung als »säkularisierungsverstärkende[r] Modernisierungsfaktor« auf die Kirchen einwirkt, geht von einer Differenz zwischen der Organisationsstruktur staatlicher und kirchlicher Ordnungen aus, die für die reformierten Kirchen grundsätzlich nicht zutrifft ${ }^{15}$. Aus historischer Sicht muss das Bedingungsverhältnis zwischen Kirchen und Staat für die reformierte Schweiz vielmehr umgekehrt werden.

4. Hinzu tritt ein in Kirche und Gesellschaft nach wie vor etabliertes Volkskirchenverständnis, dem spezifische Brechungen bei der Wahrnehmung, Zuordnung und Beurteilung von Säkularisierungs- und Modernisierungsphänomenen korrespondieren.

5. Die humanistische, epistemisch motivierte Kritik wurde keineswegs nur von außen an die Kirchen herangetragen, sondern bildet einen integralen Aspekt ihrer eigenen theologischen und politischen Entwicklungen. Sie gehört - um einen Begriff Casanovas aufzunehmen - zur "Genealogie» reformierter Kirchen und ihrer Selbstverständnisse.

6. Durch die kirchliche Absorbierung von Säkularisierungsimpulsen konnten deren kirchenkritische Tendenzen teilweise neutralisiert oder positiv integriert werden. Die Kirchen selbst - genauer: bestimmte kirchliche Strömungen und Selbstverständnisse - können als Trägerinnen gesellschaftlicher Säkularisierungsdynamiken auftreten. Paradigmatisch dafür steht der sogenannte Apostolikumstreit im 19. Jahrhundert, der, von der Zürcher Kirche ausgehend, die gesamte protestantische Schweiz erfasst und diese bis heute prägt.

7. Schließlich korrespondiert das reformierte Modell der »Königsherrschaft Christi« mit Casanovas Kritik an der - von John Rawls und Jürgen Habermas prominent vertretenen - Bipolarität von Öffentlichkeit und Privatsphäre. Im Anschluss an Alfred Stepan unterscheidet der Religionssoziologe drei Bereiche, »Arenen« bzw. »Level« von Öffentlichkeit ${ }^{16}$ : »it is conceptually and politically useful to distinguish three important arenas of the polity: civil society, political society, and the state. Obviously, in any given polity these three arenas expand and shrink at different rates,

15 Vgl. Ulrich BARTh, Säkularisierung. I. Systematisch-theologisch, in: TRE 29 (1998), S. 603-634, hier S. 624, 629.

16 Vgl. Melanie Zurlinden, Religionsgemeinschaften in der direkten Demokratie. Handlungsräume religiöser Minderheiten in der Schweiz, Wiesbaden 2015, S. 14, Fn. 14. 
interpenetrate or even dominate each other, and constantly change ${ }^{17}{ }^{17}$. Das reformierte Kirche-Staat-Verständnis bietet eine Alternative zur Kontrastfolie der katholischen Civitates- und lutherischen Zwei-Reiche- respektive Zwei-Regimenter-Lehre, die Anschlussmöglichkeiten an Casanovas triadisches Verständnis von staatlicher, politischer und zivilgesellschaftlicher Sphäre bereithältt ${ }^{18}$.

\section{Säkularisierung aus kirchlich-theologischer Sicht}

Aus binnenkirchlicher Sicht rücken von den genannten Punkten die säkularisierungsaffine Theologie, die sich in einem für gesellschaftliche Dynamiken aufgeschlossenen Volkskirchenverständnis widerspiegelt, und die Vorstellung von politischer Öffentlichkeit, in der Staat und Kirche als kooperierende und konkurrierende Akteure auftreten, ins Zentrum. Sich diesen Zusammenhängen aus theologischer Perspektive zu nähern, setzt die Unterscheidung zwischen der komplementären ekklesiologischen und ekklesialen Perspektive voraus, eine Ebenendifferenzierung, die freilich durch die zur Diskussion stehenden Sachverhalte selbst schon in Frage gestellt oder unterlaufen wird.

17 Alfred Stepan, Rethinking Military Politics. Princeton, NJ 1988, S. 3; vgl. CasaNOva, Public Religions, S. 217, vgl. dazu ZuRLINDEN, Religionsgemeinschaften in der direkten Demokratie, S. 9-12.

18 Zur Unterscheidung zwischen lutherischer Zwei-Reiche- und Zwei-Regimenterlehre vgl. die Bemerkungen von Volker Leppin, Grenzen und Möglichkeiten der Obrigkeit. Zu Entstehung und Kontext von Luthers Zwei-Reiche-Lehre, in: Irene Dingel/Christiane Tietz (Hg.), Die politische Aufgabe von Religion, Göttingen 2011 (VIEG Beiheft 87), S. 247-258. Zum reformierten Topos der Königsherrschaft Christi vgl. aus historischer Sicht Judith BECKER, Die Königsherrschaft Gottes bei Calvin und im frühen reformierten Protestantismus. Perspektiven der drei monotheistischen Religionen, in: Ebd., S. 277-298 und aus systematisch-theologischer Perspektive mit vielen Literaturhinweisen Günter Thомаs, Die politische Aufgabe der Kirche im Anschluss an das reformierte Modell der »Königsherrschaft Christi«. Beobachtungen politischer Ethik, in: Ebd., S. 299-228. Vor dem Hintergrund seiner Interpretation der Barmer Theologischen Erklärung plädiert der Bochumer Systematiker für einen christologischen Umbau der theologischen »Verbindung zwischen Sünde und Politischem" in Gestalt der Ersetzung des Dualismus von "sündiger Welt / versöhnt in Christus« durch die »Triade sündig / versöhnt/ erlöst« (S. 327). Zu der an die Religionssoziologie Luhmanns anschließenden dreistelligen Ebenendifferenzierung von Religion und Kirche vgl. die kritischen Bemerkungen gegenüber einem organisationsvergessenen zweistelligen Staat-Kirche-Verständnis von Martin Petzke/ Hartmann Tyrell, Religiöse Organisationen, in: Maja Apelt / Veronika TACKe (Hg.), Handbuch Organisationstypen, Wiesbaden 2012, S. 275-306, hier S. 284-287. Schließlich gehört in diesen Zusammenhang auch der dreistellige Kirchenbegriff von Hans-Richard Reuter, Der Begriff der Kirche in theologischer Sicht, in: Ders., Botschaft und Ordnung. Beiträge zur Kirchentheorie, Leipzig 2009, S. 13-55. 


\subsection{Konsensprinzip »Volkskirche»}

Die Zurückdrängung der ekklesiologischen Fragestellung gehört zu den Kennzeichen eines Kirchenverständnisses, das Säkularisierungsphänomene weniger als Angriff, denn als Ausdruck und Form ihres eigenen Kircheseins begreift. In diesem Sinne bemerkt das Handbuch der reformierten Schweiz von 1962:

Die allgemeine Säkularisierung des geistigen Lebens hat auch die Schweiz nicht unberührt gelassen, doch wird die Problematik der Volkskirche nicht in dem Masse empfunden, wie sie in Ländern anderer Tradition oder in der zunehmenden Verstädterung und Vermassung zwangsläufig aufbrechen muss. In der Volkskirche, die praktisch ohne weiteres mit der in der Verfassung garantierten Glaubens- und Gewissensfreiheit bestehen kann, lebt die alte zwinglische Überzeugung weiter, dass das Evangelium nicht nur da ist zur Erbauung der einzelnen Seele, sondern dass es eine Kraft ist zur Gestaltung und Erneuerung des ganzen Volkslebens ${ }^{19}$.

Und im anschließenden Abschnitt »Zum Problem der Volkskirche« spricht bereits die Formulierung für sich: »Unsere Kirche hat in der Geschichte in mancherlei Variationen die Gestalt einer bekenntnisfreien, irgendwie mit dem Staate verbundenen Volkskirche gefunden ${ }^{20}$. Ein Blick in die verschiedenen Kirchenordnungen würde diesen Eindruck erhärten.

Die Gründe für ein solches hierarchisch flaches, tendenziell egalitäres und nach synodal-presbyterialen Grundsätzen demokratisch verfasstes Kirchenverständnis sind vielfältig und reichen bis in die reformatorischen Anfänge zurück. Nicht zuletzt aus dieser Tradition folgt ein gewachsenes »Misstrauen gegenüber Institutionen", das Roland Campiche der schweizerischen Bevölkerung attestiert ${ }^{21}$. Bestätigt wird diese Beobachtung durch die kategorische Bedeutung, die der demokratischen Organisation und dem Egalitätsprinzip in Gestalt der reformatorischen Formel vom »Priestertum aller Getauften « beigemessen wird, wie das Vernehmlassungsverfahren zum Verfassungsentwurf des Kirchenbundes von 2013 eindrucksvoll bestätigt ${ }^{22}$. Das institutionentheoretisch unter- oder unbestimmte Kirchenverständnis des schweizerischen Protestantismus erklärt zugleich das Übergewicht der

19 Ernst Gerhard Rüsch, Wesen und Eigenart des schweizerischen Protestantismus, in: Schweizerischer Protestantischer Volksbund SPV (Hg.), Handbuch der Reformierten Schweiz, Zürich 1962, S. 1-10, hier S. 6.

20 Gotthard Schmid, Zum Problem der Volkskirche, in: SPV (Hg.), Handbuch der reformierten Schweiz, S. 10-14, hier S. 10.

21 CAmpiche, Die zwei Gesichter, S. 233.

22 Vgl. Schweizerischer Evangelischer Kirchenbund (SEK), Verfassungsrevision. Bericht zur Vernehmlassung, Bern 2014, URL: <http://www.kirchenbund.ch/sites/ default/files/media/pdf/themen/verfassungsrevision/140327_verfassungsrevision_ 
Organisationsperspektive, in der Fragen nach der Gestaltung und Funktion von Kirche nicht nur im Vordergrund stehen, sondern an die Stelle der klassischen ekklesiologischen Fragen nach dem Ursprung, Sein und Ziel von Kirche treten. Eine profilierte Ekklesiologie scheitert an der institutionenkritischen Grundhaltung - die sich nicht zuletzt der historischen Idee vom Ethos der »Willensnation « verdankt ${ }^{23}$ - und einem ebenso typischen Pragmatismus, der anstelle von Grundsatzentscheidungen auf die jeweils konsensualen Spielräume des Machbaren gerichtet ist.

Reformierte Kirchenverständnisse in der Schweiz orientieren sich an den jeweiligen Bedürfnissen, Erwartungen und Interessen und weisen eine Pluralität auf, die einem erkennbaren Profil nicht nur im Wege steht, sondern auch bewusst entgegenwirkt. Diese Eigenart hat unmittelbare Auswirkungen für den Säkularisierungsdiskurs. Denn diesem fehlt eine notwendige Kontrastfolie, relativ zu der Säkularisierungsphänomene überhaupt als solche sichtbar werden können. Tatsächlich finden sich Hinweise auf gesellschaftliche Anpassungszumutungen an die Adresse der Kirchen innerhalb des reformierten Protestantismus der Schweiz nur selten. Dagegen begegnen zentrale, unter der Überschrift »Säkularisierung« debattierte Phänomene etwa Individualisierung, Deinstitutionalisierung, Flexibilisierung oder Privatisierung - bereits im 19. Jahrhundert im Umfeld der Selbstbeschreibungen und -verständnisse liberaler kirchlicher Gruppierungen. Insofern liegt die Frage nach einer - wie auch immer gearteten - »internal secularization« bzw. »Selbstsäkularisierung" im schweizerischen Protestantismus nahe ${ }^{24}$. Geltungstheoretisch bestätigt wird diese kommunitär-egalitäre Struktur durch die verbreitete Transformation der ekklesiologischen Formel von der ecclesia semper reformanda in eine universal einsetzbare Erklärungsmatrix für kontingente Weltverhältnisse. Wenn Welt und Weltorientierungen als einem permanenten Wandel unterworfene - mehr oder weniger - adhoc-Phänomene betrachtet werden, sind Säkularisierungsnarrative nicht nur unspektakulär, sondern bestätigen bestenfalls, was Reformierte immer schon wussten.

bericht-vernehmlassung_de-print.pdf $>$ (30.11.2015). Die einzelnen Vernehmlassungsantworten können eingesehen werden auf URL: <http://www.kirchenbund.ch/ de/verfassungsrevision $>$ (30.11.2015).

23 Vgl. Paul Widmer, Die Schweiz als Sonderfall. Grundlagen, Geschichte, Gestaltung, Zürich ${ }^{2} 2008$.

24 Vgl. Mark Chaves, Denominations as Dual Structures. An Organizational Analysis, in: Nicholas J. Demerath u.a. (Hg.), Sacred Companies. Organizational Aspects of Religion and Religious Aspects of Organizations, New York, NY u.a. 1998, S. 175194; Hartmann Tyrell, Religion und Organisation. Sechs kirchensoziologische Anmerkungen, in: Jan Hermelink / Gerhard Wegner (Hg.), Paradoxien kirchlicher Organisation. Niklas Luhmanns frühe Kirchensoziologie und die aktuelle Reform der evangelischen Kirche, Würzburg 2008, S. 179-204; PetzKe / Tyrell, Organisationen. 


\subsection{Reformiertes Bekenntnis in der Schweiz}

\section{Der Apostolikumstreit und seine Wurzeln im Richtungswesen}

Trotz reichhaltiger Bekenntnistradition kennt die Schweiz kein für die reformierte Lehre verbindliches Bekenntnis, welches etwa Bestandteil der Taufliturgie oder der Ordination wäre. Diese Bekenntnisfreiheit hat ihren Ursprung im Apostolikumstreit. Als Reaktion auf die Herausforderungen der Aufklärung bildeten sich im 19. Jahrhundert zwei gegensätzliche Strömungen innerhalb des Protestantismus aus. Die Konservativen, die sogenannt Positiven - Selbstbezeichnungen waren "gläubige«, »evangelischkirchliche oder »biblische" Richtung ${ }^{25}$ - standen den »Freisinnigen« oder »Reformern« gegenüber, die später unter dem Label »Liberale« figurierten. Dazwischen standen vermittelnde Positionen, die später unter anderem in die »religiös-soziale« Richtung übergingen. Diese Gruppierungen konnten nebeneinander, sogar innerhalb von einzelnen Gemeinden bestehen. Nachwirkungen dieses Richtungswesens sind heute noch spürbar ${ }^{26}$. So haben die Fraktionen in der Zürcher Synode hier ihren Ursprung und noch heute gibt es vereinzelt Kirchgemeinden, die ihre Pfarrstellen traditionell zwischen liberalen und positiven Pfarrerinnen und Pfarrern aufteilen, wobei diese Praxis in den vergangenen zwanzig Jahren stark abgenommen hat ${ }^{27}$.

Die Positiven wollten »den rechten, aus der Bibel gewonnenen Glauben in der evangelischen Kirche ${ }^{28}$ bewahren und bestanden aus einer heterogenen Gruppe, in der Pietisten, Orthodoxe ${ }^{29}$ und wissenschaftliche Theologen Platz fanden. In Opposition zu liberalen Kreisen ging es ihnen darum, die christliche Lehre vor weltlichen Einflüssen zu schützen ${ }^{30}$.

Prägend für die freisinnige Theologie war Alois Emanuel Biedermann, Pfarrer in Münchenstein bei Basel ${ }^{31}$. Seine Schrift Die freie Theologie oder

25 Vgl. Rudolf Gebhard, Umstrittene Bekenntnisfreiheit. Der Apostolikumstreit in den Reformierten Kirchen der Deutschschweiz im 19. Jahrhundert, Zürich 2003, S. 46.

26 Vgl. Thomas K. Kunn, Der schweizerische theologische Freisinn und seine Folgen, in: Jochen-Christoph KaIser, Vom Ertrag der neueren Kirchengeschichte für Kirche und Gesellschaft. Symposion zum 70. Geburtstag von Martin Greschat, Marburg 2008, S. 85-104, hier S. 86.

27 Vgl. Paul Schweizer, Freisinnig - Positiv - Religiössozial. Ein Beitrag zur Geschichte der Richtungen im Schweizerischen Protestantismus, Zürich 1972, S. 8-10 und GeBhard, Umstrittene Bekenntnisfreiheit, S. 31f.

28 Ebd., S. 46.

29 Es handelt sich hierbei um die Vertreter der Altorthodoxen im Gegensatz zur vernünftigen Orthodoxie. Letztere standen der Aufklärungstheologie durchaus aufgeschlossen gegenüber. Vgl. Schweizer, Freisinnig - Positiv - Religiössozial, S. 15-18.

30 Vgl. Gebhard, Umstrittene Bekenntnisfreiheit, S. 45f. Zum theologischen Profil der positiven Strömung vgl. SchweIzer, Freisinnig - Positiv - Religiössozial, S. 111-124.

31 Nicht unwesentlich scheint der Hinweis, dass Münchenstein zur Landschaft gehörte, die sich 1832/33 politisch von der Stadt trennte. Die dadurch herrschende 
Philosophie und Christentum in Streit und Frieden ${ }^{32}$ wurde von Zeitgenossen beschrieben als »aufsteigende Rakete, die den Aufmarsch einer neuen Streitmacht, der spekulativen Theologie, ankündigte « ${ }^{33}$. Biedermann bemängelte die zunehmenden Widersprüche zwischen den theologischen Glaubensgrundlagen und der gelebten Glaubenspraxis und forderte eine Auseinandersetzung der Religion mit wissenschaftlichen und philosophischen Entwicklungen. Die Kirche habe die Aufgabe, »den Geist Christi zu vermitteln, d.h. das religiöse Selbstbewusstsein zu der Vollendung, die es in Christus hatte, zu führen " ${ }^{34}$. Der Geist Christi könne jedoch nicht in eine Form gepresst werden, weil damit sein Wirken behindert würde. Deshalb könne es kein kirchliches Bekenntnis geben, das mit einem Wahrheitsanspruch auftrete. Glaubensinhalte und ihre historischen Voraussetzungen dürften nicht vermischt werden. Der eigentliche Inhalt des Glaubens sei der Geist Christi, der sich im vollendeten Selbstbewusstsein des Menschen als Einheit mit Gott zeige. Das habe ein kirchliches Bekenntnis zum Ausdruck zu bringen. Bekenntnisse, die stattdessen auf geschichtliche Daten des Lebens Jesu referierten, würden ihren Zweck verfehlen, den Geist Christi als den zu erfassen, der die Kirche bestimme und in ihr lebe ${ }^{35}$.

Nachdem die reformatorischen Bekenntnisse schon früher ihre rechtliche Funktion verloren hatten, konzentrierten sich die Angriffe auf das altkirchliche Bekenntnis ${ }^{36}$. Neben inhaltlichen Aspekten - der Jungfrauengeburt, der Höllenfahrt Christi und der Auferstehung des Fleisches ${ }^{37}$ - spielten auch antikatholische Reflexe eine große Rolle ${ }^{38}$. Der eigentliche Streit wurde im Großen und Ganzen - je nach Kanton mit anderen Nuancierungen - darüber geführt, ob das Apostolische Glaubensbekenntnis in der Taufliturgie

Aufbruchsstimmung im neuen Kanton Basel-Landschaft und die damit einhergehenden liberalen politischen Verhältnisse wirkten sich auch auf die kirchenpolitische Situation aus. Im Gegenüber zum pietistischen Basel war man hier für freisinnige Entwicklungen empfänglicher. Vgl. Thomas K. Kunn, Alois Emanuel Biedermann (1819-1885) und die Anfänge eines theologischen Liberalismus in reformierter Tradition, in: Matthias Freudenberg (Hg.), Profile des reformierten Protestantismus aus vier Jahrhunderten. Vorträge der ersten Emder Tagung zur Geschichte des reformierten Protestantismus, Wuppertal 1999, S. 131-139, hier S. 138.

32 Ursprünglich lautete der Titel »Der Philosoph in der Kirche«. Vgl. ebd., S. 131.

33 Georg FInSLER, Geschichte der theologisch-kirchlichen Entwicklung in der deutschreformierten Schweiz seit den dreissiger Jahren, Zürich 1881, S. 7.

34 Ebd., S. 10.

35 Vgl. Gebhard, Umstrittene Bekenntnisfreiheit, S. 33f. und Schweizer, Freisinnig Positiv - Religiössozial, S. 57.

36 Vgl. Matthias D. WÜTHRICH, Theologische Überlegungen zur reformierten Bekenntnisbildung in der Schweiz, in: SJKR/ASDE 15 (2010), S. 37-62, hier S. 50.

37 Vgl. Gebhard, Umstrittene Bekenntnisfreiheit, S. 354.

38 Vgl. ebd., S. 450f. 
und bei der Ordination obligatorisch zu verwenden $\operatorname{se}^{39}$. Nach über einem halben Jahrhundert der Auseinandersetzungen war schließlich das Apostolikum in keinem Kanton mehr verbindlich.

\section{Schweizer Eigenheiten}

Über die Frage, warum der Streit um das Apostolikum in der Schweiz - im Gegensatz zu entsprechenden Kontroversen in anderen Kirchen ${ }^{40}$ - in die radikale Konsequenz der Bekenntnisfreiheit mündete, kann nur spekuliert werden ${ }^{41}$. Dazu beigetragen haben mag etwa die spezifisch reformierte Bekenntnistradition, welche das Bekenntnis als norma normanda - als von der Schrift her zu normierende Norm - auffasst und seine Autorität als relativ gegenüber der Schrift setzt ${ }^{42}$. Zahlreiche reformierte Bekenntnisse stellen sich selbst unter den Vorbehalt zukünftiger besserer Einsichten ${ }^{43}$. Es zeigen sich aber im Zusammenhang mit der Bekenntnisfreiheit spezifisch schweizerische Eigenheiten, die - auch heute noch - tief im Selbstverständnis verwurzelt sind.

\section{Gemeindeautonomie}

Im Verlaufe des Apostolikumstreits stießen einzelne Kirchgemeinden intern und eigenmächtig Entwicklungen an - etwa die Einführung neuer Gottesdienstformulare -, auf die die kantonalen Behörden keinen Einfluss hatten und zogen so die Kompetenz über die Gottesdienstgestaltung immer weiter auf ihre Seite ${ }^{44}$. Diese Autonomie der einzelnen Kirchgemeinden ist zentral für das schweizerische Kirchenverständnis.

39 Eine detaillierte Rekonstruktion für die Deutschschweiz liefert Gebhard, Umstrittene Bekenntnisfreiheit.

40 Der Streit ums Apostolikum hat in der Schweiz früher eingesetzt und weitreichendere Folgen gezeitigt als in Deutschland. Leider ist dieser Sachverhalt außerhalb der Schweiz selbst unter Kirchenhistorikern kaum bekannt. Vgl. Kunn, Der schweizerische theologische Freisinn, S. 88.

41 Vgl. Emidio CampI, Bekenntnis oder Bekennen?, in: Matthias KrIEG/Hans Jürgen Luibl (Hg.), In Freiheit Gesicht zeigen. Zur Wiederaufnahme des liturgischen Bekennens im reformierten Gottesdienst, Zürich 1999, S. 53-61, hier S. 55.

42 Vgl. WÜтнRICH, Theologische Überlegungen, S. 44.

43 Der Berner Synodus von 1532 formuliert bspw.: »Würde uns aber etwas von unseren Pfarrern oder anderen vorgebracht, das uns näher zu Christus führt und nach Vermögen des Wortes Gottes allgemeiner Freundschaft und christlicher Liebe zuträglicher ist als die jetzt aufgezeichnete Meinung, das wollen wir gern annehmen und dem heiligen Geist seinen Lauf nicht sperren«. Gottfried W. Locher (Hg.), Der Berner Synodus von 1532. Edition und Abhandlungen zum Jubiläumsjahr 1982, Bd. 1, Neukirchen-Vluyn 1984, S. 26 .

44 Vgl. GebHard, Umstrittene Bekenntnisfreiheit, S. 437f., $449 f$. 
Esgehörenzu»Wesen und Eigenart desschweizerischen Protestantismus « ${ }^{45}$ die föderale Struktur und die demokratische Ordnung, die ihren Ursprung in der Entstehung der Schweiz aus selbstständigen »Orten«, ohne ausgeprägtes Nationalstaatswesen, haben. Daraus wurde die starke Stellung der einzelnen Kirchgemeinde abgeleitet. Die demokratisch-republikanischen Eigenarten des Schweizer Protestantismus wurden - mit einem gewissen nationalen Bewusstsein versehen - einem » starre[n] Luthertum « « ${ }^{46}$ gegenübergestellt. Entsprechend heißt es in der Kirchenkunde der reformierten Schweiz von 1910:

Die Kirchgemeinde besitzt eine fast souveräne Stellung, wie es die Demokratie mit sich zu bringen pflegt. Inwiefern ihre Freiheit in jedem einzelnen Kanton durch das kantonale Kirchengesetz beschränkt wird, wird bei den kantonalen Kirchverfassungen deutlich werden. Die Beschränkung ist jedoch unbedeutend. Im allgemeinen lässt sich sagen, dass jede Kirchgemeinde ihre Ordnungen nach eigenem Ermessen trifft ${ }^{47}$.

Und das nachfolgende Handbuch der reformierten Schweiz formuliert:

In einzelnen Kantonen geht die Souveränität der Kirchgemeinde sehr weit. Sie ist die eigentliche Zelle des kirchlichen Lebens. Sie ist durchweg presbyterial organisiert [...]. In diesem »Gemeindeprinzip « treffen sich altchristliche, ins Neue Testament zurückweisende Kirchenformen mit der alteidgenössischen Überlieferung, die bis in die altgermanische Marktgenossenschaft hinabreicht. Schon die Alte Eidgenossenschaft fasste ihre Orts- und Talgemeinschaften als Einheiten des christlichen Volkes Gottes auf; für Zwingli sind die politische Gemeinde und die »Kilchöri« eine einzige Lebensgemeinschaft $^{48}$.

Diese pathetische Überhöhung der Gemeindeautonomie ist heute zwar einer pragmatischeren Sichtweise gewichen, an der Sache hat sich aber grundsätzlich nichts geändert. Geblieben ist die starke Identifikation des Schweizer Protestantismus mit seinen unabhängigen Kirchgemeinden. Diese Sicht wird im Vernehmlassungsverfahren zur Verfassungsrevision des Schweizerischen Evangelischen Kirchenbunds (SEK) ebenso greifbar, wie die große Zurückhaltung, Aufgaben an eine höhere Ebene zu delegieren ${ }^{49}$.

45 Rüsch, Wesen und Eigenart, S. 1.

46 Gebhard, Umstrittene Bekenntnisfreiheit, S. 440 zitiert hier eine anonyme Basler Streitschrift aus dem Jahr 1871 mit dem Titel »Fort mit dem Bekenntnisszwang!«.

47 Carl Stuckert, Kirchenkunde der reformierten Schweiz, Gießen 1910, S. 12.

48 RüsCH, Wesen und Eigenart, S. 4f.

49 Vgl. SEK, Verfassungsrevision, S. 14f., 19. 


\section{Verhältnis Staat - Kirche}

Das 19. Jahrhundert brachte ebenso im Verhältnis von Kirche und Staat große Veränderungen. Die Kirchen verloren an politischem Einfluss und sollten sich auf »die geistlichen, moralischen oder auch sozialen Bedürfnisse der Bevölkerung beschränken $\aleph^{50}$. Der politische Liberalismus war äußerst stark, entsprechend wurden die liberalen Strömungen innerhalb der Kirche von den korrespondierenden politischen Kräften unterstützt und befördert ${ }^{51}$, was zu einer innerkirchlichen Kräfteverschiebung zugunsten der liberalen Stimmen führte ${ }^{52}$. Besonders in einer vermittlungstheologischen Variante konnten ihre Positionen die Kluft zwischen Glauben und Wissen sowie Staat und Kirche produktiv und pragmatisch überwinden. Ferner führte auch die neue eidgenössische Bundesverfassung von 1848 innerhalb der Kirche zu einem Demokratisierungsschub. Damit waren in der Schweiz die politischen Voraussetzungen für einen möglichst freien Diskurs über das Bekenntnis günstiger als im monarchisch und episkopal strukturierten Deutschland ${ }^{53}$.

So wurde die »Verbindung zwischen Kirche und Volk [...] gestärkt, ohne die Kirchlichkeit des Volkes zu fördern ${ }^{54}$. Das volkskirchliche Modell der Schweizer Kirchen gibt der konstruktiven Verbundenheit von Kirche und Staat Ausdruck. Die Kirchen leisten ihren Beitrag zum Wohl des ganzen Volkes, gleichzeitig ist die Mitgliedschaft nicht an ein Bekenntnis gebunden $^{55}$. Damit wird der Glaubens- und Gewissensfreiheit innerhalb der Kirche Rechnung getragen und der Raum für eine Vielfalt von Glaubensformen und Frömmigkeitsstilen eröffnet.

50 Vischer (Hg.), Ökumenische Kirchengeschichte, S. 229.

51 Vgl. Gebhard, Umstrittene Bekenntnisfreiheit, S. 436 und Kunn, Der schweizerische theologische Freisinn, S. 88.

52 Zeugnis davon gibt das Gelübde, welches die Pfarrer im liberalen Kanton BaselLandschaft vor dem Regierungsrat (Exekutivbehörde) ablegen mussten. Der Schwur zum Halten der Verfassung war ebenso Bestandteil, wie die Verpflichtung niemanden außer den staatlichen Behörden als weisungsbefugt anzuerkennen. Vgl. KuHN, Der schweizerische theologische Freisinn, S. 90f.

53 Vgl. ebd., S. $88 f$.

54 Schweizer, Freisinnig - Positiv - Religiössozial, S. 261.

55 Die Bekenntnisgrundlagen der heutigen Kantonalkirchen finden sich - analog zu staatlichen Verfassungen - in der Präambel der Kirchenordnungen. Vgl. dazu Rudolf GebHard, Kirchenordnung und Bekenntnis, in: Cla Reto Famos / Ingolf U. Dalferth (Hg.), Das Recht der Kirche. Zur Revision der Zürcher Kirchenordnung, Zürich 2004, S. 183-207. Für die Schweizerische Evangelische Synode wurden Ende der 1980er-Jahre die Bekenntnisgrundlagen aller evangelischen Kirchen der Schweiz zusammengetragen. Gerade die Landeskirchen belassen es - im Gegenüber zu den nicht staatlich anerkannten freikirchlichen Gemeinschaften - bei einem allgemeinen Bekenntnis zu Jesus Christus und zur Normativität der Schrift, ohne weitergehende inhaltliche Bestimmungen zu machen. Vgl. Was bekennen die evangelischen Kirchen in der Schweiz? Eine Übersicht über die Bekenntnisgrundlagen der evangelischen Kirchen, Freikirchen und Gemeinschaften in der Schweiz, Bern 1987. 


\section{Bekenntnisfreiheit heute?}

Die Herausforderungen des 19. Jahrhunderts wurden gut schweizerisch gelöst: pragmatisch und nüchtern, aber auch entschiedener und radikaler als anderswo ${ }^{56}$. Die Kluft zwischen Glauben und Moderne führte nicht zu Spaltungen, sondern wurde von der Kirche produktiv aufgenommen. Das Handbuch der reformierten Schweiz resümiert: »Regeneration, Liberalismus und Kulturkampf ließen die kirchliche `Reform` vordringen, d.h. ein Christentum, das entschieden der modernen Weltanschauung $\mathrm{zu}$ folgen gewillt war und die altprotestantisch-orthodoxe oder pietistische Glaubenswelt ablehnte«. Dies weil »die Aufklärungstheologie [...] in manchen Punkten der nüchternen Schweizerart entgegenkam" und "seither die schweizerische Volksfrömmigkeit weitgehend mitgeform ${ }^{57}{ }^{57}$ hat.

Das zeigt eine Volkskirche, die sich durch Lernbereitschaft und Lernfähigkeit auszeichnet ${ }^{58}$, weil sie auf gesellschaftliche Veränderungen und Strömungen reagieren kann, da sich diese in ihr selbst abbilden ${ }^{59}$. Diese Vielstimmigkeit wird befördert durch die volkskirchliche Verfasstheit und die Konzentration auf die Kirchgemeinde. Dabei besteht die Gefahr, sich ungeprüft dem Mainstream anzupassen und sich damit den Vorwurf der Beliebigkeit einzuhandeln; einer Beliebigkeit, der der religiöse Liberalismus nicht das Wort geredet hatte. Dieser verstand die Bekenntnisfreiheit nicht als Freiheit vom Bekennen, sondern als Freiheit im Bekennen, was Biedermanns Auftrag an die Kirche, dem Heiligen Geist Raum zu lassen, illustriert.

Tatsächlich scheinen sich die Schweizer Kirchen derzeit stark an ihrer Außenwirkung zu orientieren. Davon zeugen soziologische Studien, welche die Gründe für die leeren Kirchen zu ergründen versuchen und Strategien formulieren, wie dem entgegenzuwirken sei. Jedoch bleibt es oft auf einer formalen Ebene der Strukturdiskussion und Organisationsentwicklung. Doch gerade in diesem Zusammenhang sind Stimmen zu hören, die sich ein verbindliches Bekenntnis wünschen, um sich im Wettbewerb der Sinnanbieter profilieren zu können. Die Motivation mag fragwürdig sein, der Sache nach zeigt sich jedoch eine Stärke der bekenntnisfreien Kirche: Man ist in einem ständigen Bekenntnisprozess begriffen. Um Glaubensinhalte kann und muss gerungen werden: ein hoher Anspruch angesichts der zum Programm gehörenden Pluralität innerhalb der Volkskirche. Das Beispiel der Zürcher Initiative zur Einführung eines Bekenntnisses in den Gottesdienst

56 Vgl. Kunn, Der schweizerische theologische Freisinn, S. 103.

57 Rüsch, Wesen und Eigenart, S. 9.

58 Christoph Morgenthaler hat dies am Beispiel der Seelsorge skizziert, vgl. Christoph Morgenthaler, Volkskirche - bescheiden, frech. Praktisch-theologische Thesen zur Zukunft der Volkskirche: Claudia Kohli Reichenbach / Matthias Krieg (Hg.), Volkskirche und Kirchenvolk. Ein Zwischenhalt, Zürich 2015, S. 69-75.

59 Vgl. Campiche, Die zwei Gesichter, S. 173. 
vor etwa zehn Jahren, die auf breites Echo in den Gemeinden stieß, zeigt, dass dies nicht bloß theologisch wünschenswert wäre, sondern einem Bedürfnis des Kirchenvolkes entspräche ${ }^{60}$. Als sicher kann jedoch gelten, dass es in den reformierten Kirchen der Schweiz auf absehbare Zeit kein exklusives für alle verpflichtendes Bekenntnis oder eine Sammlung solcher geben wird. Dafür ist das Credo »Einheit in Vielfalt«, auch was die Bekenntnistradition betrifft, zu stark in ihrer reformierten DNA eingebrannt ${ }^{61}$.

\section{Christliche Werte in Staat und Politik}

Bleibt die Frage nach einer Korrespondenz zwischen der theologischen und politisch-rechtlichen Sicht auf Kirche, Staat und Gesellschaft. Für eine solche Gegenprobe spricht auch der semantische Befund, dass beim Volkskirchenbegriff neben der Bedeutung von Kirche für das Volk häufig die alternative Konnotation von Kirche des Volkes mitschwingt. Zwar wird die zweite Variante in der Regel von den Kirchen zurückgewiesen, begegnet aber gleichwohl in diversen kirchlichen und gesellschaftspolitischen Begründungszusammenhängen. Kirche begegnet dort als normative Orientierungsinstanz, als Garantin traditioneller Werte, moralischer Kohärenz und gesellschaftlicher Kohäsion. Einige wenige Hinweise müssen genügen.

Prominent begegnet ein christlicher Wertebezug in der invocatio Dei der schweizerischen Bundesverfassung, die im Vorfeld der Totalrevision von 1999 kontrovers debattiert wurde. Die mit dem Vorentwurf betraute Expertenkommission sprach sich für ihre Beibehaltung aus, weil darin Wertvorstellungen aufbewahrt würden, »deren Herkunft aus einem christlichen Verständnis von Staat und Gesellschaft erkennbar ist, die aber darüber hinaus heute als Gemeingut säkularisierter Humanität gelten können « ${ }^{62}$. Die Verbindung oder sogar Identifikation von christlichen Werten und Humanität gehört zu einem beliebten Topos in politischen und kirchlichen Debatten, dem im Recht seit den 1990er Jahren eine weitere theologische Kategorie zur Seite tritt. Im Rahmen der rechtlichen Regelung der Gentechnologie wurde 1992 Artikel 24 novies Abs. 3 (heute Art. 120) in die Bundesverfassung aufgenommen, der den Bund darauf verpflichtet, »der Würde der Kreatur sowie

60 SEK, Werkbuch Bekenntnis, Motion der Evangelisch-reformierten Landeskirche des Kantons Zürich, der mitunterzeichnenden Reformierten Kirchen Bern-JuraSolothurn und weiterer mittragender Kirchen vom 14.-16. Juni 2009. Bericht zur Vernehmlassung, Bern 2012, URL: <http://www.kirchenbund.ch/sites/default/files/ AV/08_Werkbuch_Bekenntnis_Bericht_Vernehmlassung.pdf> (27.10.2016), S. 11f.

61 Vgl. ebd., S. 14f.

62 Expertenkommission für die Vorbereitung einer Totalrevision der Bundesverfassung, Bericht, Bern 1977, S. 17, URL: <https://www.bj.admin.ch/dam/data/bj/staat/ gesetzgebung/archiv/bundesverfassung/ber-expkomm-d.pdf> (30.11.2015). 
der Sicherheit von Mensch, Tier und Umwelt Rechnung « zu tragen ${ }^{63}$. Bemerkenswert ist nicht nur die Aufnahme des paulinischen Begriffs der Kreatur aus Röm 8,22 in die Verfassung, sondern auch die signifikante Abweichung der französischen Übersetzung, in der aus der »Würde der Kreatur« "'intégrité des organismes vivants" wird. Die Spannbreite zwischen den Begriffen "Kreatur" und »lebenden Organismen« bildet metaphorisch den Spielraum ab, in dem plurale normative Vorstellungen und Traditionen auf säkulares Recht treffen. Die Tatsache, dass ein genuin biblisch-theologischer Begriff in die Rechtssprache einwandert, ist gewiss säkularisierungstheoretisch interessant. Eindrücklicher und für die schweizerische Perspektive bezeichnender ist allerdings der Befund, dass in der Bundesverfassung je nach Sprache - und offensichtlich komplikationslos - theologische durch säkulare Gehalte und umgekehrt ersetzt werden können.

Dass es sich dabei nicht um missverständliche Formulierungen handelt, zeigt ein Blick in die Kantonsverfassungen, in deren Präambeln äußerst heterogene Bezüge zu einer göttlichen Instanz und der Kreatur resp. Schöpfung begegnen: So verpflichten sich die Verfassungen der Kantone Aargau (1980), Basel-Stadt (2005), Bern (1993) und Zürich (2005) auf die "Verantwortung gegenüber der Schöpfung«, die Luzerner (2007), St. Galler (2001) und Schaffhauser Verfassung (2002) auf die »Verantwortung vor Gott«, die Verfassungen von Uri (1984) und Wallis (1907) »im Namen Gottes«. Die Genfer Verfassung (2012) ergeht »in Anerkennung seines humanistischen, geistigen, kulturellen und wissenschaftlichen Erbes « und die Freiburger Verfassung (2004) gilt denjenigen bzw. uns, »die wir an Gott glauben oder unsere Werte aus anderen Quellen schöpfen". Ohne die Symbolgehalte von Verfassungspräambeln über zu bewerten oder in sie bestimmte normative Überzeugungen hineinlesen zu wollen, zeigt sich auch hier ein für die Schweiz typischer Variantenreichtum und eine Fluidität, die nicht als stoßend oder inkommensurabel wahrgenommen wird. In der alternativen Spitzenformulierung der Freiburger Präambel stehen religiöse und säkulare Fundamente - mit einem »oder« verbunden - wechselseitig unbestritten nebeneinander.

Traditionell religiöse Überzeugungen kommen vor allem in ethischen und sozialen Zusammenhängen ins Spiel. Die kohäsive Funktion gemeinsamer Wertefundamente und die ökologische Verantwortung lassen sich entweder nicht in säkulare Sprache fassen oder religiöse Codierungen bestimmter Themen gehen selbstverständlich und weitgehend unspektakulär in die

63 Vgl. Ina Praetorius / Peter Saladin, Die Würde der Kreatur Art. 24 novies Abs. 3 BV. Gutachten, hg. von Bundesamt für Umwelt, Wald und Landschaft (BUWAL), Bern 1996; Eidgenössische Ethikkommission für die Biotechnologie im Ausserhumanbereich (EKAH) (Hg.), Die Würde der Kreatur bei Pflanzen, Bern 2008; Dagmar RichteR, Die Würde der Kreatur. Rechtsvergleichende Betrachtungen, in: ZaöRV 67 (2007), S. 319-349. 
säkularen Sprachspiele von Politik und Recht ein. Diese Beobachtung widerspricht der von Rawls geforderten Verzichtserklärung und dem von Habermas erhobenen Übersetzungsvorbehalt gegenüber religiös motivierten Äußerungen im Rahmen politischer Grundlagendiskussionen. Die Übersetzungsleistungen werden von der pluralen Gesellschaft im säkularen Staat offensichtlich selbst erbracht, wobei - wie das Beispiel der Würde der Kreatur in der Bundesverfassung zeigt - eine vertikale von einer horizontalen Übersetzung unterschieden werden kann: Die vertikale Variante garantiert die Adaptionsfähigkeit religiöser Begriffe in säkulare Kontexte, ohne damit bestimmte Inhalte zu präformieren. Die horizontale Version erlaubt den kommunikativen Wechsel zwischen den Begrifflichkeiten, ohne dass damit notwendig das Bewusstsein eines Übergangs zwischen zwei Sprachspielen verbunden sein muss. Die Übersetzung religiöser Sprache in säkulares Recht arbeitet ebenso im Rücken der Bürgergemeinde, wie die unter dem Säkularisierungsbegriff subsumierten Phänomene die real existierende Christengemeinde prägen. Für einen ausgewiesenen Säkularisierungsdiskurs fehlt beiden ein Säkularisierungsnarrativ. Der Geschichte von der wissenschaftlich-technologischen »Entzauberung der Welt ${ }^{64}{ }^{4}$ stemmt sich nach wie vor erfolgreich das schweizerische Narrativ von der Verzauberung durch Freiheit entgegen.

64 Max Weber, Wissenschaft als Beruf, in: Max Weber-Studienausgabe I/17, Tübingen 1994, S. 1-24, hier S. 9. 


\section{Michael Germann}

\section{Säkularisierung und Religion in der Perspektive des Religionsverfassungsrechts*}

Auf der Vorderseite dieses Tagungsbandes ist ein Bild zu sehen, das gut zur Perspektive des Religionsverfassungsrechts auf das Thema "Säkularisierung und Religion" paßt. Auf dem Bild erkennen wir die Türme des Zürcher Grossmünsters, auf denen ganz oben, wo bei manchen anderen Kirchen ein Kreuz ist oder ein Hahn, die schweizerische Nationalflagge flattert. Auf dem der Religion gewidmeten Gebäude ist also das Symbol des Staates gehißt. Da es die Flagge der Schweiz ist, präsentiert sich im Zentrum dieses Staatssymbols das Kreuz - das prominente Symbol der christlichen Religion. Das Kreuz versinnbildlicht als Symbol der christlichen Religion nun gerade die äußerste Verweltlichung Gottes, der sich in Jesus Christus eben ans Kreuz schlagen läßt, das insofern wiederum ein Symbol des Staates, eine Demonstration der römischen Staatsgewalt ist. Der römische Staat schlägt Jesus ans Kreuz, nachdem er von der religiösen Autorität der jüdischen Hohepriester andeutungsweise auf seine Sakralität angesprochen wird (Joh 19,7,12b,15), ohne sich an diesem Anspruch besonders interessiert zu zeigen; Pilatus begegnet Jesus ja nur mit dem Verweis auf seine Macht (Joh 19,10) und mit der lakonischen Frage: „Was ist Wahrheit? (Joh 18,38). Wie auch immer die eidgenössische Flagge diese Frage aufruft: An Tagen ohne Beflaggung ${ }^{1}$ sind die Türme des Grossmünsters - bis auf die dekorativen Knäufe, die nur von ferne aussehen wie kleine Kreuze - mehr oder weniger leer. So illustrieren die Türme des Grossmünsters die Frage nach dem Verhältnis von Säkularisierung und Religion mit einer Kette von Assoziationen, in denen das Verhältnis von Religion und Staat mehrfach das Vorzeichen wechselt.

* Die Herausgeberinnen respektieren auf Wunsch des Autors die alte Rechtschreibung.

1 Das Reglement der Stadt Zürich über die Beflaggung öffentlicher Standorte, Amtliche Rechtssammlung Nr. 700.230, zuletzt in der Fassung vom 30.03.2016, URL: <https:// www.stadt-zuerich.ch/portal/de/index/politik_u_recht/amtliche_sammlung/ inhaltsverzeichnis/7/700/230.html> (24.03.2017), führt das Grossmünster nicht unter den »öffentlichen Standorten« in Art. 3 Satz 2 auf. Seine Beflaggung lehnt sich offenbar gleichwohl an das Reglement an. Das Pfarramt des Grossmünsters selbst unterlegt seinen Internet-Auftritt mit einem Bild des Kirchturms unter der eidgenössischen Flagge, URL: <https://www.grossmuenster.ch/de/gemeinde/uber-uns/ pfarramt/> (24.03.2017). 


\section{Die Perspektive des Religionsverfassungsrechts}

Mit der Rolle des Staates und seiner Haltung zur Religion im Paradigma der Säkularisierung ist die Perspektive des Religionsverfassungsrechts ${ }^{2}$ aufgerufen $^{3}$. Sie beschränkt sich auf das Juristische und bezieht sich auf positives Verfassungsrecht. Es gibt sie nicht als Perspektive des Religionsverfassungsrechts schlechthin, sondern zunächst nur aus dem Blickwinkel einer bestimmten Verfassungslage. Diese begegnet als eine Dezision darüber, wie sich das Recht und der Staat zur Religion verhalten sollen. Als ein Beispiel für ein Religionsverfassungsrecht, das den Staat ganz bewußt als einen säkularen Staat verfassen will und verfaßt, bietet sich das geltende Religionsverfassungsrechts der Bundesrepublik Deutschland an. Selbstverständlich folgen Entscheidungen wie die für die Säkularität des Staates historischen und rechtskulturellen Bedingungen ${ }^{4}$. Nicht diese sollen hier näher in den Blick genommen werden, sondern die juristischen Strukturen, in denen das deutsche Grundgesetz die Säkularität des Staates verfaßt.

Mit der Entscheidung für die Säkularität des Staates ist noch nicht gesagt, wozu der Staat säkular sein soll. Aber für das Verständnis des Religionsverfassungsrechts macht es einen Unterschied, auf welche Ratio, welches Telos hin die Säkularität des Staates gedeutet wird. Soll die Säkularität des Staates ein vorbestimmtes Modell des säkularen Staates exerzieren? Oder verwirklicht sie ein bestimmtes Bild von Gesellschaft, von gesellschaftlicher Öffentlichkeit, vom säkularen Menschen? Es bedarf einer Reflexion, die den Sinn der verfassungsrechtlichen Entscheidung für die Säkularität des Staates durch Auslegung ihres verfassungsrechtlichen Zusammenhangs erschließt und dann wiederum für die Auslegung der einzelnen Normen fruchtbar macht.

Für das Religionsverfassungsrecht Deutschlands läßt sich die These aufstellen: Das Grundgesetz verfaßt den Staat als säkularen Staat um der Religionsfreiheit willen. So trivial das klingt, stellt dies eine entscheidende Weiche für die Auslegung der einzelnen Verfassungsnormen. Für eine auf die

2 Synonym: Staatskirchenrecht. Zur Verwendung der beiden Bezeichnungen des Fachs siehe Michael Germann, Entwicklungstendenzen im Verhältnis von Staat und Kirche unter dem Grundgesetz der Bundesrepublik Deutschland, in: ÖARR 61/1 (2014), S. 41-88, hier S. 52f. mit weiteren Nachweisen.

3 Aus ähnlicher Perspektive siehe etwa Ernst-Wolfgang BöCKenförde, Der säkularisierte Staat. Sein Charakter, seine Rechtfertigung und seine Probleme im 21. Jahrhundert, München 2006; Horst Dreier u.a., Säkularisierung und Sakralität. Zum Selbstverständnis des modernen Verfassungsstaates, Tübingen 2014.

4 Dazu ausführlich im hier behandelten Zusammenhang Martin Heckel, Säkularisierung. Staatskirchenrechtliche Aspekte einer umstrittenen Kategorie, in: ZRG 97 KA 66 (1980), S. 1-163, auch in: Ders., Gesammelte Schriften. Staat, Kirche, Recht, Geschichte, hg. v. Klaus SchlaIcH, Bd. 2, Tübingen 1989, S. 773-911. 
Religionsfreiheit ausgerichtete Säkularität des Staates ist das Religionsverfassungsrecht des deutschen Grundgesetzes exemplarisch. Es ist ein Beispiel unter anderen. Exemplarisch kann man es aber auch in dem Sinn nennen, daß es als Vorbild taugt für Verfassungen und ihre Deutungen, die die Säkularität des Staates auf die Religionsfreiheit ausrichten wollen. Auch wenn seine Vorbildlichkeit immer einmal eine Erwähnung verdient, kommt es hier nicht darauf an. Es soll jedenfalls eine Möglichkeit darstellen, wie die Säkularität des Staates freiheitlich verstanden und gestaltet werden kann.

Wenn im interdisziplinären Gespräch auf die »Wechselseitigkeit von Säkularisierungs- und Religionskonzepten « hingewiesen und ein Begriff von »säkularer Religion" postuliert wird, »die sich den in einer pluralen Gesellschaft notwendigen Säkularisierungen nicht verweigert ${ }^{5}$, wirft das Fragen auch an das Religionsverfassungsrecht auf - Fragen, auf deren Beantwortung in Thesen (s.u. 6) hier eine Erörterung des Religionsverfassungsrechts nach dem deutschen Grundgesetz (s.u. 2-5) hinführen soll:

- Findet sich im Religionsverfassungsrecht eine »Wechselseitigkeit von Säkularisierungs- und Religionskonzepten«?

- Unterstützt das Religionsverfassungsrecht einen Begriff von »säkularer Religion«?

- Welchen Ort gibt das Religionsverfassungsrecht der Religion »in einer pluralen Gesellschaft«?

- Inwiefern sind »Säkularisierungen« in einer pluralen Gesellschaft »notwendig«?

- Wie soll sich eine »säkulare Religion« $\mathrm{zu} » d e n$ in einer pluralen Gesellschaft notwendigen Säkularisierungen« verhalten?

2. Säkularisierung und Religion im Text des Grundgesetzes der Bundesrepublik Deutschland

\section{1 »S̈̈kularisierung«?}

Die programmatische Enthaltsamkeit des Grundgesetzwortlauts

Im Text des Grundgesetzes (GG) kommt das Wort »Säkularisierung« nicht vor. Die stärkste Aussage in diese Richtung trifft Art. 137 Abs. 1 der Weimarer Reichsverfassung (WRV) von 1919, den Art. 140 GG zum Bestandteil des Grundgesetzes erklärt, also in den Text des Grundgesetzes von 1949 inkorporiert und nach Rang und Normgehalt vollgültig in das Verfassungsrecht 
aufnimmt ${ }^{6}$. Art. 137 Abs. 1 WRV bestimmt recht lakonisch: »Es besteht keine Staatskirche«. Hier hat die Weimarer Verfassung eine Systementscheidung getroffen, die wir als eine Aussage über die Säkularität des Staates lesen können. Diese verfassungsrechtliche Aussage bezieht die Säkularisierung auf den Staat und sein institutionelles Verhältnis zur Religion. Weitere Programmsätze zur Säkularisierung enthält das Grundgesetz wie schon die Weimarer Verfassung nicht. Darin unterscheiden sich die deutschen Verfassungen von der Verfassung Frankreichs, die in ihrem ersten Artikel der französischen Republik das Attribut »laïque vorgibt ${ }^{7}$.

Die im Vergleich deutliche programmatische Enthaltsamkeit der Weimarer Verfassung und des Grundgesetzes erklärt sich in ihrer Entstehungsgeschichte: In beiden Verfassungskonventen, also in der Weimarer Nationalversammlung wie im Parlamentarischen Rat, hinderten tiefe Gegensätze in den Anschauungen über das Verhältnis von Staat und Kirche die Durchsetzung eines bestimmten religionsverfassungsrechtlichen Programms. Erst der weitgehende Verzicht auf ein solches Programm machte einen Kompromiß über die »Kirchenartikel« möglich. Daher verhält sich die Verfassung also nicht ausdrücklich zur Säkularisierung.

\section{$2.2 »$ Religion«: Freiheit und Gleichheit}

Religion hingegen kommt im Grundgesetz ganz prominent zur Sprache. Hier ist in erster Linie selbstverständlich die Garantie der Religionsfreiheit zu nennen. Art. 4 Abs. 1 und 2 GG erklärt die Freiheit des Glaubens und des religiösen und weltanschaulichen Bekenntnisses für unverletzlich und gewährleistet die ungestörte Religionsausübung. Die Freiheit der Religion ist flankiert durch die religiöse Gleichheit, die Art. 3 GG über den allgemeinen Gleichheitssatz (Abs. 1) hinaus zu einem speziellen Verbot religiöser Diskriminierung zuspitzt: Niemand darf wegen seines Glaubens oder seiner religiösen Anschauungen benachteiligt oder bevorzugt werden (Abs. 3 Satz 1). Besonders werden der Genuß bürgerlicher und staatsbürgerlicher Rechte und der Zugang zu öffentlichen Ämtern von jeder Bindung an ein religiöses Bekenntnis oder an die Zugehörigkeit oder Nichtzugehörigkeit zu einem Bekenntnis oder einer Weltanschauung freigestellt (Art. 33 Abs. 3 GG). In

6 BVerfG (Bundesverfassungsgericht), Urteil vom 14.12.1965 - 1 BvR 413, 416/60 -, E 19, 206 (219); Urteil vom 09.06.2004 - 1 BvR 636/02 -, E 111, 10 (50); Beschluß vom 22.10.2014 - 2 BvR 661/12 -, Abs. 83.

7 Constitution de la République française vom 04.10.1958, Art. 1 Abs. [1] Satz 1: »La France est une République indivisible, laïque, démocratique et sociale«. 
seinen Bestimmungen zur religiösen Freiheit und Gleichheit macht das Grundgesetz die Religion also ganz ausdrücklich zu seinem Thema. Indem das Grundgesetz religiöse Freiheit und Gleichheit grundrechtlich gewährleistet, trifft es zu diesem Thema der Religion zugleich eine prägnante Aussage.

Diese grundsätzlichen Aussagen des Grundgesetzes über religiöse Freiheit und Gleichheit haben auch eine grundsätzliche Bedeutung für unser Thema der Säkularisierung. Zum Gegenstand der Säkularisierung bestimmen sie in spezifischer Weise den Staat. Der Staat ist es, an den die aus der Garantie religiöser Freiheit und Gleichheit folgenden Pflichten adressiert sind.

Das Grundrecht der Religionsfreiheit verpflichtet den Staat, Eingriffe in die religiösen Interessen der Bürger zu unterlassen, welche nicht durch überwiegende Zwecke verfassungsrechtlich gerechtfertigt sind. Solche Eingriffszwecke müssen säkular sein. Diese Bedingung ergibt sich nicht aus dem Wortlaut des Grundgesetzes, aber aus der Intention der Religionsfreiheit: Die Religionsfreiheit soll davor schützen, sein Glauben, Bekennen und Handeln anderen religiösen Maßstäben unterwerfen zu müssen als denen der eigenen religiösen Überzeugung. Der Staat darf in die Religionsfreiheit eingreifen, um anderen Interessen dagegen Geltung zu verschaffen; aber diese anderen Interessen dürfen nicht in einem eigenen Interesse des Staates an einer anderen Religion aufgehen, sondern müssen sich auf nichtreligiöse, in diesem Sinn säkulare Belange richten.

Das Recht auf religiöse Gleichheit verpflichtet den Staat, die Ungleichbehandlung religiöser Interessen zu unterlassen, sofern die Ungleichbehandlung nicht durch einen sachlichen Grund gerechtfertigt ist. Nur ein säkularer Grund kann als ein solcher sachlicher Grund eine Ungleichbehandlung rechtfertigen.

Den Bürger hingegen verpflichtet das Grundgesetz nicht zur Achtung religiöser Freiheit und Gleichheit. Das ist eine wichtige Abgrenzung in der religionsverfassungsrechtlichen Perspektive auf die Säkularisierung. Sie kennt keine Bürgerpflicht zur Säkularität. Anders als der Staat darf der Bürger seine eigensinnigen religiösen Zwecke verfolgen und andere Bürger aus religiösen - oder überhaupt beliebigen anderen - Gründen ungleich behandeln. Das juristische Verständnis kann hier dem Allgemeinverständnis von den Freiheits- und Gleichheitsrechten des Grundgesetzes anstößig erscheinen. Denn zur allgemein verbreiteten Auffassung von der Grundrechtsordnung gehört es, daß die durch sie gewährleistete Achtung religiöser Freiheit und Gleichheit selbstverständlich das gesellschaftliche Miteinander zu prägen habe. Das kann zu der Vorstellung führen, daß ein Bürger den anderen mit den Äußerungen seiner religiösen Einstellungen verschonen müsse, ihm also eine säkulare Behandlung schulde. Eine solche Übertragung der Grundrechtsverpflichtung vom Staat auf den Bürger ginge offensichtlich auf Kosten der Freiheit. Einer liberalen Verfassung wie dem Grundgesetz ist das fremd. 
Sie bindet unmittelbar nur den Staat an die Grundrechte und wendet diese nicht gegen die Freiheit der Bürger selbst.

Mittelbar allerdings wirken sich die Grundrechte auch für das Verhältnis der Bürger untereinander aus. Es gehört zu den Aufgaben des grundrechtsgebundenen Staates, zwischen den Bürgern für Frieden zu sorgen und eine Ordnung zu schaffen, in der sie ihre grundrechtlich geschützten Interessen möglichst frei entfalten können. Der Staat muß die Bürger vor Übergriffen schützen, indem er Konflikte zwischen religiösen oder anderen Interessen der Bürger rechtlich reguliert. Dazu beschränkt er durch Gesetz um der Freiheit des einen willen die Freiheit des anderen. Die Grundrechte nehmen den Staat beiderseits in die Pflicht.

Dabei bleibt es der Staat, der Adressat der Grundrechtsverpflichtung ist. Die wechselseitigen Pflichten der Bürger, die um ihrer religiösen Freiheit und Gleichheit erforderlich sind, folgen aus den Grundrechten nicht unmittelbar, sondern sind über die Inpflichtnahme durch das staatliche Gesetz vermittelt. Diese wichtige, liberale Unterscheidung bewahrt die grundgesetzlichen Gewährleistungen religiöser Freiheit und Gleichheit davor, zum Hebel für eine den Bürgern aufgedrückte Säkularisierung der Gesellschaft gemacht zu werden. Sie richtet die Forderung nach Säkularisierung und Säkularität allein gegen den Staat.

\subsection{Das Gebot religiöser und weltanschaulicher Neutralität des Staates}

Der Schlüsselbegriff für diese Verpflichtung des Staates in der Auslegung des Religionsverfassungsrechts unter dem Grundgesetz ist weniger die »Säkularität« als die »Neutralität« des Staates: Seine Säkularität wird in seine Verpflichtung zu religiöser und weltanschaulicher Neutralität gefaßt. Auch der Begriff der Neutralität kommt im Text des Grundgesetzes nicht vor, sondern ist Ergebnis einer Gesamtdeutung seiner religionsverfassungsrechtlichen Bestimmungen.

Die Herleitung und Reichweite des Gebots religiöser und weltanschaulicher Neutralität ist immer wieder Gegenstand von Kontroversen. Doch in

8 Siehe allgemein BVerfG, Urteil vom 19.12.2000 - 2 BvR 1500/97 -, E 102, 370 (394); Beschluß vom 26.06.2002 - 1 BvR 670/91 -, E 105, 279 (294f.); Urteil vom 24.09.2003 2 BvR 1436/02 -, E 108, 282 (299-301) mit weiteren Nachweisen; Klaus ScHlAICH, Neutralität als verfassungsrechtliches Prinzip. Vornehmlich im Kulturverfassungsund Staatskirchenrecht, Tübingen 1972; Eilert Herms, Die weltanschaulich-religiöse Neutralität von Staat und Recht aus sozialethischer Sicht, in: Der Staat 40 (2001), S. 327-347; Stefan Huster, Die ethische Neutralität des Staates. Eine liberale Interpretation der Verfassung, Tübingen 2002; ergänzend Thomas Fritsche, Der Kulturbegriff im Religionsverfassungsrecht, Berlin 2015: »Kulturneutralität«; zum neueren Stand der Debatte um Methode und Programm siehe Hans Michael Heinig, 
der Mitte der Diskussion steht eine Umschreibung des Neutralitätsgebots, an der auch das Bundesverfassungsgericht festhält und die in ihrer Leistungsfähigkeit noch nicht überholt erscheint. Sie übersetzt das Gebot zur Neutralität in ein Verbot der Identifikation mit partikularen religiösen oder weltanschaulichen Positionen. Das Bundesverfassungsgericht hat dieses Identifikationsverbot emphatisch mit der Forderung plausibel gemacht, daß der Staat des Grundgesetzes »Heimstatt aller Bürger« zu sein hat ${ }^{9}$. Wenn er sich selbst mit partikularen religiösen oder weltanschaulichen Positionen identifizierte, grenzte er die Menschen, die diese Positionen nicht teilen, gewissermaßen aus dem Staatsbürgerstatus aus.

Dieser Gedanke ist jedenfalls im Ansatz ganz gut geeignet zu beschreiben, was auch die Säkularität des Staates ausmacht. Zu den Funktionen des Staates gehört eine Integrationsfunktion, selbst wenn man sie nicht zum Dreh- und Angelpunkt des Staatsverständnisses machen muß. Diese Integrationsfunktion kann der Staat nur erfüllen, indem er den Bürgern als ein säkularer Staat begegnet, der sich aus der Konkurrenz der diversen religiösen und weltanschaulichen Positionen heraushält und sein Handeln nicht an solche partikularen Positionen bindet. Das ist kurzgefaßt der Grundgedanke, der die Neutralität und damit auch die Säkularität des Staates als ein Identifikationsverbot deutet.

\section{Besondere Verfassungsnormen zur Ausgestaltung der Säkularität des Staates}

$\mathrm{Zu}$ diesem Grundgedanken können die verschiedenen Regelungen des Grundgesetzes, die die Religion betreffen, ins Verhältnis gesetzt werden. Dabei ist stets im Blick zu halten, daß sich der Grundgedanke von Neutralität und Säkularität des Staates der Auslegung des Grundgesetzes verdankt und nicht etwa umgekehrt die Bestimmungen des Grundgesetzes einem metaverfassungsrechtlichen Prinzip unterzuordnen wären. Nach der eben unter diesem Gesichtspunkt besprochenen individuellen Religionsfreiheit werden im folgenden fünf Regelungen aus dem Religionsverfassungsrecht des Grundgesetzes auf ihr Verhältnis zur Säkularisierung hin betrachtet.

Verschärfung der oder Abschied von der Neutralität? Zwei verfehlte Alternativen in der Debatte um den herkömmlichen Grundsatz religiös-weltanschaulicher Neutralität, in: JZ 2009, S. 1136-1140; auch in: Ders., Die Verfassung der Religion. Beiträge zum Religionsverfassungsrecht, Tübingen 2014, S. 133-145; Stefan Huster, Erwiderung: Neutralität ohne Inhalt?, in: JZ 2010, S. 354-357; Hans Michael HeInIG, Schlusswort: Verschleierte Neutralität, ebd., S. 357-360.

9 BVerfG, Urteil vom 14.12.1965 - 1 BvR 413, 416/60 -, E 19, 206 (216); Urteil vom 24.09.2003 - 2 BvR 1436/02 -, E 108, 282 (299); Beschluß vom 27.01.2015 - 1 BvR 471/10, 1181/10 -, Abs. 109. 


\subsection{Korporative Religionsfreiheit und Selbstbestimmungsrecht der Religionsgemeinschaften}

Das Grundgesetz schützt die Religionsfreiheit auch in ihrer korporativen Dimension. Art. 4 Abs. 1 und 2 GG verspricht die Freiheit des Glaubens, des religiösen Bekenntnisses und der Religionsausübung nicht nur dem religiösen Individuum, sondern auch den Religionsgemeinschaften. Jede Mehrheit von Menschen, die sich zur Verwirklichung ihrer Religionsfreiheit organisieren, kann sich als Vereinigung selbst auf die Religionsfreiheit berufen ${ }^{10}$. Das ist der Sinn der korporativen Religionsfreiheit.

Sie erhält eine Verstärkung in dem über Art. 140 GG in das Grundgesetz inkorporierten Art. 137 Abs. 3 WRV: "Jede Religionsgesellschaft ordnet und verwaltet ihre Angelegenheiten selbständig innerhalb der Schranken des für alle geltenden Gesetzes«. Dieser Satz ist als ein Freiheitsversprechen zu verstehen und fügt sich so als Garantie des Selbstbestimmungsrechts der Religionsgemeinschaften unschwer in eine insgesamt auf religiöse Freiheit angelegte Deutung der Religionsverfassung des Grundgesetzes ein. Heute bietet die allgemeine Dogmatik der Freiheitsrechte die Denkformen für ein freiheitsrechtliches Verständnis, das in den ersten Ansätzen in der Auslegungsgeschichte zu dieser Vorschrift von 1919 noch unter anderen Vorstellungen über das Verhältnis von Staat und Kirche verborgen sein konnte ${ }^{11}$. Jedenfalls erweist sich dieser Satz aus der Zeit vor den heute prägenden Entwicklungen der allgemeinen Grundrechtsdogmatik, wie sie sich insbesondere in der Rechtsprechung des Bundesverfassungsgerichts niedergeschlagen haben, als lückenlos anschlußfähig an deren freiheitsrechtliche Differenzierung zwischen dem Schutzbereich des Freiheitsrechts, der Zurechnung von Eingriffen in den Schutzbereich und der verfassungsrechtlichen Rechtfertigung von Eingriffen durch die in der Verfassung angelegten Schranken des Freiheitsrechts.

Aus der reichen Diskussion um die Auslegung des Selbstbestimmungsrechts der Religionsgemeinschaften gemäß Art. 137 Abs. 3 WRV ist hier ein Ansatz erwähnenswert, in dem der Gedanke, Säkularisierung anhand einer Aufteilung von »Räumen« zu begreifen und darzustellen ${ }^{12}$, eine Entsprechung findet. Dieser Gedanke folgt der Beobachtung, daß erst mit der

10 Nachweise bei Michael Germann, in: Volker Epping / Christian Hillgruber (Hg.), Grundgesetz. Kommentar, München ${ }^{2} 2013$, aktualisiert: Beck'scher Online-Kommentar, Edition 28 (Stand 01.03.2016), Art. 4, Rn. 29-35.

11 Zur Entwicklung zusammenfassend Germann, Entwicklungstendenzen, S. 48-52 mit Nachweisen.

12 Richard Amesbury, Secularity, Religion, and the Spatialization of Time, in: JAAR 86/3 (2018), S. 591-615. 
Distinktion eines religiösen »Raumes« die Säkularisierung überhaupt zum Phänomen werden kann. Säkularisierung beschreibt so den »Raum«, der außerhalb des distinkt religiösen Raumes bleibt.

Ein solches Bild distinkter »Räume« des Religiösen einerseits, des Säkularen andererseits wurde auch für das in Art. 137 Abs. 3 WRV aufgespannte Verhältnis zwischen »eigenen Angelegenheiten« der Religionsgemeinschaften einerseits, den durch »das für alle geltende Gesetz« zu regelnden Angelegenheiten des Staates andererseits verwendet. Danach versuchte man beides in zwei gegenständliche »Bereiche« zu unterscheiden. Der »kirchliche Bereich" - allgemeiner gesprochen: der "religionsgemeinschaftliche Bereich " - sollte alle Angelegenheiten, also Gegenstände umschreiben, die "materiell, der Natur der Sache oder Zweckbeziehung nach als eigene Angelegenheit der Kirche anzusehen seien $^{13}$. Dieser "Bereich " sollte von staatlicher Einflußnahme freizuhalten sein. Umgekehrt sollte der »staatliche Bereich «, und damit der Geltungs-, Anwendungs- und Wirkungsbereich des »für alle geltenden Gesetzes«, für alle übrigen Gegenstände religiöse Ansprüche ausschließen. Insofern findet sich hier die Vorstellung eines »säkularen Raumes«, in dem der säkulare Staat die säkularen Angelegenheiten von religiösen Motiven, Vorstellungen und Interessen freizuhalten hätte.

Die nach dieser räumlichen Vorstellung sogenannte Bereichslehre oder Bereichsscheidungslehre hatte in den ersten Jahren der Geltung des Grundgesetzes Konjunktur und kann bis zum Ende der 1960er Jahre als herrschende Lehre bezeichnet werden ${ }^{14}$. Reste davon finden sich bis heute

13 So die vielverwendete Formulierung in BVerfG, Beschluß vom 17.02.1965 - 1 BvR 732/64 -, E 18, 385 (387).

14 BVerfG, Beschluß vom 17.02.1965 - 1 BvR 732/64 -, E 18, 385 (388); beispielhaft aus der Literatur Paul Mikat, Kirchen und Religionsgemeinschaften, in: Karl August Bettermann u.a. (Hg.), Die Grundrechte. Handbuch der Theorie und Praxis der Grundrechte, Bd. IV/1, Berlin 1960, S. 111-243, auch in: Ders., Religionsrechtliche Schriften. Abhandlungen zum Staatskirchenrecht und Eherecht, hg. v. Joseph ListL, Berlin 1974, S. 29-161, hier S. 63f., 93-119; Joseph LISTL, Das Grundrecht der Religionsfreiheit in der Rechtsprechung der Gerichte der Bundesrepublik Deutschland, Berlin 1971, S. 398f., 416f. Es überwog dabei eine Begründung mit einem vorverfassungsrechtlichen Verhältnis der »Koordination« von Staat und Kirche; hierzu Germann, Entwicklungstendenzen, S. 48-51; allgemein zur Entwicklung Fabio Borggreve, Wissenschaftliche Positionen zum Staatskirchenrecht in der frühen Bundesrepublik Deutschland (1949-1969), Frankfurt a.M. 2015. Zu einer im Ergebnis verwandten Bereichsscheidung kam aber auch die Opposition gegen die Koordinationslehre; etwa Helmut QuARITsch, Kirchen und Staat. Verfassungs- und staatstheoretische Probleme der staatskirchenrechtlichen Lehre der Gegenwart, in: Der Staat 1 (1962), S. 175-197, 289-320, hier S. 185, 197 und vor allem S. 295, auch in: Ders. / Hermann Weber (Hg.), Staat und Kirchen in der Bundesrepublik. Staatskirchenrechtliche Aufsätze 1950-1967, Bad Homburg v. d. H. u.a. 1967, S. 265-310; Hermann Weber, Die Religionsgemeinschaften als Körperschaften des öffentlichen Rechts im System des Grundgesetzes, Berlin 1966, S. 38f.; Wolfgang MARTENS, Öffentlich als Rechtsbegriff, Bad Homburg v. d. H. u.a. 1969, S. 139f.; ebenso 
in der Rechtsprechung, wenn einzelne Gerichtsurteile die alten Bereichsscheidungsformeln weiterschleppen und die Vorstellung anklingen lassen, für das Verhältnis zwischen den Angelegenheiten der Kirche und dem für alle geltenden Gesetz des Staates seien »Bereiche« begrifflich gegeneinander abzugrenzen ${ }^{15}$.

Diese Vorstellung ist einer anderen gewichen ${ }^{16}$ : Besser sprechen wir freiheitsrechtsdogmatisch davon, daß dieselben Gegenstände von zwei Positionen aus in Anspruch genommen werden können. Es kann nämlich dieselbe Angelegenheit sowohl Gegenstand eines religiösen Interesses als auch Gegenstand der säkularen Gemeinwohlverantwortung des Staates sein. Religiöses Interesse und säkulare Gemeinwohlverantwortung lassen sich nicht räumlich voneinander trennen und allenfalls mit einer gewaltigen begriffsdogmatischen Akrobatik in »Bereiche« scheiden.

Zum Beispiel kann ein kirchliches Krankenhaus weder ausschließlich der Selbstbestimmung des kirchlichen Trägers noch ausschließlich der Determinierung durch das staatliche Krankenhausrecht zugewiesen werden. Vielmehr hat beides sein Recht: Daß der kirchliche Träger mit dem Betrieb des Krankenhauses eine religiöse Motivation verfolgt und ihn dieser Motivation gemäß zu gestalten beansprucht, kann ihn nicht den staatlichen Gesetzen über den Betrieb von Krankenhäusern entziehen. Daß das staatliche Recht

noch Joachim Wieland, Die Angelegenheiten der Religionsgesellschaften, in: Der Staat 25 (1986), S. 321-350, hier S. 346. - Weitere Nachweise und Kritik bei Axel Frhr. v. Campenhausen / Peter Unruh, in: Hermann v. Mangoldt u.a. (Hg.), Kommentar zum Grundgesetz, 6. Aufl., München 2010, Bd. 3, Art. 140 / Art. 137 WRV, Rn. 45, 115-120, 127, 144-146.

15 Nachweise zur Rechtsprechung und der Kritik daran bei Germann, in: Epping/ Hillgruber, GG, Art. 140, Rn. 55.1, 55.3.

16 Ansatzweise bereits Siegfried Grundmann, Das Bundesverfassungsgericht und das Staatskirchenrecht, JZ 1966, S. 81-86, hier S. 84f.; auch in: Ders., Abhandlungen zum Kirchenrecht, hg. v. Reinhold Zippelius u.a., Köln u.a. 1969, S. 327-344; bahnbrechend dann Martin Heckel, Die Kirchen unter dem Grundgesetz, in: VVDStRL 26 (1968), S. 5-56, hier S. 31-35, 40-48, 54f. - Thesen 39-46, auch in: Ders., Gesammelte Schriften, Bd. 1, Tübingen 1989, S. 402-446; zusammenfassend Konrad Hesse, Das Selbstbestimmungsrecht der Kirchen und Religionsgemeinschaften, in: Joseph Listu / Dietrich Pirson (Hg.), Handbuch des Staatskirchenrechts der Bundesrepublik Deutschland, Bd. 1, Berlin ${ }^{2} 1994$, S. 521-559, hier S. 550-552. So hat sich denn auch das Bundesverfassungsgericht von der Bereichsscheidungslehre gelöst: BVerfG, Beschluß vom 25.03.1980 - 2 BvR 208/76 -, E 53, 366-407 (399-401); Beschluß vom 13.12.1983 - 2 BvL 13, 14, 15/82 -, E 66, 1 (22); Beschluß vom 04.06.1985 - 2 BvR 1703, 1718/83 und 856/84 -, E 70, 138 (167); Beschluß vom 14.05.1986 - 2 BvL 19/84 -, E 72, 278 (289); Beschluß vom 17.10.2007 - 2 BvR 1095/05 -, DVBl. 2007, S. 1555 (1561-1563, Abs. 90-107); Beschluß vom 22.10.2014 - 2 BvR 661/12 -, Abs. 110f.; dem ausdrücklich folgend beispielhaft BVerwG (Bundesverwaltungsgericht), Urteil vom 27.02.2014 - 2 C 19.12 -, Abs. 18-25. Zur Entwicklung der bundesverfassungsgerichtlichen Rechtsprechung siehe Wolfgang Воск, Das für alle geltende Gesetz und die kirchliche Selbstbestimmung. Eine verfassungsrechtliche Untersuchung am Beispiel des Amtsrechts der evangelischen Kirchen, Tübingen 1996, S. 139-156. 
den Betrieb von Krankenhäusern regelt, fordert nicht die Unterdrückung einer religiösen Motivation und einer ihr gemäßen Gestaltung des Krankenhauses. Wollte man dem in einer Bereichsscheidung gerecht werden, müßte man den Betrieb des Krankenhauses in alle seine Einzelheiten zerlegen, um diese auf begrifflich entsprechend abgegrenzte "Bereiche« aufteilen zu können. Dabei wäre es vielleicht noch möglich, einen Bereich der Hygiene zu definieren und dem »staatlichen Bereich « zuzuordnen, die Krankenhausseelsorge hingegen in den "religiösen Bereich" fallen zu lassen. Spätestens bei den arbeitsrechtlichen Pflichten der Mitarbeiter im kirchlichen Krankenhaus würde die begriffliche Abgrenzung aber undurchführbar.

Eine freiheitsrechtliche Dogmatik findet einen anderen Weg: Sie erkennt zunächst die Freiheitsinteressen an, die ein Freiheitssubjekt - hier eine Religionsgemeinschaft - auf einen Gegenstand richtet. Sie schützt sie vor staatlichen Eingriffen, nicht indem sie den Regelungsanspruch des Staates ausschließt, sondern indem sie ihn an verfassungsrechtliche Anforderungen für die Rechtfertigung eines Eingriffs bindet. Die Anforderungen an die verfassungsrechtliche Rechtfertigung von Eingriffen setzen die widerstreitenden Ansprüche und Belange zueinander ins Verhältnis, ohne sie räumlich oder quasiräumlich voneinander abgrenzen zu müssen.

Die stattdessen erforderlichen Abwägungen müssen und können methodisch so gefaßt werden, daß sie nicht den Vorwurf auf sich ziehen, nur ein Passepartout für die willkürlichen Präferenzen des Rechtsanwenders zu $\operatorname{sein}^{17}$. Ihre Rationalität ist in der sprachlich geordneten, auf Verallgemeinerbarkeit angelegten Bewertung und Gewichtung der im Konfliktfall betroffenen Interessen zu suchen. Damit wird die Abwägungsdogmatik nicht jeden Wunsch nach einer abstrakten Erwartungssicherheit für künftige Konflikte erfüllen können - wie auch eine begriffliche Bereichsscheidung sie mehr verspricht als einzulösen vermag. Sie hält aber Denkformen bereit, in denen die divergenten Ansprüche auf denselben Gegenstand jeweils optimal zur Geltung gebracht werden können.

In dieser Auslegung der verfassungsrechtlichen Normen über das Verhältnis von Staat und Religion fußt die Säkularisierung des Staates also nicht auf der Distinktion eines religiösen von einem säkularen sozialen Raum, sondern auf den Bedingungen für eine freiheitsoptimierende Koordination religiöser und säkularer Interessen in demselben sozialen Raum.

17 Exemplarisch für diesen Einwand Stefan Muckel, Religiöse Freiheit und staatliche Letztentscheidung. Die verfassungsrechtlichen Garantien religiöser Freiheit unter veränderten gesellschaftlichen Verhältnissen, Berlin 1997, S. $278 \mathrm{f}$. 


\subsection{Erweiterung der Organisations- und Handlungsformen durch} die Rechte einer Körperschaft des öffentlichen Rechts

Das Grundgesetz stellt für die Entfaltung korporativer Religionsfreiheit besondere, nämlich öffentlich-rechtliche Organisations- und Handlungsformen zur Verfügung. Säkularität und Neutralität des Staates zeigen sich hier darin, daß die Verfassung den Religionsgemeinschaften die Wahl der Organisations- und Handlungsformen freigibt, die ihrem religiösen Selbstverständnis womöglich am besten entsprechen.

Der damit angesprochene Art. 137 Abs. 5 WRV, über Art. 140 GG ebenfalls in das Grundgesetz inkorporiert und damit eine Regelung des geltenden Verfassungsrechts, beantwortete 1919 die Frage, was aus den mit Art. 137 Abs. 1 und 3 WRV in die Selbstbestimmung entlassenen Staatskirchen werden sollte. In der Weimarer Nationalversammlung wurden hierzu zwei gegensätzliche Optionen vertreten. Die eine Option hätte die früheren Staatskirchen als öffentlich besonders anerkannte Korporationen in einer Sonderbeziehung zum Staat belassen. Die andere Option wollte die früheren Staatskirchen hinabdrücken in die privatrechtlichen Formen des Vereins; Vorbild hierfür war zu dieser Zeit natürlich das französische Trennungsgesetz von $1905^{18}$. Keine dieser beiden gegensätzlichen Optionen hat sich in der Weimarer Nationalversammlung ganz durchgesetzt. Beide hätten sich mit der Neutralität und Säkularität des Staates schlecht vertragen: die erste Option durch eine fortgesetzte Ungleichbehandlung der Religionsgemeinschaften, die zweite Option durch empfindliche, im Ergebnis auch diskriminierende staatliche Eingriffe in ihre Selbstorganisation.

Es hat sich ein Kompromiß durchgesetzt, der als »dilatorischer Formelkompromiß « für manche erst einmal faul gerochen haben mag, der das Problem aber geradezu genial gelöst hat und sich bis heute bewährt: Er vereinbart die Kontinuität der besonderen Rechts- und Handlungsformen für das Wirken der Religionsgemeinschaften, die gemäß Art. 137 Abs. 1 WRV aus dem Staatskirchentum entlassen wurden, mit der Gleichstellung aller Religionsgemeinschaften. Statt einer Gleichstellung "nach unten«, die alle Religionsgemeinschaft gleichermaßen auf den Status von privaten Vereinen herabgedrückt hätte, bewirkte er umgekehrt eine Gleichstellung »nach oben", indem er allen Religionsgemeinschaften gleichermaßen die öffentlich-rechtlichen Organisations- und Handlungsformen zugänglich machte. Dies sind die Rechte einer »Körperschaft des öffentlichen Rechts« in Art. 137 Abs. $5 \mathrm{WRV}^{19}$. Der erste Satz des Art. 137 Abs. $5 \mathrm{WRV}$ bestimmt für die

18 »oi concernant la séparation des Églises et de l’État« vom 09.12.1905.

19 Dazu besonders Hans Michael HeINIG, Öffentlich-rechtliche Religionsgesellschaften. Studien zur Rechtsstellung der nach Art. 137 Abs. 5 WRV korporierten Reli- 
Religionsgemeinschaften, die bisher - also in den staatskirchlichen Verhältnissen - Körperschaften des öffentlichen Rechts waren, daß sie es bleiben. Der zweite Satz bestimmt, daß anderen Religionsgemeinschaften auf Antrag die gleichen Rechte zu gewähren sind, wenn sie durch die Zahl ihrer Mitglieder und ihre Verfassung die Gewähr der Dauer bieten. Diese Regelung - der auch im Hinblick auf ihre Rechtsfolgen eine freiheits- und gleichheitsgemäße Auslegung zukommt - ermöglicht es dem Staat, in Hinsicht auf die Organisation der Religionsgemeinschaften seiner Säkularität und Neutralität gerecht zu werden.

\subsection{Säkularität der öffentlichen Schule durch Integration freiwilligen Religionsunterrichts}

Nach Art. 7 Abs. 3 GG ist der Religionsunterricht an allen öffentlichen Schulen ordentliches Lehrfach. Ausgenommen sind die bekenntnisfreien Schulen, die wegen ihres weltanschaulichen Profils ${ }^{20}$ in einen anderen Zusammenhang gehören.

Der Religionsunterricht an den staatlichen Schulen scheint zur Säkularität und Neutralität des Staates in Spannung zu stehen. Die Garantie des Religionsunterrichts wird aber in zweierlei Hinsicht so ausgestaltet, daß sie die Säkularität und Neutralität des Staates nicht berührt, sondern bestätigt. Hinsichtlich der Schüler und ihrer Eltern hält Art. 7 Abs. 2 GG das Recht der Erziehungsberechtigten fest, über die Teilnahme des Kindes am Religionsunterricht zu bestimmen. Die Teilnahme am Religionsunterricht ist freiwillig, sie ist Ausdruck der Religionsfreiheit der Erziehungsberechtigten und der Schüler selbst. Hinsichtlich der korporativen Religionsfreiheit bindet Art. 7 Abs. 3 S. 2 GG den Inhalt des Religionsunterrichts an die Grundsätze der Religionsgemeinschaften.

Manche Deutungen des Art. 7 Abs. 3 S. 2 GG betrachten diese Bindung als eine Ausnahme, eine Durchbrechung der Neutralität $t^{21}$. Sie sieht ja auch so aus: In der staatlichen Schule wird Religion nach den Grundsätzen der beteiligten Religionsgemeinschaften unterrichtet.

gionsgesellschaften in Deutschland und in der Europäischen Union, Berlin 2003; Stefan Magen, Körperschaftsstatus und Religionsfreiheit. Zur Bedeutung des Art. 137 Abs. 5 WRV im Kontext des Grundgesetzes, Tübingen 2004.

20 Siehe Christoph Link, »Bekenntnisfreie« Schulen, in: Max-Emanuel GeIs/Dieter Lorenz (Hg.), Staat - Kirche - Verwaltung, Festschrift für Hartmut Maurer zum 70. Geburtstag, München 2001, S. 397-407.

21 So etwa BVerwG, Urteil vom 06.07.1973 - VII C 36.71 -, E 42, 346 (347f.); weitere Nachweise bei Frauke Brosius-Gersdorf, in: Horst Dreier (Hg.), Grundgesetz Kommentar, Bd. 1, Tübingen ${ }^{3} 2013$, Art. 7, Rn. 88, Fn. 482, die hier zu recht »eine spezielle Ausprägung des Neutralitätsgebotes« erkennt. 
Bei Licht betrachtet ist dies die Lösung eines Dilemmas, das ohne den Religionsunterricht an der staatlichen Schule unlösbar wäre: Denn indem der Staat die öffentliche Schule organisiert und gestaltet, nimmt er die Bildung und Erziehung, die Sozialisation der Jugend in die eigene Hand und verfolgt damit unausweichlich ein eigenes Erziehungskonzept. Ein religiöses Erziehungskonzept kann sich der säkulare Staat dabei nicht zueigen machen. Er begegnet aber mit der öffentlichen Schule Bildungs- und Erziehungskonzepten in der Gesellschaft, die die religiöse Bildung und Erziehung als einen integralen Bestandteil der schulischen Bildung und Erziehung begreifen. Wie soll er mit ihnen umgehen? Er kann ihnen aus eigener Kraft nicht entgegenkommen, ohne von seiner Säkularität und Neutralität abzuweichen. Er kann nicht selbst die religiösen Grundsätze des Religionsunterrichts bestimmen wollen, ohne für diese und gegen andere religiöse Grundsätze Partei zu nehmen. Zugleich kann er aber auch die Erziehungskonzepte, die die religiöse Bildung und Erziehung als einen integralen Bestandteil der schulischen Bildung und Erziehung begreifen, nicht aus der Schule fernhalten, ohne wiederum Partei zu ergreifen: Die einheitliche und ausschließliche Durchsetzung eines »säkularen« Bildungs- und Erziehungskonzepts wäre die Negation jener religiösen Bildungs- und Erziehungskonzepte. Sie würde insofern auch in die Religionsfreiheit eingreifen.

Art. 7 Abs. 3 S. 2 GG löst dieses Dilemma ${ }^{22}$. Er ermöglicht es dem Staat, sowohl der Religionsfreiheit und dem Interesse an einer Integration religiöser Bildung und Erziehung in die Schule als auch zugleich seiner Pflicht

22 Zur verfassungsrechtstheoretischen Begründung des Religionsunterrichts zusammenfassend z.B. Martin Heckel, Der Rechtsstatus des Religionsunterrichts im pluralistischen Verfassungssystem des Grundgesetzes, in: ZThK 96 (1999), S. 525554; 97 (2000), S. 128-146; wieder abgedruckt in: Ders., Der Rechtsstatus des Religionsunterrichts im pluralistischen Verfassungssystem, Tübingen 2002, S. 1-62; Hans Michael Heinig, Religionsunterricht nach Art. 7 Abs. 3 GG - Rechtslage und Spielräume, in: Bernd SchröDER (Hg.), Religionsunterricht - wohin? Konzepte zur Weiterentwicklung eines Faches im Überblick, Neukirchen-Vluyn 2014, S. 141-154; auch in: Ders., Die Verfassung der Religion, S. 338-351; Karl-Hermann Kästner, Religiöse Bildung und Erziehung in der öffentlichen Schule - Grundlagen und Tragweite der Verfassungsgarantie staatlichen Religionsunterrichts, in: Heiner MARRÉ u.a. (Hg.), Der Beitrag der Kirchen zur Erfüllung des staatlichen Erziehungsauftrags. Essener Gespräche zum Thema Staat und Kirche, Bd. 32, Münster 1998, S. 61-96, hier S. 63-71, mit Diskussion S. 97-120; auch in: Ders., Gesammelte Schriften, hg. v. Hans Ulrich Anke u.a., Tübingen 2011, S. 235-282; Stefan Korioth, Der Auftrag des Religionsunterrichts nach Art. 7 Abs. 3 GG, in: Burkhard KäMPer/Klaus PfefFER (Hg.), Religionsunterricht in der religiös pluralen Gesellschaft. Essener Gespräche zum Thema Staat und Kirche, Bd. 49, Münster 2016, S. 7-37, mit Diskussion S. 38-54; Christoph Link, Religionsunterricht (\$ 54), in: HSKR ${ }^{2}$, Bd. 2, Berlin 1995, S. 439-509, hier S. 503-509; Arnd Uhle, Die Verfassungsgarantie des Religionsunterrichts und ihre territoriale Reichweite - Ein Beitrag zum Verhältnis von Art. 7 Abs. 3 S. 1 GG zu Art. 141 GG, in: DÖV 1997, S. 409-417, hier S. 411-414; Heinrich DE WALL, Das Verhältnis von Gesellschaft, Staat und Kirche in Deutschland, in: 
zur Säkularität und Neutralität gerecht zu werden, indem er die ihm nicht zustehende Verantwortung für den Inhalt des Religionsunterrichts den Religionsgemeinschaften überläßt. Die Bestimmung der Grundsätze für den Religionsunterricht steht wiederum nicht etwa nur einer bestimmten Auswahl von Religionsgemeinschaften zu, sondern grundsätzlich jeder kooperationswilligen und -fähigen Religionsgemeinschaft, für deren Grundsätze sich eine praktisch ausreichende Zahl von Schülern oder Eltern interessiert.

Aus dieser Sicht ist der Religionsunterricht keine Ausnahme von der Säkularität und Neutralität des Staates, sondern ihre folgerichtige Ausgestaltung. Eine Säkularität des Staates, die die öffentliche Schule ohne das Angebot einer Integration auch religiöser Bildung und Erziehung gestalten will, ist in diesem Punkt defizitär. Wenn es die Garantie des Religionsunterrichts in Art. 7 Abs. 3 GG noch nicht gäbe, müßte man sie erfinden, um die Säkularität und Neutralität des Staates so perfekt zu machen, wie ein Jurist etwas perfekt nennen kann.

\subsection{Säkularität des Sonn- und Feiertagsschutzes}

Art. 140 GG i. V. m. Art. 139 WRV gewährleistet den gesetzlichen Schutz des Sonntags und der staatlich anerkannten Feiertage "als Tage der Arbeitsruhe und der seelischen Erhebung ${ }^{23}$. Es ist deutlich, daß der Schutz des Sonntags den ursprünglich religiös motivierten Wochenrhythmus aufnimmt. Die Auswahl der Feiertage bleibt der staatlichen Anerkennung durch den Gesetzgeber vorbehalten, der dabei die von der Verfassung vorausgesetzte, historisch und kulturell vom christlichen Kalender geprägte, aber natürlich grundsätzlich wandelbare Feiertagskultur zu beachten hat.

Säkularisierung des Staates heißt hier wieder nicht, daß der Staat der Gesellschaft eine religiöse Sonn- und Feiertagskultur ab- und einen »säkularisierten« Kalender anzugewöhnen hätte, wie es im Gefolge der französischen Revolution bekanntlich versucht wurde. Die Säkularisierung des staatlichen Sonn- und Feiertagsschutzes zeigt sich vielmehr in der Offenheit seiner Zweckbestimmung: »Arbeitsruhe« und »seelische Erhebung " heben eine religiöse Sonn- und Feiertagspraxis in keiner Weise hervor, schneiden

Burkhard KäMPER / Michael SCHLAgheck (Hg.), Zwischen nationaler Identität und europäischer Harmonisierung. Zur Grundspannung des zukünftigen Verhältnisses von Gesellschaft, Staat und Kirche in Europa, Berlin 2002, S. 85-100, hier S. 92-94.

23 Allgemein dazu Karl-Hermann Kästner, Der Sonntag und die kirchlichen Feiertage (\$ 51), in: HSKR ${ }^{2}$, Bd. 2, S. 337-368; auch in: Ders., Gesammelte Schriften, S. 712-740; Wolfgang Mosbacher, Sonntagsschutz und Ladenschluß. Der verfassungsrechtliche Rahmen für den Ladenschluß an Sonn- und Feiertagen und seine subjektiv-rechtliche Dimension, Berlin 2007; Frank Stollmann, Der Sonn- und Feiertagsschutz nach dem Grundgesetz, Stuttgart u.a. 2004. 
sie aber auch nicht ab, sondern lassen ihr schlicht Raum in der sich aus den vielfältigen in der Gesellschaft wirksamen Interessen ergebenden Pluralität religiösen und säkularen Freiheitsgebrauchs an Sonn- und Feiertagen ${ }^{24}$.

\subsection{Säkularität der Verfassungslegitimation}

Die Präambel des Grundgesetzes nimmt auf »Gott« bezug: »Im Bewußtsein seiner Verantwortung vor Gott und den Menschen [...] hat sich das Deutsche Volk kraft seiner verfassungsgebenden Gewalt dieses Grundgesetz gegeben«. Daß dieser Satz, der die Legitimationsgrundlage der Verfassung benennt, dabei eine Verantwortung "vor Gott« anspricht, erscheint leicht als ein Widerspruch zur Säkularität des durch dasselbe Grundgesetz verfaßten Staates. Aber die raffinierte Formulierung vermeidet sehr sorgfältig, die Legitimation des Grundgesetzes positiv auf Gott zurückzuführen. Es handelt sich eben nicht um eine Invocatio Dei, wie sie in der schweizerischen Bundesverfassung und etwa auch in der irischen Verfassung anklingt. Deren Text wird nämlich in geradezu liturgischer Form »im Namen« Gottes eingeleitet $^{25}$. Wörtlich genommen ist diese Anrufung Gottes die Inanspruchnahme einer göttlichen Vollmacht zur Verfassungsgebung. Hier wäre in der Tat darüber nachzudenken, wie eine Verfassung so sprechen kann, wenn sie einen säkularen Staat verfassen soll. Nach dem deutschen Grundgesetz gibt das deutsche Volk die Verfassung im eigenen Namen und benennt sich damit selbst als Legitimationssubjekt der Verfassung. Indem es sich im selben Atemzug als Subjekt des Bewußtseins »seiner Verantwortung vor Gott und den Menschen« benennt, sagt es etwas über sich selbst aus.

Der normative Gehalt dieses Gedankens wird maßgeblich von der Gewährleistung der Religionsfreiheit in Art. 4 Abs. 1-2 GG bestimmt. Damit wäre eine Auslegung der Präambel unvereinbar, die den Bürger oder das staatliche Handeln gegenüber dem Bürger auf ein Bewußtsein von »Verantwortung vor

24 BVerfG, Urteil vom 09.06.2004 - 1 BvR 636/02 -, E 111, 10 (51); Urteil vom 01.12.20091 BvR 2857, 2858/07 -, Rn. 139-148; hierzu rechtsvergleichend Julian von Lucius, Sonntag für alle - Rechtsvergleichende Anmerkungen zur verfassungsrechtlichen Rechtsprechung zum gesetzlichen Sonntagsschutz -, in: KritV 2010, S. 190-211; siehe ferner BVerfG, Beschluß vom 27.10.2016 - 1 BvR 458/10 -, Abs. 60f., 66f., 71f., 75f., $83-85,87$.

25 Bundesverfassung der Schweizerischen Eidgenossenschaft vom 18.04.1999: »Im Namen Gottes des Allmächtigen! Das Schweizervolk und die Kantone [...] geben sich folgende Verfassung". - Bunreacht na hÉireann (Constitution of Ireland) vom 01.07.1937: »In the Name of the Most Holy Trinity, from Whom is all authority and to Whom, as our final end, all actions both of men and States must be referred, We, the people of Éire, Humbly acknowledging all our obligations to our Divine Lord, Jesus Christ, Who sustained our fathers through centuries of trial, [...] Do hereby adopt, enact, and give to ourselves this Constitution«. 
Gott« festlegen wollte. Wie man die Aussage der Präambel über die »Verantwortung vor Gott« so auslegen kann, daß sie mit der Religionsfreiheit und der darin prominent zum Ausdruck gebrachten Säkularität des Staates in Einklang kommt, ist in einer Reihe von Vorschlägen diskutiert worden ${ }^{26}$. Eine Lösung für dieses Auslegungsproblem kann in einem allgemeinen Rahmen für die Begegnung des säkularen Staates mit religiösem »Bewußtsein« gesucht werden (s.u. 5.4).

\section{Säkularität des Staates und Trennung von Staat und Kirche}

Wenngleich der Text des Grundgesetzes ein Programm der »Säkularisierung« nicht enthält, ist doch das Verbot der Staatskirche durchaus eine programmatische Entscheidung für die Trennung von Staat und Kirche. Es ist recht populär, diese Trennung von Staat und Kirche nach der Weimarer Reichsverfassung und dem Grundgesetz zusammenfassend als »hinkende Trennung" (so Ulrich Stutz ${ }^{27}$ über die Weimarer Verfassung) zu charakterisieren. Das klingt nach einer Behinderung, als ob der Staat wegen eines schweren Klotzes von Staatskirchenresten am Bein dem Zug in die am Horizont leuchtende Zukunft der Säkularisierung nur mühsam hinterherhumpeln könnte. So ein Bild wird dem Religionsverfassungsrecht des Grundgesetzes nicht gerecht. Denn seine freiheitsorientierte Auslegung muß nirgends einen Abstrich von der Trennung zwischen Staat und Kirche machen.

Zugleich müssen wir die Trennung von Staat und Kirche, so entschieden sie in der Weimarer Verfassung und im Grundgesetz vollzogen worden ist, als eine Dezision erkennen, die mit Prozessen der Säkularisierung weder historisch noch vergleichend notwendig verbunden ist. Besonders im europäischen Vergleich wird das deutlich ${ }^{28}$. Unter den gegenwärtigen religionsverfassungsrechtlichen Systemen in Europa sind Arrangements anzutreffen, die sich durchaus in die allgemeine Entwicklung der Säkularisierung stellen und die Säkularität des Staates ausgestalten und zugleich anstelle einer Trennung Sonderbeziehungen zwischen staatlichen Institutionen und einer Kirche oder einer Mehrheitsreligion pflegen. Die Vielfalt reicht vom laizistischen Umgang mit Religionsgemeinschaften in Frankreich bis zu den

26 Siehe die Nachweise und Diskussion zum Beispiel bei Henner Jörg BoEHL/Stephan Нове, in: Berliner Kommentar zum Grundgesetz, hg. v. Karl Heinrich Friauf / Wolfram Höfling, Losebl., Präambel (2009), Rn. 121-132; Horst Dreier, in: Ders., Grundgesetz, Bd. 1, Präambel, Rn. 32-41.

27 Ulrich Stutz, Die päpstliche Diplomatie unter Leo XIII. Nach den Denkwürdigkeiten des Kardinals Domenico Ferrata, Berlin 1925, S. 54 Anm. 2.

28 Siehe die Länderberichte bei Gerhard Robbers (Hg.), Staat und Kirche in der Europäischen Union, Baden-Baden ${ }^{2} 2005$. 
Staatskirchensystemen im Vereinigten Königreich, Skandinavien und Griechenland und dem pseudo-laizistischen Staatsislam in der Türkei. Aus der Perspektive dieser Vielfalt sind Sonderbeziehungen mit der Säkularität des Staates vereinbar, die mit der Trennung von Staat und Kirche nach der deutschen Verfassung unvereinbar wären.

Da allerdings die Säkularisierung dem Religionsverfassungsrecht überall ähnliche Aufgaben stellt, liegt es nahe zu erwarten, daß die allgemeine Entwicklung der Lösungen nach und nach konvergiert ${ }^{29}$. Aus den Fluchtlinien einer solchen Konvergenz der religionsverfassungsrechtlichen Ordnungen in Europa ließe sich ein europäisches Programm für die Ausgestaltung der Säkularität des Staates ableiten.

Ein Antrieb und Maßstab hierfür wäre jedenfalls in der allen gemeinsamen Garantie der Religionsfreiheit in Art. 9 der Europäischen Menschenrechtskonvention (EMRK) zu suchen. Diese normative Vorgabe enthält selbst kein Säkularisierungsprogramm im Sinne eines bestimmten religionsverfassungsrechtlichen Systems. Sie verpflichtet die Mitgliedstaaten des Europarats nur auf die Religionsfreiheit. Deshalb muß sie so ausgelegt werden, daß die verschiedenen religionsverfassungsrechtlichen Systeme Europas darin Platz finden. Rechtstechnisch leistet dies der Europäische Gerichtshof für Menschenrechte, indem er den Mitgliedstaaten für die Auslegung und Beachtung der Religionsfreiheit eine "marge d'appréciation « (»margin of appreciation «) zubilligt $^{30}$, einen Spielraum, in dem sie ihre religionsverfassungsrechtlichen Systeme gestalten dürfen, wie es ihren eigenen historischen Erfahrungen mit der Religion und ihren eigenen verfassungsrechtlichen Dezisionen für das

29 Eine solche Konvergenz beobachtet ders., Staat und Kirche in der Europäischen Union, in: Ders. (Hg.), Staat und Kirche in der Europäischen Union, S. 629-641, hier S. 631f. Ihre Merkmale in der Vielfalt der religionsverfassungsrechtlichen Ordnungen ausgewählter Mitgliedstaaten der Europäischen Union (Vereinigtes Königreich, Frankreich, Spanien und Deutschland) und ihr Verhältnis zum Europarecht untersucht Lasia BLoss, Cuius religio - EU ius regio? Komparative Betrachtung europäischer staatskirchenrechtlicher Systeme, status quo und Perspektiven eines europäischen Religionsverfassungsrechts, Tübingen 2008.

30 Allgemein Christoph Grabenwarter/Katharina Pabel, Europäische Menschenrechtskonvention. Ein Studienbuch, München ${ }^{6} 2016, \$ 18$, Rn. 20-22, bezogen auf die Prüfung der Verhältnismäßigkeit. Die Konzeptneutralität des Art. 9 EMRK wurde verletzt durch den Europäischen Gerichtshof für Menschenrechte (EGMR), Urteil vom 03.11.2009 - 30814/06 - Lautsi gegen Italien - hiergegen Ino AugsBerg / Kai ENGELBRECHT, Staatlicher Gebrauch religiöser Symbole im Licht der Europäischen Menschenrechtskonvention, in: JZ 2010, S. 450-458 -, in derselben Sache korrigiert durch EGMR (Große Kammer), Urteil vom 18.03.2011; dazu Christian Walter, Religiöse Symbole in der öffentlichen Schule. Bemerkungen zum Urteil der Großen Kammer des Europäischen Gerichtshofs für Menschenrechte im Fall Lautsi, in: EuGRZ 2011, S. 673-677; s.a. Richard WiedemanN, Der Streit um das Schulkreuz in Deutschland und Italien. Weltanschaulich-religiöse Neutralität und laicità des Staates im Vergleich, Berlin 2012. 
eine oder andere Verhältnis zwischen Staat und Religion entspricht. Damit hat die Reichweite der Religionsfreiheit nach der Europäischen Menschenrechtskonvention einen Maßstab in der Vielfalt der religionsverfassungsrechtlichen Systeme.

Auf bestimmte Ausgestaltungen der Religionsverfassung hat die konventionsrechtliche Garantie der Religionsfreiheit trotzdem einen Einfluß ausgeübt. Zum Beispiel hat der Europäische Gerichtshof für Menschenrechte einzelne Benachteiligungen von Religionsgemeinschaften gegenüber der staatskirchlichen Sonderstellung der griechisch-orthodoxen Kirche in Griechenland als unvereinbar mit der Garantie der Religionsfreiheit in Art. 9 EMRK beurteilt ${ }^{31}$. Auch Frankreich bekommt durch die Europäische Menschenrechtskonvention eine Richtung für den Umgang mit Religion aufgezeigt. Die französische Religionspolitik lotet am europäischen Maßstab der Religionsfreiheit die Grenzen des Laizismus aus. Das jüngste Beispiel dafür ist das Burka-Verbot. Der Europäische Gerichtshof für Menschenrechte ${ }^{32}$ hat es zwar im Ergebnis passieren lassen. Aber das sollte nicht darüber hinwegtäuschen, daß der Gerichtshof in der Begründung seiner Entscheidung dem Laizismus weite Teile seines Arsenals an Argumenten aus der Hand genommen hat. Übriggeblieben ist bloß ein Zugeständnis an die in Frankreich bevorzugte Variante des Religionsverfassungsrechts, die es dort nun einmal dem Staat erlaubt, Merkmale einer Kleiderordnung im öffentlichen Raum zur Bedingung des Dazugehörens zu erklären und allen zur Pflicht zu machen. Alle weiteren laizistischen Anschauungen, die im Gesetzgebungsverfahren und vor den Gerichten vorgebracht worden waren, hat der Europäische Gerichtshof für Menschenrechte abgeräumt. Damit hat er die starke Spannung, die zwischen Art. 9 EMRK und der repressiven Religionspolitik in Frankreich besteht, deutlich gemacht, auch wenn er das Burka-Verbot im Ergebnis noch der marge d'appréciation zugeordnet hat ${ }^{33}$.

31 So die Beschränkung der Nutzung eines Gebäudes durch die Zeugen Jehovas: EGMR, Urteil vom 26.09.1996 - 18748/91 - Manoussakis u.a. gegen Griechenland. Auch Sonderregelungen gegenüber anderen Religionen als der »vorherrschenden« orthodoxen Religion, die sie in eine staatskirchenähnliche Stellung bringen, sind Gegenstand einer Verurteilung am Maßstab des Art. 9 EMRK geworden, so die Bestrafung eines abweichend von der staatlichen Regelung gewählten muslimischen Muftis wegen Amtsanmaßung: EGMR, Urteil vom 17.10.2002 - 50776/99, 52912/99 - Agga gegen Griechenland. Siehe allgemein - ohne Erwähnung des Art. 9 EMRK - Charalambos Papastathis, Staat und Kirche in Griechenland, in: Robbers (Hg.), Staat und Kirche in der Europäischen Union, S. 125-150.

32 EGMR (Große Kammer), Urteil vom 01.07.2014 - 43835/11 - S.A.S. gegen Frankreich.

33 Ebd., Abs. 106-159; dagegen Christoph Grabenwarter/Katharina Struth, Das französische Verbot der Vollverschleierung - Absolutes Verbot der Gesichtsverhüllung zur Wahrnehmung der »Minimalanforderungen des Lebens in einer 
Schweden hat zum 1. Januar 2000 das bis dahin bestehende Staatskirchentum aufgehoben. Staat und Kirche sind dort jetzt getrennt. Dieser Schritt nähert sich also von der Seite des Staatskirchentums her einer europäischen Konvergenzlinie. Das geschieht offenbar mit einiger Unbefangenheit gegenüber Regelungen, die von der Trennung des Staates von der Kirche unberührt geblieben sind und insofern als Reste des Staatskirchentums angesehen werden können ${ }^{34}$. Dabei mag es noch den Besonderheiten der Monarchie geschuldet sein, daß das Thronfolgegesetz den Monarchen nach wie vor an das lutherische Bekenntnis bindet. Ein institutioneller Rest des Staatskirchentums ist es vor allem, daß das staatliche Gesetz der ehemaligen Staatskirche spezielle Vorschriften macht: So muß ihr Bekenntnis lutherisch bleiben und ihre Organisation »demokratisch" sein. Diese staatskirchlichen Reste und ihre beschränkenden Folgen für die korporative Religionsfreiheit der ehemaligen Staatskirche liegen im weiten Rahmen der Religionsfreiheit nach der Europäischen Menschenrechtskonvention, die sich ja selbst im Staatskirchentum Raum zu schaffen verstanden hat und versteht. Daran gemessen, stellen sie auch die Säkularität des schwedischen Staates nicht in Frage.

Die Schweiz kann als ein Laboratorium für den religionsverfassungsrechtlichen Systemvergleich gelten. Die Kantonsverfassungen ordnen das Verhältnis des Staates zu den Kirchen unter der bundesverfassungsrechtlichen Garantie der Religionsfreiheit und auch unter dem Einfluß der Europäischen Menschenrechtskonvention in bemerkenswerter Vielfalt ${ }^{35}$. Die darin vertretenen Beispiele für eine enge Verbindung von Staat und Kirche fallen nicht aus dem weiten Mantel der Entwicklung staatlicher Säkularität heraus.

\section{Das Verhältnis des säkularen Rechts zur Religion}

In jedem vorstellbaren religionsverfassungsrechtlichen System trifft das Recht des säkularen Staates auf die Religion und Weltanschauung seiner Bürger, muß mit ihr umgehen und sich zu ihr verhalten. Vier Schnittstellen, an denen die Säkularität und religiös-weltanschauliche Neutralität des Rechts unter dem deutschen Religionsverfassungsrecht religiösen und weltanschaulichen Positionen begegnet, verdienen hier eine kurze Betrachtung.

Gesellschaft«?, in: EuGRZ 2015, S. 1-8; Beate SüNDHOFER, Konventionskonformität des Gesichtsverdeckungsverbots in der Öffentlichkeit, in: Austrian Law Journal 2/1 (2015), S. 88-98.

34 Per Pettersson, State and Religion in Sweden. Ambiguity Between Disestablishment and Religious Control, in: NJRS 2011, S. 119-135.

35 Siehe vor allem Dieter Kraus, Schweizerisches Staatskirchenrecht. Hauptlinien des Verhältnisses von Staat und Kirche auf eidgenössischer und kantonaler Ebene, Tübingen 1993; zur Kompatibilität mit Art. 9 EMRK besonders S. 108 mit Fn. 155, S. 119, 142, 424. 


\section{1 »Religion« und »Weltanschauung» als Rechtsbegriffe}

Die Garantie der Religions- und Weltanschauungsfreiheit setzt einen Rechtsbegriff von Religion und Weltanschauung voraus. Dieser Rechtsbegriff verweist zugleich auf religiöse Selbstverständnisse. Diese Doppelseitigkeit der Begriffe von Religion und Weltanschauung führt in ein Definitionsdilemma. Religionsfreiheit muß das Recht umfassen, sich einen Begriff von Religion und Weltanschauung zu machen. Das erfordert es, den Rechtsbegriff für die Selbstverständnisse der Freiheitssubjekte offenzuhalten ${ }^{36}$. Trotzdem darf das Recht die Tatbestände seiner Freiheitsgarantien nicht der Selbstdefinition dessen ausliefern, der sie in Anspruch nehmen will. Sie müssen so gefaßt werden, daß sie sowohl offen für religiöse Pluralität sind als auch eine Abgrenzung von anderen als religiösen Interessen leisten. Begriffliche Operationen und Definitionsformeln ${ }^{37}$ führen nicht zu einer Lösung.

Eine dem Sinn der Religionsfreiheit besser entsprechende Auslegung des Art. 4 Abs. 1 und 2 GG knüpft für den Tatbestand der "Religion" und der "Weltanschauung" primär an das Selbstverständnis des Grundrechtsprätendenten $a^{38}$. Die staatlichen Gerichte, die im Konfliktfall über die Sub-

36 Martin Heckel, Religionsfreiheit. Eine säkulare Verfassungsgarantie, in: Ders., Gesammelte Schriften, Bd. 4, Tübingen 1997, S. 647-859, hier S. 674f., 680-691; ders., Zur Zukunftsfähigkeit des deutschen »Staatskirchenrechts« oder »Religionsverfassungsrechts«?, in: AöR 134 (2009), S. 309-390, hier S. 368f., 376f., 379-385, auch in: Ders., Gesammelte Schriften, Bd. 6, Tübingen 2013, S. 507-589; Martin MorLoK, in: Dreier, Grundgesetz, Bd. I, Art. 4, Rn. 60, 66-68; Peter Unruh, Religionsverfassungsrecht, Baden-Baden ${ }^{2} 2012$, Rn. 83-87.

37 Wie die in BVerwG, Urteil vom 27.03.1992 - 7 C 21.90 -, E 90, 112 (115): Unter Religion oder Weltanschauung ist eine mit der Person des Menschen verbundene Gewißheit über bestimmte Aussagen zum Weltganzen sowie zur Herkunft und zum Ziel des menschlichen Lebens zu verstehen; dabei legt die Religion eine den Menschen überschreitende und umgreifende (`transzendentes) Wirklichkeit zugrunde, während sich die Weltanschauung auf innerweltliche (simmanente`) Bezüge beschränkt«.

38 BVerfG, Beschluß vom 16.10.1968 - 1 BvR 241/66 -, E 24, 236 (247f.); Urteil vom 24.09.2003 - 2 BvR 1436/02 -, E 108, 282 (298f.); Beschluß vom 24.10.2006 - 2 BvR 1908/03 -; aus der Literatur: grundlegend Axel IsAK, Das Selbstverständnis der Kirchen und Religionsgemeinschaften und seine Bedeutung für die Auslegung staatlichen Rechts, Berlin 1994; Martin MorLoK, Selbstverständnis als Rechtskriterium, Tübingen 1993; ferner Martin Borowski, Die Glaubens- und Gewissensfreiheit des Grundgesetzes, Tübingen 2006, S. 251-291; Axel Frhr. v. Campenhausen/Heinrich DE WALL, Staatskirchenrecht. Eine systematische Darstellung des Religionsverfassungsrechts in Deutschland und Europa. Ein Studienbuch, München ${ }^{4} 2006$, S. 56; MorloK, Art. 4 GG, Rn. 60; kritisch, eine Differenzierung nach verschiedenen Gewährleistungsinhalten fordernd Muckel, Religiöse Freiheit und staatliche Letztentscheidung; ders., Schutz von Religion und Weltanschauung (\$ 96), in: Detlef Merten/Hans-Jürgen PaPIER (Hg.) Handbuch der Grundrechte in Deutschland und Europa, Bd. 4: Grundrechte in Deutschland: Einzelgrundrechte I, Heidelberg 2011, Rn. 54; ähnlich Huster, Die ethische Neutralität des Staates, S. 382-385; klärend gegen eine überhöhte Alternative »objektiver« oder »subjektiver« Grundrechtsauslegung Heckel, Religionsfreiheit, S. 680-691; ders., Kontinuität und Wandlung 
sumtion eines Interesses unter den Schutzbereich der Religions- und Weltanschauungsfreiheit zu entscheiden haben ${ }^{39}$, haben daher zunächst das Selbstverständnis des Betroffenen zur Kenntnis zu nehmen. Sie haben es nicht an einem vorgegebenen, allgemeinen Begriff von »Religion « oder »Weltanschauung « zu messen, sondern an den mit »Plausibilität« und »Konsistenz« formal gehaltenen Anforderungen an die Darstellung des Selbstverständnisses. Danach können sie ein Interesse, das vollständig in anderweitig geschützten, etwa wirtschaftlichen oder politischen Interessen aufgeht, sowie eine selbstwidersprüchliche Inanspruchnahme der Religions- oder Weltanschauungsfreiheit aus deren Schutzbereich heraushalten.

\subsection{Identifikationsgebot und verfassungsrechtliche »Werteordnung»}

Übersetzt man die Säkularität des Staates in ein Identifikationsverbot gegenüber partikularen religiösen und weltanschaulichen Überzeugungen, kann sie in Spannung geraten zu einer Verpflichtung des Staates auf die in der Verfassung niedergelegten oder in ihr vorausgesetzten Wertentscheidungen. Auch der säkulare Staat ist auf Fundamentalpositionen verwiesen, die ungeachtet eines denkbaren religiös oder weltanschaulich begründeten Widerspruchs verbindlich sind. Zu ihnen gehören die Verpflichtung auf die Achtung und den Schutz der Menschenwürde nach Art. 1 Abs. 1 GG, die Geltung unveräußerlicher Menschenrechte, zu denen sich das deutsche Volk nach Art. 1 Abs. 2 GG in auffälliger Diktion »bekennt«, die Legitimation der Staatsgewalt nach dem Prinzip der Volkssouveränität, wie es in der Präambel mit der Inanspruchnahme der verfassungsgebenden Gewalt durch das Volk und in Art. 20 Abs. 2 S. 1 GG mit der Forderung, daß alle Staatsgewalt vom Volk ausgeht, Ausdruck findet. Diese Positionen stehen der im Grundgesetz verfaßten Staatsgewalt nicht zur Disposition, sie sind durch Art. 79 Abs. 3 GG der Verfassungsänderung entzogen.

Aus der Perspektive religiös oder weltanschaulich begründeter Antithesen können sie als negative Identifikationen erscheinen. Ihnen gegenüber kann der Staat nicht neutral sein und nicht auf Identifikation verzichten. Das Grundgesetz sieht auch Instrumente zu ihrer Durchsetzung vor, etwa die Befugnis zum Verbot einer verfassungsfeindlichen politischen Partei in

des deutschen Staatskirchenrechts unter den Herausforderungen der Moderne, in: ZevKR 44 (1999), S. 340-384, hier S. 354-364, auch in: Ders., Gesammelte Schriften, Bd. 5, Tübingen 2004, S. 243-286; Christian WALTER, Religionsverfassungsrecht, Tübingen 2006, S. 506f.

39 BVerfG, Beschluß vom 05.02.1991 - 2 BvR 263/86 -, E 83, 341 (353); s.a. BVerwG, Urteil vom 15.06.1995 - 3 C 31.93 -, E 99, 1 (4); Urteil vom 23.03.2005 - 6 C 2/04 -, E 123, 49 (54). 
Art. 21 Abs. $2 \mathrm{GG}^{40}$. Der Verfassungsfeind, der die Menschenwürde anderen Vorstellungen unterordnet, das »Bekenntnis« zu Menschenrechten nicht teilt oder das Volk nicht als Legitimationssubjekt der Verfassungsordnung anerkennt, erscheint im Verhältnis zu diesen der staatlichen Ordnung zugrundeliegenden, religiös und weltanschaulich ihm gegenüber nicht neutralen Positionen wie ein Häretiker ${ }^{41}$.

Der Versuch einer Letztbegründung dieser Positionen führt aus dem hinaus, was die Verfassung selbst leisten kann. Der Verweis auf ein »säkulares Naturrecht" könnte eine religiöse oder weltanschauliche Identifikation allenfalls verschleiern, nicht surrogieren ${ }^{42}$. Es führt kein Weg an der Einsicht vorbei, daß die Grenze zwischen der Säkularität des Staates und seiner religiösen oder weltanschaulichen Voreingenommenheit nur von einer Position aus gezogen sein kann, die sich selbst dieser Unterscheidung entzieht: von einer Position aus, die der verfassungsgebenden Gewalt (pouvoir constituant) selbst zugerechnet wird. Die verfassungsgebende Gewalt, die in dem durch die Präambel dem deutschen Volk als Legitimationssubjekt der Verfassung zugeschriebenen Akt der Verfassungsgebung konstitutiv ist und im täglichen Vollzug der Verfassung halb schlummernd, halb bewußt aktiv bleibt ${ }^{43}$, trifft ihre Entscheidung für die Säkularität des auf Volkssouveränität gegründeten und auf die Menschenrechte verpflichteten Staates; und indem sie dies tut, definiert sie auch die Säkularität des »Bekenntnisses « zum Prinzip der Volkssouveränität und zu den Menschenrechten.

40 Dazu zuletzt BVerfG, Urteil vom 17.01.2017 - 2 BvB 1/13 -.

41 Diese drastische Redeweise soll nur die Grenzen der Neutralität markieren; sie bedeutet nicht, daß der Verfassungsstaat ein Bekenntnis einfordert. Der Unterschied wird herausgearbeitet von Franziska Kelle, Der Verfassungsfeind als Häretiker. Eine Untersuchung über den Wahrheitsgehalt des Grundgesetzes, Halle ${ }^{2} 2009$.

42 Zur Reflexion darüber aus römisch-katholisch grundierter Perspektive siehe HannsGregor Nissing (Hg.), Naturrecht und Kirche im säkularen Staat, Wiesbaden 2016.

43 Siehe Ernst-Wolfgang Böckenförde, Die verfassunggebende Gewalt des Volkes ein Grenzbegriff des Verfassungsrechts, Frankfurt a.M. 1986, wieder abgedruckt in: Ders., Staat, Verfassung, Demokratie. Studien zur Verfassungstheorie und zum Verfassungsrecht, Frankfurt a.M. 1991, S. 90-112, hier S. 99f. und insbesondere S. 104: "Indem das Volk [die] ihm [in der Verfassung zur politischen Einwirkung] eröffneten Möglichkeiten wahrnimmt, >lebt es die Verfassung und erneuert im aktualisierten Konsens ihre Legitimation«. Dagegen Martin KRIEle, Einführung in die Staatslehre, Stuttgart u.a. ${ }^{6} 2003, \S 31$, S. 101-106: »Im Verfassungsstaat gibt es keinen Souverän«; ferner $₫ 69$ (besonders S. 240f.): »Volkssouveränität [...] erschöpft sich im Akt der Verfassunggebung und ist alsdann, bis zu erneuter Verfassunggebung, in der Verfassung aufgehoben «. »Die demokratische Souveränität ruht, solange der Verfassungsstaat besteht«. 


\subsection{Identifikationsverbot und Freiheit zur Identifikation}

Während dem säkularen Staat die Identifikation mit partikularen religiösen oder weltanschaulichen Positionen verwehrt ist, bedeutet die Religions- und Weltanschauungsfreiheit für den Bürger die Freiheit zu einer solchen Identifikation. Keineswegs also führt die Säkularität des Staates zur Säkularisierung der Gesellschaft. Im Gegenteil: Die Freiheit des Bürgers zu religiöser und weltanschaulicher Identifikation ist geradezu die ratio des Verbots einer religiösen oder weltanschaulichen Identifikation des Staates.

\section{4 »Religiöse Bezüge« des säkularen Rechts als Identifikationsangebote}

Auch in einem auf Nichtidentifikation bezogenen Verständnis von Säkularität und Neutralität des Staates unter dem Grundgesetz ist die Verfassungsund Rechtssymbolik offen für religiöse Bezüge. Das beginnt schon mit dem Gottesbezug in der Präambel (s.o. 3.5). Die gesetzlichen Bestimmungen über die Eidesleistung vor Gericht oder bei der Übernahme eines öffentlichen Amts sehen regelmäßig eine religiöse Beteuerungsformel vor, die also der Staat entgegennimmt, allerdings unter Wahrung der Freiheit des Schwörenden selbst, sie wegzulassen. In öffentlichen Amtsräumen wie Gerichtssälen und Schulräumen kann grundsätzlich ein Kreuz angebracht sein.

Diese Präsenz christlicher oder sonst religiöser Symbole im Staatsleben stünde mit dem Neutralitätsprinzip in Widerstreit, wenn sie eine Identifikation des Staates mit den symbolisierten Glaubenspositionen bedeutete. Im systematischen Zusammenhang mit dem Neutralitätsprinzip läßt sie sich aber als ein religiös und weltanschaulich offener Verweis auf die dem Staat unzugänglichen Dimensionen menschlicher Wirklichkeit deuten. Der Bürger, dem der Staat so begegnet, kann diesen offenen Verweis mit seiner religiösen oder weltanschaulichen Position füllen: Als Rechtsunterworfener und als Teilnehmer an der demokratischen Willensbildung kann er sein nichtneutrales religiöses oder weltanschauliches Verständnis vom Verfassungsstaat zur Basis seines Bürgerethos machen und im Gottesbezug der Präambel die Offenheit dafür finden; vor Gericht oder bei der Übernahme eines öffentlichen Amtes kann er sein religiöses oder weltanschauliches Verständnis von seiner Bürgerpflicht im Eid mit religiöser Beteuerung zum Ausdruck bringen; als Adressat des staatlichen Bildungs- und Erziehungsauftrags in der Schüler- oder Elternrolle an einer öffentlichen Schule kann er sein religiöses oder weltanschauliches Verständnis von Persönlichkeitsbildung im Kreuz an der Wand versinnbildlicht sehen.

Dieser Form der Identifikation des Bürgers geben die für religiöse und weltanschauliche Deutungen offenen Symbole des neutralen Staates Raum, 
ohne sie vorwegzunehmen oder zu erzwingen. Sie können deshalb»Identifikationsangebote " genannt werden. In ihnen identifiziert sich nicht der Staat, sondern der Bürger mit einer religiösen oder weltanschaulichen Position. Durch solche Identifikationsangebote wird die Säkularität des Staates und seine religiöse und weltanschauliche Neutralität also nicht in Frage gestellt. Umgekehrt wird sie vielmehr gegen die apokryphen Identifikationen einer Staatssymbolik gesichert, welche für religiöse und weltanschauliche Deutungen keinen Raum mehr lassen wollte.

\section{Säkularisierung und Religion unter dem Primat der Freiheit}

Die zusammenfassenden Schlüsse aus diesen Überlegungen lassen sich als thesenhafte Antworten auf die eingangs aufgezählten Leitfragen formulieren:

\subsection{Findet sich im Religionsverfassungsrecht eine »Wechselseitigkeit von}

Säkularisierungs- und Religionskonzepten«?

Ein Konzept von "Säkularisierung" wendet ein Religionsverfassungsrecht nach Art des deutschen Grundgesetzes auf das staatliche Handeln an, um Raum zu lassen für die individuelle und gesellschaftliche Freiheitsentfaltung in der Pluralität der in ihr wirksamen Konzepte von Religion. Das Konzept von »Religion «, das das Religionsverfassungsrecht der Religionsfreiheit zugrundelegt, sucht einen säkularen Rahmenbegriff von Religion. Die Religionsfreiheit verlangt, jedes Konzept von Religion als Selbst-Konzept, als einen Gegenstand des religiösen und weltanschaulichen Selbstverständnisses des Freiheitssubjekts zu verstehen. Der Rechtsbegriff der Religionsfreiheit macht den religiösen und weltanschaulichen Selbstverständnissen keine Konkurrenz, nötigt sie nicht unter ein säkulares oder sonst »leitkulturelles" Über-Konzept von Religion, sondern nimmt sie gerade in ihrer Konvergenz oder Divergenz, in ihrer Anpassungsfähigkeit oder Widerständigkeit, in ihrer Evidenz oder Hermetik als Freiheitsentfaltung in sich auf.

Alle rechtsbegrifflichen Bemühungen um eine Abgrenzung des Schutzbereichs der Religionsfreiheit stoßen sich an diesem Anspruch, nämlich der Offenheit für die Pluralität von »Religionskonzepten«. Zugleich fordert die Anwendung der Religionsfreiheit als einer Norm des staatlichen Rechts eine säkulare Unterscheidung zwischen Religion und Nicht-Religion. Statt sie am Maßstab eines »Konzepts« von Religion treffen zu können, muß sie bei Anforderungen an die Plausibilität und Konsistenz der Darstellung des Selbstverständnisses des Freiheitssubjekts stehenbleiben. 
Mit der Subsumtion eines Interesses unter den Schutzbereich der Religionsfreiheit ist noch nicht über seine effektive Durchsetzung gegen die damit kollidierenden Interessen entschieden. Sie bestimmt sich nach den differenzierten Maßstäben für die verfassungsrechtliche Rechtfertigung von Grundrechtseingriffen. Diese Maßstäbe sind wiederum säkular, ihre Anwendung sucht einen wechselseitig schonenden Ausgleich mit dem religiösen und weltanschaulichen Selbstverständnis. In ihnen werden aber auch die keinem Ausgleich zugänglichen Positionen, auf die sich der säkulare Verfassungsstaat »unverhandelbar" verpflichtet sieht, als unbedingte Schranken der Religionsfreiheit zur Geltung gebracht: darunter die Unveräußerlichkeit der Menschenrechte und der Menschenwürde, die Volkssouveränität als das Legitimationsprinzip aller staatlichen Gewalt (im Fall des demokratischen Verfassungsstaats) - und seine Säkularität selbst.

\subsection{Unterstützt das Religionsverfassungsrecht einen Begriff von »säkularer Religion«?}

Die Säkularität des Staates bedeutet nicht, daß er sich einen Begriff von »säkularer Religion « zueigen machen müßte oder auch nur dürfte. Das unterscheidet eine freiheitliche von einer laizistischen Säkularität des Staates: Eine laizistische Staatsraison neigt dazu, sich mit einem partikularen Konzept von Säkularität zu identifizieren und es als Säkularisierungsprogramm auf die Gesellschaft wirken zu lassen. Die freiheitliche Säkularität des Staates nimmt von jeder Identifikation mit partikularen Konzepten Abstand, um den Freiheitssubjekten die Identifikation mit partikularen Konzepten zu überlassen: Die ratio des Identifikationsverbots ist die Freiheit zur Identifikation. Die Nichtidentifikation des Staates dient den Identifikationen der Freiheitssubjekte. So schafft sie gleichermaßen einer Säkularisierung der Gesellschaft und einer religiösen Prägung der Gesellschaft Raum. Sie ermöglicht beides nebeneinander, bewirkt insofern religiöse und weltanschauliche Pluralität, wiederum ohne etwa eine eigene Agenda für den religiösen Pluralismus zu verfolgen.

Die Annahme, daß die Säkularität des Staates die Pluralisierung von Religion und religiösen Haltungen zur Voraussetzung habe, kann deshalb allenfalls empirische, nicht hingegen normative Gültigkeit beanspruchen. Die religiöse und weltanschauliche Pluralität ist nicht in dem Sinne geboten, daß der Staat sie um seiner Säkularität willen zu erhalten und zu pflegen hätte, so als hätte er für einen Wettbewerb auf dem religiösen Markt einzustehen. Damit würde er nämlich wiederum ein eigenes Programm gegen die prinzipielle Offenheit der Religionsfreiheit setzen. Gerade indem er dies nicht tut, bleibt er säkular. Die Säkularität des Staates bliebe auch unbeschadet, wenn 
die Religionsfreiheit - in einem Gedankenspiel gegen alle Empirie und Differenzierungstheorie - homogen genutzt würde; nicht daß unsere Phantasie ausreichte, um die Rückkehr zu einer homogen christlichen Gesellschaft zu erdenken, eher vielleicht die Entwicklung zu einer homogen religionsindifferenten oder areligiösen Gesellschaft, wobei das wahrscheinlich nicht minder ein Gedankenspiel ist. Auch mit solchen Szenarien steht jedenfalls nicht die Säkularität des Staates auf dem Spiel.

Ein Begriff »säkularer Religion« ist deshalb für den säkularen Staat eine beliebige Position in der religiösen und weltanschaulichen Pluralität der Freiheitsentfaltung.

\subsection{Welchen Ort gibt das Religionsverfassungsrecht der Religion »in einer pluralen Gesellschaft»?}

Mit der spezifischen Gewährleistung der Religionsfreiheit erkennt das Religionsverfassungsrecht die spezifische Schutzbedürftigkeit religiöser Interessen an. Insofern knüpft es an ein »Menschenbild« an, das zumindest aus empirischen Gründen mit religiösen und weltanschaulichen Positionen und mit spezifisch daraus motivierten Interessen rechnet. Dabei schließen die geschützten Positionen und Interessen jeweils das positive wie das negative Verhältnis zu anderen religiösen und weltanschaulichen Positionen und Interessen ein. Das Religionsverfassungsrecht betrachtet Assoziation wie Dissoziation, die in der Gesellschaft wirksamen Konzepte von Religion wie die von Säkularisierung als Äußerungen derselben Freiheit. Schon deswegen rechnet es mit religiöser und weltanschaulicher Pluralität in der Gesellschaft.

Insofern steht das gegen das Postulat eines "postsäkularen" Staates, der von jedem Bezug auf Religion abzusehen versuchen, sich »religionsblind « $\mathrm{zu}$ machen versuchen soll ${ }^{44}$. »Postsäkular» wäre so ein Staat in dem Sinn zu nennen, daß er die Säkularität des Staates gegen eine staatliche Weltanschauung eintauschte. Dagegen steht aber tatsächlich nicht die Vorstellung einer "postsäkularen« Gesellschaft, die sich überrascht auf das Fortleben der Religion einzustellen hat ${ }^{45}$, sondern der säkulare Staat: Es ist die Garantie der Religionsfreiheit, mit der der säkulare Staat auf die Religion verweist und sich zu ihr ins Verhältnis setzt. Will er davon absehen, verliert er seine Säkularität.

Das Religionsverfassungsrecht sieht eine differenzierte Regelung von Konflikten vor, die aus der Entfaltung religiöser und weltanschaulicher Freiheit

44 Wiedergegeben bei Hartmut von SAss, Von Deutungsmächten wunderbar verborgen. Habermas, Taylor und die Metakritik der Säkularisierungstheorie, in diesem Band, S. 11-37, hier S. 30 (über Dalferth).

45 Wiedergegeben bei von SAss, ebd., S. 11-36 (über Habermas). 
entstehen. Wie alle grundrechtlichen Freiheiten, so unterliegt auch die Religions- und Weltanschauungsfreiheit Schranken. Darüber kann der Staat Eingriffe in die Religions- und Weltanschauungsfreiheit rechtfertigen, die zum Schutz eines kollidierenden Rechtsguts oder sonst zur Verwirklichung kollidierender Interessen erforderlich und verhältnismäßig sind. Maßstab der Konfliktregelung sind die qualifizierten Anforderungen an die verfassungsrechtliche Rechtfertigung von Eingriffen in die Religions- und Weltanschauungsfreiheit. Die für alle geltenden, säkularen Schranken der Religions- und Weltanschauungsfreiheit begegnen den verschiedenen religiösen und weltanschaulichen Freiheitsäußerungen in der pluralen Gesellschaft je nach deren Konfliktträchtigkeit in unterschiedlicher Schärfe.

Die Säkularität des Staates macht ihn nicht blind für die Beiträge religiöser und weltanschaulicher Freiheitsäußerungen zum Gemeinwohl, wie es im Prozeß der demokratischen Willensbildung definiert wird, etwa in Sozialtätigkeit, Bildung, politischer Ethik, Kunst, Baukultur etc. Der religiösen Freiheit sind auch die dem demokratischen Diskurs und dem bürgerlichen und republikanischen Ethos und der Verantwortungsübernahme für das Recht in Rechtsgehorsam und Rechtskritik vorausliegenden »Motivationsquellen « zuzuordnen. Ihre Integration in den säkularen Diskurs ist ein Thema für sich. Der säkulare Staat fördert sie und integriert sie in die Pflege des Gemeinwohls nach wiederum säkularen Maßstäben, also weder um ihrer religiösen oder weltanschaulichen Motivation selbst willen noch umgekehrt unter der Bedingung ihrer Ausgrenzung.

Auch diese für alle geltenden, säkularen Gemeinwohlkriterien begegnen den verschiedenen Freiheitsäußerungen in der pluralen Gesellschaft je nach deren Wirkungen für das Gemeinwohl unterschiedlich. Entsprechende Erwartungen an die Gemeinwohldienlichkeit von Religion und Weltanschauung können der Kategorie der Verfassungserwartungen ${ }^{46}$ zugerechnet werden. Sie dürfen sich wohlgemerkt nicht - etwa über die Verfestigung und Verselbständigung empirischer Muster von Gemeinwohlnähe - auf bestimmte Religionen oder die Religion als solche projizieren. Erwartungen an die Gemeinwohldienlichkeit dürfen auch nicht in die Gewährleistungen eindringen, die das Religionsverfassungsrecht um der Freiheitsentfaltung selbst willen bietet.

Ein Beispiel sind die Rechte einer Körperschaft des öffentlichen Rechts: Deutet man sie als Hilfe zum Dienst am Gemeinwohl, können sie von der Gemeinwohldienlichkeit ihrer Ausübung abhängig gemacht werden. Deutet

46 Josef Isensee, Verfassungsstaatliche Erwartungen an die Kirche, in: Heiner Marré / Johannes Stüting (Hg.), Die Verantwortung der Kirche für den Staat. Essener Gespräche zum Thema Staat und Kirche, Bd. 25, Münster 1991, S. 104-146 mit Aussprache S. 147-167. 
man sie als Hilfe zur Freiheitsentfaltung, unterliegen sie nur den Schranken des für alle geltenden Gesetzes, aber nicht darüber hinaus der Bedingung einer besonderen Leistung für das Gemeinwohl.

So hat es das deutsche Bundesverfassungsgericht im Fall der Zeugen Jehovas entschieden ${ }^{47}$, und es hat recht: Die Rechte einer Körperschaft des öffentlichen Rechts erweitern die Organisations- und Handlungsformen für die Religionsgemeinschaften um ihrer Freiheit willen ${ }^{48}$. Das Bundesverwaltungsgericht hatte im Fall der Zeugen Jehovas die Körperschaftsrechte an eine besondere, über die gesetzestreue Einhaltung von Freiheitsschranken hinausgehende »Loyalität« gegenüber dem staatspolitisch definierten Gemeinwohl gebunden gesehen ${ }^{49}$. Das Bundesverfassungsgericht hingegen hat sie nicht als einen Konnex von privilegierender Staatsnähe und Inpflichtnahme für das Gemeinwohl gedeutet, sondern als »ein Mittel zur Entfaltung der Religionsfreiheit ${ }^{50}$.

Die Kritik dieser Entscheidung wendet sich gegen eine »Vergrundrechtlichung “ des Religionsverfassungsrechts ${ }^{51}$. Sie stellt der Freiheitsratio ein Interesse des Staates an der Förderung von Religionsgemeinschaften gegenüber: Nicht um der Religionsfreiheit willen, sondern zur »Pflege von Gemeinschaftsinteressen im Bereich des Öffentlichen, hier: der Stabilisierung und Perpetuierung der kulturellen Identität ${ }^{52}$ gehe das Religionsverfassungsrecht mit institutionellen Gewährleistungen über die individualrechtliche Gewährleistung der Religionsfreiheit hinaus.

47 BVerfG, Urteil vom 19.12.2000 - 2 BvR 1500/97 -, E 102, 370-400.

48 BVerfG, Urteil vom 19.12.2000 - 2 BvR 1500/97 -, E 102, 370 (387); HeINIG, Öffentlich-rechtliche Religionsgesellschaften, S. 265-269, 497; MAGEN, Körperschaftsstatus und Religionsfreiheit, S. 197-289; zur Einbettung in das "grundrechtsorientierte Religionsverfassungsrecht« WALTER, Religionsverfassungsrecht, S. 562f., 565f., 591f.; speziell zur Organisationshoheit von CAMPEnHausen/DE WALL, Staatskirchenrecht, S. 257-260; Rainer MAINUSCH, Staatskirchenrechtliche Überlegungen zur kirchlichen Organisationsgewalt, in: ZevKR 49 (2004), S. 285-310; Wolfgang RüfNER, Die Gründung juristischer Personen des öffentlichen Rechts durch die Kirchen, in: Josef IsenseE u.a (Hg.), Dem Staate, was des Staates - der Kirche, was der Kirche ist. Festschrift für Joseph Listl zum 70. Geburtstag, Berlin 1999, S. 431-447.

49 BVerwG, Urteil vom 26.06.1997 - BVerwG 7 C 11.96 -, E 105, 117-127 (125-127).

50 BVerfG, Urteil vom 19.12.2000 - 2 BvR 1500/97 -, E 102, 370 (387).

51 Die allgemeinen Einwände gegen eine »Vergrundrechtlichung« finden sich zusammengefaßt bei Christian WALDHOFF, Staatskirchenrecht - Eine Begriffsbestimmung, in: Thomas Holzner/Hannes Ludyga (Hg.), Entwicklungstendenzen des Staatskirchen- und Religionsverfassungsrechts. Ausgewählte begrifflich-systematische, historische, gegenwartsbezogene und biographische Beiträge, Paderborn u.a. 2013, S. 13-27, hier S. 24f. mit weiteren Nachweisen.

52 Arnd Uhle, Staat - Kirche - Kultur, Berlin 2004, S. 134f. mit weiteren Nachweisen. In diese Richtung zuvor beispielsweise Christian Hillgruber, Der deutsche Kulturstaat und der muslimische Kulturimport. Die Antwort des Grundgesetzes auf eine religiöse Herausforderung, in: JZ 1999, S. 538-547, hier S. 547; Paul Kirchноғ, Die 
Dazu passen allerdings schon die Rechtsfolgen der institutionellen Gewährleistungen nicht gut. Sie haben keinen unmittelbaren Zusammenhang mit ihrem Gebrauch im Sinne des Gemeinwohls. Denn nicht für die »Pflege von Gemeinschaftsinteressen im Bereich des Öffentlichen «, sondern für die Freiheitsentfaltung einer Religionsgemeinschaft nach ihrem Selbstverständnis macht es einen Unterschied, ob etwa - um es an den Rechtsfolgen des öffentlich-rechtlichen Körperschaftsstatus zu zeigen - sie ihre Mitgliedschaftsverhältnisse nach dem Vereinsrecht durch Rechtsgeschäft oder aber nach dem Parochialrecht durch Kirchengesetz begründen und ausgestalten können, ob sie Mitarbeiter im vertraglichen Arbeitsverhältnis oder im öffentlich-rechtlichen Dienstverhältnis beschäftigen und ob sie Mitgliedsbeiträge vor den Zivilgerichten einklagen müssen oder als Kirchensteuer erheben können. Das sind Funktionen und Wirkungen des öffentlich-rechtlichen Körperschaftsstatus, die mit dem Gemeinwohl nichts zu tun haben.

Vor allem kann das Religionsverfassungsrecht nicht mit institutionenpolitischen Zwecken befrachtet werden, ohne es in Spannung zur religiösen Freiheit und Gleichheit treten zu lassen. Der Eigensinn der Freiheit verträgt keine Indienstnahme für öffentliche Interessen. Jede Koppelung von Gemeinwohlerwartungen mit den Voraussetzungen für die Verleihung jener Rechte würde die Freiheitsentfaltung funktionalisieren und damit die Freiheit schmälern.

Nur mittelbar - aber immerhin mittelbar - darf man erwarten, daß sich die damit in ihrer Freiheitsentfaltung gestärkten Religionsgemeinschaften auch im Sinne des Gemeinwohls nützlich machen. Denn die Behauptung der Freiheitsratio gegen eine Teleologie der "Gemeinschaftsinteressen im Bereich des Öffentlichen« verkennt ja nicht die Gemeinwohlerwartungen, die sich auch auf das Wirken von Religionsgemeinschaften in der Gesellschaft richten. Damit ist aber nicht mehr und nichts anderes beschrieben als das allgemeine öffentliche Interesse am Freiheitsgebrauch. Auch die Verfassungserwartungen an Religionsgemeinschaften für das Gemeinwohl bleiben stets über ihre Freiheit vermittelt ${ }^{53}$. Auf das Gemeinwohl zielen die institutionellen Vorkehrungen des säkularen Religionsverfassungsrechts demgemäß nicht an ihrer Freiheitsratio vorbei, sondern durch sie hindurch.

Kirchen und Religionsgemeinschaften als Körperschaften des öffentlichen Rechts, in: $\mathrm{HSKR}^{2}$, Bd. 1, S. 651-687, hier S. 667-669, 682-684. Siehe außerdem Arnd Uhle, Freiheitlicher Verfassungsstaat und kulturelle Identität, Tübingen 2004, S. 454-458.

53 So auch der Ansatz bei Isensee, Verfassungsstaatliche Erwartungen an die Kirche, S. 111f., 114, 118-120, 122f.; siehe ferner etwa HeINIG, Öffentlich-rechtliche Religionsgesellschaften, S. 262-265, 269f.; MAGEN, Körperschaftsstatus und Religionsfreiheit, S. 153-189; DE WALL, Das Verhältnis von Gesellschaft, Staat und Kirche in Deutschland, S. 86; WALter, Religionsverfassungsrecht, S. 552f. - Die Ausführungen hier lehnen sich an frühere an: GERmanN, Entwicklungstendenzen, S. 53-56 u.ö. 


\subsection{Inwiefern sind »Säkularisierungen« in einer pluralen Gesellschaft »notwendig«?}

Aus Sicht des Religionsverfassungsrechts beziehen sich alle für eine plurale Gesellschaft »notwendigen« Säkularisierungen auf das staatliche Handeln. Das macht die Säkularisierung nicht zum Postulat für die plurale Gesellschaft selbst, auch nicht für die gesellschaftliche Öffentlichkeit, und dies auch nicht dort, wo die gesellschaftliche Öffentlichkeit von staatlichen Institutionen gewährleistet, organisiert und moderiert wird, etwa in der staatlichen Schule. Die Säkularität des Staates dient gerade dazu, alle Prozesse der Säkularisierung ebenso wie der religiösen oder weltanschaulichen Konnotation der Dynamik gesellschaftlicher Freiheit zu überlassen und über deren säkulare Schranken nur in ihren Folgen zu moderieren.

6.5 Wie soll sich eine »säkulare Religion« $\mathrm{zu}$ »den in einer pluralen Gesellschaft notwendigen Säkularisierungen« verhalten?

Aus der Sicht des Religionsverfassungsrechts hat somit jedes Konzept von Religion, etwa in Gestalt einer "säkularen Religion", die Freiheit, sich den Säkularisationsprozessen in einer pluralen Gesellschaft auf seine Art anzuverwandeln; jedes Konzept von Religion hat aber ebenso die Freiheit, sich den Säkularisationsprozessen in einer pluralen Gesellschaft zu verweigern. 


\section{Autoren- und Mitarbeiterverzeichnis}

Marion Bechtold-Mayer M.A., Leibniz-Institut für Europäische Geschichte, Abteilung für Abendländische Religionsgeschichte, Alte Universitätsstraße 19, 55116 Mainz, bechtold-mayer@ieg-mainz.de

Prof. Dr. Irene Dingel, Leibniz-Institut für Europäische Geschichte, Abteilung für Abendländische Religionsgeschichte, Alte Universitätsstraße 19, 55116 Mainz, dingel@ieg-mainz.de

Matthias Felder MTh, Schweizerischer Evangelischer Kirchenbund, Institut für Theologie und Ethik (ITE), Sulgenauweg 26, Postfach, 3001 Bern (CH), matthias.felder@sek-feps.ch

Dr. Rebecca Milena Fuchs, lic. theol., Meichelbeckstraße 15, 81545 München, rebecca.fuchs@rebeccafuchs.de

Prof. Dr. Michael Germann, Martin-Luther-Universität Halle-Wittenberg, Lehrstuhl für Öffentliches Recht, Staatskirchenrecht und Kirchenrecht, Universitätsplatz 5, 06108 Halle (Saale), michael.germann@jura.uni-halle.de

Prof. Dr. Jan Kusber, Johannes Gutenberg-Universität Mainz, Historisches Seminar, Arbeitsbereich Osteuropäische Geschichte, Jakob-Welder-Weg 18, 55128 Mainz,kusber@uni-mainz.de

Prof. Dr. Frank Mathwig, Schweizerischer Evangelischer Kirchenbund, Institut für Theologie und Ethik (ITE), Sulgenauweg 26, Postfach, 3001 Bern (CH), frank.mathwig@sek.ch

Prof. Dr. Detlef Pollack, Westfälische Wilhelms-Universität Münster, Exzellenzcluster »Religion und Politik«, Johannisstraße 1, 48143 Münster, pollack@uni-muenster.de 
PD Dr. Hartmut von Sass, Universität Zürich, Institut für Hermeneutik und Religionsphilosophie, Kirchgasse 9, 8001 Zürich (CH), hartmutvonsass@access.uzh.ch

Dr. Manfred Sing, Leibniz-Institut für Europäische Geschichte, Abteilung für Abendländische Religionsgeschichte, Alte Universitätsstraße 19, 55116 Mainz, sing@ieg-mainz.de

Prof. Dr. Christiane Tietz, Universität Zürich, Institut für Hermeneutik und Religionsphilosophie, Kirchgasse 9, 8001 Zürich (CH), christiane.tietz@theol.uzh.ch

PD Dr. Christopher Voigt-Goy, Leibniz-Institut für Europäische Geschichte, Abteilung für Abendländische Religionsgeschichte, Alte Universitätsstraße 19, 55116 Mainz, voigt-goy@ieg-mainz.de 


\section{Register $^{1}$}

\section{Ortsregister}

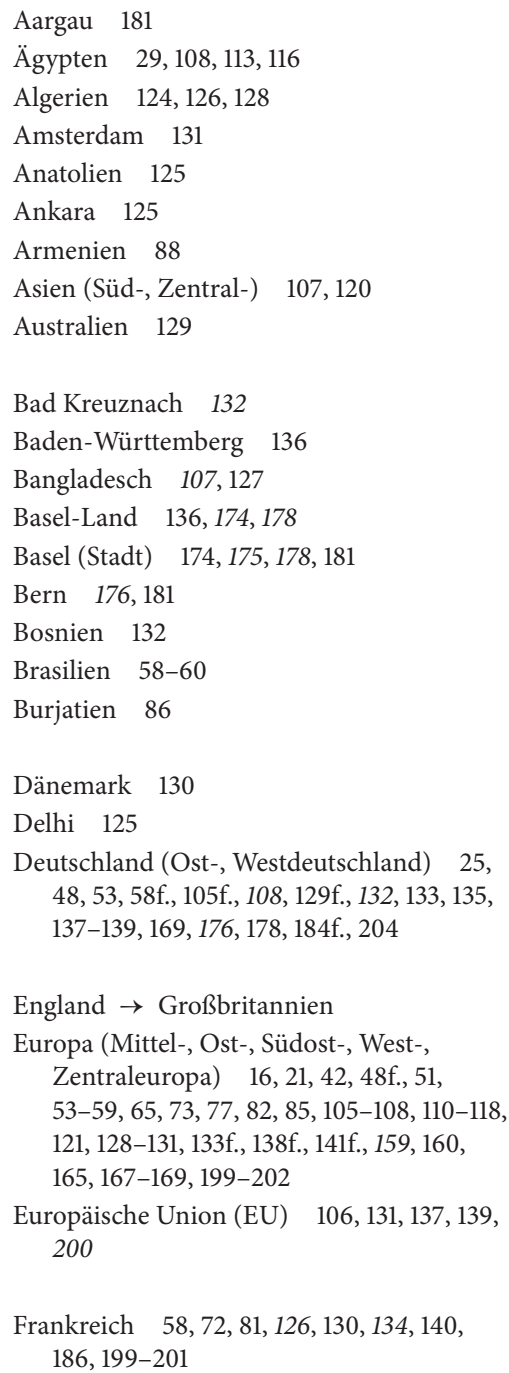

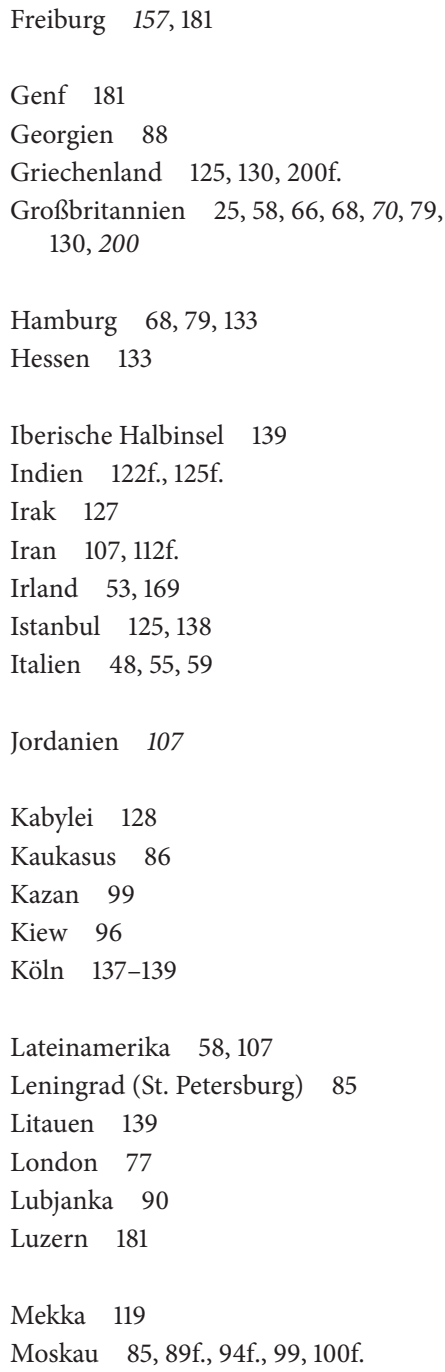

1 Kursiv gesetzte Seitenangaben verweisen auf Anmerkungen, recte gesetzte auf den laufenden Text. 
Münchenstein 174

Münster 48, 135

Niederlande (Holland) 41, 48, 53, 56, 59f., $129,131,169$

Niedersachsen 132

Nordrhein-Westfalen 135

Österreich 108, 169

Osmanische Reich 125

Osten (Naher, Mittlerer, Ferner) 98, 113-115

Pakistan 107, 112, 122, 124, 126-128, 133

Paris 73, 122

Poitiers 105

Polen 48, 52f., 55, 59, 95, 99, 139, 169

Punjab 127

Québec 53

Rom 99

Rotterdam 131

Rüdesheim 133

Russland 48, 51f., 85-88, 90, 94f., 97-102, 120

Sagorsk 96

Saudi-Arabien 106-108, 112, 119, 132

Schaffhausen 181

Schweden 202
Schweiz (Eidgenossenschaft) 108, 129, 139, 165-167, 169f., 172-174, 176-181, 183, 198, 202

Seoul 39

Sétif 126

Skandinavien 200

Solovki 95

Sowjetunion $\rightarrow$ Russland

Spanien 53, 57, 169, 200

St. Gallen 181

Südkorea 39f., 48, 52-57, 60f.

Syrien 127,136

Tatarstan 86

Tschetschenien 98

Türkei $107,113,119,124-126,129,132$, 138,200

Ukraine 88

Uri 181

USA (Amerika) 14, 42, 48, 51, 53-56, 58f., $65,111,113,121$

Vereinigtes Königreich $\rightarrow$ Großbritannien

Wallis 181

Washington 105,167

Weimar 185f., 194, 199

Westen 100, 111, 114-116

Wien 105

Zürich $7,28,181,183$ 


\section{Personenregister}

'Abd al-Nasser, Gamāl (1918-1970) 113

'Abd al-Rāziq, 'Alī (1887/88-1966) 122

'Ašmāwī, Muḥammad Sa 'īd al(1932-2013) 122

Addisons, Joseph (1672-1719) 79

Adorno, Theodor W. (1903-1969) 14

Alexander III. (Alexander Alexandrowitsch Romanow) (1845-1894) 86

Alexej II. (Patriarch von Moskau, Alexei Michailowitsch Rüdiger) (1929-2008) 99, 101

Augustinus von Hippo (354-430) 150

Badawi, Raif (geb. 1984) 107

Bacon, Francis (1561-1626) 66-70, 72, 74f., 77, 81f.

Barth, Karl (1886-1968) 22, 32, 169

Bellah, Robert (1927-2013) 51

Biedermann, Alois Emanuel (1819-1885) 174f., 179

Bonhoeffer, Dietrich (1906-1945) 32

Boubakeur, Dalil (geb. 1940) 122

Boyle, Robert (1627-1691) 68, 70-72, 77f., 80,83

Breschnew, Leonid (1906-1982) 97

Brockes, Barthold Heinrich (1680-1747) $72,77,79-82$

Bultmann, Rudolf (1884-1976) 22, 32

Čaplin, Vsevolod (geb. 1968) 101

Cassini, Jacques (1677-1756) 73

Cho, David Yonggi (geb. 1936) 39

Chruschtschow, Nikita Sergejewitsch (1894-1971) 96f.

Cooper, Anthony Ashley (3. Earl von Shaftesbury) (1671-1713) 79

d'Alembert, Jean-Baptiste le Rond (1717-1783) 74f.

Derham, William (1657-1735) 77-79

Descartes, René (1596-1650) 26, 74

Diderot, Denis (1713-1784) 68, 72, 75-78, 80,82

Donskoj, Dimitri Iwanowitsch, Großfürst von Moskau (1350-1389, reg. 1359-1389) 95

Drapers, John William (1811-1882) 65f.
Dworkin, Richard (1931-2013) 25

Dzeržinskij, Felix Edmundowitsch (1877-1926) 90

Fabricius, Johann Albert (1668-1736) 79

Frisch, Max (1911-1991) 28

Galilei, Galileo (1564-1642) 81

Gandhi, Indira (1917-1984) $122 f$.

Giddens, Anthony (geb. 1938) 43

Godwin, Francis (Domingo Gonsales) (1562-1633) 69

Gorbačevs (Gorbatschow), Michail (geb. 1931) 85f.

Habermas, Jürgen (geb. 1929) 11, 13-16, 18-25, 28-32, 35f., 158, 170, 182

Hartlib, Samuel (ca. 1600-1662) 68

Hattar, Nahed (1960-2016) 107

Hegel, Georg Wilhelm Friedrich (1770-1831) 14

Hobsbawm, Eric (1917-2012) 86

Hölderlin, Friedrich (1770-1843) 27

Illich, Ivan (1926-2002) 32

Jaroslavskij, Emeljan (1878-1943) 92

Jefferson, Thomas (1743-1826) 37

Jelzin, Boris Nikolajewitsch (1931-2007) 85, 98

Jinnah, Mohammed Ali (1876-1946) 122, $125 f$.

Johann von Kronstadt (Iwan Iljitsch Sergijew) (1829-1908) 87

Johannes Paul II. (1920-2005) 52, 160

Kant, Immanuel (1724-1804) 23

Karl der Große (747 / 48-814) 139

Kemal, Mustafa Pascha (Atatürk) (1881-1938) 113, 125

Kierkegaard, Søren (1913-1855) 22

Kirill I. (Patriarch von Moskau, Wladimir Michailowitsch Gundjajew) (geb. 1946) 98, 100

Lee, Peggy (Norma Delores Egstrom) (1920-2002) 36 
Lenin, Wladimir Iljitsch (1870-1924) 87, 90, 94

Ludin, Fereshta (geb. 1972) 136

Luther, Martin (1483-1546) 26, 171

Maritain, Jacques (1882-1973) 32

Marx, Karl (1818-1883) 44

Maupertuis, Pierre Louis Moreau de (1698-1759) 73f., 82

Medvedev, Dmitri Anatoljewitsch (Medwedew) (geb. 1965) 85

Merton, Robert K. (1910-2003) 66

Naim, Abdullahi al- (geb. 1946) 122

Nehru, Jawaharlal (1889-1964) 122

Nekkaz, Rachid (geb. 1972) 140

Newskij, Alexander Jaroslawitsch, u.a. Großfürst von Kiew (ca. 1220-1263, reg. 1249-1263) $\quad 89,95$

Newton, Isaac (1643-1727) 70, 72f., 74f.

Nikolaus II. (Nikolaus Alexandrowitsch Romanow), Zar (1868-1918, reg. 1894-1917) $86 f$.

Öcalan, Abdullah (geb. 1949) 127

Oldenbourg, Henry (ca. 1618-1677) $68 f$

Pahlavi, Reza, Shah (1878-1944, reg. 1925-1941) 114

Parsons, Talcott (1902-1979) 43

Pestré, Jean (1723-1821) 73f.

Peter I., der Große (Pjotr Alexejewitsch Romanow), Zar (1672-1725, reg. 1682-1725) 86

Pilatus, Pontius (26-36 n. Chr. röm. Statthalter in Judäa) 183

Pimen I. (Sergej Michajlowitsch Iswekow), Patriarch von Moskau (1910-1990) 85

Pobedonoscev, Konstantin Petrowitsch (1827-1907) 87

Putin, Wladimir Wladimirowitsch (geb. 1952) 85, 98-101

Ragaz, Leonhard (1868-1945) 169
Ratzinger, Joseph (Papst Benedikt XVI. 2005-2013) (geb. 1927) 23, 145, 150, 152, $156-160$

Rawls, John (1921-2002) 170, 182

Rousseau, Jean-Jacques (1712-1778) 26

Sadat, Anwar al- (1918-1981) 113

Savarkar, Vinayak Damodar (gest. 1966) 122

Schleiermacher, Friedrich (1768-1834) $22,25,29,83$

Schmaus, Michael (1897-1993) 147, 150

Sergej von Radonesch (1314-1392) 89

Sergeij I. (Iwan Nikolajewitsch Stragorodski), Patriarch von Moskau (1867-1944) 95

Sjuganov, Gennadij Andrejewitsch (geb. 1944) 101

Sprat, Thomas (1635-1713) 69f.

Stalin (Dschughaschwili), Josef Wissarionowitsch (1878-1953) 92, 94-98

Taylor, Charles (geb. 1931) 13, 16-19, 21, 24-32, 35f., 83, 162, 167

Tichon I. (Wassili Iwanowitsch Bellawin), Patriarch von Moskau (1865-1925) 89-91

Tocqueville, Alexis de (1805-1859) 43

Troeltsch, Ernst (18655-1923) 117

Trotzki, Leo (Lew Dawidowitsch Bronstein) (1879-1940) 90, 92

Voltaire (François-Marie Arouet) (1694-1778) 73

Weber, Max (1864-1920) 13, 66

Wenjamin (Vasily Pavlovich Kazansky), Metropolit von Petrograd (1873-1922) 90 Wilkins, John (1614-1672) 69

Wittgenstein, Ludwig (1889-1951) 33, 120

Zwingli, Ulrich (Hyldrich) (1484-1531) 177 